\title{
III. Zentralismus, partikulare Kräfte und regionale Identitäten im NS-Staat
}




\section{Michael Ruck}

\section{Zentralismus und Regionalgewalten im Herrschaftsgefüge des NS-Staates}

$I$.

„Der nationalsozialistische Staat entwickelte sich zu einem gesetzlichen Zentralismus und zu einem praktischen Partikularismus. " ${ }^{1}$ In dürren Worten brachte Alfred Rosenberg, der selbsternannte Chefideologe des "Dritten Reiches", die institutionellen Unzulänglichkeiten totalitärer Machtaspirationen nach dem „Zusammenbruch" auf den Punkt. Doch öffnete keineswegs erst die Meditation des gescheiterten „Reichsministers für die besetzten Ostgebiete ${ }^{\alpha 2}$ in seiner Nürnberger Gefängniszelle den Blick auf die vielfältigen Diskrepanzen zwischen zentralistischem Herrschaftsanspruch und fragmentierter Herrschaftspraxis im polykratischen „Machtgefüge" des NS-Regimes ${ }^{3}$. Bis in dessen höchste Ränge hinein hatte sich diese Erkenntnis je länger desto mehr Bahn gebrochen.

So beklagte der Reichsminister und Chef der Reichskanzlei Hans-Heinrich Lammers, Spitzenrepräsentant der administrativen Funktionseliten im engsten Umfeld des „Führers", zu Beginn der vierziger Jahre die fortschreitende Aufsplitterung der Reichsverwaltung in eine Unzahl alter und neuer Behörden, deren unklare Kompetenzen ein geordnetes, an Rationalitäts- und Effizienzkriterien orientiertes Verwaltungshandeln zusehends erschwerten ${ }^{4}$. Der tiefgreifenden Frustration, welche sich der Ministerialbürokratie ob dieser Zustände bemächtigte, hatte Fritz-Dietlof von der Schulenburg schon

\footnotetext{
${ }^{1}$ Alfred Rosenberg, Letzte Aufzeichnungen. Ideale und Idole der nationalsozialistischen Revolution, Göttingen 1955, S. 260; Hervorhebungen im Original. Vgl. dazu Dieter Rebentisch, Führerstaat und Verwaltung im Zweiten Weltkrieg. Verfassungsentwicklung und Verwaltungspolitik 1939-1945, Stuttgart 1989, S.262; ders., Verfassungswandel und Verwaltungsstaat vor und nach der nationalsozialistischen Machtergreifung, in: Jürgen Heideking u. a. (Hrsg.), Wege in die Zeitgeschichte. Festschrift zum 65. Geburtstag von Gerhard Schulz, Berlin/New York 1989, S.123-150, hier: S. 148.

${ }^{2}$ Zur „geballte(n) Unfähigkeit Rosenbergs und seiner Berater“, die sich rasch in einem selbsterzeugten Organisationschaos und endlosen Kompetenzkonflikten verfingen, vgl. Rebentisch, Führerstaat, S. 309-331, hier: S.319.

${ }^{3}$ Vgl. dazu eingehend (mit weiteren Hinweisen) Michael Ruck, Führerabsolutismus und polykratisches Herrschaftsgefüge - Verfassungsstrukturen des NS-Staates, in: Karl D. Bracher u. a. (Hrsg.), Deutschland 1933-1945. Neue Studien zur nationalsozialistischen Herrschaft, 2. Aufl., Bonn 1993, S. 32-56. Rebentisch, Führerstaat, S. 14, plädiert mit einsichtigen Argumenten dafür, den NS-Staat nicht als „Herrschaftssystem ", sondern als „Machtgebilde" oder "Herrschaftsgefüge " zu qualifizieren. Die Begriffe "Macht-“ und „Herrschaftsgefüge“ hat Kurt Düwell bereits vor geraumer Zeit verwendet; siehe ders., Die regionale Geschichte des NS-Staates zwischen Mikro- und Makroanalyse. Forschungsaufgaben zur „Praxis im kleinen Bereich“, in: Jahrbuch für westdeutsche Landesgeschichte [JWL] 9 (1983), S.287-344, hier: S.287 u. 302.
}

${ }^{4}$ Vgl. Rebentisch, Führerstaat, S.289; ders., Verfassungswandel, S. 149. 
1937 beredten Ausdruck verliehen ${ }^{5}$. Und ein weiterer Verwaltungsmann, der sich aus fundamentaler Enttäuschung darüber vom NS-Sympathisanten zum Widerstandskämpfer wandelte - Ulrich von Hassell - quittierte 1939 einen ähnlichen Bericht des Hannoveraner Regierungspräsidenten und ersten Gestapo-Chefs Rudolf Diels mit dem lapidaren Verdikt, die NS-Machthaber wüßten eben „im Grunde gar nicht, was ein Staat ist" ${ }^{\text {"6. }}$.

Doch nicht nur unter den Protagonisten des autoritären Verwaltungsstaates, auch in den oberen Etagen der NS-Hierarchie wurde die fortschreitende Desorganisation der Reichsverwaltung teilweise mit wachsender Sorge quittiert. So warnte Karl Waldmann, Staatssekretär des Stuttgarter Gauleiters und Reichsstatthalters Murr, Anfang 1938 unter der Überschrift „Einheit der Verwaltung“ öffentlich vor „Überorganisation“, „Kompetenz-

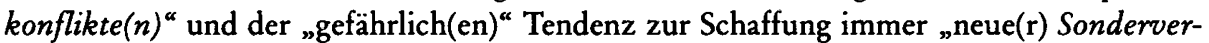
waltungen“: „De(r) Versuch der Parteien des Weimarer Systems, die Einheit des Reichs mit Mitteln der Verwaltung herzustellen statt mit politischen Mitteln sicherzustellen, [...] führten zur Zersplitterung und Unübersichtlichkeit des Behördenaufbaus [...]. Gleichzeitig wurde der Ressortpartikularismus gestärkt, der weder auf andere Verwaltungszweige noch auf die Länderverwaltung Rücksicht nahm.“ Dieser vorgebliche Hinweis auf die schlechten „Erfahrungen der überwundenen Periode" war unverkennbar auf die Situation der Jahreswende 1937/38 gemünzt ${ }^{7}$.

Im Herbst 1941 sah auch der Leiter der Parteikanzlei, Reichsleiter Martin Bormann, „für die Staatsführung ernste Gefahren“ heraufziehen, wenn dieser Prozeß nicht alsbald unter Kontrolle gebracht werde ${ }^{8}$. Allerdings konnte Hitlers neuer Intimus daran - allen seinen (partei)bürokratischen Neigungen zum Trotz $^{9}$ - letzten Endes gar nicht interessiert sein. Eröffnete ihm doch gerade und allein die polykratische „Kompetenzanarchie“ des totalitären Führerstaates ${ }^{10}$ die Chance, als alleiniger Wächter am „Korridor zur Seele

${ }^{5}$ Denkschrift über die Krise des Beamtentums v. September 1937; abgedr. in: Hans Mommsen, Beamtentum im Dritten Reich. Mit ausgewählten Quellen zur nationalsozialistischen Beamtenpolitik, Stuttgart 1966, S.146-149; vgl. ebd., S. 57 f.; Jane Caplan, Government without Administration. State and Civil Service in Weimar and Nazi Germany, Oxford 1988, S. $321 \mathrm{f}$.

${ }^{6}$ Friedrich Freiherr Hiller von Gaetringen (Hrsg.), Die Hassell-Tagebücher 1938-1944. Ulrich von Hassell. Aufzeichnungen vom anderen Deutschland, rev. u. erw. Neuausgabe, 2. Aufl., Berlin 1989, S.137f. (1.11. 1939); Hervorhebung von mir. Zur Frustration einstmaliger NS-Sympathisanten unter der höheren Beamtenschaft vgl. Caplan, Government, S.324f.; vgl. auch den Hinweis bei Martin Broszat, Reichszentralismus und Parteipartikularismus. Bayern nach dem NeuaufbauGesetz vom 30.Januar 1934, in: Ursula Büttner u.a. (Hrsg.), Das Unrechtsregime. Internationale Forschung über den Nationalsozialismus. Festschrift für Werner Jochmann zum 65. Geburtstag, Bd.1, Hamburg 1986, S.178-202, hier: S. 199.

${ }^{7}$ Der Artikel des auch auf Reichsebene exponierten NS-Verwaltungspolitikers wurde in Nr.1/1938 der von ihm herausgegebenen "Württembergischen Verwaltungszeitschrift" publiziert; das Gauorgan druckte den "richtungweisenden Aufsatz" alsbald nach (Regierungsanzeiger, Nr. 12, S. 2 f.; Beilage zum Stuttgarter NS-Kurier, Nr.47, 29.1. 1938); Hervorhebungen von mir. Zur Bedeutung Waldmanns vgl. den Hinweis bei Rebentisch, Innere Verwaltung, S.751.

${ }^{8}$ Zit. nach: Martin Broszat, Der Staat Hitlers. Grundlegung und Entwicklung seiner inneren Verfassung, München 1969, S.383f.; vgl. danach Hans-Ulrich Thamer, Verführung und Gewalt. Deutschland 1933-1945, Berlin 1986, S.677.

${ }^{9}$ Vgl. dazu Peter Longerich, Hitlers Stellvertreter. Führung der Partei und Kontrolle des Staatsapparates durch den Stab Heß und die Partei-Kanzlei Bormann, München u. a. 1992; ferner Rebentisch, Führerstaat, S. 528f.

${ }^{10}$ Rebentisch, Führerstaat, S. 552; vgl. Broszat, Staat Hitlers, S.171. 
des Machthabers“ im „Vorraum“ der absoluten Macht ${ }^{11}$ zum „Super- und Kontrollminister der Reichsregierung ${ }^{\text {" }} 2$ aufzusteigen.

Die personalistische Verfassungs- und Verwaltungsdoktrin Hitlers und seiner engsten Gefolgsleute war je länger desto weniger vereinbar mit jenem traditionell-obrigkeitsstaatlichen Zentralismus der prussifizierten Ministerialbürokratie in Berlin, den sich ihr politischer Exponent, Reichsinnenminister Wilhelm Frick, von Beginn an zu eigen gemacht hat$\mathrm{te}^{13}$. Deren hierarchisch-autoritäre, tendenziell statische Ordnungsvorstellungen standen diametral zu jenem ausgeprägten Anti-Institutionalismus, den Hitler nicht als bloße Attitüde, sondern als Kernelement seiner autokratischen Herrschaftstechnik in dynamisierender Absicht pflegte ${ }^{14}$. Die Demontage traditioneller Instanzenzüge zugunsten eines diffusen, ausschließlich auf seine Person zentrierten Geflechts personaler Herrschaftsbeziehungen gehörte zum machttechnischen Arkanbereich des Diktators ${ }^{15}$.

Als wolle er das formalistische Raunen, welches aus den ministeriellen Amtsstuben bis in seine Vorzimmer drang, ein für allemal zum Schweigen bringen, trieb Hitler den Führerabsolutismus 1942 auf die Spitze. Nachdem er im Januar die Leitung der Reichsverwaltung vom Innenminister auf seine Reichskanzlei übertragen hatte, ließ Hitler den Großdeutschen Marionetten-Reichstag am 26. April 1942 proklamieren, daß er sich „in seiner Eigenschaft als Führer der Nation, als Oberster Befehlshaber der Wehrmacht, als Regierungschef und oberster Inhaber der vollziehenden Gewalt, als oberster Gerichtsherr und als Führer der Partei“ mit seinen sogenannten „Führerbefehlen“ nach eigenem Gutdünken „jederzeit“ über „bestehende Rechtsvorschriften“ und „vorgeschriebene Verfahren“ hinwegsetzen könne ${ }^{16}$.

${ }^{11}$ Carl Schmitt, Gespräche über die Macht und den Zugang zum Machthaber [1954]. Gespräch über den Neuen Raum, Berlin 1994, S.17-20. Mit Blick auf den Zugang zu Hitler hatte Schmitt dieses treffende Bild bereits 1947 bemüht; vgl. Lothar Gruchmann, Die "Reichsregierung“ im Führerstaat. Stellung und Funktion des Kabinetts im nationalsozialistischen Herrschaftssystem, in: Günter Doeker/Winfried Steffani (Hrsg.), Klassenjustiz und Pluralismus. Festschrift für Ernst Fraenkel zum 75. Geburtstag am 26. Dezember 1973, Hamburg 1973, S.187-223, hier: S. $207,222$.

${ }^{12}$ Broszat, Staat Hitlers, S. 391-395, hier: S. 394; vgl. ferner Rebentisch, Führerstaat, S. 82-84, 411 f. (relativierend), 441-463; ebenfalls relativierend Longerich, Hitlers Stellvertreter, S. 177-179.

${ }^{13} \mathrm{Zu}$ Hitlers Führungsgrundsätzen vgl. Rebentisch, Führerstaat, S. 196, 227, 250f., 536ff. et passim; Wolfgang Benz, Expansion und Konkurrenz. Zum Verhältnis von Regierungsapparat und NSDAP [1986], in: ders., Herrschaft und Gesellschaft im nationalsozialistischen Staat. Studien zur Struktur- und Mentalitätsgeschichte, Frankfurt a.M. 1990, S. 47-62, hier: S. 50f. Zur Linie des Reichsinnenministers siehe Günter Neliba, Wilhelm Frick. Der Legalist des Unrechtsstaates. Eine politische Biographie, Paderborn u. a. 1992; vgl. Rebentisch, Führerstaat, S. 97-101. Zur „Verpreußung der Reichsregierung" während der dreißiger Jahre vgl. Broszat, Staat Hitlers, S. 156; ders., Reichszentralismus, S. 187 f.; Rebentisch, Führerstaat, S. 93 f.

${ }^{14} \mathrm{Vgl}$. Hans Mommsen, Ausnahmezustand als Herrschaftstechnik des NS-Regimes, in: Manfred Funke (Hrsg.), Hitler, Deutschland und die Mächte. Materialien zur Außenpolitik des Dritten Reiches, Düsseldorf 1976, S. 30-45; ders., Der Nationalsozialismus und die Auflösung des normativen Staatsgefüges, in: Wolfgang Luthard/Alfons Söllner (Hrsg.), Verfassungsstaat, Souveränität, Pluralismus. Otto Kirchheimer zum Gedächtnis, Opladen 1989, S.67-75. Zusammenfassend nunmehr Rebentisch, Führerstaat, S. 29-46, 395-424, 552.

${ }^{15} \mathrm{Zu}$ dem aus der "Kampfzeit" beibehaltenen, extrem personalisierten Führungsstil Hitlers vgl. Dietrich Orlow, The History of the Nazi Party, Bd.1: 1919-1933, Bd.2: 1933-1945, Pittsburgh 1969/ 1973, hier: Bd. 1, S. 81 ff. u. Bd. 2, S.7-13.

${ }^{16}$ Abgedr. in: Martin Hirsch u. a. (Hrsg.), Recht, Verwaltung und Justiz im Nationalsozialismus. Ausgewählte Schriften, Gesetze und Gerichtsentscheidungen von 1933 bis 1945, Köln 1984, S. 187; vgl. dazu Rebentisch, Führerstaat, S.418-422; Peter Hubert, Uniformierter Reichstag. Die Geschichte der Pseudo-Volksvertretung 1933-1945, Düsseldorf 1992, S. 181-196. 
Dieser bizarre Führerabsolutismus und dessen polykratischer Unterbau waren komplementäre Schlüsselelemente der monokratischen NS-Diktatur ${ }^{17}$. An den inneren Spannungen, die daraus erwuchsen, ist der Staat Hitlers bis zu seiner militärischen Niederwerfung nicht zugrunde gegangen - im Gegenteil: gerade daraus bezog dieses Machtgefüge seine verheerende Dynamik bei Wahrung relativer Stabilität. Es gehört zu den vordergründigen Widersprüchen der NS-Herrschaft, daß das Regime Zeit seines Bestehens darum besorgt war, sich gleichwohl nach außen als festgefügter Machtblock zu präsentieren. Auch diese Selbststilisierung hat nachhaltig gewirkt. Obwohl bereits die klassische Totalitarismusforschung auf "Risse im Monolith" und die Existenz einer "totalitären Polykratie“ in Deutschland aufmerksam gemacht hatte ${ }^{18}$, wurde lange Zeit - bisweilen auch heute noch

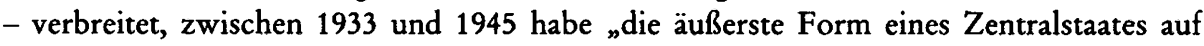
deutschem Boden“ existiert ${ }^{19}$. Erst vor dem Hintergrund dieser „, zentralistischen ${ }^{\circ} \mathrm{Ge}$ samtdeutung des Dritten Reiches ${ }^{\text {"20 }}$ vermochte die (Wieder-)Entdeckung mannigfacher Einzelinteressen und Sonderinstitutionen zu dem teleologischen Kurzschluß verleiten, der "schwache Diktator" Hitler habe einer Anarchie präsidiert, deren destruktive Entwicklungsdynamik von vornherein auf ihren Untergang programmiert gewesen $\operatorname{se}^{21}$.

„Selbst ein innerlich ruiniertes Staatsgebilde“, ist dazu treffend bemerkt worden, "(hätte) allein durch den Terror seiner Beherrscher noch relativ lange Zeit fortexistieren oder sich sogar wieder ,konsolidieren" können"22 - zumal sich die deutsche Bevölkerung bis zum bitteren Ende nicht auf breiter Front von ,ihrem Führer" abwandte ${ }^{23}$. Doch nicht nur die realhistorische Erfahrung, sondern auch theoretische Erwägungen sprechen dagegen, dem NS-Herrschaftsgefüge seinen monokratisch-totalitären Charakter und die Persistenz seiner vitalen Funktionen abzusprechen, weil es seinen ideologisch-propagan-

${ }^{17}$ Vgl. Ruck, Führerabsolutismus, S. 39, 44.

${ }^{18}$ Karl W.Deutsch, Risse im Monolith. Möglichkeiten und Arten der Desintegration in totalitären Systemen [1954], in: Bruno Seidel/Siegfried Jenkner (Hrsg.), Wege der Totalitarismus-Forschung, 3. Aufl., Darmstadt 1974, S.197-227; Karl D. Bracher, Stufen der Machtergreifung, in: Karl D. Bracher u. a., Die nationalsozialistische Machtergreifung. Studien zur Errichtung des totalitären Herrschaftssystems in Deutschland 1933/34, Köln/Opladen 1960, S.29-368, hier: S.218f.; Gerhard Schulz, Die Anfänge des totalitären Maßnahmenstaates, in: ebd., S.369-681, hier: S.680; ders., Der Begriff des Totalitarismus und der Nationalsozialismus, in: Soziale Welt 12 (1961), S. 112-128, hier: S. 120; vgl. (mit weiteren Hinweisen) Ruck, Führerabsolutismus, S. $39 \mathrm{f}$.

${ }^{19} \mathrm{Karl}$ Holl, Föderalismus zwischen Partikularismus und Zentralismus. Zur Geschichte und zur Übertragbarkeit des deutschen Modells, in: Gerhard Stuby (Hrsg.), Föderalismus und Demokratie. Ein deutsch-sowjetisches Symposium, Baden-Baden 1992, S.43-48, hier: S.45; vgl. in diesem Sinne etwa Karl D.Erdmann, Deutschland unter der Herrschaft des Nationalsozialismus 19331939. (Gebhardt Handbuch der deutschen Geschichte, Bd.20), München 1980, S. 92.

${ }^{20}$ Ulrich von Hehl, Nationalsozialismus und Region. Bedeutung und Probleme einer regionalen und lokalen Erforschung des Dritten Reiches, in: Zeitschrift für bayerische Landesgeschichte 56 (1993), S.111-129, hier: S.114; vgl. dazu Kurt Düwell, Vergleichende Strukturfragen einer Regionalgeschichte der NS-Zeit, in: Staatliches Institut für Lehrerfort- und -weiterbildung des Landes Rheinland-Pfalz (Hrsg.), Studienmaterialien, H.25, Speyer 1979, S.92-116, hier: S. 92 f.; ders., Regionale Geschichte, S.287f.

${ }^{21}$ Vgl. Ruck, Führerabsolutismus, S. 42 f. (mit Hinweisen auf die einschlägigen Beiträge Martin Broszats und Hans Mommsens).

${ }^{22}$ Düwell, Strukturfragen, S. 93.

${ }^{23}$ Vgl. etwa Ian Kershaw, Der Hitler-Mythos. Volksmeinung und Propaganda im Dritten Reich, Stuttgart 1980; Hans-Jürgen Eitner, Hitlers Deutsche. Das Ende eines Tabus, Gernsbach 1991; Marlies G.Steinert, Deutsche im Krieg: Kollektivmeinungen, Verhaltensmuster und Mentalitäten, in: Bracher u. a., Deutschland 1933-1945, S.474-487. 
distischen Zentralisierungsanspruch - vermeintlich - nicht eingelöst hat. Denn jenseits solcher Deklamationen hatte der totalitäre Zentralismus des NS-Staates mit dem bürokratisch-obrigkeitsstaatlichen Zentralismus traditioneller Prägung nur wenig gemein. In der Substanz war es kein territorial-institutioneller, sondern zuvörderst ein Fübrerzentralismus sui generis ${ }^{24}$. Dieser neue, autokratische Zentralismus zielte nicht auf die flächendekkende Integration des Herrschaftsgebietes durch hierarchische Regierungsinstitutionen, sondern auf die umfassende Mobilisierung der personellen und materiellen Ressourcen des deutschen Reiches durch Führungspersonen.

Zwar beanspruchte Hitler nach der Etablierung der "souveränen Diktatur “ in seiner Eigenschaft als unumschränkter Herr des permanenten Belagerungszustands ${ }^{25}$ eine entgrenzte Generalkompetenz für sämtliche Entscheidungen des Regimes. Praktisch indessen behielt er in aller Regel nur Fragen von strategischer Bedeutung für die Vorbereitung und Verwirklichung der territorialen Expansionspläne seiner persönlichen Entscheidung $\operatorname{vor}^{26}$. Gleichsam den Maximen eines totalitären Subsidiaritätsprinzips folgend, überließ der Diktator ansonsten die operative Politik den jeweiligen Fachressorts und jenen Sonderbehörden, welche in der Grauzone zwischen Staat und Staatspartei auf sein Geheiß oder mit seiner Billigung wie Pilze aus dem Boden schossen. In der Folge entwickelte sich ein grassierender Ressortegoismus mit der Tendenz zur vertikalen Versäulung des Herrschaftsgefüges ${ }^{27}$. Daran vermochte auch der Chef der Reichskanzlei nichts wesentliches zu ändern, obwohl Lammers seit Mitte 1936 im Auftrage Hitlers das „letztinstanzliche Prüfungs- und Vortragsrecht" in allen Angelegenheiten der laufenden Gesetzgebung ausübte ${ }^{28}$.

Noch deutlicher als auf der funktionalen bildete sich auf der borizontalen Ebene ein „Geflecht personalistischer Herrschaftsbeziehungen“ heraus ${ }^{29}$. Die fragmentierenden Wirkungen dieses Prozesses der territorialen De-Institutionalisierung sind in pointierte Wendungen gekleidet worden: Ausgehend von den besetzten und annektierten Gebieten habe sich seit Kriegsbeginn eine starke „Tendenz zur Auflösung des ,Großdeutschen Reiches“ in regelrechte Satrapien“ Bahn gebrochen - „gewissermaßen Lehensherrschaften, in denen Hitlers ,Vizekönige" nach eigenem Gutdünken schalten und walten sollten"; und diese revolutionäre Entwicklung an der Peripherie habe die NS-Gauleiter im sogenannten "Altreich“ dazu ermuntert, ihre "monokratische Territorialherrschaft" verstärkt auszubauen $^{30}$.

${ }^{24}$ Vgl. Schulz, Anfänge, S. 579f., 679f.; Broszat, Staat Hitlers, S. 167; Rebentisch, Führerstaat, S. $232 \mathrm{f}$.

${ }^{25}$ Ernst Fraenkel, Der Doppelstaat. Recht und Justiz im Nationalsozialismus, 2. Aufl., Frankfurt a.M. 1984, S.26f. (amerikan. Originalausgabe 1941) unter Rückgriff auf eine Begriffsbildung Carl Schmitts von 1921.

${ }^{26}$ Vgl. Rebentisch, Führerstaat, S. 36-46 u. S. 395-424, insbes. S. 413 f., 416.

${ }^{27}$ Vgl. dazu eingehend Broszat, Staat Hitlers, S.326ff.; Rebentisch, Führerstaat, S. 283 ff.; vgl. ferner den Überblick bei Ruck, Führerabsolutismus, S. 44 ff.

${ }^{28}$ Dieter Rebentisch, Hitlers Reichskanzlei zwischen Politik und Verwaltung, in: ders./Karl Teppe (Hrsg.), Verwaltung contra Menschenführung im Staat Hitlers. Studien zum politisch-administrativen System, Göttingen 1986, S.65-99, hier S.85; vgl. ders., Reichskanzlei und Partei-Kanzlei im Staat Hitlers. Anmerkungen zu zwei Editionsprojekten und zur Quellenkunde der nationalsozialistischen Epoche, in: Archiv für Sozialgeschichte 25 (1985), S. 611-633, hier: S.616-620; ders., Führerstaat, S. 46-67, 424-441.

${ }^{29}$ Rebentisch, Verfassungswandel, S. 147.

${ }^{30}$ Rebentisch, Verfassungswandel, S. 146f. Von "nationalsozialstischen Satrapien der Ostgaue" sprach bereits Martin Broszat, Staat Hitlers, S. 171; vgl. auch ders., Reichszentralismus, S. 198. 
Diese Formulierungen lassen darauf schließen, im Staat Hitlers habe sich - in zwei Hauptschüben - ein neuartiger Territorial-„Partikularismus“ herausgebildet; terminologisch wecken sie jedoch zugleich Reminiszenzen an die Verfassungszustände im Alten Reich. In der „res publica composita“ des 17. und 18. Jahrhunderts war aber die staatliche Souveränität ( summa potestas“) zwischen dem Oberstaat und den Unterstaaten geteilt gewesen - durch das Reichslehnsrecht aneinander gekettet, konnten Kaiser und Landesherren sie nur gemeinsam wahrnehmen. Mit kopfschüttelndem Blick auf die amorphe Struktur des Heiligen Römischen Reiches deutscher Nation und die mitunter grotesken Emanationen duodezfürstlichen Souveränitätsstrebens ist der Begriff „Partikularismus“ von der nationalstaatlichen Einigungsbewegung Mitte des 19. Jahrhunderts negativ besetzt worden. Unterlegt mit einem latenten „Separatismusverdacht“ ging er nach 1866/ 1871 als „pejorative Fremdbezeichnung“ für sämtliche Gegner der kleindeutsch-preußischen Reichseinigung und als „Ausdruck unterschwelliger Sorge um den Bestand des Reiches" in das Arsenal der politischen Alltagssprache ein ${ }^{31}$. Der Historiker Fritz Rörig hat ihn 1936 noch einmal auf den Punkt gebracht.

Bevor er sich „über die machtpolitischen oder, besser gesagt: ohnmachtspolitischen Auswirkungen“ des „deutschen staatlichen Partikularismus“ im Alten Reich und im Deutschen Bund verbreitete, kreiste Rörig seinen Erkenntnisgegenstand definitorisch ein: „Deutsche(r) staatliche(r) Partikularismus. Das heißt: das Vorhandensein einer Vielheit von Staatenbildungen innerhalb eines Volkes, das sich nicht nur als eine völkische Einheit fühlt, sondern auch ein das Ganze umfassendes staatliches Band kennt“. Dieser „bedeutet deshalb nicht nur ein Nebeneinander der verschiedenen Partikularstaaten, sondern zugleich ein Übereinander, ein ständiges Spannungsverhältnis zwischen partikularer Staatlichkeit und einer die Gebiete der verschiedenen Partikularstaaten umfassenden Staatlichkeit“. Durch die Hegemonie Preußens, der „erfolgreichste(n) jener partikularen Staatenbildungen, die in allmählicher Zerstörung des alten Reiches entstanden waren“, sei „der ewig labile Spannungszustand zwischen Reich und Partikularstaat“ zwar machtpolitisch entschärft, grundsätzlich jedoch nicht gelöst worden. Erst die Regierung Hitlers habe „das alte deutsche Problem des staatlichen Partikularismus“ aus der Welt geschafft. Mit der Übertragung der Länderhoheitsrechte auf das Reich seien die „erstarrten Zeugnisse eines ganz anders gearteten politischen Wollens, nämlich dem des dynastischen Machtkampfes", beseitigt worden. Damit sah Rörig die Bahn freigeräumt für eine „auf weite Sicht gestaltende Staatsführung, die [...] den deutschen Menschen in die gänzlich unproblematische, endlich spannungslose Einheit von Reich und Volk hineinwachsen“ lasse, ohne indessen „den landschaftlich gegliederten Reichtum deutschen Lebens (zu) zerstöre(n)“ ${ }^{\text {“32. }}$.

Es wird nun zu klären sein, ob die unablässig changierende Realverfassung des NS-Staates angesichts solcher histor(iograph)ischer Konnotationen überhaupt mit dem überkommenen Bild „Zentralismus versus Partikularismus“ begrifflich angemessen zu fassen ist ${ }^{33}$. Im Mittelpunkt steht dabei die Entwicklung des Verhältnisses zentripetaler und zentrifugaler Tendenzen auf der administrativ-politischen Ebene. Dabei konzentriert sich das Au-

${ }^{31}$ Irmline Veit-Brause, Artikel „Partikularismus“, in: Otto Brunner u.a. (Hrsg.), Geschichtliche Grundbegriffe. Historisches Lexikon zur politisch-sozialen Sprache in Deutschland, Bd.4, Stuttgart 1978, S.735-766, hier S.766.

32 Fritz Rörig, Ursachen und Auswirkungen des deutschen Partikularismus. (Vortrag, gehalten auf der Hauptversammlung des Gesamtvereins der deutschen Geschichts- und Altertumsvereine zu Karlsruhe am 22. September 1936), Tübingen 1937, S.3, 18, 32 f.

${ }^{33}$ Skeptisch schon Broszat, Reichszentralismus, S. 185. 
genmerk auf die Intentionen und das jeweilige Gewicht der maßgeblichen Akteure des territorialen Kräftemessens im Verlauf seiner Hauptetappen. Schließlich soll die Schlüsselfrage bedacht werden, ob und inwieweit jene territorialen Fragmentierungstendenzen, welche aus der Regierungspraxis Hitlers und der spezifischen Funktionsweise seines Regimes - wenn schon nicht zwangsläufig so doch folgerichtig - erwuchsen, zu irgendeinem Zeitpunkt dysfunktionale, herrschaftsbedrohende Dimensionen gewannen.

$I I$.

Nachhaltige institutionelle und politische Wirkungen vermag regionales Sonderbewußtsein nur dort zu entfalten, wo es in den Mentalitäten wesentlicher Teile der Bevölkerung kulturell verankert ist. Der symbolische Appell an land(smann)schaftliche Identitäten hatte denn auch bis $1933 \mathrm{zu}$ den Requisiten jener populistischen Mobilisierungsstrategie gehört, mit deren Hilfe die Hitlerbewegung das Berliner "System“ von der Peripherie her zu strangulieren trachtete ${ }^{34}$. Und nach der Machtübernahme diente sie dem NS-Regime dazu, bei Maifeiern, Erntedankfesten und anderen Anlässen des NS-Feierjahres seine totalitären Zentralisierungsabsichten hinter einer Fassade der Brauchtümelei zu verbergen ${ }^{35}$. Autochthonen Äußerungen des Kulturregionalismus indessen begegneten die zentralen Instanzen des NS-Staates mit äußerstem Argwohn. Sobald sich daraus auch nur Ansätze autonomistischer Identitätsbildung zu entwickeln schienen, traf sie das sanktionenbewehrte Verdikt des Kultur- „Partikularismus“ oder gar des Kultur-„Separatismus“36.

Bezeichnenderweise vermochte sich die landschaftliche und regionale Traditionspflege in ihren traditionellen Formen nur dort weitgehend unbehelligt von solchen Interventionen zu behaupten, wo dies den starken Männern der NS-Staatspartei in der Provinz politisch opportun erschien ${ }^{37}$. Doch dies ist nicht das Thema dieser Skizze ${ }^{38}$. Hier interessiert die administrative und politische Dimension des territorialen „Partikularismus“ im "Dritten Reich“, insbesondere die Entwicklung der gemeinhin als solche bezeichneten „Partikulargewalten der Oberpräsidenten, Reichsstatthalter und Landesminister “39. Von konservativen Exponenten des autoritären Verwaltungszentralismus wurde bereits nach wenigen Jahren beklagt, daß sich die NS- „Gaufürsten“ als „viel hartnäckigere Föderalisten als vor

${ }^{34}$ Zur regionalen Verankerung des NS vor 1933 siehe den Beitrag von Ursula Büttner in diesem Band. Thomas Schnabel, Württemberg zwischen Weimar und Bonn 1928 bis 1945/46, Stuttgart u.a. 1986, S.111; Kay Dohnke, „Plattdeutsch als Waffe im politischen Kampfe“. Anmerkungen zur Verwendung des Niederdeutschen in nationalsozialistischer Agitation und Propaganda, in: ders. u. a. (Hrsg.), Niederdeutsch im Nationalsozialismus. Studien zur Rolle regionaler Kultur im Faschismus, Hildesheim u.a. 1994, S.149-206; vgl. ferner die kursorischen Hinweise bei Gerhard Paul, Aufstand der Bilder. Die NS-Propaganda vor 1933, Bonn 1990, S. 85-88, 92, 209.

${ }^{35}$ Vgl. etwa Michael Ruck, Vom Demonstrations- und Festtag der Arbeiterbewegung zum nationalen Feiertag des deutschen Volkes. Der 1. Mai im Dritten Reich und die Arbeiter, in: Inge Marßolek (Hrsg.), 100 Jahre Zukunft. Zur Geschichte des 1. Mai, Frankfurt a. M. 1990, S. 171-188.

${ }^{36}$ Vgl. etwa Jan Wirrer, Sprachlicher Regionalismus, sprachlicher Partikularismus, sprachlicher Separatismus. Eine Kontroverse aus dem Jahre 1938, in: Edith Slembek (Hrsg.), Von Lauten und Leuten. Festschrift für Peter Martens zum 70. Geburtstag, Frankfurt a. M. 1989, S. 207-216.

${ }^{37}$ Vgl. den Beitrag von Walter Ziegler in diesem Band; vgl. ferner Eike Hennig, Regionale Unterschiede bei der Entstehung des deutschen Faschismus. Ein Plädoyer für „mikroanalytische Studien" zur Erforschung der NSDAP, in: Politische Vierteljahresschrift 21 (1980), S. 152-173, hier: S. 155 f.; Düwell, Regionale Geschichte, S. 304.

${ }^{38}$ Zur Kulturpolitik vgl. den Beitrag von Volker Dahm in diesem Band.

${ }^{39}$ Broszat, Staat Hitlers, S. 161. 
ihnen die Länderministerpräsidenten " gebärdeten ${ }^{40}$. An die Stelle des traditionellen Länderpartikularismus, scholl es von dort zurück, sei mittlerweile der in Berlin grassierende Ressortpartikularismus getreten ${ }^{41}$.

Offenkundig hatte die altbekannte Rivalität zwischen Reichszentralgewalt und regionalen Herrschaftszentren die erste Phase der NS-Unitarisierungspolitik - NS-Machtübernahme und "Gleichschaltungs"-aktionen 1933/34 - überdauert, allerdings in gewandelter Form. Denn der staatliche Föderalismus war durch die NS-Usurpation der Landesregierungen im März 1933, die beiden Gleichschaltungsgesetze vom 31. März und 7.April 1933 sowie das Gesetz über den Neuaufbau des Reiches vom 30.Januar 1934 und die Aufhebung der Länderkammer am 14. Februar 1934 ebenso beseitigt worden wie die Selbstverwaltungs- und teilstaatlichen Mitwirkungsrechte der preußischen Provinzen ${ }^{42}$. Die faktische Integration der preußischen Staatsregierung und -verwaltung in die Reichsregierung, die Gleichschaltung und Auflösung der Landesparlamente und der provinziellen Vertretungskörperschaften, die Inauguration von NSDAP-Gauleitern zu Reichsstatthaltern und preußischen Oberpräsidenten durch Hitler, die Ernennung der Regierungschefs und Länderminister durch diese "Vizekönige des Reiches" ${ }^{433}$ in der Provinz (seit 1935 durch den "Führer und Reichskanzler" selbst), die Liquidierung des Reichsrates - alles dies schien ,an die Stelle der bundesstaatlichen Struktur“ in der Tat jenen "rigorose( $n$ ) staatliche(n) Zentralismus ${ }^{\alpha 44}$ zu setzen, zu dem sich Hitler am 1. September 1933 nochmals bekannt hatte: Die nationalsozialistische Bewegung sei „nicht der Konservator der

${ }^{40}$ Reichsfinanzminister Graf von Schwerin Krosigk; zit. nach Broszat, Staat Hitlers, S. 154.

${ }^{41}$ So der NSDAP-Gauleiter und Reichsstatthalter Sauckel (Thüringen) in seiner umfangreichen Denkschrift v. Januar 1936; zit. nach: Peter Hüttenberger, Die Gauleiter. Studie zum Wandel des Machtgefüges in der NSDAP, Stuttgart 1969, S.112-117, hier; S.116; vgl. Rebentisch, Führerstaat, S.261; ders., Verfassungswandel, S. 140.

${ }^{42}$ Siehe allgemein Bracher, Stufen, S. 136-144, 170f.; Schulz, Anfänge, S. 584-612; Peter Diehl-Thiele, Partei und Staat im Dritten Reich. Untersuchungen zum Verhältnis von NSDAP und allgemeiner innerer Staatsverwaltung 1933-1945, München 1969, S. 37-73; Hüttenberger, Gauleiter, S.74-91; Broszat, Staat Hitlers, S. 130-161; ders., Reichszentralismus; Hans-Jürgen Sengotta, Der Reichsstatthalter in Lippe 1933-1939. Reichsrechtliche Bestimmungen und politische Praxis, Detmold 1976; Gotthard Jasper, Die gescheiterte Zähmung. Wege zur Machtergreifung Hitlers 1930-1934, Frankfurt 1986, S.139-153; vgl. zusammenfassend Dieter Rebentisch, Innere Verwaltung, in: Deutsche Verwaltungsgeschichte, Bd.4: Das Reich als Republik und in der Zeit des Nationalsozialis-

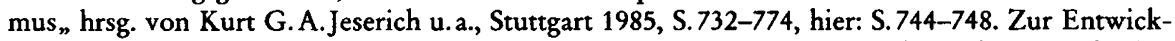
lung in Preußen siehe Sabine Höner, Der nationalsozialistische Zugriff auf Preußen. Preußischer Staat und nationalsozialistische Machteroberungsstrategie 1928-1934, Bochum 1984, S. 409-499; Karl Teppe, Provinz, Partei, Staat. Zur provinziellen Selbstverwaltung im Dritten Reich. Untersucht am Beispiel Westfalens, Münster 1977; ders., Die preußischen Oberpräsidenten 1933-1945, in: Klaus Schwabe (Hrsg.), Die preußischen Oberpräsidenten 1815-1945, Boppard 1981, S.219248, 335-338; ders., Die Oberpräsidenten der Provinz Westfalen 1919-1945. Eine sozialhistorische Studie, in: Mentalitäten und Lebensverhältnisse. Beispiele aus der Sozialgeschichte der Neuzeit. Rudolf Vierhaus zum 60. Geburtstag, Göttingen 1982, S.260-274; Horst Romeyk, Verwaltungsund Behördengeschichte der Rheinprovinz 1914-1945, Düsseldorf 1985; ders., Der Gau Moselland in der nationalsozialistischen Reichsreform, in: JWL 11 (1985), S. 247-269; Kurt Jürgensen, Die Gleichschaltung der Provinzialverwaltung. Ein Beitrag zur Durchsetzung der nationalsozialistischen Herrschaft in Schleswig-Holstein (1932-1934), in: Erich Hoffmann/Peter Wulf (Hrsg.), "Wir bauen das Reich ${ }^{\alpha}$. Aufstieg und erste Herrschaftsjahre des Nationalsozialismus in Schleswig-Holstein, Neumünster 1983, S.393-422.

${ }^{43}$ Hitler auf der Reichsstatthalter-Konferenz v. 22. März 1934; zit. nach: Broszat, Staat, S. 150; vgl. zur weiteren Verwendung des Begriffs Rebentisch, Führerstaat, S. 538.

${ }^{44}$ Erdmann, Deutschland, S. 92. 
Länder der Vergangenheit“, proklamierte ihr Führer auf der Nürnberger Heerschau seiner siegreichen Bewegung, „sondern ihr Liquidator zugunsten des Reiches der Zukunft ${ }^{\text {“45. }}$.

In der Tat wurden 1933/34 zwei konstitutive Elemente der Bundesstaatlichkeit eliminiert: die regionalen Gebietskörperschaften büßten ihre autonomen Rechtsetzungskompetenzen gänzlich ein, und sie wurden von der Teilhabe an den gesamtstaatlichen Willensbildungs- und Entscheidungsprozessen rigoros ausgeschlossen. Formal war das Deutsche Reich aus der "Nationalen Revolution“ als dezentralisierter Einheitsstaat hervorgegangen, dessen territoriale Untergliederungen ihre Handlungsbefugnisse durch einseitige, jederzeit widerrufliche Delegationsakte der Zentralgewalt verliehen bekamen ${ }^{46}$. Praktisch allerdings wirkten die föderalen Strukturen traditioneller Prägung ${ }^{47}$ nachhaltig in den NSStaat hinein und über ihn hinweg - nur ein weiteres Beispiel dafür, daß die politische „Revolution“ von 1933 durch beachtliche Momente institutioneller wie gesellschaftlicher Kontinuität unterlegt gewesen ist ${ }^{48}$.

Verantwortlich dafür waren in erster Linie die machtpolitischen Zwänge, denen sich Hitler nach der Machtübernahme einstweilen noch unterworfen sah. Der Führer der NSDAP konnte als Regierungschef nur reüssieren, sofern maßgebliche Teile der alten Macht- und Funktionseliten die Errichtung seiner „kommissarischen Diktatur“49 mehr oder minder billigend hinnahmen ${ }^{50}$. Um sich ihrer Kooperationsbereitschaft zu versi-

${ }^{45}$ Völkischer Beobachter v. 2.1. 1933; zit. nach: Diehl-Thiele, Partei, S. 62 (Hervorhebungen von mir); vgl. Walter Baum, Die "Reichsreform“ im Dritten Reich, in: Vierteljahrshefte für Zeitgeschichte [VfZ] 3 (1955), S. 36-56, hier: S. 40f.; Broszat, Reichszentralismus, S. 187.

${ }^{46}$ Vgl. Arnold Brecht, Föderalismus, Regionalismus und die Teilung Preussens, Bonn 1946, S. $192 \mathrm{f}$.

${ }^{47}$ Siehe dazu im einzelnen Ernst Deuerlein, Föderalismus. Die historischen und philosophischen Grundlagen des föderativen Prinzips, München 1972; Thomas Nipperdey, Der Föderalismus in der deutschen Geschichte [1980], in: ders., Nachdenken über die deutsche Geschichte. Essays, 2. Aufl., München 1986, S.60-109; Rudolf Vierhaus, Historische Grundlagen des Bundesrates. Politische Einheit und Staatenvielfalt in der deutschen Verfassungsgeschichte, in: Vierzig Jahre Bundesrat, hrsg. vom Bundesrat, Baden-Baden 1989, S.21-41.

${ }^{48}$ Vgl. Karl D. Bracher, Tradition und Revolution im Nationalsozialismus [1976], in: ders., Zeitgeschichtliche Kontroversen. Um Faschismus, Totalitarismus, Demokratie, 5. Aufl., München/Zürich 1984, S. 63-79; Thomas Nipperdey, 1933 und die Kontinuität der deutschen Geschichte [1978], in: ders., Nachdenken, S. 186-205. Zum revolutionären Charakter des politischen Umbruchs von 1933 vgl. Horst Möller, Die nationalsozialistische Machtergreifung. Revolution oder Konterrevolution? In: Rudolf Lill/Heinrich Oberreuter (Hrsg.), Machtverfall und Machtergreifung. Aufstieg und Herrschaft des Nationalsozialismus, München 1983, S. 121-139; Richard Löwenthal, Die nationalsozialistische „Machtergreifung“ - eine Revolution? Ihr Platz unter den totalitären Revolutionen unseres Jahrhunderts, in: Martin Broszat u. a. (Hrsg.), Deutschlands Weg in die Diktatur. Internationale Konferenz zur nationalsozialistischen Machtübernahme im Reichstagsgebäude zu Berlin, Berlin 1983, S. 42-74; Bedrich Löwenstein, Nationalsozialistische Revolution. Einige Fragezeichen zur historischen Begrifflichkeit, in: Thomas Nipperdey u. a. (Hrsg.), Weltbürgerkrieg der Ideologien. Antworten an Ernst Nolte. Festschrift zum 70. Geburtstag, Frankfurt/Berlin 1993, S. 122-134.

${ }^{49}$ Fraenkel, Doppelstaat, S.27.

${ }^{50}$ Vgl. etwa Hans Mommsen, Zur Verschränkung traditioneller und faschistischer Führungsgruppen in Deutschland beim Übergang von der Bewegungs- zur Systemphase [1976], in: ders. Der Nationalsozialismus und die deutsche Gesellschaft. Ausgewählte Aufsätze. Zum 60. Geburtstag, hrsg. von Lutz Niethammer/Bernd Weisbrod, Reinbek 1991, S.39-66; ders., Die deutschen Eliten und der Mythos des nationalen Aufbruchs von 1933, in: Merkur 38 (1984), S. 97-102; Michael Geyer, Traditional Elites and National Socialist Leadership, in: Charles S. Maier u.a. (Hrsg.), The Rise of the Nazi Regime. Historical Reassessments, Boulder, Col./London 1986, S.57-73; Alf Lüdtke, Funktionseliten: Täter, Mit-Täter, Opfer? Zu den Bedingungen des deutschen Faschismus, in: ders. (Hrsg.), Herrschaft als soziale Praxis. Historische und sozial-anthropologische Studien, Göttingen 1991, S. 559-590. 
chern, mußte Hitler ihnen die Illusion vermitteln, daß zwar die pluralistische Parteienund Verbändedemokratie von Weimar, nicht aber essentielle Strukturelemente des Rechts- und Verfassungsstaates beiseite geräumt würden. Unter den Bedingungen, welche das Zentrum an seine Zustimmung zum Ermächtigungsgesetz geknüpft hatte, stand eine Bestandsgarantie für die Länder ganz oben. So bekannte sich der Diktator in spe am 23. März 1933 in der Berliner Kroll-Oper ausdrücklich zum Fortbestand der föderalen Grundordnung, und in Artikel 2 des Staatsstreichs in Gesetzesform wurde die Institution des Reichsrates für unantastbar erklärt ${ }^{51}$. Bei diesen und anderen Lippenbekenntnissen handelte es sich lediglich um eine „bewußt eingesetzte Herrschaftstechnik" Hitlers ${ }^{52}$, mit deren Hilfe die quasi-revolutionäre Kette von Verfassungsbrüchen auf dem Weg in den totalitären Führerstaat kaschiert werden sollte.

Neben der Loyalität der Reichswehr war die reibungslose Zusammenarbeit der administrativen Funktionseliten von strategischer Bedeutung für die Konsolidierung des NSRegimes. Zwar schuf sich die "Regierung der Nationalen Einheit" mit dem sogenannten „Berufsbeamtengesetz“ (BBG) Anfang April 1933 ein Instrument für die pseudo-legale Säuberung der Verwaltungen von politisch mißliebigen Beamten ${ }^{53}$. Doch es wurde in Süd- und Südwestdeutschland kaum angewandt, und auch in Preußen erfüllte das BBG seinen Zweck in der Hauptsache als Mittel kollektiver Einschüchterung ${ }^{54}$. Im übrigen suchten Hitler, Reichsinnenminister Frick und seine führenden Gefolgsleute die Beamtenschaft mit Angeboten aus dem Repertoire des autoritären Obrigkeitsstaates für ihr Regime einzunehmen.

${ }^{51}$ Rudolf Morsey (Hrsg.), Das „Ermächtigungsgesetz“ vom 24. März 1933. Quellen zur Geschichte und Interpretation des „Gesetzes zur Behebung der Not von Volk und Reich“, Düsseldorf 1992, S. 49, 76; vgl. Baum, Reichsreform, S. 37 f. Zum pseudo-legalen Charakter des Ermächtigungsgesetzes siehe Bracher, Stufen, S.167f.; Diemut Majer, Grundlagen des nationalsozialistischen Rechtssystems. Führerprinzip - Sonderrecht - Einheitspartei, Stuttgart u. a. 1987, S.70-73.

52 Karl D. Bracher, Die deutsche Diktatur. Entstehung, Struktur, Folgen des Nationalsozialismus, 5. Aufl., Köln 1976, S. 233.

${ }^{53}$ Gesetz zur Wiederherstellung des Berufsbeamtentums v. 7.4. 33 (RGBl. I, S. 175f.); faks. abgedr. in: Hirsch u.a., S.299f. Entwürfe und eingehende Darstellung der Genese siehe Mommsen, Beamtentum; vgl. Caplan, Government, S.141-149; Jörg Grotkopp, Beamtentum und Staatsformwechsel. Die Auswirkungen der Staatsformwechsel von 1918, 1933 und 1945 auf das Beamtenrecht und die personelle Zusammensetzung der deutschen Beamtenschaft, Frankfurt u. a. 1992, S. 105-131.

${ }^{54}$ Siehe dazu eingehend Michael Ruck, $\ldots . .$. und dann kam ich in das Dritte Reich, einfach als Berufsbeamter." Zur Rolle der administrativen Eliten in Südwestdeutschland 1928 bis 1972, Habilitationsschrift Mannheim 1994, Kapitel II (München, i. E.); vgl. ders., Administrative Eliten in Demokratie und Diktatur. Beamtenkarrieren in Baden und Württemberg von den zwanziger Jahren bis in die Nachkriegszeit, in: Cornelia Rauh-Kühne/Michael Ruck (Hrsg.), Regionale Eliten zwischen Diktatur und Demokratie. Baden und Württemberg 1930 bis 1952, München 1993, S.3769, hier: S.46-56; ders., Kollaboration - Loyalität - Resistenz. Administrative Eliten und NS-Regime am Beispiel der südwestdeutschen Innenverwaltung, in: Thomas Schnabel/Angelika HauserHauswirth (Hrsg.), Formen des Widerstandes im Südwesten 1933-1945. Scheitern und Nachwirken, Stuttgart u.a. 1994, S.124-152, hier: S.129-131; vgl. allgemein Günter Püttner, Der Öffentliche Dienst [1933-1945], in: Deutsche Verwaltungsgeschichte IV, S. 1082-1098, hier: S.10841086; Bernd Wunder, Geschichte der Bürokratie in Deutschland, Frankfurt 1986, S.138-140; Caplan, Government, S.138-149; vgl. ferner Walter H.Pehle, Die nationalsozialistische Machtergreifung im Regierungsbezirk Aachen unter besonderer Berücksichtigung der staatlichen und kommunalen Verwaltung 1922-1933, Diss. Düsseldorf 1976; Klaus Schönhoven, Der politische Katholizismus in Bayern unter der NS-Herrschaft 1933-1945, in: Martin Broszat/Hartmut Mehringer (Hrsg.), Bayern in der NS-Zeit, Bd.5, München/Wien 1983, S. 541-646, hier: S.618634. 
Dazu gehörte der Verzicht auf die mancherseits erwartete Angleichung der Verwaltungsgrenzen an die Gaueinteilung der NSDAP ${ }^{55}$ ebenso wie die Einsetzung von Reichsstatthaltern und die Umgestaltung der preußischen Provinzialverwaltung. In typischer Manier wurde dabei auf Versatzstücke aus der Reichsreformdebatte der zwanziger und frühen dreißiger Jahre zurückgegriffen, diese jedoch ihres demokratisch-parlamentarischen Kontextes entkleidet und damit „ins Gegenteil“ verkehrt ${ }^{56}$. Dieses Vorgehen bediente einerseits jene technokratisch-vordemokratischen Aspirationen der preußischen und der Reichsministerialbürokratie, welche durch das Scheitern der republikanischen Reichsrefom in zentralistischer Hinsicht enttäuscht worden waren ${ }^{57}$. Andererseits trug es der Tatsache Rechnung, daß der deutsche Föderalismus respektive „Partikularismus“ des 19. und frühen 20.Jahrhunderts zuvörderst ein "gouvernementaler" gewesen war, als dessen tragende Säulen sich die regionalen Verwaltungseliten begriffen und an dessen Existenz sich ihr Status einer herausgehobenen, teilautonomen Schlüsselgruppe der deutschen Gesellschaft knüpfte ${ }^{58}$.

Nach der raschen Ausschaltung seiner innenpolitischen Gegner und der massenhaften Selbstgleichschaltung der traditionellen Eliten hatte Hitler unmittelbare Anfechtungen seiner „kommissarischen Diktatur" nur noch aus den eigenen Reihen zu gewärtigen. Mit der Proklamation des Endes der „nationalsozialistischen Revolution“ am 6.Juli 1933 waren die weitreichenden Machtansprüche vor allem der SA noch längst nicht von der politischen Tagesordnung radiert ${ }^{59}$. Vielmehr bedurfte es einer umfassenden Domestizierungsstrategie, um die Parteirevolution in den regionalen Herrschaftszentren des Reiches unter Kontrolle zu bringen. Die spontane Einsetzung der Reichsstatthalter auf persönliche Weisung Hitlers war ein erster Schritt in diese Richtung gewesen.

Seit der Jahresmitte 1933 wurde im Reichsinnenministerium mit Hochdruck an Plänen gearbeitet, das Reich unter funktionalen und herrschaftstechnischen Gesichtspunkten territorial zu reorganisieren. Vordergründiges Ziel der konstitutionellen Strategie dieser

${ }^{55} \mathrm{Vgl}$. Brecht, Föderalismus, S. 202.

${ }^{56}$ Vgl. Brecht, Föderalismus, S. 208 f.(Zitat), 179f., 194, 197 f.; Schulz, Anfänge, S. 585, 591. Zum Anknüpfen des NS-Regimes an die technokratischen Reformkonzepte der späten Weimarer Republik vgl. auch Caplan, Government, S.142-152; ferner Broszat, Reichszentralismus, S. 193; Rebentisch, Führerstaat, S.234f.

${ }^{57}$ Zur traditionellen Frontstellung der Berliner Ministerialverwaltungen gegen den (nicht nur rheinischen) „Provinzialegoismus“ vgl. Veit-Brause, Partikularismus, S.740f. Zur antiparlamentarischen Ausrichtung des Föderalismus im Kaiserreich vgl. Nipperdey, Föderalismus, S.83 f. Zur Kontinuität technokratisch-antiparlamentarischer Einstellungen der höheren Beamtenschaft nach $1918 \mathrm{vgl}$. etwa Peter-Christian Witt, Konservatismus als „Überparteilichkeit “. Die Beamten der Reichskanzlei zwischen Kaiserreich und Weimarer Republik 1900-1933, in: Dirk Stegmann u. a. (Hrsg.), Deutscher Konservatismus im 19. und 20. Jahrhundert. Festschrift für Fritz Fischer zum 75. Geburtstag und zum 50.Doktorjubiläum, Bonn 1983, S. 231-280, hier: S. 267-270; vgl. ferner Rebentisch, Verfassungswandel, S.127f. Zu den zentralistisch-antiparlamentarischen, auf eine Wiederherstellung bürokratischer Dominanz zielenden Intentionen der Brüningschen Reichsreform-Pläne vgl. Hans Mommsen, Die Stellung der Beamtenschaft in Reich, Ländern und Gemeinden in der Ära Brüning, in: VfZ 21 (1973), S.151-165, hier: S.162f. Zur Reichsreform allgemein vgl. (mit weiteren Hinweisen) Werner Frotscher, Organisation der Reichsverwaltung und der Länderverwaltungen einschließlich Vorschläge zur Reichsreform, in: Deutsche Verwaltungsgeschichte IV, S.112-137, hier: $130 \mathrm{ff}$.; Rebentisch, Verfassungswandel, S.129-132; vgl. weiterhin Brecht, Föderalismus, S. 126-180.

${ }^{58}$ Vgl. Veit-Brause, Partikularismus, S. 741; Vierhaus, Historische Grundlagen, S.41.

${ }^{59}$ Zit. nach: Albrecht Tyrell, Auf dem Weg zur Diktatur: Deutschland 1930 bis 1934, in: Bracher u. a., Deutschland 1933-1945, S. 15-31, hier: S. 28; vgl. Schulz, Anfänge, S. 585. 
zweiten Phase der NS-Unitarisierungspolitik war die Effektivitätssteigerung der Reichsverwaltung durch Zentralisierung und Vereinheitlichung. Dahinter verbarg sich jedoch die Absicht, im Zuge der normativen Verankerung eines autoritären Zentralismus die im Frühjahr 1933 versäumte Zerschlagung der traditionellen Verwaltungsstrukturen nachzuholen. Vor allem aber sollten die Gauleiter in ihrer Eigenschaft als Reichsstatthalter oder preußische Oberpräsidenten fest in den zentralisierten Instanzenzug eingebunden und so jeglichen Sonderbestrebungen von vornherein enge Grenzen gezogen werden. Nach dem Verlust ihrer führerunmittelbaren Ausnahmestellung und ihres administrativen Rückhalts in den gewachsenen Verwaltungsapparaten, so das Kalkül des Reichsinnenministers Frick und seiner Verfassungsreferenten Nicolai und Medicus, hätten die regionalen Parteiführer seinen Mediatisierungsbestrebungen nur noch wenig entgegenzusetzen gehabt ${ }^{60}$.

Gegen diese Pläne regte sich alsbald heftiger Widerstand in den Ländern und Provinzen, aber auch innerhalb der Reichsregierung. So unterstützte der preußische Ministerpräsident Göring im März 1934 wohl prinzipiell die vom Innenminister betriebene Schaffung sogenannter "Reichsgaue" anstelle der bisherigen Länder; doch ein Vierteljahr darauf veranschlagte er für diesen Umstellungsprozeß mindestens eine Dekade - im NS-Sprachgebrauch das Synonym für den St. Nimmerleins-Tag. Göring lehnte also die ReichsreformPläne Fricks strikt ab. Der Hinweis des Ministerpräsidenten auf die Fortexistenz des preuBischen "Staatsbegriff(s)" unterstrich das ebenso wie seine kategorische Absage an einen „scharf zentralisierte(n) Einheitsstaat romanischer Prägung " ${ }^{\text {"61 }}$.

Hitler teilte diese Aversion gegen ein ${ }_{n}$ zentralistisches Reichsverwaltungssystem autoritärer Prägung " ${ }^{\text {"62 }}$. Schritt um Schritt rückte der Diktator von den hochfliegenden Zentralisierungsplänen seines Innenministers ab. Bereits Ende 1933/Anfang 1934 hatte er darauf zusehends dilatorisch reagiert. Nach der gewaltsamen Lösung der innerparteilichen Machtfrage am 30.Juni/1.Juli 1934 schieden Domestizierungsgesichtspunkte für Hitler endgültig aus. Und nach der am 1. August 1934 vom Reichstag, am 19. August von der Wahlbevölkerung akklamierten Selbstinauguration zum lebenslangen Diktator ${ }^{63}$ gab es für den „Führer des deutschen Reiches und Volkes“" erst recht keinen Grund mehr, seine Allmacht durch kodifizierte Regularien und die institutionelle Stärkung der Ministerialbürokratie einschränken zu lassen ${ }^{64}$. Eine Zeitlang ließ Hitler die bürokratischen Sandkastenspieler noch gewähren. Als Frick jedoch mit dem Zweiten Reichsstatthalter-Gesetz vom 30. Januar 1935 die obligatorische Personalunion von Reichsstatthaltern und Regierungschefs einführen wollte, um die Gauleiter über ihre staatliche Funktion seiner Kontrolle zu unterwerfen, wandelte Hitler diese Gesetzesvorschrift kurzerhand in eine "Kann-Bestimmung " um ${ }^{65}$. Und im März 1935 ließ er diesem Affront die Weisung folgen, auch die

${ }^{60}$ Vgl. Baum, Reichsreform, S. 41 f.; Schulz, Anfänge, S. 579-599; Diehl-Thiele, Partei, S. 61-66; Broszat, Staat, S.150f.; Broszat, Reichszentralismus, S.187f.; Martyn Housden, Helmut Nicolai and Nazi Ideology, Houndsmills/London 1992.

${ }^{61}$ Denkschrift v. 21.3. 1934; zit. nach: Rebentisch, Führerstaat, S. 234; Rede v. 18.6. 1934 vor dem PreuBischen Staatsrat; zit. nach: Baum, Reichsreform, S. 49. Zu den Vorbehalten Görings, Bayerns und anderer Regionalgewalten gegen die Reichsreform vgl. Broszat, Reichszentralismus, S. 188-191. Zu den Reichsgau-Planungen des Reichsinnenministeriums vgl. Rebentisch, Führerstaat, S.235f.

${ }^{62}$ Rebentisch, Führerstaat, S. 235. Zur Position Hitlers vgl. ebd., S. 204, 223, 228, 267, $326 \mathrm{f}$.

${ }^{63}$ Vgl. Ruck, Führerabsolutismus, S. 32-34.

${ }^{64} \mathrm{Vgl}$. Broszat, Staat, S. 151-153, 159 f.

${ }^{65}$ Vgl. Schulz, Anfänge, S.607; Diehl-Thiele, Partei, S. 72 f.; Rebentisch, Führerstaat, S. 236. 
internen Erörterungen der Reichsreform einzustellen ${ }^{66}$. Jede öffentliche Debatte darüber war bereits im November 1933 und im Februar 1934 untersagt worden, um die ideologisch-propagandistische Fiktion der vollkommenen Einmütigkeit des NS-Regimes nicht trüben zu lassen ${ }^{67}$.

Solcherart in seinen Bemühungen um eine normative Fixierung des Verhältnisses von Reichszentralgewalt und regionalen Gewalten im NS-Staat gestoppt, konzentrierte sich Frick darauf, die Verfassungswirklichkeit in seinem Sinne umzuformen. Diese institutionelle Strategie bestimmte die dritte Phase des territorialen Kräftemessens von 1934/35 bis 1938/39.

Im Verlauf dieses Jahrfünfts wurde mit verstärktem Nachdruck jenes „Zentralregiment der inneren Verwaltung“ errichtet, welches das Reichsinnenministerium - sehr zum Bedauern seiner Beamten - mangels eines eigenen Behördenunterbaus im föderalen Staat von Weimar nicht einmal ansatzweise hatte realisieren können ${ }^{68}$. Durch das Neuaufbaugesetz vom 30. Januar 1934 wurden die Innenverwaltungen der Länder den Weisungen des Reichsinnenminister unterworfen und die Reichsstatthalter seiner Dienstaufsicht unterstellt ${ }^{69}$. Die Übernahme des Preußischen Ministeriums des Innern am 1. Mai 1934 und dessen organisatorische Eingliederung in das Reichsressort schienen aus der vielbespöttelten „Dame ohne Unterleib “70 die dominierende Exekutivbehörde des Deutschen Reiches zu machen ${ }^{71}$. Zum „Superminister mit zentraler Befugnis“ indessen vermochte sich Frick zu seinem Leidwesen niemals aufzuschwingen ${ }^{72}$. Denn parallel zum Aufstieg seines Hauses unterhöhlte die forcierte „Verreichlichung" von Aufgabenbereichen, die seit jeher zur Prärogative der Länder und der provinziellen Selbstverwaltung gehört hatten, sowohl Fricks zentralistischen Führungsanspruch als auch die Handlungsautonomie der regionalen Herrschaftszentren.

Mit der Kultur- und Bildungspolitik wurde die traditionelle Domäne der Länder frühzeitig geschleift: im März und September 1933 zogen das Reichsministerium für Volksaufklärung und Propaganda und die Reichskulturkammer, in Personalunion geleitet von dem Berliner Gauleiter Joseph Goebbels, wichtige Kompetenzen an sich ${ }^{73}$. Im Mai 1934 folgte das Reichsministerium für Wissenschaft, Erziehung und Volksbildung des Braunschweiger Gauleiters Bernhard Rust ${ }^{74}$. Zwar gelang es Hans Kerrls Mitte Juli 1935 gegründetem

${ }^{66}$ Vgl. Broszat, Staat, S. 157.

${ }^{67}$ Baum, Reichsreform, S. 42, 47.

${ }^{68}$ Schulz, Anfänge, S. 590 f.; vgl. Rebentisch, Führerstaat, S. $92 \mathrm{f}$.

${ }^{69}$ Vgl. Baum, Reichsreform, S. 42-47; Schulz, Anfänge, S. 593-599; Diehl-Thiele, Partei, S. 63-73; Neliba, Wilhelm Frick, S. 99-123.

${ }^{70}$ So das bekannte Diktum des langjährigen Verfassungsreferenten Medicus; zit. nach: Schulz, Anfänge, S. 590.

71 Vgl. Broszat, Staat, S. 156; ders., Reichszentralismus, S. 192; Neliba, Wilhelm Frick, S. 124-128.

72 Schulz, Anfänge, S. 599-607, hier: 600.

${ }^{73}$ Vgl. für vieles Willi A. Boelcke, Volksaufklärung und Propaganda, in: Deutsche Verwaltungsgeschichte IV, S. 949-958; Eugen Schöndienst, Kulturelle Angelegenheiten, in: ebd., S. 988-998; Volker Dahm, Anfänge und Ideologie der Reichskulturkammer. Die „Berufsgemeinschaft“ als Instrument kulturpolitischer Steuerung und sozialer Reglementierung, in: VfZ 34 (1986), S. 53-84. Zu den Auswirkungen auf die regionale und kommunale Kulturpolitik vgl. die eindringliche Situationsbeschreibung des Hallenser Oberbürgermeisters vom Juni 1936; zit. in: Schulz, Anfänge, S. $624 \mathrm{f}$.

${ }^{74}$ Vgl. Philipp Eggers, Bildungswesen [1933-1945], in: Deutsche Verwaltungsgeschichte IV, S. $966-$ 988; Horst Diere: Das Reichsministerium für Wissenschaft, Erziehung und Volksbildung. - Zur Entstehung, Struktur und Rolle einer zentralen schulpolitischen Institution im faschistischen Deutschland, in: Jahrbuch für Erziehungs- und Schulgeschichte 22 (1982), S. 107-120; Neliba, Wilhelm Frick, S. 126-128. 
Reichsministerium für kirchliche Angelegenheiten nicht, sich gegen die mächtige Konkurrenz des Reichsführers SS und des Stellvertreters des Führers zur Schaltstelle der NS-Kirchenpolitik aufzuschwingen ${ }^{75}$. Doch der Einflußverlust der regionalen NS-Repräsentanten verstärkte sich durch die polykratische Konkurrenz zentraler Institutionen auf diesem heiklen Feld der Innenpolitik eher noch. Allerdings wurde ihnen mit Blick auf die ganz unterschiedlichen Verhältnisse vor Ort im Rahmen der strategischen Vorgaben ein vergleichsweise großer Ermessensspielraum belassen ${ }^{76}$.

Im April 1935 fand die von Reichsminister Franz Gürtner seit 1933 gegen erhebliche regionale Widerstände vorangetriebene Verreichlichung des Justizwesens ihren Abschluß ${ }^{77}$. Und als die Sicherheits- und Ordnungspolizei im Juni 1936 dem Reichsführer SS als "Chef der Deutschen Polizei im Reichsinnenministerium" unterstellt wurde, büßten nicht nur die Länder einen weiteren Kernbereich ihrer Teilstaatlichkeit ein ${ }^{78}$; zugleich nahm Heinrich Himmler, dessen "Machtaufstiegsweg über die Länder" geführt hatte ${ }^{79}$, damit auch eine entscheidende Hürde auf dem Weg zur Formierung einer „führerunmittelbaren, außernormativen Sonderexekutive“, dem Ursprung des hyperzentralistischen „SSStaates"80.

Zu allem Überfluß wurden den NS-Führern in der Provinz bereits frühzeitig die Instrumente regionaler Strukturpolitik aus der Hand genommen ${ }^{81}$. Auf der Grundlage seines

${ }^{75}$ Vgl. Ulrich von Hehl, Die Kirchen in der NS-Diktatur. Zwischen Anpassung, Selbstbehauptung und Widerstand, in: Bracher u. a., Deutschland 1933-1945, S.153-181, hier: S.163; vgl. eingehender John S. Conway, Die nationalsozialistische Kirchenpolitik 1933-1945. Ihre Ziele, Widersprüche und Fehlschläge, München 1969, insbes. S.136-159; Leonore Wenschkewitz, Zur Geschichte des Reichskirchenministeriums und seines Ministers, in: Helmut Baier u.a., Kirche und Nationalsozialismus. Zur Geschichte des Kirchenkampfes, München 1969, S. 185-206; Ludwig Volk, Hitlers Kirchenminister. Versuch einer Gesamtdarstellung des Kirchenkampfes im NS-Staat [1970], in: Dieter Albrecht (Hrsg.), Katholische Kirche im Dritten Reich. Eine Aufsatzsammlung, Mainz 1976, S. 211-218; Heinz Boberach, Organe der nationalsozialistischen Kirchenpolitik. Kompetenzverteilung und Karrieren in Reich und Ländern, in: Karl D. Bracher u. a. (Hrsg.), Staat und Parteien. Festschrift für Rudolf Morsey zum 65. Geburtstag, Berlin 1992, S. 305-331.

${ }^{76}$ Vgl. etwa Schnabel, Württemberg, S.403-518, insbes. S. 465 f., 506.

77 Vgl. Karl E. Claussen, Justizverwaltung [1933-1945], in: Deutsche Verwaltungsgeschichte IV, S. 1044-1054; Lothar Gruchmann, Justiz im Dritten Reich 1933 bis 1940. Verwaltung, Anpassung und Ausschaltung in der Ära Gürtner, 2. Aufl., München 1990.

${ }^{78}$ Vgl. Volkmar Götz, Polizei und Polizeirecht [1933-1945], in: Deutsche Verwaltungsgeschichte IV, S. 1017-1031; Gerhard Werle, Justiz - Strafrecht und polizeiliche Verbrechensbekämpfung im Dritten Reich, Berlin/New York 1989; Johnpeter H. Grill, The Nazi Movement in Baden, 1920-1945, Chapel Hill, N.C. 1983, S.260f.; Friedrich Wilhelm, Die württembergische Polizei im Dritten Reich, Diss. Stuttgart 1989 S.142-147.

${ }^{79}$ Broszat, Reichszentralismus, S. 196; vgl. Schulz, Anfänge, S. 601 f.

${ }^{80}$ Wolfang Benz, Partei und Staat im Dritten Reich, in: Martin Broszat/Horst Möller (Hrsg.), Das Dritte Reich. Herrschaftsstruktur und Geschichte, 2. Aufl., München 1986, S.64-82, hier: 78-80; Thamer, Verführung, S.371; vgl. (mit weiteren Hinweisen) Ruck, Führerabsolutismus, S. 52 f.

${ }^{81}$ Vgl. etwa Gerhard Kratzsch, Der Gauwirtschaftsberater im Gau Westfalen-Süd, in: Rebentisch/ Teppe, Verwaltung, S.173-207, hier: S. 182; ders., Der Gauwirtschaftsapparat der NSDAP. Menschenführung - „Arisierung“ - Wehrwirtschaft im Gau Westfalen-Süd, Münster 1989, S. 46f., 501, 503; Hans Fenske, Josef Bürckel und die Verwaltung der Pfalz (1933-1940), in: ebd., S.153-172, hier: S.159; Dieter Wolfanger, Populist und Machtpolitiker. Josef Bürckel: Vom Gauleiter der Pfalz zum Chef der Zivilverwaltung in Lothringen, in: Gerhard Nestler/Hannes Ziegler (Hrsg.), Die Pfalz unterm Hakenkreuz. Eine deutsche Provinz während der nationalsozialistischen Terrorherrschaft, Landau 1993, 63-86, hier: S.68f.; Wolfgang Burth u. a., Nationalsozialistische Wirtschaftslenkung und württembergische Wirtschaft, in: Rauh-Kühne/Ruck (Hrsg.), Regionale Eliten, S.195-219. 
„Neuen Plans“ und des (Ermächtigungs-)Gesetzes über wirtschaftliche Maßnahmen vom 3.Juli 1934 trieb der neue Reichswirtschaftsminister, Reichsbankpräsident Hjalmar Schacht, die zentrale Lenkung der Binnen- und Außenwirtschaft voran ${ }^{82}$. In Konkurrenz dazu forcierte seit 1936 die Vierjahresplan-Administration des preußischen Ministerpräsidenten Göring den Prozeß des „sich Zug um Zug verstärkenden Wirtschaftsdirigismus“ im Zeichen der ökonomischen Kriegsvorbereitungen ${ }^{83}$.

Von einer "monokratischen Territorialherrschaft" der Gauleiter, Reichsstatthalter und Oberpräsidenten konnte mithin während der zweiten Hälfte der dreißiger Jahre nirgends wirklich die Rede sein. Vielmehr sahen sie sich durch die fortschreitende Auszehrung der Länderkompetenzen auf breiter Front in die „Defensive“ gedrängt ${ }^{84}$. Die bisweilen spektakulären Eigensinnigkeiten selbstbewußter Regionalpotentaten der NSDAP können nicht darüber hinwegtäuschen, daß im Konfliktfall - zumal in Fragen von grundsätzlicher Bedeutung - in aller Regel die Zentralbehörden obsiegten ${ }^{85}$. Selbst besonders tatkräftigen Gauleitern wie dem Pfälzer Reichsstatthalter Josef Bürckel wurden nur allzu bald die enggesteckten Grenzen ihrer Handlungsautonomie aufgezeigt ${ }^{86}$. Die fortschreitende Verselbständigung der Fachressorts verursachte im Reichsinnenministerium denn auch ungleich stärkere Kopfschmerzen als die gelegentlichen Extratouren mancher Gauleiter ${ }^{87}$.

Gleichwohl wurde auch die Übermacht der zentralen Institutionen durch eine Reihe von Faktoren in ihrer Nachhaltigkeit gebremst. Zum einen verhinderten die vertikale Versäulung der Reichsverwaltung und die erbitterte Konkurrenz der Obersten Reichsbehörden untereinander, daß ein ungebrochener Zentralisierungsdruck auf die sogenannte „Mittelinstanz“ ausgeübt wurde; zum anderen stand dem die Fortexistenz der hergebrachten Gebietskörperschaften entgegen. Abgeschirmt durch die faktische Bestandsgarantie Hitlers und Görings erstarkten die regionalen Herrschaftszentren allmählich wieder. Neben der Mediatisierung der Kommunalverwaltungen ${ }^{88}$ trug dazu vor allem die Entwicklung von Gegenstrategien bei, welche den spezifischen Bedingungen der NS-Polykratie angepaßt waren.

Nicht zum ersten $\mathrm{Mal}$ in der neueren deutschen Geschichte schlossen die regionalen Verwaltungseliten in Süd- und Südwestdeutschland und ihre politische Führung ein unausgesprochenes Zweckbündnis gegen Berliner Zentralisationsbestrebungen. Diesen ging es darum, ihre territoriale Machtbasis vor einer Erosion durch Kompetenzabflüsse an die

${ }^{82}$ Vgl. Schulz, Anfänge, S.785-828; Willi A. Boelcke, Wirtschaftsverwaltung, in: Deutsche Verwaltungsgeschichte IV, S.774-793; Albrecht Ritschl, Wirtschaftspolitik im Dritten Reich - Ein Überblick, in: Bracher u. a., Deutschland 1933-1945, S. 118-134; Harold James, Hjalmar Schacht - Der Magier des Geldes, in: Ronald M.Smelser u.a. (Hrsg.), Die braune Elite, Bd.2, Darmstadt 1993, S. 206-218.

${ }^{83}$ Willi A. Boelcke, Die Finanzpolitik des Dritten Reiches. Eine Darstellung in Grundzügen, in: Bracher u. a., Deutschland 1933-1945, S.95-117, hier: S. 97; vgl. dazu Dietmar Petzina. Autarkiepolitik im Dritten Reich. Der nationalsozialistische Vierjahresplan, Stuttgart 1968.

${ }^{84}$ Hüttenberger, Gauleiter, S. 112.

${ }^{85}$ In diesem Sinne Broszat, Staat, S. 161; Hüttenberger, Gauleiter, S. 112; vgl. aber auch Rebentisch, Führerstaat, S.264.

${ }^{86}$ Vgl. Fenske, Josef Bürckel, S.154, 159, 162, 172. Zur Person siehe die Hinweise in Anm. 81 u. 113.

${ }^{87}$ Rebentisch, Führerstaat, S.239; vgl. allgemein Schulz, Anfänge, S.599ff. Schon Ende 1938 begann Frick darob zu resignieren; vgl. Broszat, Reichszentralismus, S. 195.

${ }^{88}$ Vgl. Horst Matzerath, Nationalsozialismus und kommunale Selbstverwaltung, Stuttgart u.a. 1970, insbes. S.433-436; Hüttenberger, Gauleiter, S.91-107; Albert von Mutius, Kommunalverwaltung und Kommunalpolitik, in: Deutsche Verwaltungsgeschichte IV, S. 1055-1081. 
expandierenden Reichsbehörden zu bewahren; für jene stellte die Verteidigung der eingeschränkten Verwaltungsautonomie ihrer Länder ein Kernstück ihrer korporativen Selbstbehauptung als soziale Elite dar ${ }^{89}$. Das affektive Bindeglied dieser regionalen Interessenkoalitionen gegen den wachsenden Mediatisierungsdruck aus Berlin bildeten jene antipreußischen Ressentiments, welche seit Jahrzehnten im Mittelpunkt süd(west)deutschen Strebens nach Wahrung der einzelstaatlichen Identität gegenüber der Hegemonialmacht im Norden standen ${ }^{90}$.

„Dem, Berliner Schwindel" mit entsprechenden Maßnahmen zu begegnen“, gab etwa ein leitender Beamter des badischen Innenministeriums 1947 wahrheitsgetreu zu Protokoll, "war damals üblich und zur Wahrnehmung von Landesinteressen manchmal wohl auch notwendig. ${ }^{91}$ Solches Abwehrverhalten reichte im Einzelfall bis zur abgestimmten Obstruktion. So zeichnete der württembergische Innen- und Wirtschaftsminister Jonathan Schmid im August 1940 einen vorbesprochenen Aktenvermerk ab, in dem lapidar festgestellt wurde: „Der Erlaß des Reichsministers des Innern beweist, daß dort die Verhältnisse, wie sie wirklich liegen, nicht immer richtig durchschaut werden können. [...] Man kann wohl von der Herausgabe des Reichserlasses absehen. ${ }^{\text {"92 }}$ Freilich scheuten seine Spitzenbeamten sich nicht, im Bedarfsfall auf entgegenstehende Reichsrichtlinien zu verweisen, um Forderungen lokaler und regionaler NS-Gliederungen zu konterkarieren ${ }^{93}$.

Angesichts des beständigen Abflusses sachlicher Kompetenzen konzentrierten sich die Reichsstatthalter, Landesregierungen und Oberpräsidenten darauf, zumindest die Personalpolitik unter ihrer Kontrolle zu behalten ${ }^{94}$. Dieses entsprach sowohl der personalistischen Führungsdoktrin des NS-Regimes als auch dem zeitlos gültigen Erfahrungssatz, daß „eine gute Personalpolitik zu den Fundamenten einer guten Verwaltung “ gehört" ${ }^{95}$. In der Folge kam es ständig zu Konflikten mit allen möglichen Obersten Reichsbehörden, vor allem aber mit dem Reichsinnenminister und mit dem Stellvertreter des Führers. Denn die versuchten seit 1935 ihrerseits maßgeblichen Einfluß auf die Ausbildung, Rekrutierung, Beförderung und Versetzung der Beamtenschaft in der Mittelinstanz zu erlangen ${ }^{96}$.

${ }^{89}$ Vgl. Grill, Nazi Movement, S. 260-262; vgl. für Bayern Broszat, Reichszentralismus, S. 188-190.

${ }^{90}$ Vgl. Grill, Nazi Movement, S. 262; vgl. für Bayern Broszat, Reichszentralismus, S. 190; gemünzt auf den pfälzischen Gauleiter Bürckel Rebentisch, Führerstaat, S.241. Zu den Ursprüngen und Auswirkungen der anti-preußischen Zielrichtung des (süd)deutschen Föderalismus und des rheinischen Regionalismus vgl. Veit-Brause, Partikularismus, S.747, 750f., $757 \mathrm{f}$.

${ }^{91}$ Schriftsatz des Leiters der Polizeiabteilung im badischen Innenministerium, Regierungsdirektor August Schneider, v. 11.4. 1947 (Hauptstaatsarchiv Stuttgart [HSTAS], EA 1/150, Bü. 1513); Hervorhebungen von mir.

${ }^{92}$ Vermerk v. 14.8. 1940 betr. Förderung der SA-Wehrmannschaften (HSTAS, E 151/41, Bü.770, Qu. 450).

${ }^{93}$ Vgl. diverse Vorgänge in den Akten des württembergischen Innenministeriums über kommunale Leistungen an die NSDAP und ihre Gliederungen (HSTAS, E 151/41, Bü.769-771).

${ }_{94}$ Vgl. Rebentisch, Führerstaat, S. 260, 264.

${ }^{95}$ „Erklärung" des vormaligen Ministerialrats Hermann Reihling für das Spruchkammerverfahren des früheren Kanzleidirektors und Personalreferenten im Stuttgarter Innenministerium, Ministerialrat Gustav Himmel, v. 9.3. 1947 (Staatsarchiv Ludwigsburg, EL 902/20, Az.37/5/11672); vgl. in diesem Sinne Horst Romeyk, Zwischen Anpassung und Auflehnung. Zum Verhalten der Beamtenschaft in Rheinland und Westfalen 1933 bis 1945, in: Friedrich G.Schwegmann (Hrsg.), Zwischen Gehorsamspflicht und Widerstandsrecht: ein unlösbares Dilemma der Beamtenschaft? Gelsenkirchen 1989, S.137-165, hier: S. 151.

${ }^{96}$ Vgl. eingehend Caplan, Administration, S. 130-188; Longerich, Hitlers Stellvertreter, S. 40-73; ferner Mommsen, Beamtentum, S. 62-90; Teppe, Provinz, S.69-79. 
Diesen Bemühungen war regional sehr unterschiedlicher Erfolg beschieden. Eine Aufstellung des Reichsinnenministeriums vom Frühjahr 1943 spiegelt im wesentlichen das Endresultat nationalsozialistischer Gleichschaltungs- und Penetrationsversuche in der als „politisch“ eingestuften landrätlichen Verwaltung wider. Ihrzufolge amtierten im Gebiet des Altreichs Anfang 1943615 Landräte. Jeder vierte von ihnen war kein Volljurist" ${ }^{97}$. Allerdings variierte die Quote dieser NS-„Parteibuchbeamten“ stark nach Regionen. Zahlenmäßig stellten die „Außenseiter “ in Preußen mit einem guten Drittel das bei weitem größte Kontingent ${ }^{98}$. Doch auch hier unterstreicht ein Blick auf ihre Verteilung über die einzelnen Provinzen und Regierungsbezirke den hohen Stellenwert regionaler Einflußfaktoren auf die Besetzung dieser Schlüsselpositionen. So waren in Ostpreußen, Hessen-Nassau99 und Teilen der Rheinprovinz mehr als die Hälfte der seit April 1933 ernannten Landräte NS-Außenseiter, während diese sich in Pommern wie in einzelnen Regierungsbezirken anderer Provinzen mehr oder minder klar in der Minderheit befanden. Und die beiden preuBischen Landräte in den Hohenzollernschen Landen (Sigmaringen), welche zum Bezirk der Stuttgarter Gauleitung gehörten, überstanden die gesamte nationalsozialistische Herrschaft, obwohl sie bereits 1924/25 als Zentrumsleute ins Amt gelangt waren.

Auch sonst hob sich Südwestdeutschland von dem allgemeinen Trend deutlich ab. Was die Außenseiter anbelangte, fielen Baden und Württemberg - zusammen mit dem süddeutschen Nachbarn Bayern ${ }^{100}$ - markant aus dem Gesamtbild heraus. Anfang 1943 waren sämtliche dort tätigen Landräte Volljuristen. Ein Blick auf die regionale Herkunft des höheren Personals der beiden Innenverwaltungen insgesamt bestätigt die ausgeprägte personelle Beharrungskraft der regionalen Verwaltungseliten beider Länder. Im Januar 1933 waren neun von zehn badischen Beamten im Lande geboren, zwölf Jahre später immerhin noch acht; in Württemberg lagen die Anteile ein wenig höher.

Daraus, daß man sich den traditionell überaus bodenständigen Verwaltungsapparat im eigenen Interesse nicht von Berlin aus der Hand nehmen lassen wollte, machte die Stuttgarter NS-Führung keinen Hehl: Es sei unverkennbar, „daß die württembergische Verwaltung sich in einer Reihe von Punkten auf Grund der ganzen Entwicklung von den Verwaltungszuständen in anderen Ländern nicht unerheblich unterscheide“, hielt Innen- und Wirtschaftsminister Schmid dem Reichsinnenminister Mitte 1937 persönlich vor, „daß aber nach Auffassung der württembergischen Stellen gerade diese Eigenarten der württembergischen Verwaltung nicht zuletzt für die [sic!] wirtschaftliche Entwicklung Württembergs und für den [sic!] Wohlstand dieses Landes erheblich beigetragen hätten “101.

Tatsächlich hat das personalpolitische Abwehrbündnis der administrativen Funktionseliten mit den regionalen NS-Machthabern im Südwesten die Versuche der Zentralinstanzen weitgehend neutralisieren können, durch politische Protektion, interregionale Versetzungen und gezielte Nachwuchsrekrutierung die Innenverwaltungen Badens und Würt-

${ }^{97}$ Vgl. dazu und zum folgenden Ruck, Administrative Eliten, S. 43 ff. mit Tab. 1 u. 2, S. $64 \mathrm{f}$.

${ }^{98}$ Rebentisch verkennt, daß die von ihm angeführten Zahlen von 1941 für Preußen weder für dieses Land als Ganzes noch für das gesamte Altreich repräsentativ sind; vgl. ders., Führerstaat, S. 546; ders., Verfassungswandel, S.141f.

99 Vgl. dazu Thomas Klein, Leitende Beamte der allgemeinen Verwaltung in der preußischen Provinz Hessen-Nassau und in Waldeck 1867-1945, Darmstadt/Marburg 1988, S.73-77 sowie seine Kurzbiographien der betreffenden Landräte.

${ }^{100} \mathrm{Vgl}$. Schönhoven, Katholizismus in Bayern, S.618-634; Broszat, Reichszentralismus, S. $198 \mathrm{f}$.

${ }^{101}$ Begrüßungsrede v. 15.8. 1937 in Schwäbisch Hall anläßlich einer Landesbereisung Fricks (Stuttgarter NS-Kurier, Nr.377, 16.8. 1937, S.3). 
tembergs in ihrer korporativen Identität merklich zu beschädigen ${ }^{102}$. Der - wenn auch nicht dramatisch - höhere Anteil von Nicht-Landeskindern unter den Jahrgängen der 1900 und später Geborenen in den vierziger Jahren weist indessen auf die längerfristigen Grenzen dieser Defensivstrategie hin.

Während sich im Altreich trotz des Festhaltens an der hergebrachten Territorialstruktur $^{103}$ die Gewichte mehr und mehr zu Lasten der Regionalgewalten verschoben, bahnte sich dort im Saarland (1935) und in Groß-Hamburg (1937) allmählich die vierte Phase im Verhältnis von Zentral- und Regionalgewalten des NS-Staates an ${ }^{104}$. Ihr Kennzeichen waren Personalunionen führerunmittelbarer Partei- und Verwaltungschefs außerhalb des herkömmlichen Instanzenzuges. Deren weitreichende Handlungsvollmachten sollten einer „politischen Verwaltung“ den Weg bahnen, welche als Instrument der Unterdrückungs-, Ausbeutungs-, Germanisierungs- und Vernichtungspolitik Hitlers und seiner Gefolgsleute reibungslos funktionierte ${ }^{105}$. Das Grundkonzept hatten einzelne Regionalpotentaten wie der hessische Gauleiter Sprenger oder seine Amtskollegen Bürckel (Pfalz) und Saukkel (Thüringen) bereits mit begrenztem Erfolg im Altreich zu praktizieren versucht ${ }^{106}$. In den Jahren seit 1938 trat der Stellvertreter des Führers als energischer Protagonist seiner Übertragung auf Österreich und die dem Reich direkt einverleibten Teile der Tschechoslowakei und Polens auf den Plan.

Obwohl sich diese Initiativen kaum verhohlen gegen den zentralen Lenkungsanspruch seiner Behörde richteten, fanden sie die Unterstützung des Reichsinnenministers. Frick und seine Zuarbeiter glaubten offenbar, zunächst im Bündnis mit der Parteileitung die angestrebte „Einheit der Verwaltung“ auf der Mittelstufe gegen die Ressortegoismen durchsetzen zu können. In einem zweiten Schritt sollten den Chefs der neuen Reichsgaue sodann im Zuge einer großen Verwaltungs- und Territorialreform von Berlin aus wieder straffe Zügel angelegt werden ${ }^{107}$. Diese Vorstellungen erwiesen sich nur zu rasch als pure Illusion. Der Reichsgau Sudetenland, die sieben „Alpen- und Donau-Reichsgaue“ Österreichs, vor allem aber die Reichsgaue Danzig-Westpreußen und Wartheland entwickelten sich nach ihrer Errichtung im Frühjahr/Herbst 1939 unaufhaltsam zu teilautonomen Herrschaftsbezirken, deren Chefs den „verwaltungsmäßige(n) Ausnahmezustand“ zum beispiellosen Ausbau ihrer persönlichen Machtstellung nutzten ${ }^{108}$.

${ }^{102}$ Zum vorstehenden vgl. eingehend Ruck,,$\ldots$. und dann kam ich in das Dritte Reich“, Kap. II-III u. Tabellenanhang.

${ }^{103}$ Vgl. Rebentisch, Innere Verwaltung, S. 752. Zu den wenigen Modifikationen vgl. ebd., S. 749; ders., Führerstaat, S.192; Broszat, Reichspartikularismus, S. 191.

${ }^{104}$ Zur administrativen Entwicklung des Saarlandes nach der Rückgliederung 1935 vgl. Broszat, Staat, S. 164; Rebentisch, Innere Verwaltung, S.752f.; ders., Führerstaat, S. 206-210. Zur Sonderentwicklung in Groß-Hamburg, wo der Reichsstatthalter 1937 auch die alleinige Leitung der Stadtverwaltung übernahm, vgl. ebd., S. 192, 247; Broszat, Staat, S. 167.

${ }^{105}$ Zum „engen Zusammenhang" von regelloser Form und verbrecherischem Inhalt der NS-Herrschaft in den annektierten und besetzten Gebieten vgl. Broszat, Staat, S.168f.; vgl. Rebentisch, Führerstaat, S. 248-251, 313, 326.

${ }^{106}$ Vgl. Rebentisch, Innere Verwaltung, S.751 f.; ders., Führerstaat, S. 246, S.217-223 et passim (Sprenger), 237-239 (Sauckel). Zu Bürckels Ambitionen vgl. Anm. 81 u. 113.

${ }^{107} \mathrm{Zu}$ den diametralen Zielsetzungen, welche der Reichsinnenminister und der Stellvertreter des Führers/Chef der Parteikanzlei mit der Reichsgau-Errichtung verbanden, vgl. Rebentisch, Führerstaat, S. 266f., 273-277; Longerich, Hitlers Stellvertreter, S. 132-145.

${ }^{108}$ Sudetenland: Rebentisch, Innere Verwaltung, S.755; ders., Führerstaat, S. 244. Österreich: Rebentisch, Innere Verwaltung, S.753 f.; ders., Führerstaat, S.203-206, 240-244, 246. Reichsgaue Danzig-Westpreußen und Wartheland: Martin Broszat, Nationalsozialistische Polenpolitik 1939-1945, 
Das konzeptionslos zwischen den alten und neuen Regionalgewalten auf der einen sowie den Zentralbehörden der Kriegswirtschaft und des SS-Staates auf der anderen Seite lavierende Reichsinnenministerium wurde Anfang der vierziger Jahre zusehends marginalisiert. Auch seine zweite Reichsreform-Initiative blieb 1940/41 im Gestrüpp widerstreitender Einzelinteressen hängen ${ }^{109}$. Die „sukzessive Zurückdrängung der ministeriellen Bürokratie aus dem politischen Entscheidungsprozeß im Dritten Reich" hat dieser abermalige Mißerfolg des Innenressorts, das auch organisatorisch mehr und mehr zerfiel, nur noch beschleunigt ${ }^{110}$.

Der deutsche Überfall auf die Sowjetunion Mitte 1941 und der schrittweise Übergang zum „Totalen Krieg“ markieren die fünfte Phase der Auseinandersetzungen zwischen zentralen und regionalen Gewalten im nunmehrigen „Großdeutschen Reich“. Nun erst nahmen die - während der dreißiger Jahre vielfach gebremsten - Selbständigkeitsbestrebungen der Regionalherrschaften Formen an, welche die Herrschaftswirklichkeit teilweise mit jenem „Bewußtsein einer gauterritorialen Quasisouveränität ${ }^{\text {"111 }}$ zur Deckung brachte, in dem manche Gauleiter zu agieren versuchten. Das galt nicht nur für die neuen Reichsgaue in den angegliederten Gebieten, sondern in der Tendenz auch für die Länder und Provinzen im Altreich.

Besonders deutlich traten nun Symptome des „wirtschaftlichen Gaupartikularismus“112 in Erscheinung. Der Südwesten des Reiches bietet dafür ein anschauliches Beispiel. Bis 1939 bei Auftragsvergaben an die Rüstungsindustrie stets unterdurchschnittlich bedacht, hatte das strukturell benachteiligte "Grenzland" Baden länger und stärker als andere Regionen unter den Nachwirkungen der Weltwirtschaftskrise zu leiden gehabt, und auch der "Kriegsboom" setzte dort erst mit erheblicher Verzögerung ein. Die nachteiligen sozialen Folgen der peripheren Lage veränderten im Krieg lediglich ihre Erscheinungsformen und führten unverkennbar auch zu politischer Unzufriedenheit unter der Bevölkerung. Führende Vertreter der NSDAP in Baden sahen sich dadurch veranlaßt, die wirtschaftlichen Sonderinteressen ihres Herrschaftsgebietes mit Nachdruck zu vertreten. Von den ständigen Streitereien mit Berliner Zentralbehörden, welche daraus entsprangen, ließ sich Reichsstatthalter Robert Wagner (Karlsruhe/Straßburg) im Bewußtsein seiner führerunmittelbaren Stellung als Leiter eines exponierten "Grenzgaus" und Chef der Zivilverwaltung im Elsaß ebensowenig anfechten, wie sein gleichrangiger Nachbar im Norden,

Stuttgart 1961; Diemut Majer, „Fremdvölkische“ im Dritten Reich. Ein Beitrag zur nationalsozialistischen Rechtsetzung und Rechtspraxis in Verwaltung und Justiz unter besonderer Berücksichtigung der eingegliederten Ostgebiete und des Generalgouvernements, 2. Aufl., Boppard 1993; Rebentisch, Innere Verwaltung, S. 756f.; ders., Führerstaat, S. 163-188.

${ }^{109}$ Vgl. Rebentisch, Innere Verwaltung, S. 766-770; ders., Führerstaat, S. 189-215, insbes. S. 210; Neliba, Wilhelm Frick, S.318-324, 327-333.

${ }^{110} \mathrm{Karl}$ Teppe, Die NSDAP und die Ministerialbürokratie. Zum Machtkampf zwischen dem Reichsministerium des Innern und der NSDAP um die Entscheidungsgewalt in den annektierten Gebieten am Beispiel der Kontroverse um die Einsetzung der Gauräte 1940/41, in: Der Staat 15 (1976), S. 367-380, hier: S.379. Zum „progressiven Machtverfall“ des Reichsinnenministers Anfang der vierziger Jahre vgl. auch Neliba, Wilhelm Frick, S.324-353; ferner Diehl-Thiele, S. 190-197. Zur fortschreitenden Auflösung seines Ministeriums als einheitliche Verwaltungsbehörde vgl. Rebentisch, Innere Verwaltung, S.742-744. Zu den zerstörerischen Konsequenzen für die „Rechtsund Verwaltungseinheit des Hitler-Staates“ vgl. Broszat, Staat, S.167; vgl. Benz, Expansion, S.61f.

111 Teppe, Die preußischen Oberpräsidenten, S.271; vgl. Hüttenberger, Gauleiter, S.195; Rebentisch, Führerstaat, S. $263 \mathrm{f}$.

${ }^{112}$ Rebentisch, Verfassungswandel, S. 258. 
der überaus robuste und bodenständige Josef Bürckel (Pfalz/Westmark) ${ }^{113}$. Gestützt auf seine Sondervollmachten als Reichsverteidigungskommissar ${ }^{114}$ setzte sich der badische Gauleiter im Verein mit seinem Ministerpräsidenten und Wirtschaftsminister Walter Köhler immer wieder erfolgreich gegen Eingriffe im Rahmen der Kriegskommandowirtschaft zur Wehr, die aus ihrer regionalen Sicht kontraproduktiv wirken mußten. Gemeinsam unterbanden sie manche Betriebsverlagerungen und Dienstverpflichtungen von „Gefolgschaftsmitgliedern" badischer Betriebe, um der grassierenden Mißstimmung entgegenzuwirken $^{115}$.

Augenscheinlich vermag die abschätzige Bezeichnung "Gaupartikularismus" die wirtschaftlichen Sonderbestrebungen in den einzelnen Regionen nicht angemessen zu umschreiben. Denn zum einen handelte es sich dabei um ein situationsgebundenes Phänomen, das keineswegs nur unter den Bedingungen der NS-Herrschaft auftrat ${ }^{116}$. Und zum zweiten erfüllte es auch eine stabilisierende Funktion für das gesamte Herrschaftsgefüge des NS-Staates, indem potentielle Unruheherde an der Peripherie des Altreichs rechtzeitig befriedet werden konnten. Ein Beispiel mehr dafür, daß die Funktionsweise der nationalsozialistischen Polykratie - auf der funktionalen wie auf der territorialen Ebene nicht durchweg als „kumulative Radikalisierung “ mit selbstzerstörerischer Qualität ${ }^{117}$ interpretiert werden sollte.

Die Unzufriedenheit über kriegswirtschaftliche Lenkungsmaßnahmen und organisatorische Defizite beschränkte sich mitnichten auf das Grenzland Baden. Im ökonomisch be-

${ }^{113}$ Zur Tendenz, aus der Grenzlage territoriale Sonderrechte abzuleiten, vgl. mit Blick auf Bayern Martin Broszat, Der Despot von München. Gauleiter Martin Wagner - eine Zentralfigur der bayerischen NS-Geschichte, in: SZ am Wochenende. Feuilleton-Beilage der Süddeutschen Zeitung, Nr.76, 30./31.3. 1985; ders., Reichszentralismus, S. 190; Rebentisch, Innere Verwaltung, S.749. Zur Person und Politik Wagners vgl. Horst Ferdinand, Die Misere der totalen Dienstbarkeit: Robert Wagner (1895-1946), NSDAP-Gauleiter, Reichsstatthalter von Baden, Chef der Zivilverwaltung im Elsaß, in: Eberbacher Geschichtsblätter 91 (1992), S. $97-209$ u. 92 (1993), S. 208-223; Johnpeter H. Grill, Robert Wagner - Der „Herrenmensch“ im Elsaß, in: Smelser u. a., Braune Elite II, S. 254-268. Zu den allfälligen Konflikten Bürckels mit Rüstungsminister Speer vgl. Wolfanger, Bürckel, S.78; Lothar Meinzer, Von der Dauerkrise in die Staatskonjunktur. Die pfälzische Industrie in der Zwischenkriegszeit, in: Nestler/Ziegler, Pfalz, S. 161-184, hier: S.175. Zur Person und Politik Bürckels vgl. auch Lothar Meinzer, Der Gauleiter - ein Volksfreund? Josef Bürckel (1895-1944), in: Günther List (Hrsg.), „Deutsche, laßt des Weines Strom sich ins ganze Reich ergießen. " Die Pfälzer und ihre Weinstraße - ein Beitrag zur alternativen Landeskunde, Heidelberg 1985, S. 80-105; Fenske, Josef Bürckel; Rebentisch, Führerstaat, S. 241 et passim; Gerhard Paul, Josef Bürckel - Der rote Gauleiter, in: Smelser u. a., Braune Elite II, S. 51-65. Zur Entwicklung im Elsaß und in Lothringen vgl. Rebentisch, Innere Verwaltung, S.757-759; Lothar Kettenacker, Die Chefs der Zivilverwaltung im Zweiten Weltkrieg, in: Rebentisch/Teppe, Verwaltung, S. 396-417; Rebentisch, Führerstaat, S.305-309.

${ }^{114}$ Vgl. allgemein Karl Teppe, Der Reichsverteidigungskommissar. Organisation und Praxis in Westfalen, in: Rebentisch/Teppe, Verwaltung, S. 278-301; Rebentisch, Innere Verwaltung, S.763f.; ders., Führerstaat, S. 132-143, 278-281.

${ }^{115}$ Vgl. Roland Peter, NS-Wirtschaft in einer Grenzregion. Die badische Rüstungsindustrie im Zweiten Weltkrieg, in: Rauh-Kühne/Ruck, Regionale Eliten, S. 171-193; ders., Rüstungspolitik in Baden. NS-Kriegswirtschaft und Arbeitseinsatz in einer Grenzregion, München 1995. Zum Konflikt zwischen den Gauleitern und dem Rüstungsministerium vgl. allgemein Hüttenberger, Gauleiter, S. 182-187; vgl. auch den Beitrag von Walter Ziegler in diesem Band.

${ }^{116}$ Das räumt auch Rebentisch, Verfassungswandel, S.258, beiläufig ein.

${ }^{117}$ Hans Mommsen, Der Nationalsozialismus. Kumulative Radikalisierung und Selbstzerstörung des Regimes, in: Meyers Enzyklopädisches Lexikon, 9. Aufl., Bd.16, Mannheim u. a. 1976, S.785-790; vgl. Martin Broszat, Soziale Motivation und Führer-Bindung des Nationalsozialismus, in: VfZ 18 (1970), S. 392-409, hier: S. 398. 
günstigten Württemberg litt die regionale Wirtschaftspolitik ebenfalls unter dem polykratischen Kompetenzchaos im Lande, aber auch unter Überbürokratisierung und unter den fehlgeschlagenen Versuchen, die Kriegswirtschaft zentral von der Reichshauptstadt aus zu lenken. Oft mußten eigenmächtige Maßnahmen lokaler Parteifunktionäre durch die Stuttgarter Gauleitung oder irgendwelche Berliner Stellen wieder aufgehoben werden. Andererseits machten in Württemberg wie im Gau Baden regelmäßige lokale und regionale Koalitionen zwischen Betriebsleitungen, Partei- und Verwaltungsstellen Front gegen zentral verordnete Kontingentierungen, „Auskämmaktionen“, Betriebsverlagerungen oder Einquartierungen ${ }^{118}$. Unter Hinwegsetzung über den zuständigen Innen- und Wirtschaftsminister nahm Gauleiter und Reichsstatthalter Wilhelm Murr in seiner Eigenschaft als Reichsverteidigungskommissar die Wahrung der ökonomischen Interessen seines Bezirks gegenüber Berlin persönlich in die Hand. Für diesen Zweck schuf er sich einen eigenen Verwaltungsapparat, und die anstehenden Wirtschaftsfragen klärte er „weitgehend im unmittelbaren Benehmen “ mit dem Stuttgarter Kommissar des Rüstungsministers Speer. Daß alles dies „in Abweichung von den Reichsvorschriften“ geschah, wie ein betroffener Ministerialbeamter später indigniert berichtete, kümmerte Murr nicht im geringsten ${ }^{119}$.

Dieses Beispiel ist besonders geeignet, das im Laufe des Krieges wachsende Machtbewußtsein der regionalen NS-Führer zu illustrieren. Denn Murr gehörte seit jeher zu den schwächeren Mitgliedern des Hitlerschen Gauleiterkorps ${ }^{120}$. Dessen kollektiver Zuwachs an Selbstvertrauen ist wohl auch durch die verschiedenen Formen des zivilen Besatzungsregiments gefördert worden, mit denen Hitlers „Vizekönige“ ihre „Satrapien“ - hier erscheint der Rückgriff auf antikes Vokabular noch am ehesten angemessen - die eroberten Territorien vor allem in Osteuropa unter Kontrolle zu halten versuchten ${ }^{121}$. Dies allein schon deshalb, weil die dort teilweise eingesetzten Gauleiter des Altreichs ihre Reichskommissariate und ihre angestammten Herrschaftsbezirke in Personalunion führten was nicht ohne Rückwirkungen im Stil ihres Regiments in der Heimat bleiben konnte. Allerdings sollten diese Momente nicht überbewertet werden. Denn erstens erforderte die Beberrschung okkupierten Terrains im Kriege fundamental andere Strukturen und Methoden als die Verwaltung des eigenen Staatsgebiets. Zweitens war das eklatante Verwaltungschaos im Osten herrschaftstechnisch derart kontraproduktiv, daß es selbst eingefleischte Protagonisten der personalistisch-institutionenfeindlichen NS-Herrschaftsideologie

${ }^{118} \mathrm{Vgl}$. Burth u.a., Nationalsozialistische Wirtschaftslenkung. Zu ähnlichen Vorgängen im preußischen Gau Westfalen-Süd vgl. Kratzsch, Gauwirtschaftsapparat, S. 49 f., 509 et passim.

${ }^{119}$ Bericht des Ministerialrats Kurt Göbel (Stuttgart) v. 12.6. 1945 (HSTAS, E 151/21, Bü.261, zwischen Qu. 198 u. Qu. 199).

${ }^{120}$ Zur Person Murrs vgl. Kurt Gayer, Wilhelm Murr. Gauleiter und Reichsstatthalter von 1933-1945, in: ders. u.a., Die Villa Reitzenstein und ihre Herren. Die Geschichte des baden-württembergischen Regierungssitzes, Stuttgart 1988, S.119-130.

${ }^{121}$ Siehe dazu (mit weiteren Hinweisen) Klaus Oldenhage, Die Verwaltung der besetzten Gebiete, in: Deutsche Verwaltungsgeschichte IV, S.1132 ff.; Diemut Majer, „Fremdvölkische“; dies., Führerunmittelbare Sondergewalten in den besetzten Ostgebieten. Entstehung und Wirksamkeit, in: Rebentisch/Teppe, Verwaltung, S.374-395; Czesław Madajczyk, Die Herrschaftssysteme in den Okkupationsgebieten der Achsenmächte (1938-1945). Ein Vergleich, in: Ger van Roon (Hrsg.), Europäischer Widerstand im Vergleich. Die internationalen Konferenzen Amsterdam, Berlin 1985, S.1637; ders., Chaos, Systemhaftigkeit oder Systeme? Das Dritte Reich in der Phase der Militärischen Expansion, in: Ralph Melville u.a. (Hrsg.), Deutschland und Europa in der Neuzeit (Festschrift von Aretin), Stuttgart 1988, 2. Halbbd., S.931-954; Rebentisch, Führerstaat, S. 309-331. 
schwerlich als Modell für das erweiterte Altreich betrachten konnten. Und drittens verschaffte sich dort auch die stärkste zentralistische Kraft des NS-Regimes eine territoriale Basis ${ }^{122}$. Himmler hatte seinen "SS-Staat" mehr und mehr zu der machtpolitischen Klammer des "Großdeutschen Reiches" ausgebaut. Mit der Ablösung von Reichsinnenminister Frick, des gescheiterten Verfechters eines "autoritären Ordnungsstaates “123, suchte der Reichsführer SS seinen extra-institutionell begründeten Führungsanspruch seit dem August 1943 auch etatistisch zu untermauern ${ }^{124}$.

Doch es entsprach der inneren Funktionslogik des polykratischen Führerstaates, daß sich diesem Hegemonialanspruch alsbald Konkurrenten aus dem engsten Umfeld des Diktators entgegenstellten. Goebbels, Gebieter über den straff organisierten Propagandaapparat, gelang es Ende Juli 1944, sich von Hitler zum Reichsbevollmächtigten für den totalen Kriegseinsatz ernennen zu lassen ${ }^{125}$. Während Reichsminister Lammers und dann auch der zeitweilige Wirtschaftsdiktator Speer aus dem innersten Kreis der Macht abgedrängt wurden, schwang sich gleichzeitig der Chef der Parteikanzlei vollends zum Medium des absoluten Führerzentralismus auf ${ }^{126}$. Parallel dazu versuchte Bormann, die Parteiorganisation der NSDAP im allgemeinen und die Gauleiter im besonderen auf ihre Loyalität gegenüber der Reichsleitung einzuschwören ${ }^{127}$. Dahinter stand nicht zuletzt das Bestreben, das Vordringen Himmlers zu stoppen ${ }^{128}$.

Wiederum überlagerten und blockierten sich die Ambitionen zentraler Herrschaftsapparate, während der Staat Hitlers in eine Phase fortschreitender Agonie einzutreten begann. Hinzu kam, daß mit Goebbels Ernennung zugleich auch den Reichsverteidigungskommissaren erweiterte Vollmachten auf dem Gebiet der Kriegswirtschaft eingeräumt worden waren ${ }^{129}$. Die Spannung zwischen konkurrierenden Zentralinstanzen und regionalen Herrschaftszentren wurde in immer neuen Konstellationen aktualisiert. Unter diesen Voraussetzungen konnte das personell ausgezehrte Reichsverwaltungssystem dem Druck des militärischen und kriegswirtschaftlichen Desasters nicht standhalten. Auch die absurde Flut von Verhaltensmaßregeln und Einzelanweisungen, mit denen Bormann die unteren Ebenen der Parteiorganisation überschütten ließ, vermochten den um sich greifenden "Gebietsegoismus" nicht mehr zu unterdrücken ${ }^{130}$. Niemals waren die regionalen und lokalen NS-Repräsentanten unabhängiger und in ihrem jeweiligen Herrschaftsgebiet mächtiger als in den Monaten vor dem Untergang ihres Regimes.

${ }^{122}$ Vgl. Broszat, Staat, S.169-171; Benz, Expansion, S. 54, 62; Rebentisch, Führerstaat, S. 182, 296f., 301, 304, 324.

${ }^{123}$ Broszat, Staat, S. 171. Zur Vorgeschichte und zum Vollzug der Abschiebung Fricks nach Prag siehe Neliba, Wilhelm Frick, S. 324-356. Zum "Scheitern der politischen Konzeption“ Fricks und seiner Abdrängung „aus dem Kreis der Mitentscheidenden“ vgl. schon Mommsen, Beamtentum, S.89f.

${ }^{124}$ Zum Aufstieg des SS-Staats vgl. allgemein (mit weiteren Hinweisen) Ruck, Führerabsolutismus, S.55f. Zur Ernennung und zum Wirken Himmlers als Reichsinnenminister siehe Diehl-Thiele, Partei, S. 197-200; Rebentisch, Innere Verwaltung, S.771f.; ders., Führerstaat, S.499-512; Birgit Schulze, Heinrich Himmler, das Reichsministerium des Innern und das Verhältnis von Staat und Partei 1943-1945, in: Klaus Möltgen (Hrsg.), Kriegswirtschaft und öffentliche Verwaltung im Ruhrgebiet 1939-1945, Dortmund 1990, S.9-30.

${ }^{125}$ Vgl. Rebentisch, Führerstaat, S. 512-523.

${ }^{126}$ Vgl. Ruck, Führerabsolutismus, S. 56. Zur Frontstellung der regionalen NS-Hierarchie gegen Speer vgl. Hüttenberger, Gauleiter, S. 182-187; Rebentisch, Führerstaat, S. 141.

${ }^{127}$ Vgl. Hüttenberger, Gauleiter, S. $195 \mathrm{ff}$.; vgl. den Beitrag von Walter Ziegler in diesem Band.

${ }^{128}$ Vgl. Hüttenberger, Gauleiter, S. 182.

${ }^{129}$ Vgl. Hüttenberger, Gauleiter, S.186f.

${ }^{130}$ Rebentisch, Führerstaat, S. 527-531. 
III.

Mit Blick auf den Staat Hitlers mutet der histor(iograph)isch aufgeladene Begriff „Partikularismus" nicht nur seltsam unzeitgemäß an. Er reproduziert auch eine von obrigkeitsstaatlich-technokratischem Denken in Kategorien vermeintlicher Effizienz geprägte Geringschätzung dezentraler Entscheidungsstrukturen, welche die Berliner Ministerialbürokratie auf nationaler und die deutschen Länderbürokratien auf teilstaatlicher Ebene seit jeher zum normativen Postulat "rationalen" Verwaltungshandelns erhoben hatten. Dabei geraten allzu sehr Gesichtspunkte politisch-administrativer Mobilisierungskraft, der Reaktionsfähigkeit auf regionale Problemlagen und der loyalitätssichernden Wirkung kultureller Vielfalt ins Hintertreffen ${ }^{131}$. Hitler und manche seiner herausgehobenen Gefolgsleute besaßen dafür durchaus ein Gespür. Selbst bei der Aufteilung Österreichs in sieben „Alpen- und Donau-Reichsgaue" 1939/40 gab der Diktator der Rücksichtnahme auf den österreichischen "Länderpatriotismus" Vorrang vor bürokratischen Effizienzerwägungen $^{132}$. Das bewußte Festhalten an der „verworrenen Territorialstruktur des nationalsozialistischen Einheitsstaates ${ }^{4133}$ war mitnichten das Werk eines "schwachen Diktators“, der sich - den Grundsätzen des „divide et impera" folgend - nur durch die Inszenierung eines administrativen Chaos glaubte an der Macht halten zu können. Vielmehr sind dieser Politik zweckrationale Momente nicht abzusprechen.

Mit Blick auf die herrschaftstechnischen Herausforderungen, die aus seinen Expansionsplänen folgten, nahm Hitler in Kauf, daß sich das Verhältnis zwischen Zentralgewalt und Regionalgewalten keineswegs so "spannungslos" gestaltete, wie dies Fritz Rörig 1936 vorausgesagt hatte und wie es der NS-Propagandaapparat unablässig verkündete. Eine zentrifugale Tendenz mit separatistischen Implikationen, welche der Begriff "Partikularismus“ nahelegt, ist jedoch in keinem der zahllosen Konflikte erkennbar ${ }^{134}$. Zwar nahmen Hitlers Statthalter in der Provinz die ihnen ausdrücklich eingeräumten Handlungsspielräume ${ }^{135}$ extensiv wahr. Diese weitreichende Aktionsfreiheit war jedoch an zwei elementare Voraussetzungen geknüpft: erstens die unbedingte persönliche Loyalität gegenüber dem Führer $^{136}$ und zweitens den Verzicht auf jegliche Einmischung in die strategischen Entscheidungsprozesse der Reichspolitik ${ }^{137}$. Kaum einer der Gauleiter mißachtete diese Grenzen. Mit wenigen Ausnahmen, die jeweils drakonisch geahndet wurden, blieben sie Hitler bis zum Ende „sklavisch“ ergeben ${ }^{138}$. Und Versuche, von der Peripherie her direkten Einfluß

${ }^{131}$ Die implizite Neigung, Zentralisierung und Deföderalisierung an sich bereits mit Rationalisierung und Modernisierung gleichzusetzen, wird etwa deutlich bei Caplan, Government, S.332f. et passim; Rebentisch, Führerstaat, S.228 et passim (auf S.258 offenkundige Orientierung am grundgesetzlichen Leitbild "Einheitlichkeit der Lebensbedingungen ").

${ }^{132}$ Rebentisch, Führerstaat, S. $203 \mathrm{f}$.

${ }^{133}$ Rebentisch, Führerstaat, S. $228 f$.

${ }^{134}$ En passant hat Gerhard Schulz, Anfänge, S. 580 schon vor Jahrzehnten von den „herrschenden lokalen, dann regionalen Gewalten" des NS-Staates und der alsbaldigen totalitären "Ausschaltung selbst von ansatzweise vorhandenen partikulären Gewalten" gesprochen; Hervorhebungen von mir.

${ }^{135} \mathrm{Vgl}$. insbes. Hitlers Ermunterungen auf der Reichsstatthalterkonferenz v. 22.3. 1934; zit. in: Broszat, Staat, S. 150.

${ }^{136}$ Vgl. Rebentisch, Führerstaat, S. 250.

${ }^{137}$ Vgl. den Beitrag von Walter Ziegler in diesem Band.

${ }^{138}$ Hüttenberger, Gauleiter, S. 211. Zur Ablösung der insgesamt sechs verstoßenen Gauleiter vgl. ebd., S. 200-211. 
auf die Reichspolitik zu nehmen, hat es ebensowenig gegeben wie Ansätze einer gemeinsamen Fronde gegen die Metropole.

Ihre unbedingte Führerloyalität hinderte die regionalen Exponenten des NS-Regimes allerdings nicht daran, sich in der Endphase des Krieges mehr und mehr von den zentralen Weisungen abzukoppeln. Doch dieser Prozeß vollzog sich erst unter den außerordentlichen Bedingungen der Zusammenbruchsphase 1944/45. Mit „Partikularismus“ - sei er nun traditionellen oder totalitären Ursprungs - hatten die territorialen Desintegrationserscheinungen der letzten Kriegsphase nichts zu tun. Allenfalls wäre von einem situationsgeborenen Katastrophen-Partikularismus zu sprechen ${ }^{139}$. Denn im Angesicht des nahenden Untergangs verloren übergeordnete Zusammenhänge und Prinzipien zusehends an Bedeutung gegenüber dem existentiellen Primat des Durchkommens vor Ort. Aus dieser Phase lassen sich mithin ebensowenig teleologische Rückschlüsse auf die immanenten Entwicklungstendenzen des NS-Herrschaftsgefüges bis in die frühen vierziger Jahre hinein ziehen, wie von den improvisierten Unterdrückungs- und Vernichtungs- „Verwaltungen“ der frisch eroberten Territorien im Osten.

In hybrider Selbstüberschätzung hatte die politische Führung mit ihrem militärischen Expansionskurs die Möglichkeiten des Deutschen Reiches in jeder Hinsicht weit überzogen. Auch eine im klassischen Sinne wohlorganisierte, hochzentralisierte Reichsverwaltung hätte diesen Tatbestand nicht aus der Welt schaffen können. Im Gegenteil: vermutlich hat überhaupt nur die polykratische Konkurrenz der Unterführer des NS-Regimes jene Ressourcen mobilisieren helfen, die es ihm erlaubten, den Zusammenbruch so lange hinauszuzögern. Daß sich der Kollaps schließlich nicht nach den Regeln des bürokratischen Instanzenzuges vollzog, ist nicht bemerkenswert - eher schon der Umstand, daß anarchische Zustände im eigentlichen Sinne des Wortes fast nirgends eintraten. Selbst im Angesicht der totalen Niederlage blieben die gesamtstaatliche Loyalität und die Autorität der regionalen Gewalten in der Substanz ungebrochen. Das Machtgefüge des „Dritten Reichs“ ist zuvörderst nicht an den strukturellen Ungereimtheiten funktionaler oder territorialer Provenienz, sondern an den ideologischen Obsessionen und an den politischen Fehlentscheidungen seiner Spitze gescheitert.

${ }^{139}$ So mag Hüttenberger, Gauleiter, S.211 „wie dem Verhalten einiger anderer Gauleiter [...] dem Bürckels Elemente der Resistenz gegenüber der Katastrophenpolitik Hitlers in den letzten Kriegsjahren nicht absprechen". 


\section{Volker Dabm}

\section{Kulturpolitischer Zentralismus und landschaftlich-lokale Kulturpflege im Dritten Reich ${ }^{1}$}

Der Versuch, die Auswirkungen der Kulturpolitik des nationalsozialistischen Staates auf das kulturelle Leben in den Regionen zu bestimmen, begegnet erheblichen kategorialen Schwierigkeiten. So sehr sich der Begriff der Region anbietet, um in allen möglichen $\mathrm{Zu}-$ sammenhängen größere und kleinere räumliche Einheiten voneinander abzugrenzen, so beliebig erscheint seine literarische Verwendung. Was aber soll konkret im Deutschen Reich, das als Folge dynastischer Territorialherrschaft durch mehr oder weniger willkürliche innere Grenzen und staatliche Einheiten von extrem unterschiedlicher Größe gekennzeichnet war, unter „Region“ verstanden werden? Kleinere Einheiten der staatlichen und nichtstaatlichen Verwaltung, also Länder, Provinzen und Regierungsbezirke bzw. Landkreise und kommunale Landschaftsverbände? Die hiervon vielfach abweichenden Hoheitsgebiete der NSDAP? Oder auch und vielleicht sogar vorrangig quer zu aller Verwaltungsgliederung liegende, sich historisch, landschaftlich, konfessionell, sprachlich oder eben kulturell definierende Einheiten?

Die Verkoppelung der Begriffe Region und Kultur liegt nahe, macht die begrifflichen Schwierigkeiten aber keineswegs kleiner. Denn offensichtlich eignet sich Kultur nicht als Ganzes, sondern nur in Teilen zur Artikulation und Befriedigung partikularer Bedürfnisse und zur Stiftung regionaler Identitäten. Die hohen Künste, die im landläufigen Verständnis den Inbegriff von Kultur bilden, sind in ideeller Hinsicht universal und praktisch eher an eine bestimmte Gesellschaftsschicht als an einen bestimmten Raum gebunden. Die ihnen entstammenden massenkulturellen Phänomene tendieren zur Überwindung aller räumlichen und gesellschaftlichen Barrieren. Nur bestimmte, sozial niedriger legitimierte Varianten der Künste sind eindeutig Ausdruck und Movens regionalkulturellen Bewußtseins: die dialektale Literatur, Volksmusik und Volkstanz, Volkskunst und landschaftsgebundenes Bauen.

Versteht man Kultur in allgemeinster Definition als „Gesamtheit der typischen Lebensformen einer Bevölkerung einschließlich der sie tragenden Geistesverfassung “2 , so vermehren sich selbstverständlich die regionalkulturell relevanten Phänomene. Eindeutig regionalen oder gar lokalen Charakter haben Aufgaben und Tätigkeiten wie Denkmalschutz, Denkmalpflege, Heimatschutz, das kommunale Schulwesen, Schriftgutpflege, Brauchtumspflege, Ortsbilderhaltung, Landschafts- und Naturschutz. Die Wissenschaf-

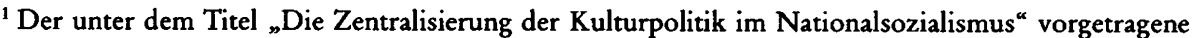
Text wurde, erheblich überarbeitet und erweitert, unter dem Titel „Nationale Einheit und partikulare Vielfalt. Zur Frage der kulturpolitischen Gleichschaltung im Dritten Reich“ in Heft 2, 1995 der

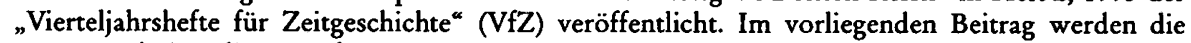
Hauptergebnisse dieses Aufsatzes resümiert.

${ }^{2}$ Brockhaus s. Enzyklopädie, 17. Aufl., Bd.10, 1970, s. v. Kultur, nach W. B. Mühlmann.
} 
ten sind meist universal oder mit nichtdeutschen Gegenständen befaßt und daher weder in nationalen noch gar in regionalen Zusammenhängen verwendbar. In Frage kommen vor allem die historischen Fächer (darunter natürlich auch Fächer wie Technik- und Rechtsgeschichte) mit der Möglichkeit, räumlich definierte Spezialdisziplinen (Landesgeschichte, Stadtgeschichte, Heimatkunde) herauszubilden, die Volkskunde sowie die deutsche Literatur- und Sprachwissenschaft mit der dialektalen Literaturgeschichte und den Dialektphilologien.

Wenn man alle diese kulturellen Phänomene einbezieht und den Begriff der Region offenhält, so daß er sich im jeweiligen Verwendungszusammenhang neu konkretisieren kann, um etwa auch die Kommunen als wichtigsten Faktor des öffentlichen Kulturlebens berücksichtigen zu können, dann erscheint es durchaus sinnvoll, der hier gestellten Frage nachzugehen.

Der Prozeß der Neuformierung der kulturpolitischen Verhältnisse nach 1933 hatte vier Komponenten: Kultur wurde unter prinzipieller Beibehaltung einer bürgerlichen, die Individualität des künstlerischen Schöpfungsaktes und die kommerzielle Kulturvermittlung bejahenden Kulturauffassung in den Rang einer Staatsaufgabe erhoben; die Kulturpolitik des Staates wurde rigoros zentralisiert; die diesbezüglichen Kompetenzen wurden neu verteilt; die Partei organisierte und kontrollierte bisher der privaten Initiative überlassene Aktivitäten und versuchte darüber hinaus staatliche Kompetenzen zu usurpieren.

Im Bereich des Staates erfolgte diese Neuordnung innerhalb der ersten beiden Jahre nationalsozialistischer Herrschaft. Danach waren die kulturpolitischen Zuständigkeiten im wesentlichen auf drei Zentralbehörden verteilt, auf das „Reichsministerium für Volksaufklärung und Propaganda" (RMfVuP), das „Reichsministerium für Wissenschaft, Erziehung und Volksbildung" (RMfWEuV) und das "Reichsministerium des Inneren (RMdI)“.

Mit Fachabteilungen für Rundfunk, Presse, Film, Theater, Schrifttum, Bildende Kunst und Musik bildete das Propagandaministerium das eigentliche Reichskulturministerium. Als „Unterbau“ wurde durch Reichsgesetz vom 22. September 1933 eine Reichskulturkammer (RKK) auf berufsständischer Grundlage geschaffen ${ }^{3}$. In ihren Fachkammern für Presse, Rundfunk, Film, Theater, Schrifttum, bildende Künste und Musik wurden alle auf diesen Gebieten tätigen Personen zwangsweise zusammengefaßt. Organisationsrechtlich waren die Kammern Körperschaften des öffentlichen Rechts, faktisch nachgeordnete Einrichtungen des Ministeriums. Während die Reichskulturkammer als Gesamtgebilde Goebbels in seiner Eigenschaft als Präsident der RKK unterstand, waren die von Präsidenten geleiteten Fachkammern den entsprechenden Fachabteilungen des Ministeriums und damit Goebbels in seiner Eigenschaft als Propagandaminister nachgeordnet.

Zur Durchsetzung seiner Kulturpolitik in den Ländern bediente sich Goebbels nicht der weiterbestehenden Länderverwaltungen, vielmehr schuf er neue Mittelbehörden, die institutionell und personell mit der Partei verkoppelt waren. Die territoriale Zuständigkeit der "Landesstellen“ des Ministeriums, die 1937 die Bezeichnung „Reichspropagandaämter" erhielten, deckte sich stets mit den Gauen der NSDAP, und die Leiter dieser Behörden waren in Personalunion immer die Goebbels als Reichspropagandaleiter der NSDAP unterstehenden Leiter der Gaupropagandaämter. 1934 wurden diese zusätzlich zu sogenannten Landeskulturwaltern ernannt und mit der Leitung der Gaugliederungen der RKK beauftragt; in diesem Amt unterstanden sie Goebbels in seiner Eigenschaft als RKK-Präsident. Durch die Zusammenlegung der Ämter des Reichspropagandaleiters der NSDAP,

${ }^{3}$ RKK-Gesetz vom 22.9. 1933, in: Reichsgesetzblatt (RGBl.) I 1933, S. $661 \mathrm{f}$. 
des Reichspropagandaministers und des Präsidenten der RKK sowie der Ämter des Gaupropagandaleiters, des Reichspropagandaamtsleiters ${ }^{4}$ und des Landeskulturwalters entstand ein neuer, nationalsozialistischer Typus von Reichsbehörde, die sich in der Mittelinstanz selbst vertrat und lediglich auf der unteren Ebene der Kreis- und Kommunalverwaltung auf die traditionellen Behörden angewiesen war.

Goebbels verfügte aber nicht nur über diesen eigenen, von der Länderverwaltung abgekoppelten Apparat, er war für die in seiner Zuständigkeit liegenden Gebiete auch der alleinige Herrscher über das Kulturrecht. Wenn es im Geschäftsbereich anderer Ressorts noch Reste von Landesrecht und Landesgesetzgebung gab, so war das gesamte, unter den gegebenen totalitären Bedingungen riesige Ausmaße annehmende Kulturrecht völlig neu geschaffenes Reichsrecht und lag die Gesetzgebung vollständig in der Hand des Progagandaministers. Durch die Kammern übte Goebbels die unbeschränkte Kontrolle über die personelle Zusammensetzung der kulturellen Berufsstände aus. Auch die Zensur lag - nach anfänglich chaotischen Kompetenzverhältnissen - ab 1936 ganz in der Gewalt des Reiches und hier in der Hand des Propagandaministers.

Anders als Goebbels bedienten sich der Reichserziehungs- und der Reichsinnenminister in der Mittelinstanz der Reichsstatthalter in den Ländern bzw. der von diesen kontrollierten Länderverwaltungen. Der Reichserziehungsminister hatte die Zuständigkeiten für Wissenschaft, Erziehung und Unterricht, für die Erwachsenenbildung und das Volksbüchereiwesen, für die Angelegenheiten des Deutschen Sprachpflegeamts und des Deutschen Sprachvereins sowie für die Denkmalpflege. Die Zuständigkeit für den Heimatschutz teilte er mit dem Reichsinnenminister. In dessen Portefeuille lagen außerdem der Denkmalschutz, der Schriftdenkmalschutz, der Schutz des national wertvollen Kunstgutes und die Reichsarchive. Darüber hinaus war der Reichsinnenminister durch die von ihm ausgeübte Kommunalaufsicht an der kulturpolitischen und kulturellen Tätigkeit der Gemeinden, Landkreise, Bezirks-, Provinzial- und Zweckverbände beteiligt.

Schwieriger und langwieriger war die Entwicklung bei der NSDAP, die zum Zeitpunkt der Machtergreifung über keine kulturpolitischen Einrichtungen verfügte, wenn man von der fast bedeutungslosen Abteilung „Volksbildung" in der Reichsleitung und Alfred Rosenbergs parteinahem, nie parteiamtlichem „Kampfbund für Deutsche Kultur“ absieht. 1934 errichtete Rosenberg auf Grund eines Führerauftrags eine neue kulturpolitische Dienststelle mit der Bezeichnung „Der Beauftragte des Führers für die Überwachung der gesamten geistigen und weltanschaulichen Schulung und Erziehung der NSDAP“ („Reichsüberwachungsamt“) mit Ämtern bzw. Abteilungen für Schulung, Kunstpflege, Schrifttumspflege, Vor- und Frühgeschichte, Wissenschaft u. a.m. Rosenbergs Hauptbastion aber war bis 1937 die „Nationalsozialistische Kulturgemeinde“ (NSKG), eine Theaterbesucherorganisation, die 1934 durch pseudolegale Verschmelzung des „Verbandes der freien Volksbühnen“ und des „Bühnenvolksbunds“ entstand. Die organisatorisch bis auf Kreisebene präsente NSKG stand in einem äußerst schwierigen, teils durch Kooperation, teils durch schärfste Konflikte gekennzeichneten Verhältnis zu dem Anfang 1934 gegründeten Kulturamt der zur Deutschen Arbeitsfront (DAF) gehörenden „NS-Gemeinschaft Kraft durch Freude" (NSG KdF). In der Leitung von KdF bestand außerdem seit Ende 1933 ein „Amt für Volkstum und Heimat“, dem der nur vorübergehend bestehende, parteiamtliche „Reichsbund Volkstum und Heimat“ angeschlossen war. Anfang 1936 wurden

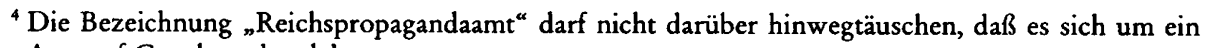
Amt auf Gauebene handelte. 
die beiden KdF-Ämter als Abteilungen im neuen „Amt Feierabend“ vereinigt. In der Folge sich ständig verschärfender Auseinandersetzungen zwischen DAF-Chef Robert Ley und Rosenberg ging die NSKG durch eine Entscheidung Hitlers 1937 in der NSG KdF auf, wo die Millionen von der NSKG übernommenen Theaterbesucher vom Amt Feierabend betreut wurden.

Ein zweites KdF-Amt mit massenkultureller Wirksamkeit war das im Juni 1936 gegründete Amt „Deutsches Volksbildungswerk“. Seine Aufgabe war die „Betreuung und Förderung der bestehenden sowie die Errichtung neuer Volksbildungsstätten und ähnlicher Einrichtungen“ und die „Einrichtung und Durchführung von Vortragsreihen, Volksbildungskursen, Arbeitsgemeinschaften sowie Volksbildungsabenden in den Betrieben, in der Stadt und auf dem Lande“5. Mit diesem Programm trat das KdF-Amt in direkte Konkurrenz zu den Kommunen, die den überwiegenden Teil der Volkshochschulen unterhielten. Um die Verhältnisse neu zu ordnen, wurde eine „Reichsarbeitsgemeinschaft für Erwachsenenbildung“ gegründet, der u.a. Vertreter der Kommunen und des „Deutschen Volksbildungswerks" sowie des fachlich zuständigen Reichserziehungsministers angehörten. Auf Grund von „Richtlinien“ dieser Arbeitsgemeinschaft, die durch den Reichsinnenminister am 18. April 1939 in Kraft gesetzt wurden ${ }^{6}$, ging die Trägerschaft der Volkshochschulen und Volksbildungsvereine zu diesem Zeitpunkt auf das KdF-Volksbildungswerk über.

Erst verhältnismäßig spät kam es zur Gleichschaltung der zahllosen Heimat-, Volkstums-, Brauchtums- und Laienkunstvereine. Ein Teil von ihnen war nach der Auflösung des „Reichsbunds Volkstum und Heimat“ Anfang 1935 wohl unter der Obhut des KdFAmts „Volkstum und Heimat“ geblieben, andere - wie der „Deutsche Bund Heimatschutz $^{\text {“ }}$ - waren zur NSKG abgewandert und nach deren Eingliederung in KdF vielleicht wieder dort angebunden worden; wieder andere - wie die Vereine des Sängerbunds - gehörten Verbänden der Kulturkammer, also staatlichen Verbänden an, offenbar nicht wenige Vereine waren weder in einem Reichs- noch in einem Gauverband organisiert. Noch 1941 sprach Robert Ley von einem „Chaos der vielen Laienverbände"

Nachdem ein Plan, die NSGKdF in den Rang einer Volkskulturkammer im Rahmen der RKK zu erheben und dadurch mit einem gesetzlichen Erfassungsanspruch auszustatten, gescheitert war, wurde durch Verfügungen Goebbels' vom 24. April und 7.Mai 1942 in der Reichspropagandaleitung der NSDAP ein nationalsozialistisches Volkskulturwerk errichtet. Zweck des „NS-Volkskulturwerks“ war es, „die einheitliche kulturpolitische Ausrichtung der volkskulturellen Verbände und Gemeinschaften sicherzustellen, alle für ihren Einsatz bei der NSDAP, ihren Gliederungen und angeschlossenen Verbände erforderlichen Maßnahmen zu treffen, sowie die gemeinsamen Angelegenheiten seiner Mitglieder zu bearbeiten und eine enge Zusammenarbeit unter ihnen herbeizuführen ${ }^{\text {*8 }}$. Die Gründung des Volkskulturwerks im Rahmen der Partei bedeutete den Verzicht auf die zunächst angestrebte zwangsweise Erfassung der einschlägigen Vereine und Verbände. Um

${ }^{5}$ Zit. n. Wolfhard Buchholz, Die Nationalsozialistische Gemeinschaft „Kraft durch Freude“. Freizeitgestaltung und Arbeiterschaft im Dritten Reich, Diss. phil. München 1976, S. 237.

${ }^{6}$ Neugestaltung der Erwachsenenbildung, Runderlaß des RMdI vom 18.4. 1939, in: Ministerialblatt des Reichs- und Preußischen Ministers des Inneren (MiBliV), Jg. 4 (1939), S. 939.

${ }^{7}$ Ley an Rosenberg, 6.8. 1941, IfZ-Archiv MA-596, B1.965-967.

${ }^{8}$ Bundesarchiv (BA) R 55 (RMfVuP)/409, Bl.261, Anordnung über das NS-Volkskulturwerk vom 7.5. 1942; die Verfügung vom 24. April ist nicht in den Akten. Die vor der Transferierung der Reichs- und Parteiakten nach Potsdam benutzten Akten des Bundesarchivs werden mit den alten Signaturen des Bundesarchivs Koblenz zitiert. 
diese zum „freiwilligen“ Beitritt $\mathrm{zu}$ bewegen, genügten aber zweifellos entsprechende Aufforderungen der Parteiorganisation auf Reichs-, Gau- oder Kreisebene.

Erst mit dieser späten Aktion kam die politische Neuordnung der kulturellen Verhältnisse, der Prozeß der totalen Erfassung, der Zentralisierung und der Machtverteilung, zu einem gewissen Abschluß. Schematisch läßt sich die daraus hervorgegangene kulturpolitische Organisationsstruktur mit der Formel „Verwaltung contra Menschenführung“ (D. Rebentisch) beschreiben. Während es Aufgabe des Staates war, den kulturellen Bestand zu sichern und die kulturelle Produktion und Distribution zu steuern und zu überwachen, oblag es der Partei, den kulturellen Konsum zu aktivieren, zu organisieren und auszurichten. Es handelte sich, dem Dualismus von Staat und Partei entsprechend, um eine Doppelstruktur, deren hervorstechendstes Merkmal ein extremer Zentralismus war.

Dieser kulturpolitische Zentralismus war den politischen Zielen des Regimes vollkommen adäquat. Nach nationalsozialistischer Überzeugung hatte der Weimarer Staat ein gedemütigtes, von fremden Mächten ausgeplündertes, von inneren Gegensätzen zerrissenes und durch den Klassenkampf gelähmtes Volk hinterlassen. Die Wiederherstellung der nationalen Größe und der inneren Einheit, die Verwirklichung der „Volksgemeinschaft" wurden so zu erstrangigen Aufgaben von Staat und Partei. Die Volkskräfte sollten entfesselt und zugleich gebündelt werden, um Wirtschaft, Technik und Gesellschaft an den internationalen Standard heranzuführen und die revisionistisch-expansionistischen außenpolitischen Pläne verwirklichen zu können. Daraus erwuchs auch das Bedürfnis nach kultureller innerer Einheit, das ideologisch dem Rassendenken entsprach und auch entsprechend begründet wurde.

Auf der anderen Seite konfligierte dieser kulturpolitische Unitarismus grundlegend mit den völkischen Ideologemen der nationalsozialistischen Weltanschauung, die geradezu nach partikularen kulturellen Aktivitäten verlangten. Blut, Boden, Volkstum, Stamm, Landschaft, Heimat und Verwurzelung sind ideologische Schlüsselbegriffe, die in unzähligen Propaganda- und Legitimationstexten bis zum Überdruß benutzt wurden. Damit wurde der traditionellen Orientierung der Bevölkerung an überschaubaren und vertrauten Strukturen entsprochen und den mit den industriellen Modernisierungsprozessen verbundenen Entwurzelungs- und Existenzängsten entgegengewirkt. Die Liebe der Menschen zur angestammten Heimat und Mundart, ihre landschaftliche Prägung und ihre Einbindung in regionale und lokale soziokulturelle Milieus waren wichtige Faktoren der Lebenswirklichkeit, die sich in vielfältigen Formen von Kultur-, Heimat- und Brauchtumspflege artikulierten und von keiner auf Massenwirksamkeit bedachten politischen Formation ignoriert werden konnten. Darüber hinaus diente die Volkstumsideologie dem Nationalsozialismus dazu, die völkischen und nationalkonservativen Gruppen und Aktivisten, die diese Bedürfnisse vertraten, nicht zuletzt die Exponenten der regionalkulturellen Strömungen, in die nationalsozialistische Bewegung und später den nationalsozialistischen Staat zu integrieren. Der „Volkstumsgedanke“ wurde so zur „regionalen Ergänzung zu Nationalismus und Rassismus ${ }^{\text {“9 }}$, eine höchst widersprüchliche Ergänzung freilich, weil sich rassisch-unitaristisch-nationales Denken mit völkischem „Stammes“ - und RaumDenken ebensowenig vereinbaren ließ wie sich die antizivilisatorischen Affekte, die antimodernen Einstellungen und das bürgerlich-elitäre Kulturverständnis der völkischen Kreise mit den egalitären Tendenzen, der wirtschaftlichen und technischen Modernität und der massenkulturellen Orientierung des Nationalsozialismus vertrugen.

\footnotetext{
${ }^{9}$ Karl Ditt, Raum und Volkstum. Die Kulturpolitik des Provinzialverbandes Westfalen, 1923-1945,
} Münster 1988, S.307. 
Politisch bildeten sich diese Gegensätze im Widerspruch zwischen einer zentralistischen Kulturpolitik und dem Beharren auf landschaftlicher und lokaler kultureller Eigenständigkeit ab. Dieser Widerspruch wurde selbstverständlich auch damals wahrgenommen und reflektiert. Zum Beispiel erklärte Alfred Rosenberg auf einer 1941 abgehaltenen Kulturtagung des Deutschen Gemeindetages: „Politisch wird Deutschland künftig von einer zentralen Führung geleitet sein, es wird aber kulturelle Kräfte im ganzen Reiche unterstützen, wo sich solche zeigen. Es wird kein Reich sein, wo es nur eine Hauptstadt Berlin gibt und das übrige nur als Provinz angesehen werden kann, sondern eine Vielfachheit in einer höheren Einheit. [...] Eine Einheit ohne jede Aufgabe der Persönlichkeit und eine Vielgestaltigkeit ohne Züge der Zerrissenheit, das zu formen ist das große Problem, das unserer Revolution übertragen worden ist [...]. Wenn wir diese Einheit in der Vielgestaltigkeit und die Vielgestaltigkeit in dieser Einheit begreifen, dann, glaube ich, haben wir das tiefe Gesetz des schöpferischen Lebens erfaßt. " ${ }^{10}$

Anläßlich der Verkündung des Ostmarkgesetzes vom 14. April 1939 führte Reichsinnenminister Frick zum Verhältnis von Reichsverwaltung und Gauselbstverwaltung folgendes aus: „Weitgehende Selbstverwaltung, die keineswegs mit nationalsozialistischen Grundsätzen, insbesondere dem Führerprinzip im Widerspruch steht oder die Gefahr von Absonderungsbestrebungen in sich einschließt, entspricht nicht nur gesunden Verwaltungsgrundsätzen, insbesondere dem [.. . ] Grundsatz der Dezentralisation im Sinne weitgehender Aufgabenverlagerung nach unten, sondern auch bestem deutschen landschaftsgebundenem Denken. Ja man wird mit Recht sagen können, daß aus der tatsächlichen und natürlichen Gegebenheit der Landschaft heraus primär die Gauselbstverwaltung das Mittel zur Durchführung eigener landschaftsgebundener Gemeinschaftsaufgaben ist. [...] Die auf geographischen Gegebenheiten, gemeinsamer Geschichte, weitgehend einheitlicher wirtschaftlicher, sozialer und kultureller Struktur und Entwicklung beruhenden landschaftlichen Lebenseinheiten und landschaftsverbundenen Lebensgemeinschaften sind organische Glieder des vielgestaltigen deutschen Volkstums. Ein organischer Aufbau des Reiches, dessen Ziel die Weckung aller Kräfte der deutschen Nation ist, kann nicht anders als an diese gewachsenen landschaftlichen Lebenseinheiten anknüpfen. "11

So nebulös solche „Sowohl-als-auch-Konzepte“ auch waren, so geht aus ihnen doch dreierlei hervor: erstens, daß die kulturpolitische Reichsgewalt nicht unbegrenzt sein sollte, zweitens, daß die regionale und lokale Kulturpflege im Staatsinteresse lag, und drittens, daß zwischen dem Reich und den regionalen und lokalen Kulturträgern eine Aufgabenteilung stattfinden sollte, die dem Reich die Verantwortung für das Ganze, den partikularen Gewalten die Zuständigkeit für das jeweils Eigene gab. Anders als in einem föderalistischen System, wo die Zuständigkeiten zwischen der Zentralgewalt und den Partikulargewalten unter sachlichen Gesichtspunkten, also horizontal, aufgeteilt werden, erfolgte hier eine vertikale Teilung. Von bestimmten exklusiven Reichsaufgaben abgesehen (Gesetzgebung, Berufszulassung, Zensur), waren die partikularen Kulturträger im Rahmen ihrer gebietlichen Hoheitsgewalt für sämtliche Kulturfragen zuständig, teilten diese Zuständigkeit aber mit dem Reich, das darüber wachte, daß ihre Arbeit „,im Geiste der nationalsozialistischen Weltanschauung ausgerichtet ist und ihre Kulturpolitik mit den großen Richtlinien des Reiches übereinstimmt ${ }^{\text {“12. }}$.

${ }^{10}$ Zit. n.: Die Kulturverwaltung. Zeitschrift für gemeindliche Kulturpflege, Jg. 5 (1941), S.3 f.

${ }^{11}$ Reichsminister Frick über Selbstverwaltung und Kunstpflege, in: Die Kulturverwaltung, Jg.6 (1942), S.15f.

${ }^{12}$ Kerber, Die Gemeinde und die Kulturpflege, in: Die Kulturverwaltung, Jg. 2 (1938), S.2-7, hier S.7. 
Da sich die nicht inhaltlich, sondern hierarchisch definierten Zuständigkeiten von Reich, Gau, Kreis und Kommune ebenso wie ihre ideellen Äquivalente, „Einheit und Vielfalt“, theoretisch kaum voneinander abgrenzen ließen, mußte sich die tatsächliche Aufgabenverteilung - kooperativ oder konfliktär - in der kulturpolitischen und kulturellen Tätigkeit selbst herausbilden.

Die Beobachtung der Praxis zeigt, daß die kulturpolitische Zentralgewalt tatsächlich nur von begrenzter Reichweite war. So bereitete es dem Propagandaminister erhebliche Schwierigkeiten, seine formalen Zuständigkeiten immer und überall im Reich durchzusetzen. Noch 1942 kam es zu grundsätzlichen Auseinandersetzungen zwischen dem Ministerium und den Gauleitern, die seit 1941 in verstärktem Maße eigene kulturpolitische Aktivitäten entwickelten, wobei offenbar die ungehemmte Art der Gauleiter in den neuen Reichsgauen, ihren Gau „nach eigenem Belieben“ zu regieren und „nach persönlichem Gutdünken maßzuschneidern ${ }^{“ 13}$, auch auf das Altreich zurückwirkte. Am 3. März 1942 machte der Reichsinnenminister auf Veranlassung des Propagandaministers die Gauleiter/Reichsstatthalter in den neuen Reichsgauen aus gegebenem Anlaß darauf aufmerksam, daß kulturelle Angelegenheiten, die in die Zuständigkeit des Propagandaministers fielen, in der Gaustufe ausschließlich im Reichspropagandaamt zu bearbeiten seien. Eine Bearbeitung solcher Angelegenheiten auch in der Reichsstatthalterbehörde müsse zwecks Vermeidung von Überschneidungen und Doppelarbeit entfallen ${ }^{14}$. Nachdem eine Reihe von Gauleitern auch im Altreich eigene Gaukulturverbände oder Gauheimatwerke gegründet hatten, die mit den staatlich kontrollierten Kommunal- und Provinzialverbänden konkurrierten, kam es zu einer Besprechung zwischen Innen-, Wissenschafts- und Propagandaministerium, Gemeindetag und Partei-Kanzlei, die zwar zu dem Ergebnis führte, daß die NSDAP keine eigenen Kultureinrichtungen gründen, sondern nur die „Kulturarbeit als Motor" betreuen sollte, faktisch aber nicht die Einstellung der parteieigenen Kulturaktivitäten nach sich $\operatorname{zog}^{15}$. In diesem Zusammenhang hatten sich acht Gauleiter im „Altreich“ auch persönliche Kulturreferenten attachiert. Das Propagandaministerium versuchte, mit fraglichem Erfolg, in persönlichen Schreiben des Staatssekretärs Gutterer, in denen dieser auf die Zuständigkeit der Reichspropagandaämter hinwies, die Gauleiter im Interesse einer „einheitlichen Reichsverwaltung“ zur Rücknahme dieser Bestellungen zu bewegen ${ }^{16}$.

Neben diesem Gaupartikularismus bereitete dem Ministerium auch die zu große Eigenständigkeit der Gemeinden Sorgen. Schon in dem Erlaß vom 3.März waren die Reichsstatthalter aufgefordert worden, hinsichtlich der kulturellen Tätigkeiten der Gemeinden und Landkreise die Beteiligung der Reichspropagandaämter sicherzustellen. Aber noch im März 1944 erschien ein gemeinsamer Erlaß des Innen- und Propagandaministers nötig, um eine bessere Zusammenarbeit zwischen den Reichspropagandaämtern und den Ländern, Gemeinden und Gemeindeverbänden zu erreichen. „Nach wie vor“ sollten deren kulturelle Einrichtungen „in erster Linie den örtlichen und landschaftlichen Bedürfnissen gerecht werden“, jedoch müßten die regionalen und lokalen Instanzen die Propagandaämter „über alle wichtigen Maßnahmen auf dem Gebiete der Kulturpflege, vor allem

${ }^{13}$ Karl Teppe, Provinz, Partei, Staat. Zur provinziellen Selbstverwaltung im Dritten Reich. Untersucht am Beispiel Westfalens, Münster 1977, S. 224 bzw. S. 225.

${ }^{14}$ BA R 55/618, Bl.5, RMdI an die Reichsstatthalter in den Reichsgauen, 3.3. 1942.

${ }^{15}$ Vgl. Ditt, Raum, S. $200 f$.

${ }^{16}$ BA R 55/618, Bl.4, RMfVuP an diverse Gauleiter. 
über besondere Veranstaltungen künstlerischer Art unterrichten und ihre kulturpolitische Linie mit ihnen abstimmen ${ }^{417}$.

Von solchen praktischen Schwierigkeiten abgesehen, war die kulturpolitische Reichsgewalt auch durch ihre Zielorientierung begrenzt. Sie zielte nämlich nicht darauf, die regionalen und lokalen Verhältnisse zu steuern und zu reglementieren, sondern beschränkte sich auf die Wahrnehmung einer allgemeinen Fachaufsicht. Dies soll am Beispiel der Maßnahmen des Reiches auf dem Gebiet der Kunst- und Literaturpreise verdeutlicht werden, wo sich zentrale und partikulare Interessen in geradezu prototypischer Weise überlagerten, weil die Vergabe solcher Preise eine traditionelle Aufgabe der Länder und Kommunen war, während die Zuständigkeit des Reiches nur durch die allgemeine Verordnung über die Aufgaben des Propagandaministeriums vom 30.Juni 1933 $3^{18}$, nicht aber durch eine spezielle gesetzliche Regelung gegeben war.

Erst 1937 wurde im Propagandaministerium erkannt, daß auf diesem Gebiet kulturpolitischer Regelungsbedarf bestand. Internen Ermittlungen zufolge wurden im Deutschen Reich zu dieser Zeit jährlich 65 Literaturpreise vergeben, vier durch das Reich, sechs durch Zentralämter der NSDAP, 19 durch Länder, Gaue und Oberpräsidien, 13 durch Städte und 23 durch private Stifter. Am 24. August 1937 verfügte Goebbels in einem nicht veröffentlichten Erlaß an die Reichsstatthalter und Landesregierungen, daß die Verleihung von Kunstpreisen aus öffentlicher Hand seiner Zustimmung bedürfe und daß ihm deshalb „jeweils rechtzeitig vor einer Verleihung Mitteilung über die Person des in Aussicht genommenen Preisträgers" zu machen sei. Mangels einer eindeutigen gesetzlichen Zuständigkeit vertraute Goebbels darauf, daß die Länder- und Gemeindeverwaltungen „das notwendige Verständnis für die Gesamtbelange der deutschen Kultur aufbringen und im Einzelfall ihre örtlichen Interessen zurückstellen, wenn dies für notwendig gehalten wird“ ${ }^{19}$. Als sich das Ministerium in der Folge darauf beschränkt sah, von den Vergabegremien getroffene Entscheidungen nachträglich abzusegnen, wirkte es erfolgreich darauf hin, die territorial zuständigen Leiter der Reichspropagandaämter bzw. deren Kulturreferenten an den Gremien zu beteiligen, um selbst auf die Wahl des Preisträgers Einfluß nehmen zu können.

Am 26. Januar 1939 wurde die Anweisung vom 24. August 1937 durch Ausführungsbestimmungen präzisiert. Danach bedurfte die Verleihung aller Kunstpreise, die mit 2000.RM und mehr dotiert waren, der Zustimmung des Propagandaministers. Die in Aussicht genommenen Preisträger waren dem Ministerium wenigstens vier Wochen vor der Preisvergabe zu benennen. Falls die Auswahl des Preisträgers durch ein Gremium vorgenommen wurde, mußte diesem der Leiter des zuständigen Reichspropagandaamts angehören ${ }^{20}$.

1942 wurden die Kunstpreise in drei Gruppen eingeteilt, in "I. reichswichtige Kunstpreise, II. wichtige Kunstpreise von lokaler Bedeutung, III. Kunstpreise von lokaler Bedeutung". Gemäß Verfügung vom 21.Juli 1942 mußte vor Verleihung eines in den Gruppen I und II aufgeführten Preises die Zustimmung des Ministers eingeholt werden. Bei der

${ }^{17}$ Zusammenarbeit auf kulturellem Gebiet, Runderlaß des RMdI und des RMfVuP vom 16.3. 1944, MiBliV, Jg. 9 (1944), S. 298.

${ }^{18}$ RGBl.I 1933 , S. 449.

${ }^{19}$ BA R 55/122, Bl. 1, Goebbels an die Reichsstatthalter und Landesregierungen sowie an den RMdI, 24.8. 1937.

${ }^{20}$ Anordnung des RMfVuP über die Verleihung von Kunstpreisen vom 26.1. 1939, in: Karl Friedrich Schrieber, Alfred Metten, Herbert Collatz, Das Recht der Reichskulturkammer, 2 Bde., Berlin 1943, RKK III, 24 (S.25). 
Gruppe III mußte nicht die Verleihung, aber die Schaffung neuer Preise vom Minister genehmigt werden. Über Kunstpreise der Gruppe I durfte in der gesamten Reichspresse, über die der Gruppe II nur in der Gau- und Lokalpresse und über die der Gruppe III nur in der Lokalpresse berichtet werden ${ }^{21}$.

Welche Absichten wurden mit den geschilderten Maßnahmen verfolgt? Der Erlaß vom 24. August 1937 wurde intern damit begründet, daß es nicht darum gehe, „den einzelnen Städten das Recht, Kunst- oder Literaturpreise zu verleihen, zu nehmen, sondern nur darum, eine Wahl- und Planlosigkeit auf diesem Gebiet unmöglich zu machen“. Der Reichsminister für Volksaufklärung und Propaganda müsse insbesondere in der Lage sein, zu niedrig dotierte Preise zu untersagen bzw. eine Erhöhung zu erwirken und eine Namensänderung zu verlangen, „wenn der Name andere Preise beeinträchtigt oder wenn staatspolitische Gesichtspunkte eine Änderung erforderlich machen “22. In diesem Zusammenhang setzte sich die Schriftumsabteilung des Ministeriums mit der Fehlentwicklung auf dem Gebiet der Literaturpreise auseinander. Die große und zunehmende Zahl von Preisen habe zu einer „Entwertung der Literaturpreise in der öffentlichen Meinung“ geführt, "die sich bis in die Spitzenpreise hinauf bemerkbar" mache. Es sei eine "Tatsache, daß es im Jahre 50 preiszukrönende Dichter und Schriftsteller nicht “ gebe. Mangels geeigneter Bewerber, seien ,junge Talente bereits für ihr erstes oder zweites Buch preisgekrönt worden“. So frühe Auszeichnungen könnten sich aber "schädigend auf das weitere Schaffen der Ausgezeichneten auswirken“. Es sei deshalb erwünscht, die Zahl der Preise zu vermindern ${ }^{23}$.

Auf solchen Überlegungen beruhte dann die alle Kunstpreise betreffende Verfügung vom 26. Januar 1939. In Anbetracht der zahlreichen, nach verschiedenen Gesichtspunkten verliehenen Preise könnten nur durch zentrale Aufsicht „kulturpolitisch unerwünschte Entscheidungen“ vermieden werden. Für die Anordnung, daß Preise in Höhe von 2000.- RM und mehr der Zustimmung des Ministers bedürften, sei auch der Gesichtspunkt maßgebend gewesen, „daß die Verleihung dieser Preise für den öffentlichen Aufstieg der prominenteren Kräfte von erheblicher Bedeutung" sei ${ }^{24}$.

Die Interessen, die die Aufsichtspflicht des Reiches über das Kunstpreiswesen begründeten, waren also sehr allgemeiner Art: die Sicherung einer finanziellen Mindestausstattung der Preise, die Wahrung des öffentlichen Ansehens des Preises, das Bedürfnis nach signifikanten, nicht konkurrierenden und politisch opportunen Preisbezeichnungen und der Wunsch, die wichtigeren Künstler bevorzugt zu fördern. Die öffentlichen Stiftungsträger wurden, gewissermaßen der Kommunalaufsicht des Reichsinnenministers vergleichbar, der Dienstaufsicht der zuständigen Fachverwaltung des Reiches unterworfen. Diesem Befund entspricht die Praxis der Vergabe des 1934 vom Provinzialverband Westfalen gestifteteten „Westfälischen Literaturpreises“. Die zweijährliche Preisverleihung wurde zwar durch einen Beirat vorbereitet, dem auch ein Vertreter des Reichspropagandaamts angehörte, je-

${ }^{21}$ BA R 55/122, Bl.386, RMfVuP an die Reichspropagandaämter, 21.7. 1942.

22 BA R 55/122, Bl. 150, Interner Vermerk RMfVuP (RKW. Schmidt-Leonhardt) vom 14.7. 1937.

${ }^{23}$ BA R 55/122, Bl.137-141, Interner Vermerk RMfVuP, Abt. Schrifttum (Erckmann), vom 13.12. 1937.

${ }^{24}$ BA R 55/122, Bl.309, Goebbels an die Reichsstatthalter, Landesregierungen u.a., 26.1. 1939. Mit Erlaß vom 8. Februar 1943 wurde die Schaffung neuer und die Erweiterung bestehender Preise durch die öffentliche Hand für die Dauer des Krieges untersagt; das Verbot wurde mit den Notwendigkeiten des totalen Krieges begründet. (BA R 55/122, Bl.396f., RMfVuP, StS Gutterer, an die Reichsstatthalter u.a., 8.2. 1943). 
doch wurde die Entscheidung satzungsgemäß durch den Landeshauptmann getroffen, der sich ab 1939 mit den Gauleitern von Westfalen-Nord und Westfalen-Süd abstimmte ${ }^{25}$.

Das Beispiel der Kunst- und Literaturpreise zeigt, daß sich die zentralen kulturpolitischen Ambitionen und Maßnahmen des Regimes im allgemeinen auf die Durchsetzung übergeordneter, nationalkultureller Intentionen und Interessen reduzierten, die die regionalen und lokalen kulturellen Verhältnisse zwar tangieren konnten, sie aber als solche nicht in Frage stellten. Andererseits sind aber auch keine besonderen Anstrengungen zur Förderung regionaler und landschaftlicher Kulturen erkennbar. Wie sich die partikularen kulturellen Bedürfnisse und Bestrebungen unter diesen Bedingungen entwickelten, kann nur durch Untersuchung der tatsächlichen Verhältnisse festgestellt werden.

Hierzu ist es zum Beispiel lohnend, einen Blick auf den Bereich der öffentlichen Theater und Orchester zu werfen. Wie schon vor 1933 wurde der ganz überwiegende Teil dieser Einrichtungen von den Kommunen getragen und unterhalten. Unter Reichsverwaltung standen 194118 Orchester und Bühnen, darunter das Berliner Philharmonische Orchester, alle großen Berliner Bühnen, das Wiener Burgtheater und die Wiener Staatsoper, das Deutsche Theater in Wiesbaden und die "Deutschen Theater" in Lille, Oslo und Prag alles nachgeordnete Einrichtungen des Propagandaministeriums. Aber nur ein Teil dieser Reichsbühnen wurde durch das Ministerium selbst beaufsichtigt. Die „Notwendigkeit, die Theater nach landschaftlichen und örtlichen Gesichtspunkten“ zu leiten, veranlaßte das Ministerium, die Leitung außerhalb der Reichshauptstadt gelegener Bühnen, zum Beispiel der Wiener Oper und des Wiener Burgtheaters, an die territorial zuständigen Reichsstatthalter zu delegieren ${ }^{26}$. Sie blieben damit zwar formell unter Reichsverwaltung, unterstanden aber faktisch der Länderverwaltung bzw. - in den neuen Reichsgauen - der Gauselbstverwaltung. 1938 gab es insgesamt ca. 120 öffentliche Theater, von denen ca. 80 von den Gemeinden und Gemeindeverbänden und ca. 12 von den Ländern getragen wurden, wobei diese Staatstheater von den Standortgemeinden subventioniert wurden. Ähnlich wie bei den Theatern war das Verhältnis bei den Kulturorchestern. Von ca. 100 Orchestern wurden rund 70 von den Gemeinden und etwa 15 von Ländern und Gemeinden gemeinsam getragen ${ }^{27}$.

Aufschlußreich ist auch in diesem Zusammenhang der Bereich der Literaturpreise. Die schrittweise durchgesetzte Fachaufsicht durch das Propagandaministerium änderte nichts an deren Zahl und Vielfalt. Neben wenigen Reichspreisen (Deutscher Nationalpreis für Kunst und Wissenschaften, Nationalpreis des 1.Mai bzw. Nationaler Buchpreis, Schillerpreis, Verdun-Preis) und Preisen der Reichsleitung der NSDAP (u.a. Preis der NSDAP für Kunst- und Wissenschaft, „Hilf mit!“-Preis, Hans-Schemm-Preis für deutsches Jugendschrifttum) gab es zahlreiche Landschafts- und Städtepreise. Von den Landschaftspreisen seien beispielhaft genannt: der Preis der Westmark, der Preis zur Förderung des deutschen Schrifttums in der Provinz Sachsen, der Schlesische Literaturpreis, der Literaturpreis der Provinz Hannover, der Badische Kulturpreis, der Lessing-Preis (Hamburg), der Mecklenburgische Literaturpreis, der Johann-Hebel-Preis für deutsche Dichtung (Ba-

${ }^{25}$ Vgl. Ditt, Raum, S. $362 \mathrm{ff}$.

${ }^{26}$ O[tto] B[ennecke], Kulturelle Zusammenarbeit, in: Die Kulturverwaltung, Jg. 8 (1944), S. 20-23, hier S.21.

${ }^{27}$ Ebd.; Gemeindekulturtagung Gau Köln-Aachen, in: Die Kulturverwaltung, Jg. 2 (1938), S.49-51, hier S. 49 (Bericht über die Rede des Beigeordneten des Deutschen Gemeindetags, Otto Bennecke, über Aufgaben der gemeindlichen Kulturpflege). 
den), der Westfälische Literaturpreis und der Schwäbische Dichterpreis. Städtepreise wurden verliehen von Berlin, München, Frankfurt, Heidelberg, Hamburg, Braunschweig, Dessau, Dresden, Jena, Wandsbek, Magdeburg, Wuppertal, Düsseldorf (ImmermannPreis), Leipzig, Chemnitz, Stuttgart, Babenhausen, Rostock und Tilsit ${ }^{28}$. Dabei handelt es sich nur um Preise von größerer Bedeutung. Die regionale Verzweigung des Preissystems veranschaulichen die ausschließlich oder unter anderen an niederdeutsche Autoren vergebenen Preise im niederdeutschen Raum: Klaus-Groth-Preis für plattdeutsche Lyrik, Schleswig-Holsteinischer Literaturpreis, John-Brinckmann-Preis, Mecklenburgischer Schriftumspreis, Hermann-Boßdorf-Preis, Emanuel-Geibel-Preis der Stadt Lübeck, Literaturpreis der Provinz Hannover, Dietrich-Eckart-Preis, Münchhausen-Preis, JohannHinrich-Fehrs-Preis für plattdeutsche Prosadichtung, Goldener Spatz von Wuppertal ${ }^{29}$.

Sowenig die Fachaufsicht des Propagandaministeriums über die Kunst- und Literaturpreise zu einer Einschränkung der regionalen und lokalen Preise oder zu einer die Autonomie der Vergabegremien prinzipiell in Frage stellenden zentralen Steuerung der Preisvergabe führte, sowenig waren die öffentlichen Kultureinrichtungen bloße Befehlsempfänger der Reichsgewalt, solange sie sich an die vom Reich gesetzten politisch-ästhetischen Normen (keine Juden, keine Kommunisten, keine „Verfallskunst“) und an einzelne kulturpolitische Direktiven (z. B. keine Feindliteratur während des Krieges, keine Berücksichtigung bestimmter Autoren) hielten.

Das zeigte sich auch bei den Theatern. Die Gestaltung der Spielpläne lag wie vor 1933 in der Verantwortung der - jetzt natürlich politisch selektierten - Intendanten. Der nach 1945 mehr berüchtigte als vor 1945 gefürchtete „Reichsdramaturg“ in der Theaterabteilung des Propagandaministeriums (1934-1945 Rainer Schlösser) beschränkte sich darauf, die Intendanten kollegial auf neue aufführungswürdige Stücke hinzuweisen, ohne deren Aufführung zu fordern oder gar zu erzwingen. Die Nichtbeachtung solcher Anregungen hatte für die Theater keinerlei Folgen. Für den Bereich der Oper wurde ermittelt, daß Schlössers Empfehlungen, soweit sie nicht ohnehin etablierte Komponisten betrafen, so gut wie erfolglos waren. Umgekehrt gab es auch keine Spielplankontrolle im Sinne einer systematischen Vorzensur. Der Reichsdramaturg nahm die von den Intendanzen zur Genehmigung vorgelegten Spielpläne im wesentlichen zur Kenntnis. Hielt er ausnahmsweise ein Stück für ungeeignet, so versuchte er den Intendanten auf gütlichem Wege zu veranlassen, dieses zurückzuziehen oder abzusetzen. Regelrechte Aufführungsverbote, die sich der Propagandaminister gesetzlich vorbehalten hatte ${ }^{30}$, waren offenbar sehr selten ${ }^{31}$.

Schwieriger stellen sich die Verhältnisse zum Beispiel bei den durchweg von den Gemeinden unterhaltenen Volksbüchereien dar, die sich an ein Massenpublikum wandten und deshalb im Konzept der totalen Erfassung und ideologischen Durchdringung der Bevölkerung eine besonders wichtige Rolle spielten. Nach einer Phase der rigiden staatlichen

${ }^{28}$ BA R 55/122, Bl. 142-145, Verzeichnis der deutschen Literaturpreise [1937]; BA R 55/122, Bl.320323, Verzeichnis der deutschen Literaturpreise [1939]; Deutsche Literaturpreise, in: Die Kulturverwaltung, Jg. 2 (1938), S. $87 \mathrm{f}$.

${ }^{29}$ Kay Dohnke, Norbert Hopster, Jan Wirrer (Hg.), Niederdeutsch im Nationalsozialismus. Studien zur Rolle regionaler Kultur im Faschismus, Hildesheim 1994, S. $324 \mathrm{f}$.

${ }^{30} \$ 5$ des Theatergesetzes vom 15.5. 1934, $\$ 14$ der Verordnung zur Durchführung des Theatergesetzes vom 18.5. 1934, RGBl.I 1934, S.411-415.

${ }^{31}$ Vgl. hierzu Konrad Dussel, Ein neues, ein heroisches Theater? Nationalsozialistische Theaterpolitik und ihre Auswirkungen in der Provinz, Bonn 1988, S. 88-100, S. 227-239; Ders.: Provinztheater in der NS-Zeit, in: VfZ 38 (1990), S.75-111, hier S. 93-98. 
Kontrolle durch die im Reichserziehungsministerium ressortierende „Reichsstelle für volkstümliches Büchereiwesen " bzw. die ihr nachgeordneten Büchereiberatungsstellen kam es aber auch hier ab 1936/37 zu einer deutlichen Liberalisierung der Bestimmungen, durch die die Autonomie der Großstadtbüchereien wiederhergestellt und die Abhängigkeit der Mittel- und Kleinbüchereien von den staatlichen Stellen verringert wurde ${ }^{32}$.

Das Volksbüchereiwesen ist auch ein gutes Beispiel für die nach 1933 zu beobachtende Vermehrung regionaler und lokaler kultureller Dienststellen und Einrichtungen. Im Jahre 1933 gab es nur ca. 6231 als akzeptabel anzusehende Volksbüchereien. Bis 1940 wurden weitere 7677 Büchereien neu gegründet oder funktionsfähig gemacht, wobei sich das Tempo von Jahr zu Jahr steigerte. 1933-1936 handelte es sich um jeweils 650, 1937 um 1086, 1938 um 2265 und noch im ersten Kriegsjahr um 1644 Büchereien, die neu gegründet oder reorganisiert wurden, die weit überwiegende Zahl in Kleinstädten und auf dem Lande ${ }^{33}$.

Auffällig hoch ist auch die Zahl neu eingerichteter regionaler und lokaler Kulturbehörden, Kulturverbände und kulturwissenschaftlicher Institute. Eine Einrichtung ganz neuer Art waren zum Beispiel Musikbeauftragte in den Städten und Landkreisen. Neue Kulturämter entstanden u. a. in Erfurt, Wien, Schneidemühl und Reichenberg, Gemeindekulturverbände u. a. in Sachsen, Württemberg und Hessen, in Braunschweig und im Gau Mainfranken. Ausstellungen bodenständiger Maler, Bildhauer und Veranstaltungen mit einheimischen Musikern und Schriftstellern sind Legion. In großer Zahl entstanden neue Bühnen, nicht zuletzt als Wanderbühnen konzipierte Regionaltheater. Auf die enorme Zunahme der Kunstpreise wurde bereits hingewiesen. Diese beruhte hauptsächlich auf neuen Landes-, Gau- und Städtepreisen ${ }^{34}$.

Die neue kulturpolitische Zentralgewalt hat also nicht zu einer Einschränkung oder gar Lähmung partikularer kultureller Bestrebungen geführt. Für die im Gegenteil zu konstatierende Zunahme solcher Aktivitäten sind drei Gründe erkennbar. Erstens ist darauf hinzuweisen, daß es im Zuge der totalitären Neuformierung von Staat und Gesellschaft zu einem geradezu hypertrophen Zuwachs an Organisationen, Verbänden und Behörden kam, die sich in der Regel auch auf Gau- und Kreisebene etablierten. Beispielhaft seien die Landeskulturwaltungen der RKK, die Landesleitungen ihrer Einzelkammern, die Gau- und Kreisämter von KdF und die kulturpolitische Abteilung des Deutschen Gemeindetags mit ihren Landes- und Provinzialvertretungen als sachlich zuständige Einrichtungen genannt, aber etwa auch die Gliederungen und angeschlossenen Verbände der NSDAP, die sich nach 1933 gemäß dem Muster der Politischen Organisation überall im Reich verzweigten. Alle diese Dienststellen mußten ihre regionale oder lokale Existenz durch regional- oder lokalspezifische Aktivitäten legitimieren. Dem Totalitätsprinzip des Nationalsozialismus entsprechend, wurden dabei auch Ämter, deren Aufgaben eigentlich auf anderen Gebieten lagen, kulturell aktiv. Zweitens ist die Zunahme partikularer kultureller Aktivitäten auf die - dem Nationalsozialismus wie jedem anderen "revolutionären“ Regime eigene - Hyperaktivität und auf das Konkurrenzdenken zwischen den einzelnen Gauen und Kreisen zurückzuführen. Schließlich ist, drittens, auf die Wirkungskraft der Volkstums-

${ }^{32}$ Vgl. hierzu Engelbrecht Boese, Das öffentliche Bibliothekswesen im Dritten Reich. Bad Honnef 1987, S. 95-271, S. 311-352 passim; Ders.: Die Bestandspolitik der öffentlichen Büchereien im Dritten Reich, in: Bibliotheksdienst 17 (1983), S. 263-282.

${ }^{33} \mathrm{Vgl}$. Boese, Bibliothekswesen, S. 131 und 311.

${ }^{34} \mathrm{Zahllose}$ Hinweise auf regionale und lokale kulturelle Veranstaltungen und Ereignisse finden sich in den Rubriken "Mitteilungen" und "Ereignisse und Erfolge" der Zeitschrift "Die Kulturverwaltung“, von der hier die Jahrgänge 2 (1938) bis 6 (1942) benutzt wurden. 
ideologie hinzuweisen. Sowohl Nationalsozialisten wie NS-nahe und auch nichtnationalsozialistische Vertreter der landschaftlichen und lokalen Kulturszene konnten aus der Tatsache, daß die völkischen Ideologeme Teil der Staatsideologie geworden waren, den - freilich trügerischen - Schluß ziehen, daß nach der Ausmerzung der Weimarer „Verfallskultur" jetzt auch die Tage der egalitären, alles Spezifische eliminierenden Massenkultur gezählt waren, und darauf hoffen, daß die vor 1933 im Niedergang begriffenen landschaftlichen Kulturen in der jetzt angebrochenen Zeit eine neue Blüte erleben würden, die es durch gesteigerte eigene Aktivitäten zu fördern galt.

Nun könnte hier eingewendet werden, daß die Frage des Verhältnisses zwischen Reichsgewalt und Partikulargewalten, zwischen Reichsinteressen und regionalen und lokalen Interessen nur von nebensächlicher Bedeutung sei, wenn doch alle Behörden, Organisationen, Verbände und Vereine gleichgeschaltet waren, von Nationalsozialisten kontrolliert wurden und damit auch weltanschaulich im nationalsozialistischen Sinne ausgerichtet waren. Daß aber der Nationalsozialismus Deutschland, bei aller zu konstatierenden intellektuellen und kulturellen Verarmung, keineswegs in eine Wüste geistiger Uniformität verwandelt hat, läßt sich auf allen kulturellen Feldern belegen.

Instruktiv sind zum Beispiel die Verhältnisse bei den Volksbüchereien. Obwohl diese zwischen 1932 und 1936 einer rigorosen politischen Säuberung unterzogen wurden, obwohl der Neuaufbau der Bestände in den kleinen und mittleren Büchereien zentral gesteuert wurde, haben sich die Volksbüchereien nicht in nationalsozialistische Kampfbüchereien verwandelt. Der notorische Mangel an neuer nationalsozialistischer Literatur, die intellektuelle Begrenzung und kulturelle Unfruchtbarkeit der NS-Ideologie, aber auch die unabweisbaren informatorischen Bedürfnisse einer modernen, arbeitsteiligen Industriegesellschaft haben eine solche Entwicklung gar nicht zugelassen. Zwar war ein Kernbestand an nationalsozialistischer und verwandter Literatur selbstverständlich überall vorhanden, doch war er von einem zwar „um entscheidende Bestandteile“ reduzierten, nichtsdestoweniger noch immer breiten „Literaturspektrum“ umgeben, „das auf die Verschiedenartigkeit der Benutzerschichten, mit denen es die Bücherei zu tun hatte, abgestimmt war und sich nicht in seiner Propagandafunktion erschöpfte ${ }^{\alpha 35}$. Den Bibliothekaren blieb trotz des ihnen zugedachten politischen Erziehungsauftrags noch genügend Spielraum, an der bibliothekarischen Tradition festzuhalten, für ihre Leser „einen Querschnitt aus der zeitgenössischen Literaturproduktion" bereitzuhalten ${ }^{36}$ - und die war eben, auch eingedenk des Aderlasses durch Emigration und Zensur - alles andere als bloß nationalsozialistisch. Dem entspricht, daß aus den Münchener Stadtbüchereien nach 1945 nicht mehr als 20 Prozent der Bestände ausgesondert werden mußten ${ }^{37}$.

Ähnlich lagen die Dinge bei den Theatern. Obwohl die Intendanzen mit politisch zuverlässigen Persönlichkeiten besetzt wurden und trotz der Tätigkeit des Reichsdramaturgen, kann lediglich von nationalsozialistisch infizierten, nicht aber von nationalsozialistischen Spielplänen gesprochen werden. Gemäß den exemplarischen Spielplanuntersuchungen von Konrad Dussel, entfiel zwar in den "Revolutionsjahren“ 193333 Prozent der Aufführungen auf das „Theater der Rechten“, also nationalsozialistische oder NS-nahe Stücke, jedoch ging deren Anteil dann kontinuierlich wieder zurück, um sich in den Kriegsjahren bei nur noch 10 Prozent einzupendeln. Die Jahre 1934-1944 zusammenge-

\footnotetext{
${ }^{35}$ Boese, Bibliothekswesen, S. 344.

36 Ebd., S. 270.

${ }^{37}$ Ebd., S. 255, Anm. 144.
} 
nommen, ergeben sich folgende Werte: Klassiker 19,5\%, Theater der Rechten 16 Prozent und Unterhaltungstheater 52,5 Prozent $^{38}$.

Vergleichbare Beobachtungen hat Karl Ditt hinsichtlich der von dem nationalsozialistischen Landeshauptmann Karl Friedrich Kolbow, Parteigenosse seit 1921, und seinem nationalkonservativen Kulturdezernenten Ernst Kühl geführten kulturellen Einrichtungen des Provinzialverbands Westfalen gemacht. Der Westfälische Heimatbund steuerte „trotz aller Einbeziehung von Nationalsozialisten im Ursprungsbereich seiner konkreten Arbeit weiter den traditionellen [d.h. provinziell-konservativen] Kurs" und wich auch, z.B. in Fragen des Landschaftsschutzes, nicht vor Konflikten mit Reichsbehörden zurück. Das "Provinzialinstitut für westfälische Landes- und Volkskunde“ und seine Kommissionen ließen in ihrer Tätigkeit „im großen und ganzen“ ebenfalls „keine nationalsozialistische Orientierung erkennen“. Und auch das „Landesmuseum für Kunst und Kulturgeschichte und Kunstförderung “ bewahrte gegenüber der nationalsozialistischen Kulturpolitik seine Eigenständigkeit. Im „Provinzialmuseum für Naturkunde und Naturschutz“ kam es zwar zu einer bemerkenswerten Modernisierung der Bestände und der museumsdidaktischen Präsentation, jedoch nicht zu einer Umsetzung der NS-Rassenlehre ${ }^{39}$.

Sowenig es in der Tätigkeit der staatlichen bzw. staatlich kontrollierten Institutionen zu einer alles Nichtnationalsozialistische eliminierenden ideologischen Durchdringung kam, sowenig war dies auch bei den gleichgeschalteten Verbänden und Vereinen der Fall. Selbst bei der Reichsschrifttumskammer, bei der es sich um einen jener bürokratischen Großapparate handelte, die nach Alfred Neumann die dort zwangsweise zusammengeschlossenen Menschen tendenziell aller Privatheit und Autonomie beraubten ${ }^{40}$, ist eine differenzierte Betrachtung am Platze. Obwohl per Gesetz dazu bestimmt, ein dem nationalsozialistischen „Kulturwollen“ entsprechendes Schrifttum zu fördern ${ }^{41}$, wurde die RSK kaum in diesem Sinne aktiv; sie beschränkte sich - in Übereinstimmung mit der Schrifttumsabteilung des Propagandaministeriums - in der Praxis darauf, alles zu bekämpfen, was unter rassischen, politischen, sittlichen und ästhetischen Gesichtspunkten antinationalsozialistisch, regimegegnerisch und regimeabträglich war. Nationalsozialistische Literatur wurde gewünscht und gefördert, aber nicht gefordert oder gar erzwungen. Das von der Kammer geduldete Schrifttum umfaßte so, trotz des Verbots der sogenannten Verfallsliteratur, noch ein relativ breites Spektrum, das - gegenüber der Weimarer Zeit auf der Skala politischer Einstellungen deutlich nach rechts verschoben - von der Parteiliteratur und dem NS-nahen Schrifttum über die Fach-, Sach- und Unterhaltungsliteratur bis hin zur christlich-humanistischen Literatur der "Inneren Emigration“ und anderer nichtnationalsozialistischer Belletristik reichte ${ }^{42}$.

${ }^{38}$ Vgl. Dussel, Provinztheater, S. 80-93, besonders die Tabelle S. 82.

${ }^{39}$ Vgl. Ditt, Raum, S.229f., S. 241-348, bes. S. 277 f., S. 288, S. 290, S. 327, S. 348.

${ }^{40}$ Franz Neumann. Behemoth. Struktur und Praxis des Nationalsozialismus 1933-1944 (1942/44), hrsg. von Gert Schäfer, Köln 1977, S.427-429.

${ }^{41}$ Vgl. die erste Durchführungsverordnung vom 1. November 1933, \$3, RGBI.I 1933, S. 797-800 und die Amtliche Begründung zum RKK-Gesetz vom 26.9. 1933, u. a. in: Handbuch der RSK, S.6f.

${ }^{42}$ Diese Einschätzung beruht hauptsächlich auf der Auswertung von mehr als 2000 Mitgliedschaftsakten der RSK und der Durchsicht der verschiedenen Verbotsverzeichnisse. Zu den Indizierungskriterien siehe Dietrich Aigner, Die Indizierung "schädlichen und unerwünschten Schrifttums" im Dritten Reich, in: Archiv für Geschichte des Buchwesens, Bd.11 (1971) (Separatdruck), Sp. 933-1034, hier Sp.983-1006. Von literaturwissenschaftlicher Seite wird dieses Urteil bestätigt durch Hans-Dieter Schäfer, Das gespaltene Bewußtsein. Über deutsche Kultur und Lebenswirklichkeit 1933-1945, München 1981. 
Wer sich als Schriftsteller, Verleger und Buchhändler innerhalb dieses Spektrums bewegte, der bekam mit der Kammer keinerlei Schwierigkeiten und konnte fast so leben und arbeiten, als gäbe es sie gar nicht. Bei einer vom Institut für Zeitgeschichte 1988 unter noch lebenden Schriftstellern der NS-Zeit durchgeführten Fragebogenaktion erklärten von 85 Rücksendern mit verwertbaren Angaben nur vier (darunter ein ehemaliger RSK-Landesleiter), mit der Kammer in regelmäßigem Kontakt gestanden zu haben. Und nur ein Autor, Rolf Italiaander, der Probleme mit seinem Abstammungsnachweis hatte, antwortete, die Kammer sei ihm „während der ganzen Nazi-Zeit lästig, fast lebensbedrohend “ für seine "ganze Familie“ gewesen. Dagegen meinten 79 Autoren, also fast $93 \%$, mit der Kammer "selten“, „keinen“, "gar keinen“, „nicht den geringsten“ Kontakt gehabt zu haben $^{43}$. Mögen diese Antworten in einzelnen Fällen auf Erinnerungslücken und Verdrängungsleistungen zurückzuführen sein, so belegen sie doch im ganzen, daß die Kammer für die meisten ihrer Mitglieder ein „anonymes Büro“ (Albrecht Goes) gewesen ist, mit dem man im Normalfall nur durch die jährliche Beitragsveranlagung, gelegentliche Fragebogenzusendungen und routinemäßige Glückwünsche des Präsidenten anläßlich runder Geburtstage zu tun hatte. Dies wird auch durch das Studium einer genügend großen Zahl von Mitgliedschaftsakten der Reichsschrifttumskammer sehr deutlich ${ }^{44}$.

Zusammenfassend kann gesagt werden, daß das regionale und lokale kulturelle Leben durch zwei politische Parameter bestimmt wurde. Erstens durch eine unscharf begrenzte, vermutlich nicht in allen Territorien gleich große Autonomie der kulturell tätigen Institutionen und Individuen, zweitens durch eine unscharf begrenzte, vermutlich nicht in allen kulturellen Betätigungsfeldern gleich große Gestaltungsfreiheit. In einer mathematischen Figur dargestellt, handelt es sich um zwei randunscharfe Schnittmengen, deren Deckungsbereich den Freiraum für landschaftliche und lokale kulturelle Bestrebungen und Tätigkeiten bildet.

Diesen Freiraum näher zu inspizieren, wäre Aufgabe einer an kulturellen Fragen interessierten zeitgeschichtlichen Regional- und Lokalforschung. Diese hätte das kulturelle Leben in sinnvoll definierbaren Kulturräumen mit Konzentration auf die lebenswirklichen Verhältnisse, d.h. methodisch mit überwiegend empirischen Mitteln, zu untersuchen. Die Begrenzung solcher Studien auf bestimmte Territorien ist aus forschungsökonomischen Gründen unvermeidbar, sie darf aber nicht - wie das vor allem in lokalgeschichtlichen Studien der letzten Jahrzehnte vielfach geschehen ist - dazu verleiten, die politischen, historischen und interregionalen Zusammenhänge auszublenden. $\mathrm{Zu}$ wünschen wären thematisch oder räumlich ansetzende Einzelstudien mit diachronischer und synchronischer Perspektivierung.

Diese dürten sich nicht auf die Auswertung statistischer Erhebungen zu Umfang und Struktur der regionalen und lokalen kulturellen Produktion und Distribution beschränken. Sie hätten vielmehr auch deren Formen und Inhalte zu untersuchen, um herauszufinden, in welchem Umfang die kulturellen Veranstaltungen und Gegenstände nationalsozialistisch infiziert bzw. in welchem Umfang sie ideologieresistent waren oder sogar Raum für geistige Widersetzlichkeit boten - ob sie mehr dem Regime genützt oder mehr den Menschen geholfen haben, in einem durch die Allgegenwärtigkeit des Politischen bestimmten Alltag bei sich selbst zu bleiben, eine Sphäre der Privatheit und zwischen-

${ }^{43}$ Akten zur Fragebogenaktion, IfZ/Dahm.

${ }^{44}$ Berlin Document Center (jetzt Bundesarchiv Außenstelle Berlin-Zehlendorf), Reichskulturkammer/Reichsschrifttumskammer. 
menschlicher Unmittelbarkeit zu erhalten, in der Geborgenheit des traditionellen sozialen oder konfessionellen Milieus weiterzuleben. Erst dadurch würde deutlich werden, wie erfolgreich der Nationalsozialismus die regionalen und lokalen kulturellen Bestrebungen und Aktivitäten für seine $Z$ wecke zu instrumentalisieren vermochte. Umgekehrt wäre zu fragen, in welchem Umfang und mit welchem Erfolg regionale und lokale kulturelle Eliten - bewußt oder unbewußt - den Nationalsozialismus und seinen fanatischen Neuordnungswillen für ihre Interessen instrumentalisierten, indem sie eigene Vorstellungen und Ziele zu nationalsozialistischen erklärten und in der Maske nationalsozialistischer Rhetorik vertraten. Ein sachlich weites und methodisch schwieriges Feld, das im Rahmen dieses Beitrags nur vermessen werden konnte. 


\section{Walter Ziegler \\ Gaue und Gauleiter im Dritten Reich}

Als im Januar 1931 der Fuldaer Ortsgruppenleiter und NS-Stadtrat Rudolf Jordan zu Hitler nach München gebeten wurde und zu seiner Überraschung, wie er selbst berichtet hat, die Gauleitung des Gaues Halle-Merseburg übertragen bekam, äußerte sich Hitler, wie sich Jordan noch nach dem Krieg erinnerte, auch über die Arbeit in den Gauen: Er lasse seinen Gauleitern bekanntlich in der Führung ihrer Gaue volle Bewegungsfreiheit, sofern nicht grundsätzliche Entscheidungen zu fällen seien: „Die eigentliche Frontarbeit der Partei liege in den Gauen. Er hasse die Gleichheit; jeder Gau solle - je nach der Persönlichkeit seines Führers und den besonderen Problemen der Bevölkerung - ein eigenes Gesicht haben $^{\text {"1 }}$. Ein weiterer memoirenschreibender Gauleiter, der seit 1940 in Süd-HannoverBraunschweig tätige junge Hartmann Lauterbacher, stellt in der Rückschau fest: „Als Gauleiter war man nicht nur der weltanschauliche Repräsentant der Partei und damit Adolf Hitlers, sondern auch der politische Arm der Reichsregierung und der Reichsleitung der NSDAP draußen im Lande. Es kam dabei darauf an, die Dinge nach den besonderen Eigenarten der Länder und der Bevölkerung auszurichten. Ein Gauleiter im Rheinland hatte sich ganz anders zu verhalten als einer in Bayern oder in Niedersachsen, $d . h$. Auftreten, Methoden und Taktik mußten natürlich jeweils den Gegebenheiten angepaßt sein “2. Wenn die Gauleiter tatsächlich die Repräsentanten des Führers im Land und als „Frontgeneräle“ die Vertreter ihres Landes bei der Führung waren, also jene Vizekönige darstellten, wie Hitler sie einmal genannt hat, so erstaunt das relativ geringe Interesse, das bisher den Gauen und Gauleitern, vor allem in ihrer Bedeutung als Akteure im Land, gewidmet worden ist. Zu nennen ist als maßgebliche Studie eigentlich nur die 1969 von Peter Hüttenberger bei Bracher gefertigte Dissertation über die Gauleiter ${ }^{3}$, die durch ihre Zusammenstellungen und durch ihre Darstellung zwar wichtig bleiben wird, die jedoch, wie der Untertitel „Studie zum Wandel des Machtgefüges in der NSDAP“ zeigt, vor allem das Auf und $\mathrm{Ab}$ in den Kompetenzen der Gauleiter gegenüber den Partei- und Staatsbehörden verfolgt, also weder das Gauleiterkorps noch gar die Tätigkeit der Gauleiter oder die Geschichte der einzelnen Gaue ins Visier nimmt. Das ist durch spätere Arbeiten nur wenig geändert worden, weder die - wenigen - allgemeinen Geschichten der NSDAP ${ }^{4}$

${ }^{1}$ Rudolf Jordan, Erlebt und erlitten. Weg eines Gauleiters von München bis Moskau, Leoni 1971, S. 13.

${ }^{2}$ Hartmann Lauterbacher, Erlebt und mitgestaltet. Kronzeuge einer Epoche 1923-45. Zu neuen Ufern nach Kriegsende, Preußisch Oldendorf 1987, S.169.

${ }^{3}$ Peter Hüttenberger, Die Gauleiter. Studie zum Wandel des Machtgefüges in der NSDAP (Schriftenreihe der Vierteljahrshefte für Zeitgeschichte 19), Stuttgart 1969.

${ }^{4}$ Dietrich Orlow, The History of the Nazi Party 1933-1945, 2 Bde., London 1969-73; die Arbeit von Kurt Pätzold u. Manfred Weißbecker, Geschichte der NSDAP 1920-1945, Köln 1981 ist nicht nur einseitig nach DDR-Maßstab gestaltet, sondern befaßt sich kaum mit der Partei als solcher. Das Werk von Jochen von Lang, Die Partei. Mit Hitler an die Macht und in den Untergang. Ein deutsches Lesebuch, Hamburg 1989, hat eher andere als fachwissenschaftliche Ziele. 
noch die zahlreichen Untersuchungen zum Sozialprofil der Partei ${ }^{5}$ haben im einzelnen und zusammenfassend Grundlegendes zum Phänomen Gau und Gauleiter hervorgebracht. Die Gründe dafür sind nicht schwer zu finden. Neben der Konzentrierung der öffentlichen Diskussion und der Forschung in den ersten Zeiten nach dem Zusammenbruch auf Hitler und die großen Paladine in seiner Umgebung ist hier vor allem auf die schwerpunktmäßige Behandlung sozialgeschichtlicher Themen im Bereich der Strukturen von Herrschaft und Widerstand in den letzten Jahrzehnten zu verweisen, die kaum mehr Fragen nach dem administrativen Entscheidungsträgern im Lande stellen ließ. Das ist zu bedauern, da doch erst eben die reguläre Administration die Folie bildet für die Alltagserfahrung und für die Möglichkeiten von Resistenz. So weiß man heute noch kaum etwas über die Tätigkeit der preußischen und außerpreußischen Landesregierungen, und, wenn man diese im Hinblick auf die realen Machtverhältnisse für unwichtig hält, nicht viel mehr über die Gauleiter und die von ihnen geführten Gaue. Es fehlen bisher alle Gaugeschichten, die erst erkennen lassen könnten, was in den einzelnen Regionen geschehen ist, es fehlen weithin Arbeiten über die Tätigkeit und Bedeutung der Gauämter - wie wichtig deren Aufarbeitung wäre, haben erst kürzlich die Arbeiten zum Gauwirtschaftsamt im Gau Westfalen-Süd gezeigt ${ }^{6}$; von besonderer Bedeutung wäre auch die Betrachtung der Gaue im Krieg, wo mittlerweile durch eindringliche Studien zur Verwaltungsgeschichte die Gaue als maßgebliche Einheiten hervortreten? Vor allem aber fehlen noch Biographien der Gauleiter, die doch die herausragenden und allgemein bekannten Gestalten in den einzelnen Teilen Deutschlands waren; neben Goebbels, Ley und Streicher ist bisher in einer eigenen Monographie nur der bereits 1935 ums Leben gekommene Gauleiter der Bayerischen Ostmark und Führer des NS-Lehrerbundes, Hans Schemm, behandelt worden ${ }^{8}$, für andere Gauleiter liegen nur Kurzdarstellungen in den landesgeschichtlichen Werken oder kleinere spezifische Beiträge vor?. Daß es zur Erarbeitung dieser Desiderate genü-

${ }^{5}$ Vgl. z.B. Michael H. Kater, The Nazi Party. A social profile of members and leaders 1919-1945, Oxford 1983.

${ }^{6}$ Gerhard Kratzsch, Der Gauwirtschaftsberater im Gau Westfalen-Süd, in: Dieter Rebentisch u. Karl Teppe (Hg.), Verwaltung contra Menschenführung im Staat Hitlers. Studien zum politisch-administrativen System, Göttingen 1986, S. 173-207; Ders., Der Gauwirtschaftsapparat der NSDAP. Menschenführung, „Arisierung“, Wehrwirtschaft im Gau Westfalen-Süd. Eine Studie zur Herrschaftspraxis im totalitären Staat (Veröffentlichungen des Provinzialinstituts für westfälische Landes- und Volksforschung des Landschaftsverbandes Westfalen-Lippe 27), Münster 1989.

${ }^{7}$ Vgl. Dieter Rebentisch, Führerstaat und Verwaltung im Zweiten Weltkrieg. Verfassungsentwicklung und Verwaltungspolitik 1939-1945, Stuttgart 1989.

${ }^{8}$ Franz Kühnel, Hans Schemm, Gauleiter und Kultusminister (1891-1935), Nürnberg 1985; Rudolf Endres, Hans Schemm, in: Fränkische Lebensbilder 15 (1993) S. 265-284.

${ }^{9}$ In letzter Zeit sind an spezifischen Beiträgen zu den Gauen und Gauleitern erschienen (soweit bekannt): Allgemein: Karl Höffkes, Hitlers Politische Generale. Die Gauleiter des Dritten Reiches, Tübingen 1986; Jeremy Noakes, Oberbürgermeister and Gauleiter. City Government between Party and State, in: Gerhard Hirschfeld u. Lothar Kettenacker (Hg.), Der Führerstaat: Mythos und Realität, Stuttgart 1981, S.194-227. - Baden: Johnpeter Horst Grill, Robert Wagner, in: Ronald Smelser, Enrico Syring, Rainer Zitelmann (Hg.), Die braune Elite II, Darmstadt 1993, S. 254-267. Koblenz-Trier: Horst Romeyk, Der Gau Moselland in der nationalsozialistischen Reichsreform, in: Zeitschrift für westdeutsche Landesgeschichte 11 (1985) S. 247-269. - Hamburg: Frank Bajohr, Gauleiter in Hamburg. Zur Person und Tätigkeit Karl Kaufmanns (1900-1969), in: Vierteljahrshefte für Zeitgeschichte 43 (1995), S. 267-295. - Mainfranken: Thomas Reuß, Öffentlichkeit und Propaganda. Nationalsozialistische Presse in Unterfranken 1922-1945, Bad Neustadt 1988; Peter Weidisch, Die Machtergreifung in Würzburg 1933, Würzburg 1990; E.D.R.Harrison, The Nazi Dissolution of the Monasteries: A Case-Study, in: The English Historical Review 109 (1994) S. 323-355. - 
gend Quellenmaterial gibt - wenn auch in höchst unterschiedlicher Dichte -, kann man nach der Rückführung der Archivalien des Dritten Reiches nach Deutschland schon jetzt behaupten; für die Gauleiter selbst ist auch hinzuweisen auf eine nicht geringe Zahl von Publikationen von diesen selbst ${ }^{10}$, darunter mindestens sechs nach dem Krieg erfolgte Memoirenveröffentlichungen ${ }^{11}$.

Aus dem Gesamtgebiet der Geschichte von Gauen und Gauleitern wird in diesem Beitrag, der Thematik der Tagung gemäß, der Aspekt „Gau und Region“ herausgegriffen, also der Frage nachgegangen, inwiefern die Gaue mit ihren Führern eine Art regionales oder vielleicht sogar föderales Pendant zum zentralistischen Einheitsstaat des Dritten Reiches darstellten. Angesichts des noch weithin bestehenden Mangels an Vorarbeiten können die folgenden Ausführungen freilich vielfach nur Überlegungen sein, die sich als Anstöße zur Diskussion, zur Ergänzung und Vertiefung darbieten und eher methodische Fragen als Antworten bringen. Vorgegangen wird dabei so, daß in einem ersten Teil grundlegende Tatsachen über die Gaue und ihre Gauleiter, soweit dies bisher herausgearbeitet worden ist, wiedergegeben werden, in einem zweiten die methodischen Überlegungen zum speziellen Thema Gau und Region vorgetragen werden; ein kurzer Blick auf die bayerischen Gauleiter soll das Referat beschließen.

\section{Allgemeines zu Gauen und Gauleitern}

Am 22. Mai 1926 legte die Satzung der NSDAP fest: „Der Verein besteht zunächst aus Ortsgruppen, die der Parteileitung unterstellt sind. Je nach Bedarf werden diese Ortsgruppen in Gauverbänden zusammengefaßt. Die Gauleiter werden von der Reichsleitung bestimmt ... Die Reichsleitung arbeitet nur mit Ortsgruppen und mit

München-Oberbayern: München - „Hauptstadt der Bewegung“. Ausstellungskatalog, München 1993. - Pfalz: E.D.R. Harrison, Gauleiter Bürckel and the Bavarian Palatinate 1933-1940, in: Proceedings of the Leeds Philosophical and Literary Society, Literary and Historical Section 20, 3, 1986, S. 271-291; Dieter Wolfanger, Ernst Ludwig Leyser. Stellvertretender Gauleiter der NSDAP in der Saarpfalz, in: Jahrbuch für westdeutsche Landesgeschichte 14 (1988) S. 209-217; Ders., Josef Bürckel, in: Gerhard Nestler u. Hannes Ziegler (Hg.), Die Pfalz unterm Hakenkreuz, Landau 1993. S.63-86; Gerhard Paul, Josef Bürckel - Der rote Gauleiter, in: Smelser u.a., Elite II, S. 51-65. Süd-Hannover-Braunschweig: Hanna Behrend, Die Beziehungen zwischen der NSDAP-Zentrale und dem Gauverband Süd-Hannover-Braunschweig 1921-1933, Frankfurt 1981. - Thüringen: Peter W. Becker, Fritz Sauckel, in: H. Ronald Smelser u. Rainer Zitelmann (Hg.), Die braune Elite. 22 biographische Skizzen, 3. Aufl. Darmstadt 1993, S. 236-245. - Westfalen-Nord: Heinz-Jürgen Priamus, Alfred Meyer - Selbstinszenierung eines Gauleiters, in: Ders. u. Stefan Goch (Hg.), Macht der Propaganda oder Propaganda der Macht? Inszenierung nationalsozialistischer Politik im Dritten Reich am Beispiel der Stadt Gelsenkirchen, Essen 1992, S.48-67. Vgl. auch den Beitrag von Heinz-Jürgen Priamus in diesem Band. - Wien: Peter Black, Odilo Globocnik, in: Smelser u. a., Elite II S.103-115.

${ }^{10}$ Zusammengestellt von Günter Plum, Bibliographie der Gauleiter der NSDAP, 1970 (Manuskript im Institut für Zeitgeschichte).

${ }^{11}$ Außer Jordan, Erlebt und erlitten, und Lauterbacher, Erlebt und mitgestaltet, noch: (Vor 1933) Alfred E. Frauenfeld, Und trage keine Reu. Vom Wiener Gauleiter zum Generalkommissar der Krim. Erinnerungen und Aufzeichnungen, Leoni 1978; Albert Krebs, Tendenzen und Gestalten der NSDAP. Erinnerungen an die Frühzeit der Partei, Stuttgart 1959 (Gau Hamburg); (Nach 1933) Karl Wahl, „... es ist das deutsche Herz“. Erlebnisse und Erkenntnisse eines ehemaligen Gauleiters, Augsburg 1954; Ders., Patrioten oder Verbrecher. Aus 50jähriger Praxis, davon 17 als Gauleiter, 3. Aufl. Heusenstamm 1975 (Gau Schwaben). Außerdem ist zu verweisen auf: Baldur von Schirach, Ich glaubte an Hitler, Hamburg 1967 (Gau Wien); Peter Schmidt, 20 Jahre Soldat Adolf Hitlers, 10 Jahre Gauleiter, Köln 1941 und auf die Goebbels-Tagebücher (Gau Berlin). 
Gauen"12. Damit war die regionale Grundstruktur der Partei, die im August 1925 noch Landesverbände über den Gauen vorgesehen hatte ${ }^{13}$, sehr schnell so festgelegt worden, wie sie die längste Zeit des Dritten Reiches überdauert hat: nämlich mit den Gauen und Ortsgruppen als den eigentlich entscheidenden, denn auch etatisierten Organisationseinheiten. Die Begründung dafür, daß man die Partei nicht nach Ländern, sondern nach Gaueinheiten gliederte, wird in dieser Grundentscheidung nicht deutlich, doch wird man davon ausgehen dürfen, daß die Gaugliederung nicht nur von den Turn- und Sportverbänden seit dem 19. Jahrhundert her bekannt und weithin, besonders im nationalen Lager geläufig war ${ }^{14}$, sondern daß diese Gliederung, da von allen staatlichen Strukturen deutlich abgesetzt, einem Grundanliegen des Propagandisten Hitler entgegenkam, daß nämlich im Vordergrund der Organisation das Führertum stehe, die Organisation also nicht Selbstzweck sei: Im Gründungsdokument vom Februar 1925 war ausdrücklich festgelegt, nicht die Wahlkreiseinteilung des Reiches, sondern Fragen der Zweckmäßigkeit, der Propaganda und das vorhandene Führungspersonal seien maßgeblich für die Bildung von Unterverbänden ${ }^{15}$, und Hitler wurde nicht müde, dies seinen Parteigenossen stets neu einzuschärfen. Das entscheidende Grundprinzip war damit für die Gaugliederung gelegt: der Gauleiter erkämpft sich seinen Gau selbst, nur dort entstehen Gaue, wo kampfbereite Nationalsozialisten Erfolge erzielen ${ }^{16}$.

Dieses von Hitler propagierte Prinzip war freilich in der konkreten Wirklichkeit nur eines; das wird sogleich deutlich, wenn man auf die Karte der Gaue, wie sie seit 1933, nur wenig verändert, gültig blieb, sowie auf die konkrete Entwicklung der Gaue blickt ${ }^{17}$. Da in der „Kampfzeit“ das Parteileben vor allem von den einzelnen Wahlvorgängen geprägt war und die NS-Aktivisten sich vornehmlich in größeren Städten ansiedelten, war nämlich entgegen dem Hitlerschen Prinzip tatsächlich eine weitgehende Parallelisierung von Reichswahlkreis und Gau eingetreten, im Norden etwa bei den Gauen Weser-Ems oder Ost-Hannover, im Westen in Köln-Aachen oder Koblenz-Trier, im Süden in Niederbayern (bis 1933) oder in der Pfalz - Hitler selbst trug dem dadurch Rechnung, daß er 1928 die Angleichung der Gaue an die Reichswahlkreise verfügte ${ }^{18}$. Andererseits zeigen Gaue wie Sachsen oder Franken, auch Kurhessen oder Mecklenburg, denen keine Wahlkreise entsprachen, daß noch andere Prinzipien regionaler oder politischer Art die Gaubildung beeinflußt haben: In BerlinBrandenburg etwa bedeutete die ständige Auseinandersetzung zwischen dem Hitler- und dem Straßer-Flügel 1929 die endgültige Trennung in einen Gau Berlin und einen Gau Brandenburg (später Kurmark), im Rheinland wurde der 1926 gebildete Großgau Ruhr bis 1932 unter Versetzung der damit betrauten Führer in die Gaue Essen, Westfalen-Süd und Westfalen-Nord zerlegt, in Bayern 1933 durch Absetzung der beiden Gauleiter von Oberpfalz

${ }^{12}$ Hitler. Reden, Schriften, Anordnungen: Februar 1925 bis Januar 1933, hg. v. Institut für Zeitgeschichte, Bd.I: Die Wiedergründung der NSDAP Februar 1925-Juni 1926, hg. v. Clemens Vollnhals, München u.a. 1992, S. 463.

${ }^{13}$ Ebd. S. 149.

${ }^{14}$ Vgl. etwa Christian Zentner u. Friedemann Bedürftig, Das große Lexikon des Dritten Reiches, München 1985, S. 203; auch der Rote Frontkämpferbund benutzte diese Gliederung.

${ }^{15}$ Hitler. Reden I, S. 8.

${ }^{16}$ Wie Frauenfeld, Und trage keine Reu, S.32f. berichtet, war dies in Österreich besonders ausgeprägt.

${ }^{17}$ Vgl. Michael Freeman, Atlas of Nazi Germany, London 1987, S. 66 f.; Hüttenberger, Gauleiter, passim und Karte S.226.

${ }^{18}$ Hitler, Reden Bd. III/1: Zwischen den Reichstagswahlen Juli 1928-Februar 1929, hg. v. Bärbel Dusik u. Klaus A.Lankheit, München 1994, S. 56-62 (3. September 1928); Geoffrey Pridham, Hitler's Rise to Power. The Nazi Movement in Bavaria 1923-1933, London 1973, S. $94 \mathrm{ff}$. 
und Niederbayern und die Übernahme der Gebiete durch den Bayreuther Gauleiter Schemm der Großgau Bayerische Ostmark geschaffen ${ }^{19}$, hier weniger um, wie die Propaganda verkündete, die Wacht gegen das Slawentum zu organisieren, als vielmehr um die im katholischen Osten Bayerns besonders darniederliegende NS-Partei durch den dynamischen Bayreuther Gauleiter zu stärken. Bayern und besonders München spielten übrigens eine Sonderrolle, da hier noch Ursprünge der Gesamtpartei sichtbar waren, etwa in der Ortsgruppe München, die bis 1929 mit der Reichsleitung verbunden war, in der starken Position Streichers in Nürnberg, in einer dynamischen Parteizelle in Augsburg; es ist bemerkenswert, daß hier die Anfangsstrukturen weitgehend erhalten blieben, nicht einmal der starke Adolf Wagner, seit 1929 Gauleiter in München, konnte trotz seiner engen Beziehungen zu Hitler das Bild entscheidend verändern ${ }^{20}$. Insgesamt zeigt sich das Gausystem im Altreich, das seit 1933 kaum mehr Veränderungen erfuhr, als eine Mischung von gewachsenen Regionalitäten, praktischen Erwägungen, kämpferischen Erfolgen und personalpolitischen Eingriffen, das jedoch überschlagsweise, durch eine annähernd gegebene Mittelgröße der Gaue, dem zentralisierten Reich ein regionales System entgegenstellte.

„Die Gauleitung“, so das Organisationsbuch der NSDAP, „hat einen bestimmten Teil des Reichs politisch zu führen und gestaltend in ihm zu wirken. Innerhalb ihres Hoheitsbereiches ist der Gauleiter für die gesamte politische, kulturelle und wirtschaftliche Gestaltung aller Lebensäußerungen nach nationalsozialistischen Grundsätzen verantwortlich“21. So klar diese Sätze scheinen - was diese Feststellung nach der Machtübernahme, nachdem der Sieg errungen war, konkret bedeutete, war durchaus unklar, auch das Organisationsbuch spricht nur von Aufsicht und Erziehung des Gaues und schränkt dies noch ein durch Hinweis auf die Aufträge des Führers und die bestehenden Verordnungen. Plakativ faßte Gauleiter Wahl von Augsburg dies mit den Worten zusammen: „Ein Gauleiter war nichts anderes als ein von Hitler beauftragter Schwerstarbeiter, der in seinem Arbeitsgebiet für alles verantwortlich war", also ein ,Mädchen für alles ${ }^{22}$. Diese offenkundige Reduktion der frühen Aufgaben und Machtstellung der Gauleiter, die einst den Kampf in ihrem Gebiet umfassend geführt hatten, auf Erziehungs- und Schulungsaufgaben, was übrigens bald von den Gauleitern gesehen und kritisiert wurde ${ }^{23}$, hatte zwei grundlegende Folgen. Die erste wurde schon 1933 sichtbar, als, zum Teil von der obersten Führung gefördert, die Gauleiter mit staatlichen Ämtern betraut wurden, ja zum Teil in diese flüchteten: in die der preußischen Oberpräsidenten (1938: 7), der außerpreußischen Reichsstatthalter (1938: 10), der Chefs von Landesregierungen (1938: Sachsen, Hessen, Lippe, Hamburg) oder der Reichs- und Landesminister (Reich: Goebbels, Rust; Bayern: Wagner, Schemm); sogar als Regierungspräsidenten ließen sich einige verwenden ${ }^{24}$. Dies konnte eine Vernachlässigung des Gaues mit sich bringen, so bei Rust in Hannover ${ }^{25}$, mußte dies

${ }^{19}$ Fritz Wächtler (Hg.), Bayerische Ostmark. Vier Jahre nationalsozialistische Aufbauarbeit in einem deutschen Grenzgau, Bayreuth 1937, S. 58 ff.; Hüttenberger, Gauleiter S. 70.

${ }^{20}$ Vgl. die Schilderung der Selbstbehauptung des Gaues Schwaben gegen Adolf Wagner bei Wahl, Herz, S. $90 \mathrm{ff}$.

${ }^{21}$ Organisationsbuch der NSDAP, 5. Aufl. München 1938, S. 136.

${ }^{22}$ Wahl, Patrioten, S. 42.

${ }^{23} \mathrm{Vgl}$. Hüttenberger, Gauleiter, S. $118 \mathrm{ff}$.

${ }^{24}$ Karl Teppe, Die preußischen Oberpräsidenten 1933-1945, in: Klaus Schwabe (Hg.), Die preußischen Oberpräsidenten 1815-1945, Boppard 1985, S. 219-248 u. S. 335-338; Wolfgang Benz, Herrschaft und Gesellschaft im nationalsozialistischen Staat, Frankfurt 1990, S. $29 \mathrm{f}$.

${ }^{25}$ Vgl. Lauterbacher, Erlebt und mitgestaltet, S. 176. 
aber nicht, wie etwa das Beispiel des Oberpräsidenten und Gauleiters Josef Wagner in Schlesien zeigt. Eine zweite, noch wichtigere Folge war, daß die Gauleiter, die als staatliche Beauftragte nun den Reichsbehörden unterstellt waren, als Parteiführer aber selbständig blieben, das ganze Dritte Reich über als vom Staat getrenntes Element für außerstaatliche, spezifisch politische, die staatliche Administration überlagernde Führungsaufgaben zur Verfügung standen, was Hitler, insbesondere seit Kriegsbeginn, in laufend stärkerem Maß entgegenkam. Die einzelnen Schritte, die bereits 1935 mit der Institutionalisierung des Parteieinflusses gegenüber den Kommunen in der deutschen Gemeindeordnung begonnen hatten ${ }^{26}$, wurden von Hüttenberger zusammenfassend dargelegt ${ }^{27}$ : sie reichen über die Ernennung 1939 zuerst von einigen, 1942 dann von allen Gauleitern zu Reichsverteidigungskommissaren mit umfassenden Vollmachten, über Beauftragungen zu intensiverer Propaganda und Kontrolle im Krieg und umfassende Kompetenzen für die Evakuierung bis hin fast zu unmittelbarer Kriegführung durch den Aufbau des Volkssturms und oberer Reichsverteidigungskommissariate 1944/45 ${ }^{28}$. Zeichen dieses ständigen Aufstiegs der Gauleitermacht in den späteren Jahren waren die Organisierung der neuen Reichsgebiete wie Österreich und Wartheland als Reichsgaue oder die Betrauung von Gauleiter Sauckel in Thüringen mit der Organisation des Arbeitseinsatzes in Deutschland.

Die Tatsache, daß ein Teil der Gauleiter mit staatlichen Aufgaben, seit Kriegsbeginn dann alle Gauleiter mit spezifischen Kriegsführungsaufgaben betraut waren, läßt erneut und nun in aller Schärfe danach fragen, ob denn die Gauleiter ihre eigentliche Aufgabe, nämlich die politische Führung der Partei im Gau, überhaupt noch erkannten, worin diese Aufgaben eigentlich bestanden und wie sie ausgefüllt wurden. Wenn es hier zuerst scheinen könnte, als sei eben die eigentliche Gauparteiarbeit ganz in den Hintergrund getreten - 1935 waren nur 9 von 30 Gauleitern ohne Staatsamt ${ }^{29}$-, so stellt sich das, sieht man genauer $\mathrm{zu}$, schnell als Irrtum heraus, und nicht nur weil zu den genannten neun so rührige Gauleiter wie Streicher, Bürckel, Jordan oder Grohé zählten, sondern weil offenbar tatsächlich eine erhebliche Zahl der Gauleiter die nichtstaatlichen Aufgaben im Gau, also Propaganda und Erziehung, dazu die Überwachung allgemeiner Art - „Menschenführung" war der NS-Begriff -, sehr aktiv wahrnahm. Adolf Wagner etwa, obwohl schon zweifacher Landesminister in Bayern, war unentwegt mit nichtstaatlichen Organisationsaufgaben im Gau aktiv, 1936 führte er, den übrigen Gauen als Vorbild, die Kreistage der NSDAP ein; Gauleiter Lauterbacher, Oberpräsident in Hannover, bereiste eifrig die Kreise seines Gaues, hielt Sprechabende ab, veranstaltete gemeinsame Tagungen aller Hoheitsträger, um seinem Grundsatz „Führen und nochmals führen“ gerecht zu werden ${ }^{30}$; Gauleiter Wahl versuchte im Krieg, mit einer Gau-Soldatenzeitung Verbindung zur Front zu halten $^{31}$ - es ist vor allem auf den ganz ungenügenden Stand der Arbeiten über die NS-Gaue zurückzuführen, wenn man bisher den Eindruck hat, daß die Parteigaue als solche bedeutungslos geworden seien. Hier wäre freilich das Tätigkeitsfeld der Gauleiter näher zu bestimmen, wofür die bekannten Idealgraphiken des Organisationsbuches nicht genügen:

${ }^{26}$ Peter Diehl-Thiele, Partei und Staat im Dritten Reich, München 1969, S. $154 \mathrm{ff}$.

${ }^{27}$ Hüttenberger, Gauleiter S. $138 \mathrm{ff}$.

${ }^{28}$ Höffkes, Generale S. $22 \mathrm{f}$.

${ }^{29}$ Hüttenberger, Gauleiter, S. 80 (Florian, Grohé, Jordan, Simon, Streicher, Wächtler, Weinrich, Telschow, Bürckel).

${ }^{30}$ Kreistage der NSDAP im Traditionsgau München-Oberbayern, München o. J.; Lauterbacher, Erlebt und mitgestaltet, S. 177 u. passim.

${ }^{31}$ Front und Heimat. Soldatenzeitung des Gaues Schwaben, hg. v. Karl Wahl. 
Von den dort aufgeführten Ämtern waren ja eine Reihe der Reichsleitung zugeordnet (Gauschatzamt, Gauorganisationsamt), eine Reihe nur in Verbindung mit den angeschlossenen Verbänden von Bedeutung und nur wenige, wie die Gauinspektion oder das Gaugericht, originäre Machtpositionen der Gauleitung; auch das Verhältnis zu den Kreisen, deren Leiter nun den eigentlichen Dienst an der Basis taten, wäre zu untersuchen ${ }^{32}$. Aber auch wenn die Gauaktivitäten bisher noch nicht umfassend dargestellt sind, eines fällt schon bei der ersten Durchsicht zeitgenössischer Publikationen über die Gaue auf, wie sie etwa das „Buch der deutschen Gaue“ von 1938 repräsentiert ${ }^{33}$ : fast nie steht die Partei und ihre Organisation im Vordergrund, fast immer dagegen das Land und die Aufbauleistung für dieses, auf die die Partei und ihre Führer stolz sind.

Gauleiterherrschaft und charismatische Herrschaft Hitlers bedingten einander, hat Hüttenberger formuliert ${ }^{34}$, und in der Tat sind noch heute von den verschiedenen Männern im Dritten Reich, die Geschichte machten, neben den Gestalten an der Reichsspitze vor allem die Gauleiter bekannt, von Kaufmann in Hamburg bis Murr in Württemberg, von Hofer in Tirol bis Terboven in Essen; daher sind die Gauleiter selbst hier noch mit wenigen Worten vorzustellen. Für die 30 Gaue - 1938-1944 waren es 42 - stellt Hüttenberger als die wichtigsten Gauleiter, die schon 1932 im Amt waren und dies lange Zeit blieben, 29 Persönlichkeiten vor ${ }^{35}$; in der Tat ist ein erstes Mittel, um die Gesamtzahl der Gauleiter 1925-45 in den Griff zu bekommen - Hoeffkes ${ }^{36}$ nennt 123 Gauleiternamen und 10 nicht klar einzuordnende Ergänzungen -, sie nach ihrer Bedeutung zu strukturieren. Von den über einen längeren Zeitraum nach 1933 amtierenden Gauleitern, also ohne Straßer, der 1929, oder Ley, der 1932 schon als Gauleiter abtrat, stachen neben Goebbels und Streicher einige besonders hervor: Koch in Ostpreußen, Josef Wagner in Westfalen und Schlesien und Mutschmann in Sachsen. Nach Orlow ${ }^{37}$ waren diese in den $30 \mathrm{er} \mathrm{Jahren} \mathrm{am} \mathrm{mäch-}$ tigsten und standen auch jeweils für einen bestimmten Gauleiter-Typ, Koch als Prototyp eines kolonialen Vizekönigs, der alle rivalisierenden Kräfte aus Partei und Staat systematisch sich unterordnete, Josef Wagner, seit 1935 zweifacher Gauleiter von Westfalen-Süd und Schlesien, dazu Reichskommissar für die Preisbildung, als ergebener Gefolgsmann Hitlers, der einst das Röhm-verseuchte Schlesien gesäubert hatte, und König „Mu“ (Mutschmann), der seinen Gau wie ein patriarchalischer Gutsbesitzer des 19.Jahrhunderts regierte. Als weitere charakteristische, selbstbewußte und unabhängige Satrapen des Führers können gelten Adolf Wagner (München-Oberbayern), der aus der Münchner Clique Hitlers kam, als dessen Double fungierte und ihm an Fanatismus glich, Sauckel in Thüringen, stark kulturell interessiert, Terboven in Essen, der die Eroberung des Ruhrgebietes für die Partei sich zuschrieb, Bürckel in der Pfalz, bald Anschlußspezialist für die Saar und Österreich, und der Rheinländer Kaufmann, der seit 1929 Gauleiter in Hamburg

${ }^{32}$ Gauleiter Wilhelm Kube (Kurmark): „Und wenn wir im Anfang unserer Partei- und Gauarbeit einst gezeigt haben, daß wir keine Arbeit scheuen und daß wir jede Arbeit bewältigen, so haben wir in größerer Verantwortung gezeigt, daß wir zu Adolf Hitlers Führerkorps gehören und den Gamaschendienst denen überlassen, die dazu bestimmt sind“ (Nationalsozialistisches Jahrbuch 1935, S. 220).

${ }^{33}$ Otto Dietrich (Hg.), Das Buch der deutschen Gaue. Fünf Jahre nationalsozialistische Aufbauleistung, Bayreuth 1938.

${ }^{34}$ Hüttenberger, Gauleiter S. 198.

35 Ebd., S. 213-220.

${ }^{36}$ Höffkes, Generale.

${ }^{37}$ Orlow, History II, S. 156f.; vgl. ebd., S. 54. 
war und dort ganz zum Hanseaten wurde. Nach 1938 kamen als besonders bemerkenswert hinzu die Gauleiter Forster in Danzig und Greiser im Wartheland sowie Schirach in Wien und Rainer in Salzburg und später Kärnten. Demgegenüber standen andere im zweiten Glied, der beflissene Jordan in Halle-Merseburg, der brutale Wächtler, der 1935 den charismatischen Schemm in der Bayerischen Ostmark abgelöst hatte, oder der bescheidene Wahl in Augsburg.

Ein zweiter Zugriff ist der nach Generationen. Während das mittlere Alter der Gauleiter 1933 bei 40 Jahren lag und dann kontinuierlich mit den Jahren stieg - die jüngsten waren übrigens mehrheitlich Akademiker ${ }^{38}$-, gab es, dem Eintrittsalter nach, doch deutliche Unterschiede. Man kann dabei der Übersicht von Lauterbachers Memoiren folgen, der vier Generationen unterscheidet ${ }^{39}$ : Als erstes die Kämpfer der Frühzeit, die nach seiner Aussage fest mit dem Land verwurzelt waren, der Sachse Mutschmann, der Kölner Grohé oder in Mecklenburg Friedrich Hildebrandt; auch Straßer in Niederbayern wird man dazu rechnen können. Zum zweiten, ebenfalls noch vor 1933, der Ersatz für Ausfälle oder ganz neue Kräfte, die aber eher landfremd war, wie Kaufmann, Goebbels und Koch, die aus dem Ruhrgebiet kamen und einheimische Kräfte, in Berlin etwa den Märker Dr. Schlange, ablösten, oder Sauckel, der den früheren Kämpfer Dinter ersetzte (der seinerseits freilich aus dem Elsaß gekommen war - man sieht, daß solche Einteilungen nie ganz aufgehen). Als dritte Generation folgen die neuen Gauleiter in den Ostgebieten, wobei die österreichische Entwicklung, wo fast durchwegs die illegalen Gauleiter 1938 durch neue abgelöst wurden, ein besonderes Phänomen darstellt. Als letzte Gruppe sind junge meist erst im Krieg berufene Gauleiter zu nennen, so Lauterbacher selbst (1940), vorher stellvertretender Reichsjugendführer, Hanke in Niederschlesien (1941), vorher Mitarbeiter von Goebbels, oder Scheel, SS-Mann und Reichsstudentenführer, in Salzburg (1941). Deutlich ist bei dieser Klassifizierung eine Verschiebung von selbständigen und selbstbewußten Kräften der Frühzeit zu Funktionären des Parteiapparates, wobei Borman vor allem bemüht war, unter den Gauamtsleitern über den von ihm geschaffenen Gauführungsstab Gauleiteranwärter erst durch Abordnung in der Parteikanzlei zu schulen, bevor sie im Gau eingesetzt wurden ${ }^{40}$. Leider gibt es noch nicht einmal genaue und zuverlässige $\mathrm{Zu}$ sammenstellungen, in welcher Reihenfolge die Gauleiter die einzelnen Gaue verwaltet haben - die Voraussetzung vergleichender Arbeiten.

Schließlich zum Sozialprofil. Hier hat vor allem Rogowski gezeigt, daß keine Rede davon sein kann, daß es sich bei den Gauleitern um in ihrem Beruf gescheiterte Existenzen handelte, wie dies etwa bei Dinter oder Kaufmann festzustellen ist, daß vielmehr die Gauleiter eher am oberen Rand einer aufwärts strebenden Gruppe lagen, mit sicherer Berufsposition und großem Aufstiegswillen - extreme Beispiele sind dafür der studierte Bergwerksdirektor Adolf Wagner in München oder sein Namenskollege Robert Wagner in Baden, der bis 1923 Reichswehroffizier war ${ }^{41}$. Es ist aber auch gezeigt worden, daß das Gauleiterkorps schon sozial keineswegs eine Einheit darstellte, weshalb mit starken Spannungen unter den Gauleitern zu rechnen ist. In der Tat sind Konflikte unter den Gauleitern häufig, etwa wenn der junge Lauterbacher, als Reichsinspekteur für den Luftschutz, Dres-

${ }^{38}$ Kater, Party, S. 257.

${ }^{39}$ Lauterbacher, Erlebt und mitgestaltet, S. $170 \mathrm{ff}$.

${ }^{40}$ Hüttenberger, Gauleiter, S. $205 \mathrm{ff}$.

${ }^{41}$ Ronald Rogowski, The Gauleiter and the social origins of Fascism, in: Comparative Studies in Society and History 19 (1977) S. 399-430, hier S. 406. 
den besuchte und von Mutschmann des Gaues verwiesen und erst nach Intervention Hitlers zugelassen wurde ${ }^{42}$; seit der Frühzeit gab es auch schon territoriale Grenzstreitigkeiten, etwa zwischen Hamburg und Schleswig-Holstein oder zwischen Thüringen und Mainfranken ${ }^{43}$. Natürlich waren die Gauleiter auch bezüglich der einzuschlagenden Politik oft verschiedener Meinung; daran änderten auch die - im ganzen nicht sehr häufig veranstalteten - Gauleitertagungen (zuletzt in Posen 1944) nichts, die namentlich nach dem Ausscheiden von Heß 1941 unter Bormann doch eher Appelle zum Durchhalten und Befehlsempfang wurden ${ }^{44}$.

Wie die Beschäftigung mit den Gauleitern mit Hitler begann, so muß sie auch mit Hitler enden: im unmittelbaren Zugang zu ihm, der bis zuletzt, trotz Bormannscher Einschränkungen, erhalten blieb, lag ihre wahre Macht, in der "Hitler-Legende“, daß der Führer das Böse nicht kenne, nur schlechte Berater ihn verführten, ihre Selbstrechtfertigung bis über den Zusammenbruch hinaus. Daß Hitlers Macht über die Gauleiter eben deshalb grenzenlos war, das bezeugen nicht nur in den letzten Monaten vor der Katastrophe Gauleiter wie Forster, Lauterbacher oder Jordan, die mitten im Zusammenbruch in der Reichskanzlei von Hitler moralisch wieder aufgerichtet wurden und ihm bedingungslos gehorchten ${ }^{45}$, das zeigt sich auch bei den - freilich nicht häufigen - Gauleiterabsetzungen, vor allem bei der des mächtigen Josef Wagner in Schlesien, den Hitler am 9. November 1941 im Braunen Haus in München vor allen Gauleitern wegen seiner religiösen Einstellung und seiner politischen Eigenständigkeit mit einem Eklat aus seinem Amt wies und ihn sogar aus der Partei ausschließen wollte; als im Februar 1943 das mit vier Gauleitern besetzte Parteigericht den Parteiausschluß, da unbegründet, nicht vollzog, setzte sich Hitler wütend darüber hinweg und stieß Wagner persönlich aus der Partei - Widerstand gab es im Gauleiterkreis dagegen keinen $\mathrm{mehr}^{46}$. Auch sonst kam es nicht so selten vor, daß Hitler Gauleiter absetzte, etwa schon 1936 den Brandenburger Gauleiter Kube, 1940 Streicher in Nürnberg, oder noch 1943 Gauleiter Weinrich von Kurhessen, doch - anders als bei Josef Wagner, der überwacht und schließlich nach dem 20. Juli erschossen wurde - versorgte er sie meist mit anderen Ämtern oder ließ sie wenigstens unbehelligt (Kube und Streicher durften sogar ihren Titel behalten). Die Mitglieder seiner alten Garde waren ihm wohl zugleich Bausteine im Herrschaftskalkül wie nostalgische Erinnerung.

\section{Gaue als konstitutive Regionen}

Der zweite Teil des Beitrags stellt vor allem methodische Überlegungen an, wie nämlich die ins Auge gefaßte Frage, ob die Gaue und Gauleiter spezifisch regional bestimmt waren bzw. regional handelten, beantwortet werden könnte. Dabei soll zuerst ein Blick auf

${ }^{42}$ Lauterbacher, Erlebt und mitgestaltet S. 208 u. S. 248.

${ }^{43}$ Krebs, Tendenzen, S.210f.; Hans-Stephan Brather, Der „Frosch-Mäuse-Krieg “ um die Exklave Ostheim vor der Rhön (1939-1945). Rivalisierende Gauführer im Gestrüpp ihrer Zuständigkeitsüberlagerungen, in: Michael Gockel u. Volker Wahl (Hg.), Thüringische Forschungen, Weimar 1993, S. 533-562.

${ }^{44}$ Über die Gauleitertagungen vgl. die zahlreichen Hinweise in den Goebbels-Tagebüchern, z. B. Elke Fröhlich (Hg.), Die Tagebücher von Joseph Goebbels, II 9, München 1993, S. 272 ff. (Tagung Februar 1943 in Posen), sowie in den Akten der Partei-Kanzlei der NSDAP, hg. v. Institut für Zeitgeschichte, München 1983-1992, passim.

${ }^{45}$ Joachim C. Fest, Hitler, Frankfurt 1973, S. 994 (Forster); Lauterbacher, Erlebt und mitgestaltet, S. 320; Jordan, Erlebt und erlitten, S.266f.

${ }^{46}$ Teppe, Oberpräsidenten, S. $227 \mathrm{f}$. 
die Gaue als regionale Untergliederungen der Partei geworfen werden: übernahmen sie, so ist zu fragen, im zentralistischen Reich die regionale Funktion, die die Länder seit der Verreichlichung 1933/35 weitgehend verloren hatten?

Hier ist zu konstatieren, daß, ganz gleich wie die Gaue entstanden waren, sie besser den historischen Landschaften entsprachen als die alten Länder oder deren Provinzen ${ }^{47}$. Daß Preußen, 1932 bereits gleichgeschaltet, seit 1933 schrittweise zum Reichsland gemacht und damit faktisch aufgelöst wurde, war, wenn auch nur das Ende einer langen Entwicklung, in dieser Hinsicht ein Fortschritt. Die Gaue entsprachen zum Teil historisch gewachsenen preußischen Provinzen (z. B. Ostpreußen, Pommern, Kurmark, Schlesien), zum Teil zerlegten sie übergroße wie die Rheinprovinz oder Hannover in kleinere Einheiten (z. B. Köln-Aachen, Koblenz-Trier), was, vor allem im letztgenannten Fall, sicher angemessener war als die staatliche Einteilung. Sehr bemerkenswert ist, daß Klein- und Restgebiete, wie etwa die Grenzmark Posen-Westpreußen, das preußische Emsland oder Lübeck mit größeren Gebieten vereinigt wurden (hier mit Pommern, Weser-Ems, Schleswig-Holstein) und daß anstehende territoriale Fragen wie die im Bereich von Hessen und Nassau oder von Thüringen bereinigt wurden - die Gaue Hessen-Nassau und Kurhessen stellen damit einen Trittstein dar von der alten hessischen Zersplitterung zum heute fast alle hessischen Gebiete umfassenden Bundesland. Wie bedeutungsvoll das sein konnte, sieht man am ewig zersplitterten Land Thüringen, dessen Neugründung 1920 die preußischen Teile um Erfurt und Nordhausen nicht umfaßt hatte: daß der Parteigau Thüringen demgegenüber alle historischen thüringischen Gebiete einschloß, hat schließlich 1944 auch die staatliche Verwaltung zur Änderung veranlaßt, wodurch der Weg zum heutigen Gesamtbundesland mit seiner Hauptstadt Erfurt erst frei gemacht worden ist; das 1945 begründete und 1990 wiederbegründete Land Thüringen ist mit dem Gau Thüringen identisch. Nicht überall hatten die Gaue diese modernisierende Funktion, die Gaue Baden und Württemberg etwa entsprachen den in der Napoleonzeit gebildeten Ländern, die wenig Rücksicht auf die historischen Einheiten genommen hatten, und in Bayern, das im Dritten Reich oft die traditionellsten NS-Strukturen aufwies, finden sich die territorialen Prinzipien gewissermaßen ganz gemischt: den Regierungsbezirksgauen Oberbayern, Schwaben und Unterfranken standen der als Landschaftsgau prätendierte Gau Franken um Nürnberg und im Osten wie im Westen je ein politisch-geographischer Grenzgau gegenüber, die Bayerische Ostmark nämlich und, seit 1940, die Westmark, wobei seit 1935/38 diese beiden Grenzgaue die alte bayerische Staatsgrenze überschritten, im Westen durch die Einbeziehung der Saar und dann Lothringens, im Osten durch den Anschluß des Böhmerwaldes an Bayern und durch bayerische Parteibetreuungsaufgaben im Protektorat. Insgesamt dürfte eine präzise Untersuchung, die noch aussteht, ergeben, daß die Gaue tatsächlich zum Teil Schrittmacherfunktion in der Auflösung der alten Länderstrukturen übernahmen und die Bedeutung der Regionen in Deutschland vermehrten, allerdings mit nicht wenigen, meist machtpolitisch begründeten Ausnahmen. Für die Administration war diese Einteilung vor allem deshalb wichtig, weil man stets auf die Reichsreform, die schon 1933 steckengeblieben war, wartete, durch die eine Angleichung von Gau und staatlichen Strukturen, wie dies später im Osten erreicht worden ist, geschaffen werden sollte. Selbst an Kleinigkeiten ist die Verwaltungsbedeutung der Gaue zu beobachten, etwa wenn 1941 bei der Einführung der ersten Postleitzahlen in Deutschland nicht die Länder, sondern die Gaue zur

${ }^{47}$ Vgl. die verschiedenen Karten bei Freeman, Atlas, oder bei Werner Hilgemann, Atlas zur deutschen Zeitgeschichte 1918-1948, München 1984. 
Grundlage genommen wurden. Freilich, dies ist noch zu ergänzen, die Gaueinteilung war nicht die einzige, die damals neu sich über das Reich legte, auch SA, SS, die HJ, die DAF, der Reichsarbeitsdienst, der Reichsnährstand, weitere Organisationen und nicht zuletzt die Armee hatten spezifische regionale Einteilungen; wieweit diese wirksam und zukunftsträchtig waren, ist noch nicht untersucht.

Sodann müssen wieder die Gauleiter und ihre Tätigkeiten betrachtet werden, ob und inwieweit sie sich selbst und in diesen sich regional verstanden oder nicht. Grundsätzlich, das hat schon Hüttenberger gezeigt, hat sich Hitler in die Einzelheiten der Gaue nicht eingemischt ${ }^{48}$; diese waren in sich abgeschlossene und auf sich bezogene Einheiten, gemeinsame Verabredungen von Gauen gab es, mit Ausnahme der letzten Kriegszeit ${ }^{49}$, nicht, noch viel weniger eine Einwirkung der Gaue auf die Zentrale: Hitler, so Wahl, ließ in Gausachen große Freiheiten, liebte keine Einmischung in die Nachbargaue, aber der Einfluß der Gauleiter auf Reichssachen war gleich Null ${ }^{50}$. Hier ergibt sich nun als erste Frage die nach der Herkunft der Gauleiter: entstammten sie ihrem Gau oder waren sie von außen importiert? Geht man dem Geburtsort der (ab 1933) tätigen Gauleiter nach, so zeigt sich, daß von 70 Gauleitern in Deutschland jeweils mehr als die Hälfte nicht im Gau geboren waren, also von auswärts kamen, in Österreich nach 1938 ebenfalls, während in der illegalen Zeit dort etwa die gleiche Zahl aus dem Gau und von außen stammten ${ }^{51}$. Da hierbei aber große Unsicherheiten gegeben sind, etwa wenn zwar der Geburtsort außerhalb liegt (wie etwa bei Streicher, der im Schwäbischen geboren, dann aber ausschließlich in Nürnberg tätig war) oder wenn Verwaltungsgrenzen sich änderten, sagen Beobachtungen darüber, ob die berufliche Haupttätigkeit vor der Gauleiterernennung im Gau lag, mehr aus; hier kann deutlich werden, ob der Gauleiter aus dem Land herauswuchs oder ortsfremd von der Zentrale dorthin geschickt wurde. An der kleineren Zahl von 45 deutschen Gauleitern, die hier ins Auge gefaßt wurden, ergibt sich ein deutlich anderes Bild, daß nämlich vor 1933 weitaus die Mehrzahl, insgesamt 18, mit ihrem künftigen Gau bereits eng verbunden waren, bevor sie das Gauleiteramt erhielten, gegenüber fünf mit nur lockeren Bindungen und sechs völlig Ortsfremden ${ }^{52}$. Dabei ist auf der Seite der im Gau Verwurzelten die große Zahl bekannter Landespatriarchen zu finden, von Bürckel über Murr, Robert Wagner, Grohé und Lohse bis zu Terboven, Mutschmann, Streicher und Wahl, auf der Seite der beziehungslos Berufenen aber besonders aktive Kämpfer wie Goebbels, Koch, Forster und Kaufmann, freilich auch der eher milde Jordan und der unfähige Weinrich; bei Sauckel und Adolf Wagner in München, die an sich ortsfremd waren, gab es vorher immerhin schon eine Reihe von Beziehungen. Dieses Verhältnis verschiebt sich nun seit 1933 und besonders seit 1940 deutlich, jeweils stehen Männer ohne oder nur mit geringen Bindungen wie Schwede-Coburg, der 1934 nach Pommern, oder Giesler aus Westfalen, der 1942 nach München geschickt wurde, in der Mehrzahl den Einheimischen gegenüber. Der Einfluß der Parteikanzlei in den letzten Jahren ist hier deutlich zu spüren, etwa bei Paul Hofmann, der der Reichsleitung seit 1934 angehörte und auf verschiedenen Posten in ganz Deutschland diente, bis er 1943 Gauleiter in Westfalen-Süd

${ }^{48}$ Hüttenberger, Gauleiter, S. 199.

${ }^{49}$ Vgl. Jordan, Erlebt und erlitten, S. 261: Lauterbacher, Eggeling, Sauckel und Jordan (1945).

${ }^{50}$ Wahl, Patrioten, S. 42.

${ }^{51}$ Von 70 Gauleitern: in Deutschland vor 1933: 14 im Gau geboren, 20 von außen; 1933-38: 1:3; 19391945: 4:6; Österreich vor 1938: 8:8; nach 1938: 1:5; Angaben nach Hüttenberger, Gauleiter.

5245 Gauleiter: Deutschland vor 1933: eng verwurzelt 18, lockere Bindung 5, ohne Bindungen 6; 1933-1939: 1:1:4; 1940-1945: 3:3:4; Österreich 1938-1945: verwurzelt 6, fremd 2. 
wurde; aber auch jetzt noch gibt es Beispiele regionaler Bindung, etwa in Nürnberg bei Holz, der 1940 Streicher nachgefolgt ist. In Österreich übrigens stehen bei den 1938 eingesetzten Führern der Reichsgaue sechs im Land Beheimatete zwei Neuberufungen (Globocnik und Schirach in Wien) gegenüber. Man muß also sagen, daß von der Berufstätigkeit und vom Lebensfeld her ganz deutlich die regional in ihrem Gau beheimateten Gauleiter als frühe Gefolgsleute Hitlers an Zahl und Ansehen die ortsfremden, von der Zentrale in die Gaue ausgesandten Aktivisten, wenigstens bis in die Kriegszeit, weit überwogen.

Sodann ist danach zu fragen, ob und inwieweit sich die Gauleiter mit ihren Gauen regional identifizierten. Darauf gibt es vorläufig keine Antwort. Sie kann gesucht werden zum einen in institutionellen Bindungen, die zum Teil schon angesprochen wurden, wenn nämlich Gauleiter die Ämter von Oberpräsidenten, Regierungspräsidenten, Ministern oder anderen staatlichen Führungspositionen übernommen hatten. Von besonderer Bedeutung war dabei zweifellos die Reichsstatthalterschaft, die Mutschmann in Sachsen, Murr in Württemberg, Robert Wagner in Baden, Röver in Oldenburg und Bremen, Saukkel in Thüringen, Sprenger in Hessen, Kaufmann in Hamburg, Hildebrandt in Mecklenburg, Loeper und später Jordan in Anhalt und Braunschweig und Meyer in Lippe ausübten, dazu später die Gauleiter und Reichsstatthalter in den neuen Reichsgauen; wichtig ist natürlich auch die Führung von Landesregierungen, wie sie Mutschmann in Sachsen, Sprenger in Hessen, Meyer in Lippe, Kaufmann in Hamburg und seit 1944 auch Giesler in Bayern innehatten ${ }^{53}$ - bei solchen administrativen Bindungen ist Bezogenheit auf das Land von vorneherein zu vermuten. $\mathrm{Da}$ für Preußen die Reichsstatthalterschaft wie die Ministerpräsidentschaft vom vielbeschäftigten Goering verwaltet wurden, waren bei den preußischen Gauleitern vermutlich schon von daher die regionalen Bindungen schwächer, die nichtpreußischen Regionen also bevorzugt. Die Identifikation der Gauleiter ist jedoch vor allem daran zu messen, wie sie ihren Gau verstanden haben - dafür gäbe es in dem nicht geringen zeitgenössischen Schrifttum, von den Willkommensbroschüren für Fremde bis zu den Gau-Festschriften, genügend auswertbares Material, das, soviel jetzt schon zu sehen ist, tatsächlich die enge Identifikation von Gauleiter und beherrschter Region dartut. Dafür zwei Beispiele. In dem schon erwähnten „Buch der deutschen Gaue“, das 1938 von Otto Dietrich herausgegeben wurde und für jeden Gau die fünfjährige nationalsozialistische Aufbauarbeit schildern sollte ${ }^{54}$, findet sich keineswegs, wie man erwarten möchte, eine Darstellung der Geschichte der Partei im Gau, vielmehr fast stets eine Schilderung von Landschaft, Geschichte, Kultur und neuen Initiativen, regionale Leistungsbilanzen also, die zwar in der Diktion, nicht aber in der Sache nationalsozialistisch waren. Noch deutlicher zeigt dies etwa das große zweibändige Werk über Mecklenburg („Werden und Sein eines Gaues“), das 1938 dem Gauleiter und Reichsstatthalter Hildebrandt zum 40. Geburtstag übergeben wurde, ausdrücklich veranlaßt, wie es in der Widmung heißt, durch „die tiefe Liebe, die der Gauleiter immer wieder für die Geschichte seiner engeren Heimat bekundet ${ }^{\alpha 55}$. Dieses Werk wird nicht nur eingeleitet durch ein rein geschichtliches, nur auf Mecklenburg bezogenes Vorwort des Gauleiters, es weist auch in seinem Kartenband unter 32 Karten keine einzige zeitgeschichtliche Partei- oder

\footnotetext{
${ }^{53}$ Z.T. nur mit der Führung der Geschäfte der Landesregierung beauftragt.

${ }^{54}$ Dietrich, Buch.

${ }^{55}$ Gauamtsleiter Richard Crull (Hg.), Mecklenburg. Werden und Sein eines Gaues. 2 Bde., Bielefeld 1938.
} 
Gaukarte auf, ist also trotz des Anlasses und trotz des Titels ein rein kulturgeschichtliches Werk, Gau ist hier allein als Region oder Land verstanden ${ }^{56}$. Freilich gibt es auch Publikationen, die mehr den Kampf der Partei in den Vordergrund stellen ${ }^{57}$, doch scheinen sie an Zahl weitaus den rein regionalen Veröffentlichungen unterlegen, wie solche etwa der Gauleiter Wächtler gewidmete Band „Gau Bayerische Ostmark ${ }^{458}$ oder der "Atlas Bayerische Ostmark" ${ }^{49}$ darstellen, Arbeiten, die bis heute zu Recht von der Landesgeschichte benutzt werden. Auch die in der Kriegszeit entstandene Reihe „Gaue in Einzeldarstellungen ${ }^{\text {"60 }}$ trägt dieses Gesicht, wobei es übrigens interessant wäre, Unterschiede in den einzelnen Heften zu konstatieren. „Landschaft und Volk, Kultur und Brauchtum, der wirtschaftliche Aufbau“ und erst zuletzt „Kampf und Sieg“, wie eine Broschüre nach 1942 den Gau Oberbayern den hierher Evakuierten vorstellt ${ }^{61}$, scheint die typische Reihenfolge und Gewichtung für das Selbstverständnis der Gaue gewesen zu sein. Schließlich wären hier Aktionen und Argumente zu sammeln, mit denen Gauleiter für ihren Gau eintraten, nicht nur verbal, sondern in der Sache, gewissermaßen als deren erste Lobbyisten - etwa wenn Wagner in Baden forderte, daß staatliche und Parteistellen seines Gaues Geld nur auf badischen Banken (und nicht mehr in Berlin oder München) anlegen dürften ${ }^{62}$; da solches in der nationalsozialistischen Zeit aber nicht allgemein bekannt gemacht wurde und nachher kaum Interesse fand, müßte freilich zuerst einmal danach gesucht werden. Am bekanntesten ist wohl der Fall des Gaues Schwaben, nach welchem der mächtige Adolf Wagner in München im Gefolge der Röhm-Affäre seine Hand ausstreckte und wo bereits durch Ley die Auflösungsverfügung ergangen war der Augsburger Gauleiter sollte einen hohen Posten in München erhalten; Gauleiter Wahl erreichte eine direkte Aussprache bei Hitler, „und“, so Wahl, „der Gau Schwaben war gerettet ${ }^{\text {“63 }}$. Des weiteren sind die vielen Kompetenzkonflikte zu nennen, bei denen die Gauleiter gegen die zentralen Stellen des Reiches, im Krieg dann besonders auch gegen SS, SD und das Ministerium Speer, jeweils ihren Gaubereich verteidigten, bis hin zur berühmten Szene vom Oktober 1943, als die Gauleiter, voran Bürckel, sich gegen Minister Speer tumultartig empörten, der ihnen im Fall weiteren Widerstandes gegen Betriebsstillegungen in ihren Gauen schärfste Maßnahmen angedroht hatte. Übrigens fanden sie, wie immer, letztlich dabei die Hilfe Hitlers ${ }^{64}$. In den letzten Jahren versuchten die Gauleiter oft auch ihren Gau gegen bombengeschädigte Obdachlose und gegen Flüchtlinge, die das Reich zu verteilen hatte, zugunsten der eigenen Gaubewohner zu verteidigen und abzuriegeln. Längst waren die Gauleiter die Vertreter ihrer Gaue gegen die Zentrale geworden, waren sie zum „Bewußtsein einer gauterritorialen Quasisouve-

${ }^{56}$ Ähnlich: Volk und Kultur im Gau Westfalen-Süd, Dortmund o.J.; R. Schneider-Baumbauer, Bollwerk im Westen. Gau Saarpfalz, Neustadt 1939.

${ }^{57}$ Vgl.: 10 Jahre Gau Ostpreußen, Königsberg 1938; Schmidt, 20 Jahre Soldat (über Grohé).

${ }^{58}$ Hans Scherzer (Hg.), Gau Bayerische Ostmark. Land, Volk und Geschichte, München 1940 (2. Auflage: Gau Bayreuth, München 1942). Der von dessen Bruder geplante Band "Gau Franken ${ }^{*}$ erschien erst nach dem Krieg (in veränderter Fassung): Conrad Scherzer ( $\mathrm{Hg}$.), Franken. Land, Volk, Geschichte und Wirtschaft, 2 Bde., Nürnberg 1955/59.

${ }^{59}$ Martin Kornrumpf, Atlas Bayerische Ostmark, Bayreuth 1939.

${ }^{60}$ Paul Meier-Benneckenstein (Hg.), Die deutschen Gaue in Einzeldarstellungen: z. B. Alois Roßmaier, München-Oberbayern, Berlin 1941; Hans Hertel, Thüringen, Berlin 1941.

${ }^{61}$ Herzlich willkommen im Traditionsgau München-Oberbayern, o. O. o.J. (nach 1941).

${ }^{62}$ Grill, Wagner, S. 262.

${ }^{63}$ Wahl, Patrioten, S. 49.

${ }^{64}$ Hüttenberger, Gauleiter S. 184. 
ränität" gelangt ${ }^{65}$; die zentrale Parteiverwaltung wurde ihrer kaum mehr Herr ${ }^{66}$. Wie weit sie als solche sich auch beim Zusammenbruch verhalten haben, wäre noch zu untersuchen; obwohl von einigen Gauleitern bekannt ist, daß sie sich bemüht haben, daß ihr Gau oder Teile des Gaues nicht bis zum letzten verteidigt werden sollten ${ }^{67}$, scheinen es doch eher die weniger von der Zentrale beachteten Kreisleiter gewesen zu sein, die sich bei Übergabeverhandlungen engagierten.

Die eigentlich entscheidende Frage wird freilich sein, ob die Gauleiter in ihrem Gau Wertbeständiges geschaffen haben, und zwar in Bereichen, die über die eigentlichen Partei-Aktivitäten hinausgingen; dabei kann man natürlich darüber diskutieren, ob etwa Berufswettbewerbe oder Schwimmbadbauten zur normalen Gauleitertätigkeit gehört haben bzw. wie weit solche durch die Tätigkeit der Gauleiter im staatlichen Bereich begründet sind. Die Gaupublikationen sind, wie erwähnt, voll solcher Leistungsbilanzen inneren Aufbaus, etwa wenn für den Gau Thüringen schon 1931 die Winterhilfe, dann die Hilfsprogramme für die Rhön, der Ausbau der arisierten Suhler Waffenwerke und die neugegründete Thüringer Zellwolle AG als Erfolge gepriesen werden, desgleichen die Erhaltung und der Ausbau aller sieben thüringischer Landestheater ${ }^{68}$. Doch müßte all dies erst durch die wissenschaftliche Landesgeschichte untersucht und gewertet werden, wofür es bisher aber noch kaum Beispiele gibt; meist geht man über solche Aktivitäten, ob sie nun positiv oder negativ einzuschätzen sind, verzerrend oder stillschweigend hinweg ${ }^{69}$. Detailbetrachtungen wie eine hervorragende Untersuchung über die Stuttgarter Bauschule im Dritten Reich, die traditionelle Moderne betrieb, dabei sich aber deutlich vom Troost- und Speerschen Bauen absetzte, gleichwohl größte Ausstrahlung im Dritten Reich hatte, müßten noch auf das Verhältnis zum Gauleiter befragt werden ${ }^{70}$, die im gleichen Gau Württemberg-Hohenzollern 1941 begründete wissenschaftliche Akademie des NS-Dozentenbundes, die eine Großhochschule Schwaben, eine „totale Universität“, verwurzelt in der Landschaft, hätte werden sollen und bis 1945 aktiv war, wäre ebenfalls unter diesem Gesichtspunkt zu betrachten ${ }^{71}$. Besser sind die Aktivitäten der Gauleiter der neuen Reichsgaue erforscht, etwa die von Jury in Niederösterreich, der seinen Gau nach Mähren (mit einer Gauhauptstadt Brünn) ausdehnen und so gegenüber Wien selbständig machen wollte ${ }^{72}$,

${ }^{65}$ Karl Teppe, Die Oberpräsidenten der Provinz Westfalen 1919-1945, in: Mentalitäten und Lebensverhältnisse. Beispiele aus der Sozialgeschichte der Neuzeit (Festschrift Rudolf Vierhaus zum 60. Geburtstag hg. v. Mitarbeitern u. Schülern), Göttingen 1982, S. 260-274, hier S. 271.

${ }^{66}$ Am 20.5. 1943 stellte z. B. ein Verbindungsmann der Parteikanzlei im Reichpropagandaministerium fest, die geplante Einschärfung des Verbotes, daß die Gaue Leistungsberichte oder ähnliche Schriften veröffentlichen, sei nutzlos, da „die Gauleiter zuletzt doch tun, was sie wollen": Akten der Partei-Kanzlei, II 4, S.516f., Regest Nr. 44378.

${ }^{67}$ Wahl, Patrioten, S.228ff.; Jordan, Erlebt und erlitten, S.259ff.; Lauterbacher, Erlebt und mitgestaltet, S.319f.

${ }^{68}$ Hertel, Thüringen.

${ }^{69}$ Ein negatives Beispiel: Werner Bramke, Vom Freistaat zum Gau. Sachsen unter der faschistischen Diktatur 1933 bis 1939, in: Zeitschrift für Geschichtswissenschaft 31 (1983) S. 1067-1078. Völlig ohne Bezug zu den NS-Gau- und Regierungsaktivitäten Thomas Schnabel, Württemberg zwischen Weimar und Bonn 1928 bis 1945/46, Stuttgart 1986; aufschlußreich Otto Borst (Hg.), Das Dritte Reich in Baden und Württemberg, Stuttgart 1988.

${ }^{70}$ Wolfgang Voigt, Die Stuttgarter Bauschule, in: Borst, Reich, S. 250-271.

${ }^{71}$ Hugo Ott, Universität und Hochschule, in: Borst, Reich, S.137-148, hier S.146f.

${ }^{72}$ Petr Nemec, Gauleiter Dr. Hugo Jury und sein Wirken im Protektorat Böhmen und Mähren, in: Thomas Winkelbauer (Hg.), Kontakte und Konflikte. Böhmen, Mähren und Österreich: Aspekte eines Jahrtausends gemeinsamer Geschichte, Horn 1993, S. 469-478. 
oder von Eigruber in Oberösterreich, der seinen Gau gewissermaßen als „Mehrer des Reiches" nicht nur auf Kosten Niederösterreichs und der Steiermark territorial erweitern konnte, sondern auch, immer mit Hilfe des an Linz besonders interessierten Führers, mehr Brücken- und Wohnungsbauten durchsetzte als andere Gaue, auch bei der Planung der Hütte Linz im Rahmen der Reichswerke eine erhebliche Rolle spielte ${ }^{73}$. Im allgemeinen dürften die Gauleiteraktivitäten allerdings eher im kleineren, aber regional um so wichtigeren Rahmen geblieben sein, in Werbewochen etwa für die Wirtschaft, in Notstandsprogrammen für die Elendsgebiete, in Wohnungsbau-Aktivitäten, in Förderung von Sport- und Gesundheitsinitiativen, in der Sorge um regionale und kulturelle Einrichtungen, was alles als „Sozialismus der Tat“ firmierte. Es ist keine Frage, daß viele dieser Aktivitäten vor 1933 begonnen und von den Parteileuten nur in der Fertigstellung forciert wurden, aber es ist bemerkenswert, wie selbstverständlich die Gauleiter eben in die regionalen Traditionen der Vergangenheit eingetreten sind.

Die Kehrseite der Frage nach positiven Leistungen für den Gau ist die nach den Gauleiteraktivitäten mit negativen Wirkungen. Sie zielt dabei nicht auf die allgemeinen Folgen der Gauleiterherrschaft, die zu den Stützen des Systems gehörte und damit in der Sache wie in den Personen für die Aufrichtung und Aufrechterhaltung des nazistischen Unrechtsregimes verantwortlich war - die geringe Bereitschaft der Gauleiter selbst nach dem Zusammenbruch, sich von ihrem früheren Wirken zu distanzieren und ihr Unrecht einzugestehen, spricht hier eine deutliche Sprache. Die Verführung der Bevölkerung zu Nationalismus, Rassenhaß und Kriegsbereitschaft, die Besetzung von Stellen und Anweisung der Stelleninhaber nicht nach sachlichen, sondern nach politischen Gesichtspunkten, die Korruption in der Partei und der parteiabhängigen Verwaltung, die Willkür gegen jeden beliebigen nicht völlig konform gehenden Bürger bis hin zu Veranlassung von Haft und KZ-Einweisung, die - wenn auch in unterschiedlichem Maß - ihnen zur Last $\mathrm{zu}$ legen sind, können hier das Thema nicht sein. $\mathrm{Zu}$ fragen ist dagegen, ob in der Sache negative Maßnahmen ebenfalls regionsspezifisch, also auf den Gau bezogen sein konnten. Wenn dies zuerst, da die Unterdrückungsmechanismen allgemeiner Art waren, unwahrscheinlich scheint, so könnten doch dafür zwei Gebiete besonders in Frage kommen. Zum einen der Kirchenkampf, den mancher Gauleiter, etwa Hellmuth in Mainfranken, als für seinen Bezirk besonders wichtige Aufgabe begriff $\mathrm{f}^{4}$, während andere, etwa Schemm in Bayreuth (bis 1935), dies nicht so sahen ${ }^{75}$; Gauleiter Kube in Brandenburg hatte sich 1933 sogar selbst auf religiösem Feld, als Promotor der Deutschen Christen, engagiert $^{76}$. Für die regionale Bestimmtheit des Kirchenkampfes waren freilich spezifische Bedingungen nötig, etwa die geschlossen katholische Bevölkerung des Oldenburger Münsterlandes, wo Gauleiter Röver 1936 den Kampf um die Schulkreuze vom Zaun brach und wo die Gegenseite, die letztlich triumphierte, deutlich regionale Argumente gebrauchte (... „kohlrabenschwarz ... schon über 1000 Jahre mit unserem Landsmann Widukind an der Spitze ${ }^{\text {“77}}$ ), oder ein lebendiges Brauchtum wie bei den Streitigkeiten um

${ }^{73}$ Harry Slapnicka, Oberösterreich - als es „Oberdonau“ hieß (1938-1945) (Beiträge zur Geschichte Oberösterreichs 5), Linz 1978, S. 130 u. S.452f.

${ }^{74}$ Die kirchliche Lage in Bayern nach den Regierungspräsidentenberichten 1933-1943. VI: Unterfranken, Mainz 1981, S.XLIX.

${ }^{75}$ Ebd. IV: Niederbayern und Oberpfalz, Mainz 1973, S. XXXIIIff.

${ }^{76}$ Vgl. Kurt Meier, Die Deutschen Christen, Halle 1964; Franz Menges, Wilhelm Kube, in: Neue Deutsche Biographie 13 (1982), S. $156 \mathrm{f}$.

${ }^{77}$ Joachim Kuropka (Hg.), Zur Sache - Das Kreuz!, Vechta 1987, S. 315. 
die Maibäume in Bayern, die die Partei gegen die christlichen Vereine in Beschlag nehmen und im Rahmen moderner flächendeckender Organisation allgemein durchsetzen konnte, in diesem Fall als Förderer bayerischer Traditionspflege siegreich. Der zweite Bereich ist das Verhalten der Gauleiter bei der Verfolgung der Juden, die ihnen von Hitler immer wieder ganz persönlich ans Herz gelegt wurde. Hier wäre zu untersuchen, ob es regionale Unterschiede in der Juden-„Freimachung“ des eigenen Gaus gegeben hat, ob sich etwa der Verbalradikalismus des Augsburgers Wahl bei relativer Milde in der Ausführung wenn diese Deutung richtig ist ${ }^{78}$ - vom wirklich todbringenden Radikalismus eines Goebbels regionalspezifisch unterschied; hier wäre auch das Verhältnis der Gauleiter zu den großen Konzentrationslagern - etwa Sauckels zu Buchenwald - zu untersuchen. Über diese beiden Bereiche hinaus wird man schließlich noch nach der sich oft negativ auswirkenden Gestaltung der Landschaft fragen können, nach regionalem Straßen- und Siedlungsbau, wenn er gewachsene und wertvolle Strukturen zerstörte, oder nach der Planung der Gauforen ${ }^{79}$ und der Thingplätze, die oft erheblich in die bauliche Substanz eingriffen; allerdings dürfte auf diesem Feld das für das ganze Reich musterhaft Geplante vielfach das Regionale überwiegen.

\section{Die bayerischen Gauleiter}

Die bisher mehr strukturellen Betrachtungen und die vornehmlich methodischen Überlegungen haben die Realität der Gaue und die konkreten Persönlichkeiten der Gauleiter übermäßig in den Hintergrund treten lassen. Um dem entgegenzuwirken, empfiehlt es sich, nun zuletzt auf einige Gauleiter selbst zu blicken. Wenn als Feld dafür Bayern gewählt wird, so unter anderem deshalb, weil in den bayerischen Verhältnissen das, was man das Gesicht des Dritten Reiches genannt hat ${ }^{80}$, besonders anschaulich wird. Blickt man auf diese Gauleiter, so erkennt man, daß Bayern geradezu ein klassisches Beispiel für die Selbsterkämpfung der Gaue darstellt. Das ist vor allem beim Nürnberger Julius Streicher sichtbar, der seine eigene frühe Parteigruppierung schon 1921 Hitler zugeführt hatte und sich nun als "Führer aller Franken ${ }^{*}$ gerierte, obwohl er schließlich nur das kleine Mittelfranken beherrschte; trotz aller Eigenmächtigkeiten und trotz vieler Korruptionsfälle konnte er sich bis 1940 als Gauleiter halten, stets der Sympathie Hitlers sicher $^{81}$, der ihm sogar beim Traditionsmarsch am 9. November zur Feldherrnhalle jeweils den ersten Platz überließ. In den letzten Kriegswochen, als sein Nachfolger Holz Nürnberg verteidigte, reaktivierte er sich selbst als Gauleiter und erlebte so das Kriegsende. In Konkurrenz zu den Bestrebungen Streichers, der bis 1928 Nordbayern (Gau Franken) als Untergau des Gaues Bayern geführt hatte, machten sich damals die Gauleiter von Unterfranken (das ab 1935 Mainfranken hieß) und Oberfranken selbständig. Gauleiter von Unterfranken wurde der Zahnarzt Dr. Otto Hellmuth, der schon lange der rechten Szene angehört hatte; Hellmuth, der sich 1934 als Regierungspräsident in die bayerische Verwaltung einbinden ließ, war keiner der starken Gauleiter, wurde aber bekannt durch

${ }^{78}$ Vgl. Edward N. Peterson, The Limits of Hitler's Power, Princeton/N.J. 1969, S. 348 f.

${ }^{79}$ Winfried Nerdinger (Hg.), Bauen im Nationalsozialismus. Bayern 1933-1945, Ausstellungskatalog, München 1993, S.20ff., S. $28 \mathrm{ff} .$, S. $54 \mathrm{ff}$.

${ }^{80}$ Joachim C. Fest, Das Gesicht des Dritten Reiches. Profile einer totalitären Herrschaft, München 1964; von den Gauleitern sind dort Goebbels und Baldur von Schirach behandelt.

${ }^{81}$ Vgl. etwa Werner Jochmann (Hg.), Adolf Hitler. Monologe im Führerhauptquartier 1941-1944, Hamburg 1980, S. 158f. (Dezember 1941). 
seine bösartigen antiklerikalen Nadelstiche gegen Geistlichkeit und Bischof in Würzburg $^{82}$. Wesentlich bedeutender war der Lehrer Hans Schemm im oberfränkischen Bayreuth, der, eher der linksliberalen Szene entstammend, nach dem Hitlerputsch zur Partei stieß und durch sein die Zeitgenossen begeisterndes Redetalent schnell auf sich aufmerksam machte; wichtig war auch, daß es ihm gelang, seinen oberfränkischen NS-Lehrerbund zur reichsweiten Anerkennung zu bringen. Als Reichsleiter des Lehrerbundes stieg er 1933 dann schnell auf, er konnte die Gaue Niederbayern und Oberpfalz an sich ziehen und wurde beim Umsturz 1933 bayerischer Kultusminister, als welcher er übrigens, wegen seiner verschwommen völkisch-religiösen Ideenwelt, erst einmal eher konservativ wirkte. Sehr profitiert hat von ihm seine Hauptstadt Bayreuth, in der seine Bauten noch heute eine Konstante bilden ${ }^{83}$. Als Schemm 1935 tödlich verunglückte, wurde nicht sein Stellvertreter Ruckdeschel sein Nachfolger, sondern der thüringische Volksbildungsminister Wächtler, der, ohne Staatsamt, trotz vieler heftiger Initiativen sich keine echte Machtposition aufbauen konnte; er verstand sich übrigens als Spezialist für die Gauarbeit, insbesondere in der Abwehr gen Osten. Als er 1945 vor dem Feind auswich und daraufhin von einem SS-Kommando erschossen wurde, konnte Ruckdeschel doch noch für wenige Tage das Gauleiteramt von Bayreuth übernehmen. Auch Karl Wahl, der aus Württemberg stammte und nach dem Ersten Weltkrieg als Kanzleibeamter in Augsburg ansässig war, wurde 1928 Gauleiter, nämlich im Regierungsbezirk Schwaben. $\mathrm{Daß}$ er nach eigenen Angaben $^{84}$ von der Ernennung zum Gauleiter überrascht wurde, daß er stets für ordnungsgemäße Entwicklungen eintrat und sich wie der Würzburger als Regierungspräsident aufstellen ließ, kennzeichnet ihn ebenso als eher biederen Verwaltungsbeamten wie die Tatsache, daß er Streicher für einen Schreier und Sadisten hielt ${ }^{85}$. Wie schwach Wahl letztlich war, zeigt vor allem die bekannte Episode im Juli 1943, als er, offenbar in bester Absicht, als Reichsverteidigungskommissar mit dem Aufbau einer schwäbischen Gau-Heimatschutztruppe begann - ähnlich wie übrigens die Gauleiter von Baden und Hessen-Nassau -, aber auf heftigen Widerspruch von Himmler und der Parteikanzlei hin diese nach kurzer Zeit wieder auflösen mußte ${ }^{86}$. Eine bemerkenswerte Persönlichkeit mit eigenständiger Politik war der Lehrer Josef Bürckel in der bayerischen Pfalz, der auch selbständige Wege in der Wirtschafts- und Sozialpolitik, auch in der Schulpolitik ging und schon in den ersten Jahren keine Rücksicht mehr auf Bayern nahm; schon daß seine Gauleiterresidenz nicht in der Regierungshauptstadt Speyer, sondern in Neustadt, später in Saarbrücken war, die Hauptstadt des Reichskommissariats Saarpfalz dann in Kaiserslautern, zeigt diese Ablösung an, die ab 1940 faktisch die Pfalz für Bayern verloren gehen lie ${ }^{87}$. Die entscheidende Stelle der bayerischen NSDAP war aber natürlich München, wo Hitler ursprünglich den Gau Bayern sich selbst vorbehalten hatte. Als 1928 die Gaue in Bayern selbständig und 1929 aus der Ortsgruppe München der Gau München, dann der Traditionsgau München-Oberbayern geschaffen wurde, begann der Aufstieg des Lothringers Adolf Wagner, Bergwerksdirektor und bald Gauleiter der Oberpfalz, eines der fanatischsten Gefolgsleute Hitlers in

${ }^{82}$ Vgl. dazu vorläufig Reuß, Öffentlichkeit, S. $22 \mathrm{ff}$.

${ }^{83}$ Kühnel, Schemm.

${ }^{84}$ Wahl, Herz, S.58f.; Wahl, Patrioten, S. 37.

${ }^{85}$ Jochmann, Hitler, S. 431.

${ }^{86}$ Hüttenberger, Gauleiter S. $164 \mathrm{f}$.

${ }^{87}$ Hans Fenske, Josef Bürckel und die Verwaltung der Pfalz (1933-1940), in: Rebentisch, Teppe, Verwaltung, S. 135-172, hier S.169. 
Bayern $^{88}$; als Wagner 1933 Innen-, 1936 auch noch Kulturminister in Bayern geworden war, schien es, als könne er die ganze Macht in diesem Land an sich reißen ${ }^{89}$; dies gelang ihm freilich nicht, da Hitler den Reichsstatthalter Epp, der seit 1933 die Staatsspitze in Bayern darstellte, nie fallen ließ und den Ministerpräsidenten Siebert, der ebenfalls seit 1933 amtierte, gegen Wagner deutlich unterstützte ${ }^{90}$. Trotzdem stieg Wagner durch seine enge Verbindung mit Hitler, aber auch durch sein Organisationstalent und durch seinen eruptiven Aktivismus zum wahren Tyrannen in München auf, wie ihn Broszat bezeichnet hat; in einem fast renaissancehaften, durch Kunstbestrebungen verbrämten Gewaltregime übte er seine Herrschaft von der Gauleitung in der Prannerstraße und von seinem Residenzsitz in der Kaulbachstraße über München und ganz Bayern aus. Als er, 1942 durch Schlaganfall an weiterer Tätigkeit gehindert, 1944 starb, kam Hitler zu einem seiner letzten Auftritte nach München. Nachfolger Wagners wurde Paul Giesler aus Westfalen, der Bruder von Hitlers Architekt.

Überblickt man die bayerischen Gauleiter, deren Einzelaktivitäten hier nicht geschildert werden können ${ }^{91}$, so stellt sich zum Schluß noch einmal und vertieft die Frage: vertraten sie ihre Regionen, waren sie spezifisch bayerische Gauleiter, gab es eine bayerische NSDAP? Auch wenn die Frage hier nur gestellt werden kann und eine Antwort offen bleiben muß, ist doch schon deutlich geworden, daß die bayerischen Gauleiter, bis auf Wächtler und Giesler, in ganz exemplarischer Weise, durch den Kampf um ihren Gau und durch die Tätigkeit in ihren Gauen mit diesen eng verbunden waren, freilich auch, daß manche, und nicht nur Bürckel, eigentlich aus Bayern, zumindest aus dem bayerischen Staatsverband hinausdrängten, im Osten, im Westen und auch im fränkischen Norden - ob man sie als Vorläufer heutiger Regionalisierungsbestrebungen bezeichnen darf, sei dahingestellt. Festzustellen ist aber auch, was allerdings ebenfalls der wissenschaftlichen Untermauerung noch bedürfte, daß auch die Einheit Bayerns, der staatliche Rahmen also des zweitgrößten deutschen Landes und nun, nach der faktischen Auflösung Preußens, des einzig bedeutenden, einen Verteidiger unter den Gauleitern Bayerns gefunden hat, im mächtigsten nämlich unter ihnen. Wagner war zwar in unendliche Rivalitäten mit Siebert und Epp verstrickt, verlangte aber in seiner Eigenschaft als Führer im Traditionsgau, als doppelter Minister Bayerns und seit 1939 sogar als Reichsverteidigungskommissar von ganz Bayern in der Sache strikt und unnachgiebig die Unterordnung der zentrifugal tendierenden Gauleiter Bayerns unter sein Regiment, kehrte also letztlich zum alten Hitlerschen Gesamtgau Bayern zurück. Sein Nachfolger Giesler, der dann auch bayerischer Ministerpräsident wurde, konnte, da alle anderen Gauleiter in Bayern entweder schon ausgefallen waren oder gerade verdrängt wurden, in den letzten Tagen tatsächlich dieses Gesamterbe Bayerns antreten, um dann freilich selbst in den Abgrund zu stürzen.

Die Geschichte der NS-Gaue und NS-Gauleiter ist, auch wenn nicht nur Schatten zu verzeichnen waren, weder für das Reich noch für die deutschen Regionen ein Ruhmesblatt, ja in vielem, was die Persönlichkeiten und Durchsetzungsmethoden betrifft, für die deutschen Länder beschämend. Ohne Bedeutung waren sie nicht, und manches aus ihren

${ }^{88}$ Martin Broszat, Der Despot von München. Gauleiter Adolf Wagner, eine Zentralfigur der bayerischen NS-Geschichte, in: Süddeutsche Zeitung, 30./31.3. 1985.

${ }^{89} \mathrm{Vgl}$. Walter Ziegler, München als politisches Zentrum Bayerns: Regierungssitz und Gauhauptstadt, in: München - "Hauptstadt der Bewegung“, S. 212-218, hier S.214f.

${ }^{90}$ Vgl. Jochmann, Hitler, S. 154.

${ }^{91}$ Vgl. meinen Aufsatz: Die nationalsozialistischen Gauleiter in Bayern, in: Zeitschrift für Bayerische Landesgeschichte 58 (1995), S. 427-460. 
Unternehmungen, vor allem aber ihre enge Verbindung zu den Regionen, hat weiterreichende Wirkung gehabt, deren Untersuchung auf das Verhältnis von Zentralismus und Region im 20. Jahrhundert neues Licht werfen kann.

\section{Gaue und Gauleiter 1936/1943}

(1936)

1. Baden: Robert Wagner

2. Bayerische Ostmark: -

(Hans Schemm, gest. 1935)

3. Berlin: Dr. Joseph Goebbels

4. Düsseldorf: Friedrich Karl Florian

5. Essen: Josef Terboven

6. Franken: Julius Streicher

7. Halle-Merseburg: Rudolf Jordan

8. Hamburg: Karl Kaufmann

9. Hessen-Nassau: Jakob Sprenger

10. Koblenz-Trier: Gustav Simon

11. Köln-Aachen: Josef Grohé

12. Kurhessen: Karl Weinrich

13. Kurmark: Wilhelm Kube

14. Magdeburg-Anhalt: -

(Friedrich Loeper, gest. 1935)

15. Mainfranken: Dr. Otto Hellmuth

16. Mecklenburg-Lübeck: Friedrich Hildebrandt Mecklenburg

17. München-Oberbayern: Adolf Wagner

18. Ost-Hannover: Otto Telschow

19. Ostpreußen: Erich Koch

20. Pommern: Franz Schwede-Coburg

21. Pfalz-Saar: Josef Bürckel

22. Sachsen: Martin Mutschmann

23. Schlesien: Josef Wagner

24. Schleswig-Holstein: Heinrich Lohse

25. Schwaben: Karl Wahl

26. Süd-Hannover-Braunschweig: Bernhard Rust

27. Thüringen: Fritz Sauckel

28. Weser-Ems: Karl Röver

29. Westfalen-Süd: Josef Wagner

30. Westfalen-Nord: Dr. Alfred Meyer

31. Württemberg-Hohenzollern: Wilhelm Murr

32.

33.

34.

35.

36.

37.

38.

39.

40.

41.
(Veränderungen 1943)

Bayreuth: $\quad$ Fritz Wächtler

Karl Holz

Joachim Albrecht Eggeling

Moselland

Mark Brandenburg: Emil Stürtz

Rudolf Jordan

Paul Giesler

Westmark

Niederschlesien: Karl Hanke

Oberschlesien: Fritz Bracht

Hartmann

Lauterbacher

Paul Giesler

Danzig-Westpreußen: Karl Forster

Wartheland:

Arthur Greiser

Kärnten:

Friedrich Rainer

Niederdonau:

Oberdonau:

Dr. Hugo Jury

Salzburg:

Steiermark:

August Eigruber

Tirol-Vorarlberg:

Wien:

Sudetenland:
Dr. Gustav Adolf Scheel

Dr. Siegfried Uiberreither

Franz Hofer

Baldur von Schirach

Konrad Henlein 


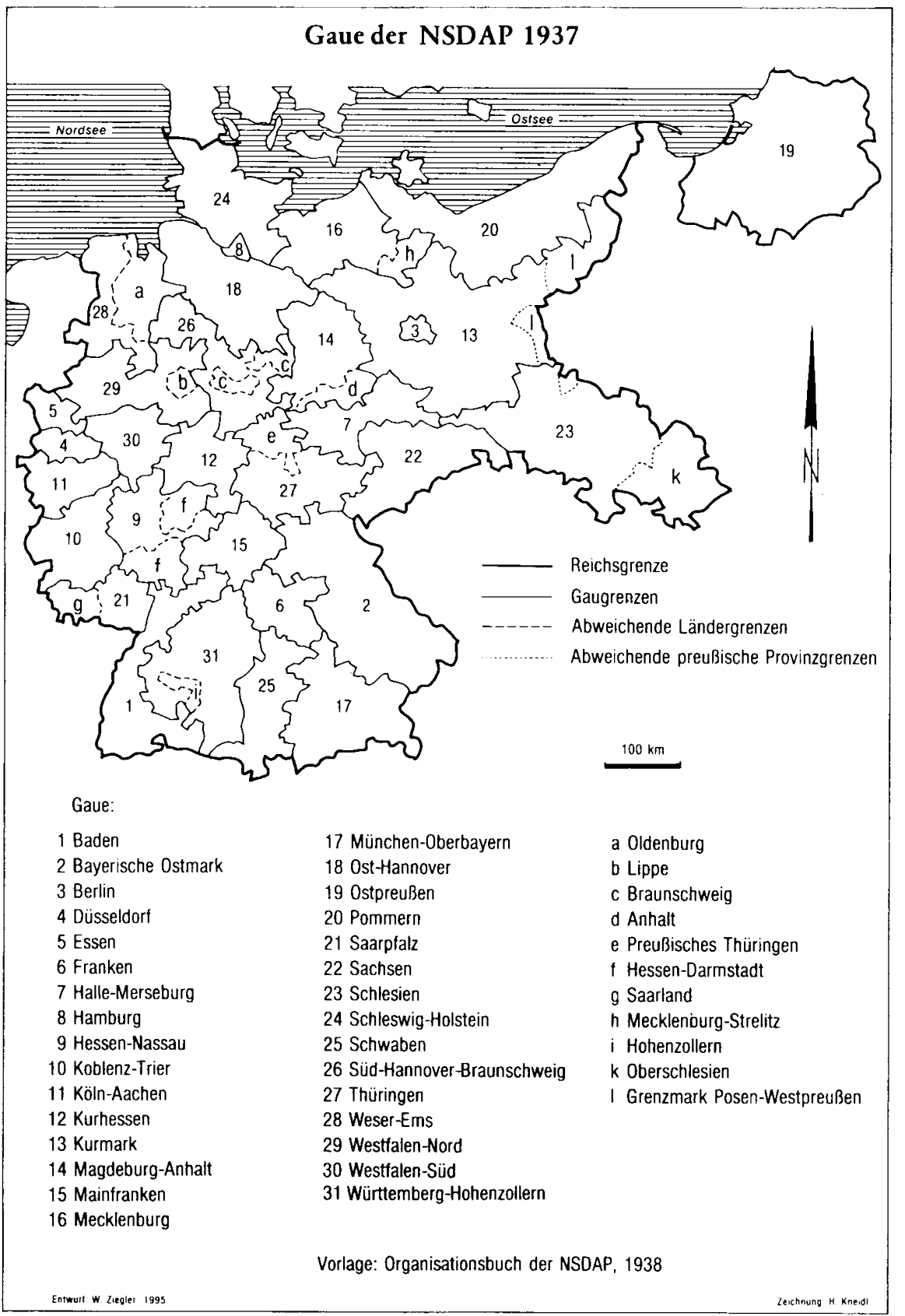




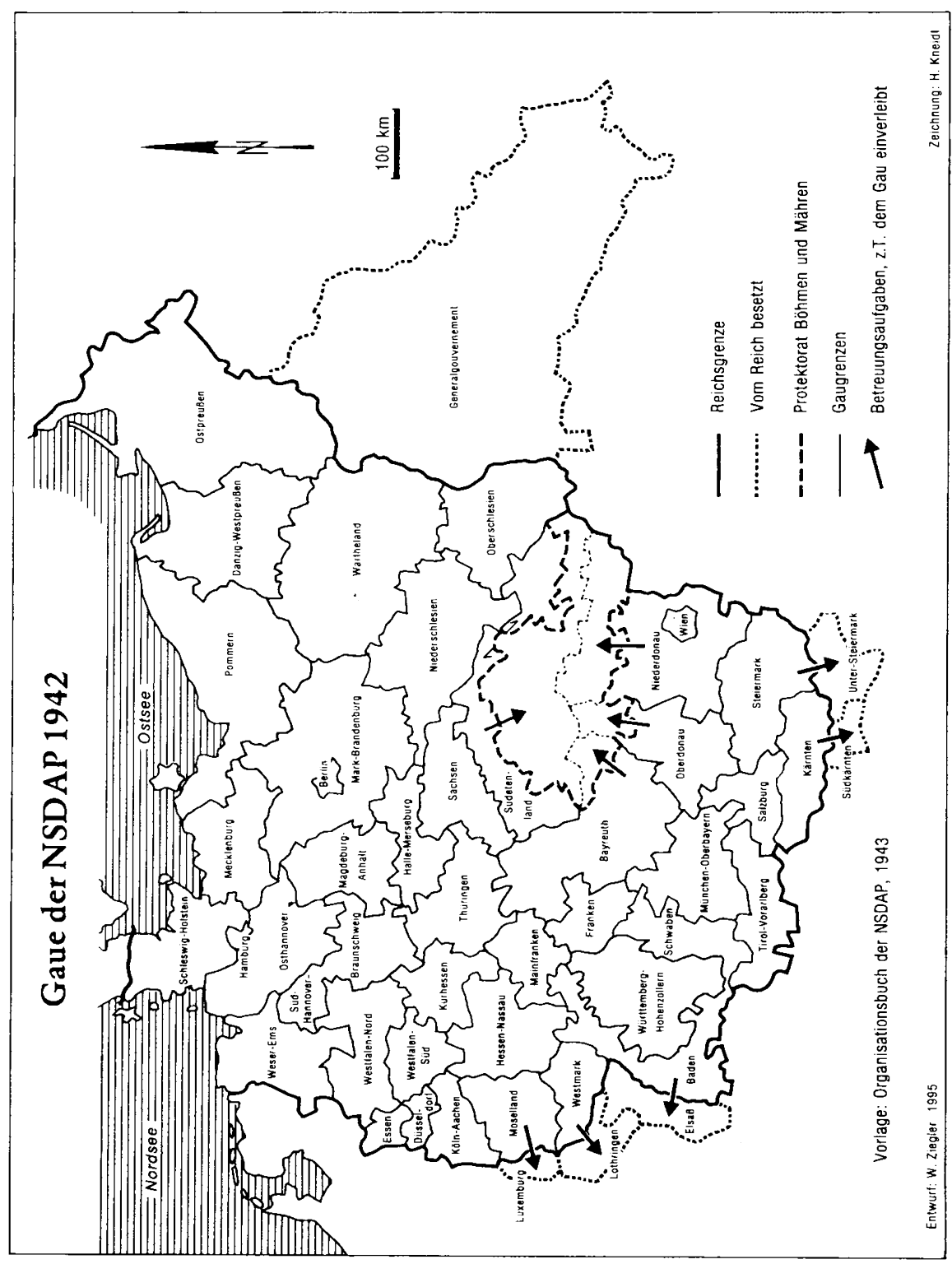




\section{Kurt Düwell \\ Gauleiter und Kreisleiter als regionale Gewalten des NS-Staates}

\section{Vorbemerkung}

Nach dem 30. Januar 1933 und den ersten Schritten der nationalsozialistischen Gleichschaltungspolitik hat das am 1. Dezember 1933 erlassene „Gesetz zur Sicherung der Einheit von Partei und Staat“ der NSDAP das Machtmonopol einer Staatspartei verschafft. Aber die Präsenz des nationalsozialistischen Staates im Alltag der Menschen wurde weniger durch die Gegenwart eines fast „entrückten“ Führers bestimmt, der nur von Zeit zu Zeit im regionalen und lokalen Blickfeld der Zeitgenossen auftauchte, als vielmehr durch die Allgegenwart der Gauleiter, der stellvertretenden Gauleiter, der Gauamts-, Kreis- und Ortsgruppenleiter, die in das alltägliche Leben unmittelbar eingriffen. Dabei waren die Gauleiter als „Vizekönige“ Hitlers besonders hervorgehoben. Denn die Omnipräsenz der Partei im NS-Staat nach 1933 war in besonderem Maße auf deren Aktivitäten zurückzuführen. Die Gauleiter unterstanden unmittelbar dem Führer bzw. dessen Stellvertreter. Sie trugen ihm gegenüber „die Gesamt-Verantwortung für den ihnen anvertrauten Hoheitsbereich"1. Sie wurden vom "Führer" ernannt, wobei in der frühen Kampfzeit ihre Nominierung zuweilen auch durch das Votum der Kreisleiter zustande kommen konnte. In der Regime-Zeit waren dem Gauleiter sämtliche politischen Leiter seines Hoheitsbereichs disziplinär unterstellt, politisch darüber hinaus auch alle Parteimitglieder und die übrige Bevölkerung. Daraus ergab sich eine beträchtliche Machtfülle der Gauleiter, die das Recht hatten, in ihrem Hoheitsbereich politische Leiter zu ernennen und ihnen besondere Aufgaben zu übertragen, sie aber auch zu beurlauben oder abzuberufen, wobei allerdings die Bestimmungen des Personalamts der Partei in München zu berücksichtigen waren. Die Gauleiter trugen Hitler gegenüber auch die Verantwortung für die „weltanschauliche Erziehung und Ausrichtung “ der politischen Leiter, der Parteimitglieder und der Bevölkerung.

Für das Verhältnis zwischen Gauleiter und Kreisleiter war wesentlich, daß dem Gauleiter in seinem Gau ein Aufsichtsrecht „über sämtliche der Partei, deren Gliederungen und angeschlossenen Verbänden als Aufgaben obliegenden Pflichten“ zustand. Er besaß das Recht und die Pflicht, Veranstaltungen und Handlungen, die der Zielsetzung der Partei zuwiderliefen, zu unterbinden. Diese durch Hitler und den Reichsorganisationsleiter der

\footnotetext{
${ }^{1}$ Vgl. Organisationsbuch der NSDAP, München 1936, S. 137. Über die Gauleiter vgl. in diesem Band den Beitrag Walter Zieglers und von den älteren Arbeiten die Untersuchung von Peter Hüttenberger, Die Gauleiter. Studie zum Wandel des Machtgefüges in der NSDAP (Schriftenreihe der Vierteljahrshefte für Zeitgeschichte 19), Stuttgart 1969. An einer vergleichbaren zusammenfassenden Untersuchung über die Kreisleiter fehlt es noch immer, obwohl für einzelne Regionen, wie z. B. die unten genannten Studien von Horst Matzerath, Dieter Rebentisch und Karl Teppe zeigen, wichtige Vorstudien bereits vorliegen.
} 
Partei festgelegten Bestimmungen grenzten das Aufsichtsrecht des Gauleiters aber zugleich auch ein, indem die in Verfolgung des Aufsichtsrechts notwendig werdenden Maßnahmen des Gauleiters sich an besonderen Vollmachten und Richtlinien zu orientieren hatten. Gewiß sah die Wirklichkeit dabei in vielem oft etwas anders aus, aber die Tatsache, daß die grundlegenden Daten der Gauleitervollmachten in allen sieben Auflagen des Organisationshandbuchs der NSDAP zwischen 1936 und 1943 im wesentlichen gleich blieben, zeigt doch, daß eine gewisse normierende Wirkung von diesen Vorgaben ausging. Die Unterordnung des stellvertretenden Gauleiters, der Gauamtsleiter, des Gauinspekteurs und der Kreisleiter unter den Gauführer war eine Folge des immer wieder zur Erklärung bemühten Führerprinzips. Dabei war die Rolle des stellvertretenden Gauleiters, des zweiten "Hoheitsträgers" im Gau, grundsätzlich nur als eine den Gauleiter entlastende und an dessen Weisungen gebundene Tätigkeit gedacht. Sie war vor allem auf informatorische Aufgaben und auf die Kontrolle der Kreisleitungen und Kreisämter sowie die der Ortsgruppen bezogen, Aufgaben, die zur Entlastung des Gauleiters wahrgenommen werden sollten. Die rednerische Tätigkeit des stellvertretenden Gauleiters hing wesentlich von der Zustimmung seines Vorgesetzten ab. Nach 1933 waren die Anforderungen an die stellvertretenden Gauleiter deutlich angehoben worden. Sie sollten zuvor Kreis- oder Ortsgruppenleiter gewesen sein, möglichst aber aus der Gruppe der Gauamtsleiter (Gaugeschäftsführer, Gaupropaganda-, -schulungs-, -organisations-, -personalamtsleiter, Gauinspekteure) stammen ${ }^{2}$. Die dem stellvertretenden Gauleiter erteilten Vollmachten konnten aber von ihm nicht auf Gauamtsleiter weiter übertragen werden, während sehr wohl im Falle der Vakanz eines Gauamts dieses dem stellvertretenden Gauleiter vom Gauleiter selbst unterstellt werden konnte.

Wie beim stellvertretenden Gauleiter handelte es sich auch bei den Gauämtern - zumindest beim Gauschatzmeister bzw. beim Gaugeschäftsführer, der seit der Kampfzeit eine besonders hervorgehobene Stellung hatte, aber auch beim Gauorganisationsleiter, beim Gaupropaganda-, beim Gaupersonalamtsleiter und beim Gauinspekteur - um hauptamtliche Tätigkeiten. Eine Personlunion mit anderen Ämtern war, mit einer Ausnahme beim Gaupropagandaleiter, ausdrücklich ausgeschlossen, um eine intensive Wahrnehmung der Gauamtsaufgaben zu gewährleisten. Die für den NS-Staat allgemein zu konstatierenden Ämterrivalitäten traten auch auf dieser Gauebene häufig auf, weil die Gauamtsleiter die Aufgabe hatten, ihre Ämter in voller Verantwortlichkeit selbst zu leiten und nur in bestimmten Fällen die Genehmigung des Gauleiters bzw. der Reichsleitung einholen mußten. Sie waren allerdings dem Gauleiter verantwortlich und standen als "Gaustab" zu ihm in einem besonderen Treueverhältnis, das bis zur "Cliquen"bildung führen konnte.

Eine herausgehobene Stellung hatten unter ihnen auch die Gauinspekteure. In jedem Gau sollte es nach den frühen Vorstellungen der Organisationsleitung für je 1 Mio. Einwohner einen Gauinspekteur als Beauftragten des Gauleiters geben. Seine Aufgabe war es, Beschwerden nachzugehen und Sonderaufträge der verschiedensten Art für den Gauleiter auszuführen. Im Falle von Beschwerden konnte der Gauinspekteur die einzelnen Gauämter zur Prüfung einschalten. Auch war er für Gnaden-, Unterstützungs- und Darlehensgesuche zuständig.

Auch die Kreisleiter, aus deren Gruppe oft die Gauinspekteure genommen wurden, waren dem Gauleiter unmittelbar unterstellt. Sie wurden auf Vorschlag des Gauleiters vom

${ }^{2}$ Organisationsbuch der NSDAP, 1936, S.139. Ab 1942 kamen hierzu noch die Gaustabsamtsleiter, auf deren Auswahl z.T. die Parteikanzlei Einfluß nehmen konnte. Vgl. unten S.170ff. 
„Führer“ ernannt, beurlaubt oder abberufen. Sie bildeten die unterste hauptamtlich geleitete Parteieinheit und waren an die fachlichen Weisungen der Gauamtsleiter gebunden. Die Zahl der Kreisleiter war im allgemeinen (ausgenommen kleine Gaue) größer als die Zahl der Ämter auf der Gauebene, und ihr Bereich deckte sich meist mit den staatlichen Verwaltungskreisen. Doch konnten auch mehrere Verwaltungskreise des Staates einen Parteikreis bilden. Dem Kreisleiter waren wiederum die politischen Leiter der Kreisämter, die vom Gauleiter ernannt wurden, unterstellt, aber auch die Ortsgruppen- und Stützpunktleiter eines Kreises. Für ihre, aber auch für die politische und weltanschauliche Erziehung der Parteimitglieder und der Bevölkerung war der Kreisleiter dem Gauleiter verantwortlich. Er besaß für seinen Hoheitsbereich ein besonderes Aufsichtsrecht und konnte Maßnahmen und Verbote treffen, in besonderen Fällen in Zusammenarbeit mit der Gauleitung oder sogar mit den Dienststellen der Gestapo. Im übrigen war seine Stellung als Beauftragter der NSDAP auch durch die Deutsche Gemeindeordnung vom 30. Januar 1935 (RGBI. I, S.49) und deren Ausführungsbestimmungen geregelt. Unter den herausgehobenen Stellen der Kreisämter befand sich meist der Kreisgeschäftsführer, der - häufig noch aus der Kampfzeit herrührend - oft auch politische Aufgaben erledigen konnte. Daneben besaßen der Kreisorganisations-, der Kreisschulungs-, der Kreispersonalamts-, der Kreispropaganda- und der Kreiskassenleiter eine besonders hervorgehobene Stellung. Diese Amtsträger durften gleichzeitig kein anderes Amt bekleiden.

Die Kreisleiter stellten das räumlich gesehen engmaschigste Netz der Parteiorganisation dar. In den Stadt- und Landkreisen außerhalb der Gauhauptstädte waren die Kreisleiter die am meisten sichtbaren Vertreter der Partei. Bis zum Erwerb des Sudetenlandes und dem Anschluß Österreichs, also für das Gebiet des sogenannten Altreichs, gab es um 1937/38 etwa 662 bis 687 Parteikreise. Hinzu kamen 1938123 Kreise Österreichs und im Krieg 41 Kreise des Warthelandes. Die Gesamtzahl unterlag aber dauernd einem gewissen Wechsel, da vor allem durch die Zusammenlegung von Parteikreisen die Zahl, wenn auch geringfügig, eher zurückging. Im Gau Kurmark ist dies sehr deutlich zu sehen, wo die Zahl der Parteikreise von 50 im Mai 1934 zunächst bis 1938 auf 37 reduziert und dann während der Kriegszeit nochmals auf 30 zurückgenommen wurde. In Bayern entfielen im Laufe der Jahre z.B. die eigenständigen Kreise Höchstadt (Gau Bayerische Ostmark), Scheinfeld und Uffenheim (Gau Franken), im Gau Süd-Hannover-Braunschweig der Parteikreis Harzburg. Dies hing z.T. auch mit Zusammenlegung einzelner Kreise zusammen, wie es z. B. für die Zusammenfassung der Kreise Münchberg und Naila (Gau Bayerische Ostmark, ab 1942 Gau Bayreuth) und im selben Gau auch für die Zusammenlegungen der Kreise Sulzbach-Rosenberg und Amberg zum Kreis Amberg-Sulzbach gilt. Im Gau Magdeburg-Anhalt wurden z.B. die Kreise Bernburg-Land und Bernburg-Stadt zum Kreis Bernburg und die Kreise Dessau-Land und Dessau-Stadt zum Kreis Dessau zusammengelegt, ähnlich die Kreise Quedlinburg und Ballenstedt zum Kreis Quedlinburg-Ballenstedt. Und auch die Schaffung des neuen Parteikreises Halberstadt stellte nach 1936 eine Zusammenfassung auf dem Gebiet der Parteikreise Wernigerode (Stadt) und Halberstadt (Stadt) sowie einiger Gemeinden im Umfeld Wernigerodes dar. Auch im Gau Ostpreußen und für den Gau Schwaben (Kreisleitungen Illertissen, Kaufbeuren und Schwabmünchen) lassen sich einzelne Zusammenlegungen nachweisen. Lediglich um Umbenennungen handelte es sich dagegen bei den Bezeichnungen der Kreise Bergstraße (vorher: Bensheim-Heppenheim) und Odenwald (vorher: Dieburg-Erbach) im Gau Hessen-Nassau. Die generelle Tendenz zur zahlenmäßigen Reduktion der Parteikreise wurde nur scheinbar durch die Erhöhung in Schlesien widerlegt, da hier durch den Krieg die zuvor 
verlorenen oberschlesischen Teile als neue Kreise hinzukamen und sich ihre Zahl von 50 auf 60 erhöhte. Im übrigen ging die Zahl der Kreise aber insgesamt leicht zurück. Während des Kriegs wurde die Besetzung der Kreisleiterstellen vielfach zu einem personellen Problem.

Das den Alltag der Bevölkerung sehr stark bestimmende groß- und kleinregionale Koordinatensystem von Gau- und Kreisleitern zwingt die zeitgeschichtliche Forschung zu einer genaueren Wahrnehmung der Vorgänge auf diesen gleichsam mittleren und unteren öffentlichen Ebenen und einer Analyse der Makro- und Mikrobereiche des NS-Staates ${ }^{3}$. Gau- und Kreisleiterebene können dadurch im Vergleich eine kritische interpretatorische Vermittlung der zentralistischen und der regionalen Aspekte des NS-Staates ermöglichen $^{4}$. In der folgenden Skizze soll daher versucht werden, die Stellung der Kreisleiter in Relation zu den Gauleitern und deren Gauämtern einerseits und zur staatlichen Verwaltung andererseits zu umreißen und insbesondere ihre Abhängigkeit von Gauleitern und stellvertretenden Gauleitern, je nach deren Rang in der Parteihierarchie, einzuschätzen. Dabei soll auch die Einflußnahme des Stellvertreters des Führers bzw. der Parteikanzlei, des Reichsschatzmeisters, der SS-Führung und einiger anderer Zentralstellen in den Grundzügen berücksichtigt werden.

\section{Gau- und Kreisleiter in vergleichender Perspektive}

Wie schon angedeutet, waren Gau- und Kreisleiter der NSDAP beide, wenn auch in unterschiedlicher Weise, mit wichtigen Kontroll- und Aufsichtskompetenzen ausgestattet. Beide konnten z.T. ihre Stellung auch durch zusätzliche staatliche Aufgaben verstärken. Wie Heinz Boberach für die Gaue Köln-Aachen und Koblenz-Trier (später „Moselland“) aufgezeigt hat, gab es in beiden Gauen 193365 Reichstagsabgeordnete und Mitglieder des Preußischen Landtags. Von ihnen waren neben den beiden Gauleitern Grohé und Simon 19 Kreisleiter und 11 Gauamtsleiter der Partei, außer weiteren 22 haupt- und nebenamtlichen Führern der SA, der SS und anderer Gliederungen. Die Kreisleiter kamen überwiegend aus dem unteren Mittelstand. Von 53, deren Lebensläufe Boberach untersuchen konnte, übten $22 \mathrm{ihr}$ Parteiamt hauptberuflich aus, die übrigen Kreisleiter waren vor allem auf die Unterstützung durch den hauptamtlichen Kreisgeschäftsführer angewiesen. Die Laufbahn eines hauptamtlichen Kreisleiters erwies sich oft als attraktiv für „alte Kämpfer“ aus dem unteren Mittelstand. Wie Boberach festgestellt hat, lagen die Monatsbezüge eines Kreisleiters 1939, je nach Größe des Kreises, zwischen 440 und 750 RM,

${ }^{3}$ Vgl. Franz-Josef Heyen, Nationalsozialismus im Alltag. Quellen zur Geschichte des Nationalsozialismus vornehmlich im Raum Mainz-Koblenz-Trier (Veröffentlichungen der Landesarchivverwaltung Rheinland-Pfalz 9), Boppard 1967, S. VIIff.; Kurt Düwell, Vergleichende Strukturfragen einer Regionalgeschichte der NS-Zeit, in: Probleme und Methoden vergleichender Landesgeschichte (Staatliches Institut für Lehrerfort- und -weiterbildung des Landes Rheinland-Pfalz, Studienmaterialien 25), Speyer 1979, S.92-116; Ders., Die regionale Geschichte des NS-Staates zwischen Mikround Makroanalyse, in: Jahrbuch für westdeutsche Landesgeschichte (JbWLG) 9 (1983), S. 287-344.

${ }^{4}$ Vgl. Kurt Düwell, Die Rheingebiete in der Judenpolitik des Nationalsozialismus vor 1942. Beitrag zu einer vergleichenden zeitgeschichtlichen Landeskunde (Rheinisches Archiv. Veröffentlichungen des Instituts für geschichtliche Landeskunde der Rheinlande 65), Bonn 1968, S. 33f.; Ders., Der Nationalsozialismus im Spiegel regional- und lokalgeschichtlicher Entwicklungen. Neuere landesgeschichtliche Ansätze und das Problem der Gesamtsicht, in: Wolfgang Isenberg (Hg.), Debatten um die lokale Zeitgeschichte. Methoden, Träger, Themen, Formen (Bensberger Protokolle 67), Bergisch Gladbach 1990, S. 45-60. 
d.h. zwischen den Endgehältern von Justizinspektoren und Landräten. Sie stiegen 1942 durch eine Besoldungsreform stärker an als die Beamtengehälter, so daß es z. B. ein früherer Schneider in einem rechtsrheinischen Landkreis als Kreisleiter auf 925 RM brachte immerhin das Endgehalt eines Oberregierungsrats in einer Großstadt. Auch konnten, wie z.B. für den Kreis Trier Stadt für 1941 nachzuweisen ist, auch besondere Aufwandsentschädigungen für Kreisleiter als Gauinspekteure oder für besondere Aufgaben in einem Grenzkreis bezahlt werden ${ }^{5}$. Nach den Berechnungen Boberachs erreichte ein Kreisleiter in einem mittelgroßen Stadtkreis mit 1187 RM fast die Bezüge eines Regierungspräsidenten! Galt dies für hauptberufliche Kreisleiter, so erwies sich aber auch die Tätigkeit als nebenamtlicher Kreisleiter als attraktive Karrierebasis, indem hierfür eine Aufwandsentschädigung gezahlt wurde und viele Kreisleiter zu Landräten, Bürgermeistern und Beigeordneten mit vollem Gehalt ernannt wurden. Im Gau Koblenz-Trier verließ, wie die Informationsmitteilungen „Der Führer" (1/1938) meldeten, ein nebenamtlicher Kreisleiter seinen Posten, weil er das Landratsamt vorzog. Ein anderer Kreisleiter wollte („Der Führer" 9/ 1938) in seinen Beruf zurückkehren, ein dritter wurde Bürgermeister und schied als Kreisleiter aus. Auch im Gau Köln-Aachen zogen (laut „Der Führer“ 3/1938 und 6/1939) zwei Kreisleiter das Landratsamt vor, ein dritter übernahm schon 1936 das Gauschulungsamt, während umgekehrt ebenfalls 1936 ein Gauamtsleiter in ein Kreisleiteramt wechselte.

Sowohl die Gauamtsleiter- als auch die Kreisleiterstellen erwiesen sich vielfach als eine Karrierebasis für weiteren Aufstieg, auch über die Parteiorganisation hinaus. Nach derselben Quelle wechselte 1940 ein Kreisleiter des Gaues Köln-Aachen auf eine der dreizehn Stellen als Reichstreuhänder der Arbeit, ein Gauamtsleiter des Gaues Koblenz-Trier wurde 1936 in die Reichspropagandaleitung nach München berufen. Ein Gauamtsleiter des Gaues Düsseldorf wurde 1936 Sparkassendirektor und gab sein Parteiamt auf. Ein Kreisleiter des Gaues Essen wurde 1938 Bürgermeister in Moers, etwa gleichzeitig ein Gauleiter desselben Gaues Hauptstellenleiter im Hauptamt Technik der Parteizentrale in München und bald darauf Amtschef im Reichsministerium für Rüstung und Kriegsproduktion.

Diese Fluktuation unterhalb der Gauleiterebene läßt sich auch für andere Gaue immer wieder feststellen. Aus dem Gau Saarpfalz wurde ein Kreisleiter 1937 Oberbürgermeister von Saarbrücken. Ein anderer übernahm 1938 den Vorsitz im Gaugericht. Zwei Gauamtsleiter desselben Gaues schieden aus, weil der eine Oberbürgermeister, der andere Kreisleiter im selben Gau wurde. Auch im Gau Baden schied 1936 ein Gauamtsleiter aus und wurde zum Kreisleiter ernannt. Solche Übergänge vom Gauamts- zum Kreisleiter ließen sich vielfach belegen und können als Zeugnis für die herausgehobene Stellung der Kreisleiter bzw. für deren relativ günstigere Karrieremöglichkeiten verstanden werden. Zwei nebenamtliche Kreisleiter gaben 1936 ihr Parteiamt im Gau Baden auf, um besser Bürgermeister bleiben zu können. Ein anderer Kreismeister wurde 1937 Polizeipräsident von Karlsruhe und schied aus dem alten Parteiamt aus.

Es scheint, daß im Durchschnitt die Gauamtsleiter bei einem Wechsel weniger oft eine hauptamtliche Parteiposition verließen als die Kreisleiter, die sehr oft in ein staatliches Amt wechselten. Im Gau Westfalen-Nord schied 1938 ein Kreisleiter aus, um wieder Kreisschulrat zu sein, ein anderer wurde im selben Jahr Hauptschriftleiter. Doch findet sich auch der Übergang eines Kreisleiters in die Gauamtsleitung (NSV-Leitung des Gaues), während ein anderer Gauamtsleiter 1938 zum Amtsleiter im Stab des Stellvertreters

\footnotetext{
${ }^{5}$ Bundesarchiv (BA), Außenstelle Berlin-Zehlendorf (früher BDC), 1080033006 Parteikorrespon-
} denz. 
des Führers ernannt und ein weiterer ebenfalls in die Reichsleitung der Partei berufen wurde. Ein anderer Gauamtsleiter wurde 1938 im selben Gau zum Kreisleiter ernannt. Auch aus dem Gau Westfalen-Süd ging 1938 ein Gauamtsleiter als Hauptstellenleiter in die Reichsorganisation nach München, während ein nebenamtlicher Kreisleiter ausschied, um sich ganz seinem Amt als Landrat zu widmen. In der Kriegszeit übernahm im selben Gau anscheinend ein Kreisleiter auch das Amt eines (kommissarischen?) Gauamtsleiters. Möglicherweise ist es dann in den späteren Kriegsjahren auch in anderen Fällen aus Personalmangel zu solchen Verbindungen gekommen. Vereinzelte Belege ließen sich hierfür schon oben nennen.

Vor dem Krieg hatte die starke Fluktuation der Gauamts- und Kreisleiter dazu geführt, daß eigens für diese ausgeschiedenen Amtsträger das Recht eingeführt wurde, spezielle Ehrenuniformen für ehemalige Gauamts- und Kreisleiter zu tragen. Dieses Recht wurde dann wohl sogar auch noch auf Personen ausgedehnt, die nie Gauamts- oder Kreisleiter gewesen waren, aber wegen ihrer Verdienste um die Partei durch ein solches Zeichen geehrt werden sollten. In einzelnen Fällen kam es groteskerweise, wie z. B. im Gau Koblenz-Trier 1938, zur Verleihung des Rechts, die Uniform eines „ehemaligen Gauleiters“ oder, wie im Gau Saarpfalz geschehen, die eines „ehemaligen Stellvertretenden Gauleiters“ tragen zu dürfen.

Diese Beispiele mögen hier genügen, um das Ansehen und die starke Fluktuation der parteilichen Amtsstellenleiter unterhalb der Gauleiterebene besonders nach 1936 aufzuzeigen. Die Wechsel wurden anscheinend besonders durch die Aufhebung der Parteiaufnahmesperre im Jahre 1937 bedingt, als die Zunahme der Mitgliederzahlen sowohl in der regionalen Organisation der NSDAP als auch in der Parteizentrale in München zu personellen Verstärkungen zwang. Auf der Ebene der Gauleiter hat es dagegen bis dahin kaum personelle Veränderungen gegeben. Auch fanden nur sehr wenige Wechsel unter den Stellvertretenden Gauleitern statt. Allerdings sind diese Positionen bis 1936 überhaupt noch nicht überall besetzt gewesen. So hat es z.B. in den westlichen Gauen Essen, Westfalen-Nord und Westfalen-Süd anscheinend erst ab 1935 offiziell Stellvertretende Gauleiter gegeben. Sie waren als „Befehlsleiter“ den Gauamts- und den Kreisleitern übergeordnet und blieben meist auch in der Kriegszeit auf ihren herausgehobenen Parteistellen. Eine der relativ wenigen Ausnahmen war der Stellvertretende Gauleiter des Gaues Koblenz-Trier („Moselland“), der nach 1942 zeitweise zum Obersten Parteigericht nach München abgeordnet war.

Angesichts der schon erwähnten relativ starken personellen Wechsel der Kreisleiter erwies sich in vielen Fällen das Verhältnis dieser Parteileute zur Zivilverwaltung, insbesondere zu den Landräten, als von großer Bedeutung und oft genug als ein Konfliktpunkt. Nicht selten kam es hier zu Spannungen, die schon bald nach dem 30.Januar 1933 deutlich wurden und unter dem Druck der Gauleitungen zu einer ganzen Reihe von Entlassungen von Landräten führten. Es gab dabei besonders krasse Fälle. Ein spektakulärer Fall war die im Juni 1933 im Landkreis Köln durch eine nationalsozialistische Demonstration erzwungene Ersetzung des Landrates durch den Kreisleiter der NSDAP. Horst Matzerath hat mehrere ähnliche Fälle auch im städtischen Bereich nachgewiesen ${ }^{6}$. Im Kreis

${ }^{6}$ Vgl. Horst Matzerath, Nationalsozialismus und kommunale Selbstverwaltung, Stuttgart 1970 , S.33ff.; Ders., Der Nationalsozialismus und die Oberbehörden und Großstadtverwaltungen in Rheinland und Westfalen, in: Kurt Düwell u. Wolfgang Köllmann (Hg.), Rheinland-Westfalen im Industriezeitalter. Beiträge zur Landesgeschichte des 19. und 20.Jahrhunderts, Bd.3, Wuppertal 1984, S. 116-136. Zu Hannover und Westfalen vgl. auch Jeremy Noakes, The Nazi Party in Lower Saxony, Oxford 1971 und Karl Teppe, Provinz, Partei, Staat. Zur provinziellen Selbstverwaltung im Dritten Reich, untersucht am Beispiel Westfalen, Münster 1977. 
Trier-Land wurde ein dem Zentrum nahestehender Landrat durch eine telegrafische Denunziation beim Innenministerium zu Fall gebracht, indem berichtet wurde, der Landrat habe anläßlich einer Eberkörung für das preisgekrönte Schwein den Namen Hitler vorgeschlagen ${ }^{7}$. Allein in den beiden Gauen Köln-Aachen und Koblenz-Trier wurden, wie Boberach feststellen konnte, zwischen 1933 und 1938 von 45 Landräten sieben entlassen und durch Nationalsozialisten ersetzt. In einem Fall wurde ein Reichsbahnassistent nach Meinung des zuständigen Referenten im Innenministerium nur deshalb zum Landrat ernannt, weil er die Prüfung für den Mittleren Dienst nicht bestanden und auch als Kreisleiter versagt hatte ${ }^{8}$.

Die nach dem Zweiten Weltkrieg vorgelegten Geschichten einzelner Landkreise gehen auf die Spannungen zwischen den Landräten und den Kreisleitern der Partei nur relativ spärlich ein'. Hier hat sich allerdings seit 1991 mit den Arbeiten von Alfred Kurt und Otto Schlander über den Kreis Offenbach sowie einer Studie von Hartmut Lohmann über den Landkreis Stade ein deutlicher Wandel angebahnt ${ }^{10}$. Auf die hier bestehende Lükke haben zuvor 1988/89 schon Peter Hüttenberger und Dieter Rebentisch hingewiesen ${ }^{11}$. Denn gerade auf der Kreisebene kam die Spannung zwischen nationalsozialistischer Parteiorganisation und ziviler Verwaltung oft sehr kraß zum Ausdruck, zumal durch die Deutsche Gemeindeordnung von 1935 die Stellung der Landräte, nicht als Selbstverwaltungsorgan der Kreise, aber als staatliche Instanz, wesentlich gestärkt worden war. Anders als im italienischen Faschismus, wo Mussolini das Prinzip der Substitution staatlicher Gewalt durch die Partei zum Prinzip erklärt und die parallel zu staatlichen Institutionen auch auf der regionalen und lokalen Ebene betriebene „Doppelung“ („duplicazione“) der Parteieinrichtungen in Konkurrenz zu staatlichen Stellen systematisch vollzogen hatte, war in Deutschland die staatliche Seite von Hitler vielfach eher stabilisiert worden. Trotzdem kam es zu zahlreichen Konflikten zwischen Landräten und Kreisleitern bzw. zu einer Auseinandersetzung zwischen dem Reichsinnenministerium, dem Stellvertreter des Führers und dem Reichsorganisationsleiter der Partei, der dabei seine Ordensjunker unterbringen wollte, über die Besetzung der Landratsstellen, eine Auseinandersetzung, auf die

${ }^{7}$ Vgl. Heinz Boberach, Funktionäre und Mitläufer. Struktur und Träger der nationalsozialistischen Herrschaft. Funkmanuskript des WDR, Landesredaktion, vom 26. Juli 1969, S. 14.

${ }^{8}$ Ebd., S.15. Vgl. zu dieser Region auch Leo Haupts u. Georg Mölich (Hg.), Aspekte der nationalsozialistischen Herrschaft im Rheinland (Geschichte in Köln, Sonderheft 3), Köln 1983.

${ }^{9} \mathrm{Vgl}$. Hans-Gerd Dick, Die Zeit des Nationalsozialismus in Kreisgeschichten. Bestandsaufnahme und neue Fragestellungen, in: Geschichte im Westen 9 (1994), S.75-83.

${ }^{10} \mathrm{Vgl}$. Alfred Kurt u. Otto Schlander, Der Kreis Offenbach und das Dritte Reich. Leben und Politik, Verfolgung und Widerstand im Kreis, 1930-1945, Dreieich 1991; Hartmut Lohmann, „Hier war doch alles nicht so schlimm “. Der Landkreis Stade in der Zeit des Nationalsozialismus (Beiträge des Landkreises Stade zu regionalen Themen 8), hg. v. Landkreis Stade, Stade 1991. - Einen wichtigen neuen, wenn auch nicht durchgehend realisierten Ansatz enthält auch die inzwischen veröffentlichte Dissertation von Manfred Kieserling, Faschisierung und gesellschaftlicher Wandel. Mikroanalyse eines nordhessischen Kreises, 1928-1935, Wiesbaden 1991. Hinzuweisen ist hier auch noch auf die umfangreiche Arbeit von Wolfgang Dietz, Der Landkreis Neuwied. Weimarer Republik, Nationalsozialismus, Nachkriegszeit, hg. v. Landkreis Neuwied, Neuwied 1992.

"Vgl. Peter Hüttenberger, Die Entwicklung der rheinisch-westfälischen Landkreise, in: $100 \mathrm{Jahre}$ Kreisordnung in Nordrhein-Westfalen, hg. v. Landkreistag Nordrhein-Westfalen, München 1988, S. 17; Dieter Rebentisch, Führerstaat und Verwaltung im Zweiten Weltkrieg, Stuttgart 1989, S.25. Vgl. als Ansatz auch Ders. (Hg.), Dreieich zwischen Parteipolitik und „Volksgemeinschaft" Gemeinden in Dokumenten aus der Weimarer Republik und der NS-Zeit, Frankfurt/M. 1984, S.287ff. 
schon Hans Mommsen 1966 hingewiesen hat ${ }^{12}$. Aber obgleich selbst die Parteikanzlei schließlich eine Personalunion von Kreisleitern und Landräten ebenso ablehnte wie eine Personalunion zwischen dem neugeschaffenen Amt des Präsidenten der Gauwirtschaftskammer und dem Gauwirtschaftsberater, ist es doch, mindestens in den besetzten Ostgebieten, vielfach zu einer Personalunion von (oft kommissarischen) Landräten und Kreisleitern gekommen. Ähnliches wurde für eine Personalunion von Kreisleiter und Bürgermeister geplant. Die von Hans Mommsen publizierten Dokumente zeigen, daß dies nach Kriegsbeginn unter den besonderen Bedingungen des Ostens, vor allem durch die besondere Stellung des Reichsstatthalters Arthur Greiser im „Reichsgau Wartheland“, möglich war und daß es hierbei vielfach um die Versorgung von Parteimitgliedern ging, die teils vom Reichsinnenministerium, teils vom Stellvertreter des Führers und teils vom Reichsorganisationsleiter der Partei vorgeschlagen wurden. Frick lehnte es jedoch in mehreren Fällen ab, die von Greiser in seiner Eigenschaft als Reichsstatthalter recht willkürlich eingesetzten Kreisleiter als Landräte anzuerkennen, weil er dadurch eine erhebliche Qualitätsminderung der Verwaltung kommen sah. Es war nämlich nach Kriegsbeginn mehr und mehr damit zu rechnen, daß auch im Altreich freiwerdende Landratsstellen mit Kreisleitern der Partei besetzt würden, wobei der Gau Saarpfalz schon Ende 1939 voranging und man im Reichsinnenministerium mit weiteren Anträgen aus Bayern rechnete ${ }^{13}$. Bürckel als Gauleiter der Saarpfalz, dann zugleich Reichsstatthalter von Österreich und schon seit September 1939 auch Reichsverteidigungskommissar, konnte in der Landratsfrage gegenüber dem Reichsinnenministerium unabhängiger auftreten als seine benachbarten Gauleiter Simon (Koblenz-Trier) und Grohé (Köln-Aachen), die über soviel staatliche Macht nicht verfügten. Im Westen war es nur der badische Gauleiter Robert Wagner, der als Reichsstatthalter aus seiner größeren Unabhängigkeit heraus ebenfalls versuchte, in seinem Gau das Amt des Landrats mit dem des Kreisleiters zu vereinigen ${ }^{14}$.

Diese Versuche waren z. T. die Folge davon, daß 1937 die Anstrengungen Fricks gescheitert waren, durch ein Kreisverfassungsgesetz den Einfluß der Partei in der ländlichen Selbstverwaltung eher einzuschränken. Vor allem war es Heß, dem das Nichtzustandekommen einer deutschen Kreisordnung zuzuschreiben war. Dies hatte umgekehrt dazu geführt, daß dem Kreisleiter als Sonderbeauftragtem der Partei für Gemeindefragen faktisch eine stärkere Stellung zuwuchs. Das lag z. T. aber auch daran, daß - worauf schon Horst Matzerath hingewiesen hat - den Kreisleitern nicht nur durch ihre Personalpolitik, sondern auch durch ihren Einfluß auf die regionalen Schulungsmaßnahmen der Partei und teilweise auch durch alltägliche Pression beträchtliche Machtmöglichkeiten entstanden waren ${ }^{15}$.

${ }^{12}$ Hans Mommsen, Beamtentum im Dritten Reich (Schriftenreihe der Vierteljahrshefte für Zeitgeschichte 13), Stuttgart 1966, S. 224ff.

${ }^{13}$ Ebd., S. 227.

${ }^{14}$ Vgl. Johnpeter Horst Grill, Robert Wagner, in: Ronald Smelser, Enrico Syring, Rainer Zitelmann (Hg.), Die braune Elite II, Darmstadt 1993, S.254-267, hier S. 262. Vgl. Klaus Tellenbach, Die Badische Innere Verwaltung im Dritten Reich, in: Zeitschrift für die Geschichte des Oberrheins 134 (1986), S.377-412, S.390. Zu Bürckel vgl. auch Hans Fenske, Josef Bürckel und die Verwaltung der Pfalz (1933-1940), in: Dieter Rebentisch u. Karl Teppe (Hg.), Verwaltung contra Menschenführung im Staat Hitlers, Göttingen 1986, S. 153-173. Allgemein zur Verwaltungsgeschichte der nördlichen Rheinlande vgl. Horst Romeyk, Verwaltungs- und Behördengeschichte der Rheinprovinz 1914-1945 (Publikationen der Gesellschaft für Rheinische Geschichtskunde 63), Düsseldorf 1985.

${ }^{15} \mathrm{Vgl}$. auch Hans Fenske, Bürokratie in Deutschland, Berlin 1985, S. $41 \mathrm{ff}$. Martin Hirsch, Diemut Majer, Jürgen Meinck (Hg.), Recht, Verwaltung und Justiz im Nationalsozialismus. Ausgewählte Schriften, Köln 1984. 
Das Problem einer Personalunion von Kreisleiter und Landrat wurde, wie schon Hans Mommsen dokumentiert hat, selbst vom Stab des Stellvertreters des Führers etwa seit Anfang des Jahres 1940 durchaus kritisch gesehen. Die Diskussion einer Unterscheidung zwischen „Aufgaben der Menschenführung“ einerseits, die von der Partei (vor allem durch die Kreisleiter) wahrzunehmen seien, und den Verwaltungsaufgaben der Landräte andererseits, war zwischen dem Reichsinnenminister und dem Stellvertreter des Führers schon in vollem Gange. Sie war in den letzten Jahren besonders Gegenstand der Forschungen von Dieter Rebentisch und Karl Teppe ${ }^{16}$. Dabei hat sich ergeben, daß die Gauleiter die Frage einer Personalunion von Kreisleiter und Landrat nicht ganz so gesehen haben, wie dies im Stabe des Stellvertreters des Führers der Fall war. Für sie war es eine Machtfrage, daß sie in wenigstens einigen Fällen einen ihrer Kreisleiter, mindestens als kommissarischen Landrat, durchsetzen und so ihren Einfluß auf die Verwaltung im Gaugebiet stärken konnten. Zwar hatte der Stab des Führers das Machtinteresse der Gauleiter wahrgenommen und diesem durch ein besonderes Informationsrecht der Kreisleiter und eine Informationspflicht des Landrats gegenüber dem Kreisleiter sowie durch den Plan zu einem politischen Weisungsrecht des Kreisleiters gegenüber dem Landratsamt zu entsprechen gesucht. Aber die Gauleiter selbst sahen dies eher als Einschränkung ihrer Macht an, auch wenn Bormann noch im August 1942 als Leiter der Parteikanzlei „eine Belastung der Partei mit Funktionen der Exekutive ${ }^{\text {"17 }}$, auch in der Form einer Personalunion von Kreisleiter und Landrat, ablehnte: „Das Amt des Oberbürgermeisters oder eines Landrats verlangt einen Mann, der die nötigen Verwaltungsfähigkeiten besitzt, das Amt des Kreisleiters jedoch einen Parteigenossen, der Menschen führen kann ${ }^{18}$." Elemente dieser Kunst der Menschenführung waren danach: Instinkt, Intuition und „dynami-

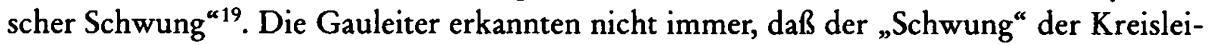
ter sie im Landratsamt, selbst wenn sie zu diesem Amt qualifiziert waren, verlassen könnte.

Im Stab des Stellvertreters des Führers hielt man es dagegen auf der Ebene der Gauleiter eher für möglich, mit diesem Parteiamt auch ein Staatsamt zu verbinden, etwa als Reichsstatthalter. Das Bemühen des Gauleiters Simon im Gau Moselland war im Krieg darauf gerichtet, wenn schon nicht zum Reichsstatthalter, so doch wenigstens zum Leiter eines „Reichsgaues“ ernannt zu werden, um so eine größere Unabhängigkeit vom Reichsinnenminister zu gewinnen. Sein Argument gegenüber dem Reichsinnenminister, aber auch gegenüber der Parteileitung, war dabei, daß mit der Besetzung Luxemburgs und der Eingliederung dieses wirtschaftlich wichtigen Nachbarlandes in den im Januar 1941 umbenannten Gau Moselland das politische und ökonomische Gewicht dieses Gaues so gewachsen sei und die Zuständigkeit des Gauleiters und Chefs der Zivilverwaltung in Lu-

${ }^{16}$ Vgl. Rebentisch u. Teppe, Verwaltung. Zur Frage der Personalunion von Parteiamt und Landrat vgl. auch Dieter Rebentisch, Innere Verwaltung. Die Behörden, ihre Aufgaben und ihr Verhältnis zur NSDAP und deren Gliederungen, in: Kurt G. A. Jeserich, Hans Pohl, Georg Chr. von Unruh (Hg.), Deutsche Verwaltungsgeschichte, Bd.IV, Stuttgart 1985, S.732-774, hier S.757; zum Gesamtzusammenhang Ders., Führerstaat und Verwaltung im Zweiten Weltkrieg. Verfassungsentwicklung und Verwaltungspolitik, 1939-1945 (Frankfurter historische Abhandlungen 29), Stuttgart 1989.

${ }^{17}$ Dazu vgl. Mommsen, Beamtentum, S.239.

18 Ebd., S. 241.

${ }^{19}$ Vgl. auch Horst Romeyk, Der preußische Regierungspräsident im NS-Herrschaftssystem. Am Beispiel der Regierung Düsseldorf, in: Rebentisch, K. Teppe, Verwaltung, S.121-140. 
xemburg - ein neues Amt Simons seit Juli 1940 - so sehr zugenommen habe, daß nur durch eine Anerkennung als "Reichsgau“ dieser Tatsache Rechnung getragen werden könne ${ }^{20}$. Auch die aufgrund des Ostmarkengesetzes vom 14. April 1939 zustande gekommenen sieben österreichischen Reichsgaue schienen dabei für Simon ein Vorbild zu sein. Simons Pläne mißlangen, obwohl er wiederholt Druck auf die Reichsleitung auszuüben versucht hatte, sei es z.B. dadurch, daß er sich gegenüber dem Reichserziehungsministerium weigerte, in seinem Gau die Richtlinien für die deutschen Lehrerbildungsanstalten einzuführen, sei es, daß er, wie ihm gar ein fanatischer HJ-Gebietsführer noch im Oktober 1944 in einem Schreiben, vermutlich an Kaltenbrunner oder sogar an Hitler, vorwarf, auch andere „partikularistische Maßnahmen“ und immer wieder „die Autorität des Führers schädigende, reichsleitungsfeindliche Handlungen“ begangen habe ${ }^{21}$. Simon habe aus seinem Hoheitsgebiet eine "moselländische, hermetisch abgeschlossene Gaueinheit“ gemacht ${ }^{22}$.

Geht man diesen dramatisch zugespitzten Vorwürfen eines höheren HJ-Führers nach, der immerhin zu diesem Zeitpunkt 36 Jahre alt war, so sind viele der machtpolitischen Aktionen der Gauleiter unter einem bestimmten sicherheitspolitischen Gesichtspunkt zu sehen, nämlich als Abwehr gegenüber dem Sicherheitsdienst der SS. Das gilt auch in diesem Fall. Die meisten Gauleiter suchten, ihren Gaustab und die Kreisleiter ihres Gaues „hermetisch" gegen den SD der SS abzuschirmen. Die Klagen der Gauleiter, daß der SD in Parteisachen „herumschnüffele“, wie es die Gauleiter Florian und Weinrich einmal bezeichneten $^{23}$, ließen sich in der Sache vielfach belegen und brachten die meisten Gauleiter dazu, ihren Gaustab und die Kreisleiter fest auf sich zu verpflichten. In dem genannten Fall ging Simon so weit, „daß er in seinem Stab und in den Kreisen durch den Kreisleiter jeden politischen Leiter vor die ultimative Forderung stellte, entweder sein Parteiamt sofort niederzulegen oder ehrenwörtlich zu erklären, daß er nicht Mitarbeiter des SD sei“24. Unter der von Himmler seit 1943/44 gewonnenen Machtstellung der SS wurde dieser Abwehrkampf der Gauleiter aber immer schwieriger, zumal sie gleichzeitig auch von Seiten der Parteikanzlei Bormanns unter zunehmenden Druck gerieten. Eines der Mittel Bormanns war dabei das neue Amt des "Gaustabsamtsleiters“.

${ }^{20}$ Auf diese Zusammenhänge wird in Kürze Herr Dr. Emile Krier in einer größeren Arbeit über die wirtschaftliche Entwicklung Luxemburgs unter der deutschen Besatzung eingehen. Vgl. auch Horst Romeyk, Der Gau Moselland in der nationalsozialistischen Reichsreform, in: JbWLG 11 (1985), S. 247-269, hier bes. S. 254 und S. 267f., sowie Paul Dostert, Luxemburg zwischen Selbstbehauptung und nationaler Selbstaufgabe, Luxemburg 1985, S.78-84. Zur Bedeutung der während des Kriegs errichteten Gauwirtschaftskammern vgl. auch die Fallstudie von Gerhard Kratzsch, Der Gauwirtschaftsapparat der NSDAP. Menschenführung, „Arisierung“, Wehrwirtschaft im Gau Westfalen-Süd. Eine Studie zur Herrschaftspraxis im totalitären Staat (Veröffentlichungen des Provinzialinstituts für westfälische Landes- und Volksforschung des Landschaftsverbandes WestfalenLippe 27), Münster 1989, S.480ff.

${ }^{21}$ BA, Außenstelle Berlin-Zehlendorf (früher BDC), Schreiben des HJ-Gebietsführers Moselland vom 5. Oktober 1944, Nr. 1050059566 und 9570 Parteikorrespondenz.

${ }^{22}$ Ebd.

${ }^{23}$ Vgl. Hüttenberger, Gauleiter, S. 176. Zu Bürckels ambivalenten Beziehungen zum SD vgl. Dieter Wolfanger, Anton Dunckern, der erste Gestapochef des Saarlandes und spätere Befehlshaber der Sicherheitspolizei und des SD in Lothringen und Saarpfalz, in: JbWLG 18 (1992), S. 303-324, bes. S.311f.

${ }^{24}$ Zitat aus dem erwähnten Bericht des in Anm. 21 schon angegebenen HJ-Gebietsführers. 


\section{Gaustab und Kreisleiter}

Die meisten Gauleiter hatten ihre Macht schon in der „Kampfzeit" allmählich auf- und ausbauen können. Einige waren in dieser Bewährungsphase sogar noch, wie Josef Bürckel 1926 im alten Gau „Rheinpfalz“, von den Kreisleitern gewählt worden ${ }^{25}$. Wie Bürckel gewannen viele Gauleiter in den folgenden Jahren ihren Gaustab ("Gauclique ") und ihre Gefolgsleute unter den Kreisleitern, so daß hier ein festes Gefüge entstand. Aber nicht immer kam es dabei zu der verschworenen Gemeinschaft, die sich wohl jeder Gauleiter wünschte. Als z. B. im Oktober 1935 der Gauleiter des Gaues Magdeburg-Anhalt und Reichsstatthalter für Braunschweig und Anhalt, Wilhelm Friedrich Loeper, starb, hatte es in diesem Gau schon zuvor scharfe Auseinandersetzungen innerhalb des Gaustabs gegeben. Diese Konflikte wirkten sich auch auf die Kreisleiterebene aus. Loeper hatte noch die Auseinandersetzungen, die auch von finanziellen Mißständen des Gaukassenwesens begleitet waren, dadurch zu beheben gewußt, daß er einen früheren Bezirksleiter der Partei aus dem Bezirk Bergisch-Land/Niederrhein, der 1933 aus Düsseldorf nach Dessau gekommen war und als ehemaliger Kaufmann und Fakturist über solide Kenntnisse im Buchhaltungs-, Bilanz- und Revisionswesen verfügte, als Gauschatzmeister gewann. Fritz Härtl, ein Deutsch-Böhme, erledigte dann auch seine Aufgaben fachlich zufriedenstellend, war aber als ehemaliger Bezirksleiter eine sehr selbstbewußte Persönlichkeit, die die von ihm bei der Konsolidierung des Gaues Magdeburg-Anhalt befolgten Grundsätze einer strengen Rechnungslegung und Kontrolle der einzelnen Kostenstellen auch dann noch weiter machtbewußt durchzusetzen suchte, als 1937 der neue Gauleiter Rudolf Jordan, zuvor Gauleiter in Halle-Merseburg, die Leitung des Gaues übernahm. Jordan bekam Schwierigkeiten mit Härtl. Die etwas bürokratische Art des alten Gauschatzmeisters schien dem Elan des neuen Gauleiters Fesseln anzulegen, so daß es zu Spannungen sowohl mit Jordan als auch dem Gaustab und den Kreisleitern kam. Der Gauschatzmeister überwachte gestreng die Verwendung der parteieigenen Kraftwagen, den Raumbedarf der Gauamtsleiter, die Ausgaben bis hin zu Schrankanschaffungen, zur Kontrolle der Rundschreiben der Gauamtsleiter, der Telefonkosten der Kreisleiter und zur Führung der Portokasse. Die Kreiskassenleiter waren vom Gauschatzmeister angeblich sogar dazu angehalten worden, die Telefongespräche der Kreisleiter zu überwachen.

Andererseits forderten viele Gauamts- und Kreisleiter vom Gauschatzmeister, den sie als ihresgleichen ansahen, die Offenlegung der Ausgaben aus dessen Dispositionsfonds. Es war daher z.T. verständlich, daß der neue Gauleiter Jordan dieses sach- aber auch machtbetonte Agieren des alten Gauschatzmeisters zum Anlaß nahm, am 13. Oktober 1937 einen langen Klagebrief an den Reichsschatzmeister der Partei, Franz Xaver Schwarz, zu richten, in dem er nicht nur die schon genannten Gravamina gegen den Gauschatzmeister auflistete ${ }^{26}$. Zusätzlich wurden Vorwürfe auf Disziplinlosigkeit des Gauschatzmeisters gegenüber dem Gauleiter, gegenüber Reichs- und „Stoßtrupprednern“, die der Gauschatzmeister u.a. als „Singvögel“ bezeichnet hatte, erhoben und ständige Klagen

${ }^{25} \mathrm{Zu}$ Bürckel vgl. außer Hüttenberger, Gauleiter, passim, auch die neueren Arbeiten von E.D. R. Harrison, Gauleiter Bürckel and the Bavarian Palatinate, 1933-1940, in: Proceedings of the Leeds Philosophical and Literary Society, Literary and Historical Section, 20,3, 1986, S.271-291; Fenske, Bürckel, sowie Gerhard Paul, Josef Bürckel - Der rote Gauleiter, in: Smelser u.a., Elite II, S.51-65.

${ }^{26}$ BA, Außenstelle Berlin-Zehlendorf (früher BDC), Personalakte Härtl. 
der Kreisleiter gegen den Gauschatzmeister zitiert. Wenn dabei auch die fachliche Kompetenz des Gauschatzmeisters nicht bezweifelt wurde, so wurde doch das Regiment Härtls vom Gauleiter als „unnatürlich sozialistisch“ bezeichnet und ihm vorgeworfen, daß sein Verhalten auf die Kreiskassenleiter „abgefärbt“ habe ${ }^{27}$.

Es erwies sich in dieser Phase 1937, daß der Reichsschatzmeister inzwischen durch die ihm von Hitler erteilten Vollmachten im Finanzwesen der Partei eine Art Kernverwaltung aufgebaut hatte, die in gerader Folge vom Münchener Zentrum über die Gauschatzmeister bis hin zu den Kreiskassenleitern reichte. Der Reichsschatzmeister hatte um diese Zeit sein Recht fast durchgesetzt, die Gauschatzmeister und über sie mehr oder weniger auch die Kreiskassenleiter zu ernennen und über sie eine straffe Finanzkontrolle über alle Gaue zu erhalten. Hüttenberger sprach daher schon 1969 von einer „einheitlichen vertikalen Bürokratie“, „der einzigen wirklich funktionierenden hierarchischen Parteibürokratie in der NSDAP, die infolgedessen auch über Finanzfragen hinaus zum Gerüst der allgemeinen Parteiverwaltung wurde ${ }^{\text {“28. }}$. Doch der schon erwähnte Dessauer Vorgang von 1937 und ähnliche Fälle in den Gauen Rheinpfalz und Sachsen ${ }^{29}$ zeigen, daß dieser Durchsetzungsprozeß erst um 1939 zugunsten des Reichsschatzmeisters abgeschlossen war. Insofern endete die Auseinandersetzung in Magdeburg-Anhalt 1937/38 noch mit einem Achtungserfolg des Gauleiters.

Während dieser Kraftprobe, bei der es dem neuen Gauleiter in Dessau darauf ankommen mußte, seinen Gaustab gegen den alten Gauschatzmeister gewissermaßen „einzuschwören“, verfing schließlich - denn ein Sonderbeauftragter des Reichsschatzmeisters hatte in einem Geheimbericht den Dessauer Gaufinanzchef z. T. in Schutz genommen nur noch ein Argument, das in der Tat eine Schwachstelle in der Arbeit des Gauschatzmeisters deutlich machte: Er habe es versäumt, die 1937 im Gau Magdeburg-Anhalt nötigen organisatorischen Vorbereitungen für die neuen Aufnahmen in die Partei zu treffen, rechtzeitig Prüfungsausschüsse für Neuaufnahmen zu bilden, an denen auch die Kreisleiter beteiligt werden sollten, und dergleichen mehr. Natürlich hätte das Ende der Aufnahmesperre für Parteieintritte 1937 für den Gauschatzmeister ein besonderes Signal zu intensiven Vorbereitungen sein müssen. Durch diese Verzögerung, so Gauleiter Jordan, sei der Gau in Rückstand geraten und hinke hinter den anderen Gauen her: „Schuld daran trägt allein der Gauschatzmeister, der sie nicht abwälzen kann auf die Ortsgruppenleiter und Kreisleiter ${ }^{* 30}$. Dies war natürlich ein Argument, dem sich ein an neuen Mitgliederbeiträgen interessierter Reichsschatzmeister der Partei nicht entziehen konnte, auch wenn es sein primäres Motiv sein mußte, die Aufnahmesperre erst dann aufzuheben, wenn die Finanzverwaltung der Partei unter zentraler Kontrolle stand.

Jordan beantragte die Untersuchung des Falles und erreichte immerhin, daß der extrem sparsame und zugleich machtbewußte Dessauer Gauschatzmeister, der u.a. die Annahme von Schreiben verweigert hatte, die an ihn "nur" als "Gauamtsleiter" adressiert waren ${ }^{31}$, zum 1.April 1938 in die Reichsleitung der Partei nach München „befördert“ wurde, dort im August zum Beauftragten des Reichsschatzmeisters für die Finanz- und Parteiverwal-

\footnotetext{
27 Ebd.

${ }^{28}$ Hüttenberger, Gauleiter, S. 126.

${ }^{29}$ Ebd., S. $127 f$.

${ }^{30}$ Ebd.

${ }^{31}$ Im Bericht Jordans hieß es, er habe „Schreiben zurückgehen lassen, da er nicht Gauamtsleiter, sondern Gauschatzmeister“ sei. Ebd.
} 
tung ernannt und im Krieg dann im Reichsrevisions- und Rechnungsamt der Partei für den Gau Wien zuständig und schließlich Bereichsleiter im Hauptamt VI des Reichsschatzmeisters wurde. Dabei spielten offensichtlich fachliche Gründe eine Rolle, daneben wohl aber auch der Gesichtspunkt, daß Härtl zehn Jahre zuvor schon einmal in der „Kampfzeit“ als Bezirksleiter im alten Gau Rheinland direkt der Reichsleitung unterstanden und sich in ihren Augen bewährt hatte. So griff sie in dieser Konfliktlage innerhalb des Gaues Magdeburg-Anhalt wieder auf ihn zurück und holte ihn in die Zentrale. Dadurch gewann der Reichsschatzmeister einen akkuraten Rechungs- und Revisionsfachmann, den er schätzte und auf diese Weise zugleich befördern konnte, und andererseits gelang es dem Gauleiter und Reichsstatthalter Jordan, den Gaustab seiner Region zu „homogenisieren“ und auch die Kreisleiter stärker einzubinden.

Dieser Fall war singulär, aber er zeigt, daß die Fluktuation der Gauleiter von der Reichsleitung wohl auch deshalb sehr gering gehalten wurde, weil es für jeden neuen Gauleiter in einem Gau sehr schwer sein mußte, sich gegen die dort vorgefundenen personellen Kräfte, finanz- und verwaltungstechnischen Strukturen durchzusetzen. Andererseits bedurfte die oft antagonistische Zusammensetzung des Gaustabs oder dessen gestörtes Verhältnis zu den Kreisleitern (in diesem Falle auch zu den Kreiskassenleitern) auch aus der Sicht der Parteileitung einer personellen Veränderung, um die Effizienz der gesamten Arbeit im Gau einigermaßen zu gewährleisten.

Aus der Sicht der Gauleiter selbst mußte natürlich die Festigung der eigenen Machtposition die unerläßliche Voraussetzung für jede Effizienz der Parteiarbeit im Gau sein. Im Krieg hat jedoch die Parteikanzlei unter Bormann ab 1942 versucht, den Prozeß einer "hermetischen“ Abschließung der Gaue durch die Einsetzung von Gaustabsamtsleitern in jedem Gau zu stoppen - eine Konkurrenz auch zu den stellvertretenden Gauleitern ${ }^{32}$. Junge Kreisleiter und Gauamtsleiter, die wegen des niedrigen Durchschnittsalters der amtierenden Gauleiter kaum Chancen sahen, in der Partei schnell aufsteigen zu können, drängten sich zu diesem neuen Amt und hofften, durch die Schulungskurse der Parteikanzlei und durch den direkten Kontakt mit der Münchener Zentrale ihre Karriere zu befördern. Vielfach gelang es zwar dem Gauleiter, das neue Amt durch einen seiner Vertrauensleute zu besetzen, aber in vielen Fällen konnte Bormann Einfluß auf die Auswahl der Kandidaten nehmen oder doch in der Folge die neuen Gaustabsamtsleiter - oft frühere Kreisleiter - durch die Schulungskurse der Parteikanzlei als eigene Vertrauensleute in den Gauen etablieren und so die Gauleiter wenigstens teilweise besser beaufsichtigen.

Dennoch sollte das oben schon erwähnte Bewegungsmoment der Partei erhalten bleiben. Hitlers bekanntes Diktum „Nicht der Staat befiehlt uns, sondern wir befehlen dem Staat!“ gewann während des Kriegs immer stärkere Aktualität, vor allem dadurch, daß die Parteikanzlei immer stärkeren Einfluß auf die Führung der Reichskanzlei nehmen konnte, ja sich mehr und mehr verselbständigte und Bormann seit dem 12. April 1943 als „Sekretär des Führers“ eine zusätzliche Schlüsselposition erhielt. Während sich daraus für die Gauleiter, trotz ihrer vermehrten Macht als Reichsverteidigungskommissare, eine Gegenkraft entwickelte, die die Position dieser Regionalgewalten einschränkte, wurde die Macht der Kreisleiter als verlängerter Arm des Gauleiters, aber auch als Repräsentanten

${ }^{32}$ Vgl. Hüttenberger, Gauleiter, S. 205. Zur Rolle der stellvertretenden Gauleiter, die noch einer besonderen Untersuchung bedürfte, vgl. die Fallstudie von Dieter Wolfanger, Ernst Ludwig Leyser, Stellvertretender Gauleiter der NSDAP in der Saarpfalz. Eine biographische Skizze, in: JbWLG 14 (1988), S. 209-217. 
der Partei vor Ort, davon zunächst weniger berührt, wenn man von der besonderen Stellung der Kreiskassenleiter und ihrer Unterordnung unter den Reichsschatzmeister einmal absieht. Zusammenfassend läßt sich sagen, daß von seiten des Reichsschatzmeisters und von seiten des Sicherheitsdienstes der SS die Stellung der Gau- und der Kreisleiter aber schließlich doch von zwei Fronten zugleich Angriffen ausgesetzt war, so daß die strategische Linie der Parteikanzlei, eine funktionale Arbeitsteilung mit der inneren staatlichen Verwaltung zu suchen und die Besetzung z. B. der Landratsstellen und anderer Verwaltungspositionen eher dem Reichsminister des Innern zu überlassen, folgerichtig war. Die Gau- und Kreisämter für Kommunalpolitik verloren dadurch zwar an Einfluß, doch das Verhältnis der Parteikanzlei zur staatlichen Verwaltung wurde verbessert, und Bormann gewann einen Partner im antagonistischen Kräftegerangel des NS-Staates. Erst als Himmler im August 1943 ohne jede zivile Verwaltungserfahrung auch Reichsminister des Innern wurde, erwies sich die Verständigungsstrategie der Parteikanzlei als Schwachpunkt, da sie nun ungewollt der SS zugute kam. Aber die negativen Auswirkungen dieser Fehlkalkulation blieben wegen der Kriegsumstände für die Parteikanzlei begrenzt. Dadurch daß z.B. weit mehr Landräte als Kreisleiter der Partei zum Fronteinsatz berufen wurden, wuchs sogar die Macht der Kreisleiter, die nun in vielen Fällen zugleich zu kommissarischen Landräten ernannt wurden. Sie waren, wie die Gauleiter meist erklärten, „unabkömmlich“. Aber auch die Gauamtsleiter der Partei wurden meist "uk" gestellt. Der oben erwähnte HJ-Gebietsführer ${ }^{33}$ beschwerte sich am 5 . Oktober 1944 darüber, daß der stellvertretende Gauleiter, der Gauinspekteur, der Gaupersonalamtsleiter, der Gauarbeitskammerpräsident, der Gauamtsleiter und Regierungsvizepräsident von Luxemburg, und Regierungspräsident von Trier, der Gauamts- und Gauverlagsleiter, der Gaurevisor - „alle nicht im Fronteinsatz gewesen" seien, obwohl alle nach dem Stichjahr 1900 geboren seien. Dies war sozusagen die andere Seite der "Sicherung der Einheit von Partei und Staat", die der Nationalsozialismus 1933 postuliert hatte.

${ }^{33}$ Vgl. Anm. 21. Vgl. dazu auch meinen Aufsatz Regionalismus und Nationalsozialismus am Beispiel des Rheinlands, in: Rheinische Vierteljahrsblätter 59 (1995). 


\section{Heinz-Jürgen Priamus}

\section{Regionale Aspekte in der Politik des nordwestfälischen Gauleiters Alfred Meyer}

$I$.

Für alle Beobachter überraschend verzichtete Dr. Alfred Meyer, seit 1929 führender Repräsentant der Gelsenkirchener NSDAP ${ }^{1}$, Anfang Januar 1931 auf seine Funktion als Leiter des zum Gau Westfalen zählenden NSDAP-Bezirks Emscher-Lippe. Ebenso legte er sein Mandat in der Gelsenkirchener Stadtverordnetenversammlung nieder - das einzige, das die Nationalsozialisten bei den Kommunalwahlen des Jahres 1929 hier hatten plazieren können ${ }^{2}$. Er hatte sich damit aber keineswegs, wie Zeitgenossen fälschlicherweise vermuteten, ins Privatleben zurückgezogen. Im Gegenteil: Alfred Meyer war von Adolf Hitler zum Leiter des neuen Gaus Westfalen-Nord ernannt worden. Er gehörte damit zu den nur 29 Gauleitern, die bereits vor 1933 in diese Funktion eingesetzt worden waren $^{3}$.

In den Augen führender Nationalsozialisten galt er weithin als "schwacher" Vertreter der keineswegs homogenen Funktionärselite der Gauleiter ${ }^{4}$, was allerdings nicht verhinderte, daß er im Gegensatz zu anderen Unterführern dieser Kategorie sehr wohl auch auBerhalb der Partei im NS-Staatssystem aufstieg. Meyer hatte dennoch jenseits der Grenzen des Gaus Westfalen-Nord zeit seines Lebens nicht aus der Rolle des weitgehend „unbekannten" Gauleiters heraustreten können, ein Attribut, das ihm in der historischen Aus-

\footnotetext{
${ }^{1} \mathrm{Zu}$ Meyer liegen nur vereinzelte Veröffentlichungen vor, die sich mit unterschiedlichen Aspekten seiner Biographie befassen. Vgl. Karl Teppe, Provinz, Partei, Staat. Zur provinziellen Selbstverwaltung im Dritten Reich untersucht am Beispiel Westfalens, Münster 1977; Karl Teppe, Der Reichsverteidigungskommissar. Organisation und Praxis in Westfalen, in: Dieter Rebentisch u. Karl Teppe $(\mathrm{Hg}$.), Verwaltung contra Menschenführung im Staat Hitlers. Studien zum politisch-administrativen System. Göttingen 1986, S.278-301; Karl Teppe, Die preußischen Oberpräsidenten 19331945, in: Klaus Schwabe (Hg.), Die preußischen Oberpräsidenten 1815-1945, Boppard a. Rh. 1985, S. 219-248; Hans-Jürgen Sengotta, Der Reichsstatthalter in Lippe 1933 bis 1939. Reichsrechtliche Bestimmungen und politische Praxis, Detmold 1976; Jutta Ciolek-Kümper, Wahlkampf in Lippe. Die Wahlkampfpropaganda der NSDAP zur Landtagswahl am 15.Januar 1933, München 1976. Vgl. auch meine eigenen in den nachfolgenden Anmerkungen erwähnten Aufsätze. Der vorliegende Aufsatz stellt eine weitere Teilstudie einer von mir gegenwärtig erarbeiteten politischen Biographie Alfred Meyers dar.

${ }^{2} \mathrm{Zu}$ den organisatorischen Veränderungen in der NSDAP Gelsenkirchens vgl. Staatsarchiv Münster (STAM), Regierung Münster VII-67, Bd.1. Zu Sauer vgl. Stadtarchiv Gelsenkirchen, Bestand 0/ XXIX-2, 31, sowie STAM, Gauleitung Westfalen-Nord (GL WN), Gauschatzamt 91.

${ }^{3}$ Vgl. Peter Hüttenberger, Die Gauleiter. Studien zum Wandel des Machtgefüges in der NSDAP (Schriftenreihe der Vierteljahrshefte für Zeitgeschichte 19), Stuttgart 1969, S.221ff.

${ }^{4}$ So nachzulesen bei Alfred Rosenberg, Letzte Aufzeichnungen. Ideale und Idole der nationalsozialistischen Revolution. Göttingen 1955, S. 145ff. u. 149. Zur Frage der Heterogenität der Gruppe der Gauleiter vgl. Hüttenberger, Gauleiter, S.7.
} 
einandersetzung auch heute noch zukommt ${ }^{5}$. In seinem eigenen Gau dagegen war Alfred Meyer keineswegs ein Unbekannter, vielmehr sorgte er dafür, daß er stets und allüberall präsent war. Was sein Ansehen bei der Bevölkerung betrifft, muß man ihn als durchaus beliebt charakterisieren ${ }^{6}$.

Die folgende Untersuchung soll insbesondere die Methoden zeigen, mit denen die Nationalsozialisten Politik in der Öffentlichkeit inszenierten, um die Massen zwecks Affirmation und Legitimation des Herrschaftssystems zu gewinnen. Wichtigste Elemente dieser Politikinszenierung waren Feier, Kult und Propaganda, mit deren Hilfe der Nationalsozialismus alltägliche Wünsche, Sehnsüchte und Phantasien der Gesellschaft einzufangen und in seinem Sinne inhaltlich zu besetzen suchte ${ }^{7}$.

Den Gauleitern kam in diesem Kontext eine besondere Mittlerrolle bzw. Funktion als Multiplikator zu. Das NS-System bediente sich zur Schaffung, Erhaltung und Verfestigung der von ihm angestrebten "neuen“ politischen Kultur gerade der Funktionärselite der Gauleiter. Angesichts noch nicht vorhandener bzw. noch nicht hinreichend ausgefeilter Kommunikationstechnologien und graduell eingeschränkter Mobilität kam dem unmittelbaren Kontakt der nationalsozialistischen Führungseliten aller Ebenen zur Bevölkerung besondere Bedeutung zu. Die Gauleiter als „allgemein bekannte Exponenten des Nationalsozialismus" und als „besonders charakteristischer Funktionärs- und Führertyp der NSDAP“, wie sie bereits 1969 von Hüttenberger charakterisiert werden ${ }^{8}$, stellten so nicht nur in organisationspolitischer Hinsicht ein wichtiges Bindeglied zwischen Parteiführung und „Reichsleitung“ auf der einen und den regionalen und lokalen Organisationseinheiten auf der anderen Seite dar. Sie waren ein wichtiges kommunikatives Relais zwischen der obersten Partei- und Staatsführung und der breiten Masse der Bevölkerung.

Zur Erfüllung dieses Teils ihrer Aufgabe konnten sie sich einerseits der zentral vorgegebenen „Feier-Propaganda“ bedienen. Dies geschah, indem sie allenthalben, d.h. an verschiedenen Orten weitestgehend zeitgleich und nach gleichen oder zu großen Teilen ähnlichen Inszenierungsschemata Ereignisse wie den Muttertag, den 1. Mai oder den sog. „Heldengedenktag“ im nationalsozialistischen Sinne feiern ließen. Andererseits konnten sie aber auch regional spezifische (Kultur- und Feier-)Elemente aufgreifen und in die von ihnen betriebene Politikinszenierung einbringen. Solche Elemente konnten durch ihren direkten, das Lebensumfeld des einzelnen unmittelbarer berücksichtigenden Bezug besonders identitätsbewahrend und -stiftend wirken und waren somit im Ergebnis für den $\mathrm{Na}$ tionalsozialismus und seine Repräsentanten besonders positiv zu bewerten. Die von den Gauleitern auf diese Weise wahrgenommene Mittlerrolle bzw. Relaisfunktion wirkte einerseits machtsedierend und stellte somit eine wesentliche Grundlage der eigenen funktio-

${ }^{5}$ Als ein Indiz für den vergleichsweise geringen Bekanntheitsgrad Meyers mag exemplarisch die Tatsache gewertet werden, daß im Register der von Thamer 1986 veröffentlichten Arbeit wohl Josef Terboven, nicht aber Alfred Meyer aufgeführt wird. Vgl. Hans-Ulrich Thamer, Verführung und Gewalt. Deutschland 1933-1945, Berlin 1986, S. 822ff.

${ }^{6}$ Die Bewertung Meyers als "beliebt" wurde immer wieder von Zeitzeugen in Interviews, die der Autor mit ihnen führte, genannt. Alle Zeitzeugen gehören der „HJ-Generation“ an. Vgl. die Bestätigung dieser Einschätzung auch bei Rosenberg, Aufzeichnungen S.146. Zur Biographie und zum Gesamtkomplex der Selbstdarstellung Meyers vgl. Heinz-Jürgen Priamus, Alfred Meyer. Selbstinszenierung eines Gauleiters, in: Heinz-Jürgen Priamus u. Stefan Goch, Macht der Propaganda oder Propaganda der Macht? Inszenierung nationalsozialistischer Politik im "Dritten Reich“ am Beispiel der Stadt Gelsenkirchen. Essen 1993, S. 48-67.

7 Vgl. Priamus u. Goch, Macht, S.7.

${ }^{8}$ Hüttenberger, Gauleiter, S.7. 
nalen Existenzsicherung des Gauleiters dar, andererseits verhalf sie gleichzeitig einem jeden Gauleiter grundsätzlich auch zur eigenen Profilierung und zielte so auf einen Zugewinn an Macht ab.

Am Beispiel des Gauleiters Alfred Meyer soll im folgenden nach der Instrumentalisierung regionaler Aspekte im Kontext der von ihm im Gau Westfalen-Nord betriebenen Politik gefragt werden. Region wird in diesem Zusammenhang - wie es z. B. Karl Bosl definiert - als "eine gewachsene historische Einheit ${ }^{\text {"9 }}$ betrachtet. Diese Einheit sei nicht als ein auf einen willkürlich gewählten geographischen Raum bezogenes administratives Konstrukt verstanden. Vielmehr sei Region als ein geschlossenes Ganzes definiert, das eine weitgehende ethnische, kulturelle und sprachliche Einheit - Elemente, die nicht alle gleichzeitig wirken müssen - zur Voraussetzung hat ${ }^{10}$, sich letztlich aber erst auf der Basis weitgehend übereinstimmender „Vorstellungswelten und Wahrnehmungsmaßstäbe, [die] als sogenannte ,mental maps ${ }^{6}$ in den Köpfen von Menschen existieren ", konstitutiert ${ }^{11}$. Das (eigene) Zugehörigkeitsgefühl zu einem bestimmten Raum als individueller Faktor bestimmt damit nicht unwesentlich die Identität einer Region.

\section{II.}

Der Gau Westfalen-Nord ${ }^{12}$ der NSDAP umfaßte mit dem nördlichen Teil der Provinz Westfalen und dem Land Lippe nahezu $15000 \mathrm{qkm}$. Auf seinem Gebiet lebten wenig mehr als 2,8 Millionen Menschen. Die hier ansässigen NSDAP-Mitglieder wurden seit 1935 organisatorisch in 19 Kreisen zusammengefaßt ${ }^{13}$, die sich 1943 in 908 Ortsgruppen, mehr als 3000 Zellen und nahezu 18000 Blocks untergliederten. Der Gau rechnete damit zu den NSDAP-Gauen mittlerer Größe ${ }^{14}$. Entstanden war er im Januar 1931 als Folge der Teilung des erst im Oktober 1928 gebildeten Gaus Westfalen. Vorausgegangen war in dieser kurzen Phase ein nahezu explosionsartiger Anstieg der Mitgliederzahlen der NSPartei und - daraus resultierend - der diese organisatorisch erfassenden Basiseinheiten. Er grenzte im Südwesten an den Gau Essen und im Westen an die Niederlande, im Norden und Osten an die NSDAP-Gaue Weser-Ems und Süd-Hannover-Braunschweig, im Südosten an den Gau Kurhessen und schließlich im Süden an den Gau Westfalen-Süd ${ }^{15}$. In regionalspezifischer Hinsicht war der Gau (mindestens) dreigeteilt. Unter dem Dach der administrativen Einheit fanden sich das katholische, im Kern agrarische Münsterland, der ungeachtet der Grenzen des Landes Lippe als regionale Einheit zu betrachtende Raum Ostwestfalen-Lippe, der im wesentlichen agrarisch-kleinstädtisch ausgerichtet und protestantisch dominiert war, sowie die hochindustrialisierte von den verschiedenen $\mathrm{Mi}$ -

${ }^{9} \mathrm{Karl}$ Bosl, Der deutsche, europäische und globale Sinn einer modernen Regionalgeschichte, in: Zeitschrift für Württembergische Landesgeschichte 36 (1977), S.1-18, hier S.4.

${ }^{10}$ Vgl. Manfred G.Schmidt, Regionalismus, in: Dieter Nohlen (Hg.), Pipers Wörterbuch zur Politik, Bd. 2, München 1983, S.380-390.

${ }^{11}$ Jürgen Reulecke, Stadtgeschichte, Urbanisierunsgeschichte, Regionalgeschichte. Einige konzeptionelle Bemerkungen, in: Heinz-Jürgen Priamus u. Ralf Himmelmann (Hg.), Stadt und Region, Region und Stadt. Stadtgeschichte, Urbanisierungsgeschichte, Regionalgeschichte, Essen 1994, S. 13-25, hier S.21.

${ }^{12}$ Eine umfassende Geschichte des Gaus Westfalen-Nord existiert bislang ebensowenig wie die eines anderen NSDAP-Gaus.

${ }^{13}$ Vgl. zur Organisationsentwicklung: STAM, GL WN, Hauptleitung, Findbuch C2, Einleitung.

${ }^{14}$ Vgl. das Organisationsbuch der NSDAP 1943, München o.J., S. 84.

${ }^{15}$ Vgl. Wilfried Böhnke, Die NSDAP im Ruhrgebiet 1920-1993, Bonn-Bad Godesberg 1974, S. 147. 
lieus der Arbeiterbewegung - dem katholischen, dem kommunistischen und dem sozialdemokratischen - in starkem Maße getragene Emscherzone ${ }^{16}$.

Der an der Spitze des Gaus stehende Alfred Meyer war vergleichsweise spät zu den Nationalsozialisten gestoßen, ein Sachverhalt, den zu kaschieren er später stets bemüht war $^{17}$. Dabei half ihm die niedrige NSDAP-Mitgliedsnummer 28 738, wonach er schon zwischen dem September 1925 und dem Januar 1926 in die Partei hätte eingetreten sein müssen. Tatsächlich aber war er erst am 1. April 1928 - gerade noch rechtzeitig, um sich später als zur „Alten Garde“ zugehörig bezeichnen zu dürfen ${ }^{18}$ - zusammen mit anderen Mitarbeitern der Zeche "Graf Bismarck", bei der er seit 1922 beschäftigt war, der NSDAP beigetreten, nachdem er zuvor als Vorsitzender eines Gelsenkirchener Kriegervereins, der dem bürgerlich-reaktionären „Kyffhäuserbund“ angeschlossen war, politische Aktivitäten entfaltet hatte ${ }^{19}$. Aus familiären Verhältnissen stammend, in denen sich Besitz- und Bildungsbürgertum vereinten ${ }^{20}$, brauchte Meyer vom Zeitpunkt seines Parteieintritts an keine drei Jahre, um vom Leiter der NSDAP-Ortsgruppe "Groß-Gelsenkirchen" über die Funktion des Bezirksleiters Emscher-Lippe in die des Gauleiters aufzusteigen ${ }^{21}$. Er war sich darüber im klaren, daß er mit der Übertragung dieser Funktion auch einen politisch und sozial außerordentlich heterogenen und schwierigen Gau übernommen hatte ${ }^{22}$. Neben seiner Eigenschaft als Gauleiter schöpfte Meyer seine Machtfülle aus dem Amt des

${ }^{16}$ Vgl. Hans-Joachim Behr, Die Provinz Westfalen und das Land Lippe 1813-1933, in: Wilhelm Kohl (Hg.), Westfälische Geschichte, Bd.2: Das 19. und das 20.Jahrhundert. Politik und Kultur, Düsseldorf 1983, S. 45-164, hier S. 149f. Zur wirtschaftsräumlichen Aufteilung Westfalens insgesamt, aus der sich auch die auf diesem Gebiet vorhandene Dreiteilung des Gaus ableiten läßt, vgl. Alois Mayr, Die Wirtschaftsräume Westfalens im Überblick, in: Wilhelm Kohl (Hg.), Westfälische Geschichte, Bd.3: Das 19. und das 20.Jahrhundert. Wirtschaft und Gesellschaft, Düsseldorf 1984, S.1-39, hier S. 15ff. Vgl. auch Arno Klönne, Die Alltäglichkeit des Faschismus, in: Wolfgang Eimer, Uwe Horst, Helga Schuler-Jung ( $\mathrm{Hg}$.), Provinz unterm Hakenkreuz. Diktatur und Widerstand in Ostwestfalen-Lippe, Bielefeld 1984, S.291-300, hier S.293f. und Wolfgang Köllmann, Die Bevölkerung des Regierungsbezirks Münster im 19.Jahrhundert, in: Westfälische Forschungen 40 (1990), S.195-222, hier S.212f., sowie Stefan Goch, Sozialdemokratische Arbeiterbewegung und Arbeiterkultur im Ruhrgebiet. Eine Untersuchung am Beispiel Gelsenkirchens, Düsseldorf 1990.

${ }^{17}$ So ist z. B. im Zusammenhang mit der Ernennung Meyers zum Oberpräsidenten der Provinz Westfalen in einem kurzen biographischen Abriß, den die National-Zeitung (NZ) am 17.11. 1938 abdruckt, davon die Rede, daß Alfred Meyer "schon früh ... den Weg zur nationalen Bewegung [fand] und ... bald ein glühender Kämpfer für den Nationalsozialismus [wurde]".

${ }^{18}$ Siehe Berlin Document Center (BDC), Prsonalakte Meyer sowie die Aussage August Mietz', der behauptet, zusammen mit Meyer am 1. April 1928 der NSDAP beigetreten zu sein, in: STAM, GLWN, Gauschatzamt 176. Zur zeitlichen Vergabe der Mitgliedsnummern vgl. Albrecht Tyrell, „Führer befiehl ...“. Selbstzeugnisse aus der "Kampfzeit" der NSDAP, Düsseldorf 1969, S. 352. Inwieweit Meyer möglicherweise im nachhinein die niedrige Mitgliedsnummer zugewiesen worden sein könnte, ist nicht zu ermitteln.

${ }^{19}$ BDC, Personalakte Meyer. Vgl. in Ergänzung BDC, Personalakten Böhmer u. Mietz. Siehe außerdem STAM, Gauschatzamt 176 u. 178. Zu den Aktivitäten Meyers als Vorsitzender des Kriegervereins vgl. NZ, 20.2. 1934 sowie NZ, 22.6. 1936.

${ }^{20} \mathrm{Vgl}$. zum folgenden Priamus, Alfred Meyer, S. $49 \mathrm{ff}$.

${ }^{21}$ Vgl. Heinz-Jürgen Priamus, Die Reihen noch nicht fest geschlossen. Entstehung und Aufstieg der NSDAP in Gelsenkirchen, in: Ders. (Hg.), Deutschlandwahn und Wirtschaftskrise. Gelsenkirchen auf dem Weg in den Nationalsozialismus, Teil 1: Die antidemokratische Allianz formiert sich, Essen 1991, S.75-130, hier S. 106.

22 Vgl. hierzu NZ, 7.7. 1935 u. 1.1. 1941. Siehe auch Arno Schröder, Mit der Partei vorwärts. Zehn Jahre Gau Westfalen-Nord, Münster 1940, S. 9 ff. 
Reichsstatthalters von Lippe und Schaumburg-Lippe (seit 16.5. 1933), als Staatsminister für Lippe und Schaumburg-Lippe und schließlich als Oberpräsident der Provinz Westfalen (seit 1938).

Den Höhepunkt der Karriereleiter erklomm Meyer im Jahre 1941. Ebenso überraschend wie die von Hitler vollzogene Ernennung ausgerechnet Alfred Rosenbergs zum Reichsminister für die besetzten Ostgebiete ${ }^{23}$ kam für die meisten die Entscheidung, Meyer zu dessen ständigem Vertreter zu machen - und dies, ohne daß jener seine Funktionen als Gauleiter, Reichsstatthalter und Oberpräsident aufzugeben brauchte ${ }^{24}$. Formal übte Meyer dieses Amt bis zum Zerfall des Regimes im Jahre 1945 aus. Wenngleich festzuhalten ist, daß diesem „Querschnittministerium“, das - als Ministerium offensichtlich zunächst gar nicht geplant - im Kompetenzgerangel des NS-Regimes zu ersticken drohte, nur geringe Bedeutung zugemessen werden darf. Das spezifische Image Alfred Rosenbergs ebenso wie die faktisch kurze Existenzdauer des neuen Ministeriums - tatsächlich endete seine Aufgabe mit dem Rückzug der deutschen Truppen aus sowjetischem Gebiet - unterstreichen eine solche Bewertung nachhaltig ${ }^{25}$. Nichtsdestoweniger zählt Meyer durch die Übernahme der Funktion des Ministervertreters damit zu jenen führenden $\mathrm{Na-}$ tionalsozialisten, die die Verantwortung für die Verschleppung sowjetischer $Z$ wangsarbeiter nach Deutschland trugen. Als Ständiger Vertreter war er zudem einer von zwei Teilnehmern, die das sog. Ostministerium bei der den Holocaust bürokratisch regelnden „Wannseekonferenz" stellte ${ }^{26}$.

\section{III.}

Alfred Meyer war ein von „preußischen Offizierstugenden“ wie Treue, Pflichterfüllung und Ehrgefühl geprägter ${ }^{27}$, zutiefst überzeugter Nationalsozialist. Dieses Bild entspricht nicht nur der NSDAP-offiziellen, von ihm selbst wie von der Münchner Parteiführung in der Öffentlichkeit verbreiteten Legende ${ }^{28}$, sondern darf durchaus als Faktum betrachtet werden ${ }^{29}$. Daraus resultierend ergab sich eine unverbrüchliche Bindung an Adolf Hit-

${ }^{23}$ Vgl. Dieter Rebentisch, Führerstaat und Verwaltung im Zweiten Weltkrieg. Verfassungsentwicklung und Verwaltungspolitik 1939-1945, Stuttgart 1989, S.311.

${ }^{24} \mathrm{Vgl}$. Rosenberg, Aufzeichnungen, S.149. Zur Ämterhäufung Meyers, die dieser betrieb, ohne darauf $\mathrm{zu}$ achten, ob er die erworbenen Ämter auch zeitlich ausfüllen konnte, vgl. Teppe, Provinz, S.88.

${ }^{25} \mathrm{Vgl}$. Bundesarchiv Abteilungen Potsdam, Einleitung zum Findbuch „Reichsministerium für die besetzten Ostgebiete".

${ }^{26}$ Siehe z. B. bei: Leon Poliakov u. Joseph Wulff, Das Dritte Reich und die Juden, 2. Aufl., Frankfurt/ M., Wien u. Berlin 1983, S.119ff.

${ }^{27} \mathrm{Vgl}$. NZ, 12.10. 1941.

${ }^{28}$ Vgl. verschiedene offizielle Lebensläufe: Die braune Post, 24.6. 1934, in: Privatbesitz Dorothee Z. (eine Tochter Meyers). Vgl. des weiteren: Völkischer Beobachter, 18.11. 1941, den im BDC befindlichen Lebenslauf („Eigenmaterial Partei-Kanzlei Zusammenstellung und Fassung II P“); Männer im Dritten Reich. Hg. von der Orientalischen Cigaretten-Compagnie "Rosma“ GmbH, Bremen o.J., S. 160 (Es handelt sich hierbei um ein Album zum Sammeln von "Zigarettenbildchen“).

${ }^{29}$ Vgl. das Bekenntnis zum Nationalsozialismus aus dem Jahre 1929, das sich in tagebuchartigen Aufzeichnungen Meyers und seiner Ehefrau findet, in: Privatbesitz Dorothee Z.; Rosenberg, Aufzeichnungen, S. 149. Siehe auch die aus dem engeren NS-Führungszirkel stammende Bewertung Meyers, der „zum Guten zu schwach und zur Sünde zu feige“ sei. (Alexander Dallin, German Rule in Russia 1941-1945. A Study of Occupation Policies, 2. Aufl. London 1981, zit. nach: Rebentisch, Führerstaat, S.318.) 
ler als (seinem messianischen) „Führer “ ${ }^{\text {30 }}$, gepaart mit einem Sendungsbewußtsein, das von einem volkserzieherischen Impetus getragen wurde. Entsprechend war Meyers Selbstverständnis als Gauleiter. Exemplarisch sei dies an einem am 15. April 1937 im Berliner Hotel Adlon "vor der auswärtigen Diplomatie und Presse“ gehaltenen Vortrag verifiziert, der mit dem Titel „Aus der Arbeit eines Gauleiters und Reichsstatthalters" überschrieben

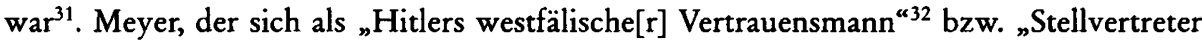

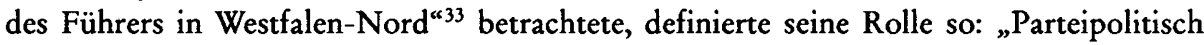
gesehen ist der Gauleiter dem Führer dafür verantwortlich, daß die Partei als Garant der Volksgemeinschaft in Deutschland ein jederzeit schlagfertiges [?] Instrument des Führers ist“"34. Hierzu bedürfe es dessen, was er in seinen Ausführungen als „die entscheidendste Aufgabe des Gauleiters" apostrophierte - der "Menschenführung“. „Diese Aufgabe“, führte Meyer weiter aus, „kann man nicht vom grünen Tisch aus lösen. Der Gauleiter muß sich die Herzen, das Vertrauen und den Glauben der ihm vom Führer anvertrauten Volksgenossen eigentlich täglich wieder erobern. Und so müssen wir immer wieder als Redner und Prediger der nationalsozialistischen Idee mitten ins Volk hineingehen, um in Städten und Dörfern bald in Großkundgebungen, bald aber auch in den kleinsten Dorfversammlungen zu sprechen“"35. Oberstes Ziel müsse es sein, „die Maßnahmen des Führers und Staates von Mund zu Mund [zu erklären,] und so die deutschen Volksgenossen langsam zum Nationalsozialismus [zu erziehen] ${ }^{\star 36}$.

In diesem Zusammenhang bedeutete aus der Sicht Meyers gerade die Kultur ein herausragendes Mittel der Volkserziehung ${ }^{37}$. Die Kultur, der Meyer wohl ohnehin sehr verbunden war, erwies sich unabhängig von ihrer (angeblichen) erzieherischen Wirkung wohl auch als eine gewisse "Nische“, ein noch nicht völlig besetzter politischer Freiraum, der ihm gewisse Karrierechancen und eine damit verbundene persönliche Ausweitung der Macht zu versprechen schien $^{38}$. Kultur - das war vor allem die sogenannte "deutsche Volkskultur", die sich abgrenzte von der europäischen Kulturgemeinschaft ${ }^{39}$. In ihr und mit ihrer Hilfe bot sich den Nationalsozialisten zudem die Möglichkeit, „die schichtspezifisch unterschiedliche Kulturteilhabe zu überwinden und der Bevölkerung, insbesondere der Arbeiterschaft, den Zugang zur Kultur materiell zu erleichtern “40. „Die Partei hat sich ... mit allen Kräften bemüht, " führte Meyer im Rahmen seines Referates vor ausländischen Diplomaten und Pressevertretern weiter aus, „um wahre Kunst an das Volk heran-

${ }^{30}$ So soll Meyer in einem dem Verf. nicht vorliegenden politischen Testament, das er bei seinem Selbstmord hinterließ, noch einmal ein eindeutiges Bekenntnis zu Adolf Hitler abgelegt haben. Interview des Verf. mit Dorothee Z. im März 1991.

${ }^{31}$ Staatsarchiv Detmold (StaDt), Bestand D 72, ,, Aus der Arbeit eines Gauleiters und Reichsstatthalters'[.] Vortrag des Gauleiters und Reichsstatthalters Dr. Alfred Meyer vor der auswärtigen Diplomatie und Presse am 15. April 1937“. Vgl. auch NZ, 23.6. 1937.

${ }^{32}$ So die Formulierung in NZ, 17.5. 1933 anläßlich der Amtseinführung Meyers als Reichsstatthalter von Lippe und Schaumburg-Lippe.

${ }^{33} \mathrm{NZ}, 15.8$. 1933. Vgl. auch NZ, 5.10. 1933: Aus Anlaß des Geburtstages Meyers erscheint ein Artikel über ihn, in dem er als „der getreue Ekkehard unseres großen Volksführers“ bezeichnet wird.

${ }^{34} \mathrm{StaDt}, \mathrm{D} 72$, Aus der Arbeit eines Gauleiters, S.3.

${ }^{35}$ Ebd., S. 10.

${ }^{36}$ Ebd., S. 3.

${ }^{37}$ Vgl. ebd., S. 4.

${ }^{38}$ Vgl. Priamus, Alfred Meyer, S. 63.

${ }^{39}$ Vgl. Karl Ditt, Raum und Volkstum. Die Kulturpolitik des Provinzialverbandes Westfalen 19231945, Münster 1988, S. 152 u. 157.

${ }^{40}$ Ebd., S. 155. 
zutragen. Die Auffassung, daß die Kunst nur für die Gebildeten da sei, ist längst abgetan.“ Und zuvor hatte er festgestellt: „In vielen Theatervorstellungen wurde dem schaffenden Menschen durch reine und sehenswerte Volkskunst ein bisher nie gekanntes Erlebnis vermittelt. Einen sehr schönen Besuch hatten auch die volkstümlichen Veranstaltungen im Gau zu verzeichnen; Veranstaltungen, in denen westfälisches Brauchtum, alte Volkstänze, Laienspiel und volkstümliche Musik den Arbeitern wieder nahegebracht wurden“41. „Es ist das überhaupt eine der schönsten Aufgaben des Gauleiters,“ schloß Meyer seine Ausführungen über seine kulturellen Aufgaben ab, „wahrer und reiner Kunst die Bahn zu brechen, [!] und die Kunst an die Menschen heranzutragen"42. Auf der Basis eines solchen Selbstverständnisses verband Meyer seine kulturell-volkserzieherischen Intentionen mit einer regionalen Ausrichtung und Orientierung. Damit suchte er zugleich den Gau Westfalen-Nord von anderen Gauen positiv abzuheben. So schrieb etwa die National-Zeitung, das offizielle Parteiorgan des Gaus, im Jahre 1938, daß Meyer trotz der „starken Beanspruchung mit den Fragen des wirtschaftlichen Aufbaus seines Gaugebietes ... noch Zeit [findet], sich in weitgehendem Maße mit den Fragen der Neugestaltung des kulturellen Lebens zu beschäftigen. Und gerade auf diesem Gebiet kann er Erfolge verzeichnen, die für

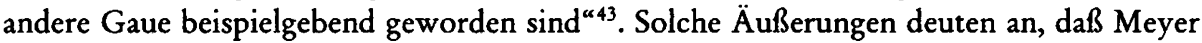
in der Beachtung der regionalen und lokalen Komponente eine Schlüsselfunktion für die Akzeptanz des Nationalsozialismus in der Bevölkerung sah. Nun war sich Meyer offenkundig bereits frühzeitig der regionalen sozio-ökonomischen und politischen Unterschiede innerhalb des Gaus bewußt ${ }^{44}$. Die je spezifische Beachtung der Regionen des Gaus Westfalen-Nord mußte daher ein stetiger Bestandteil der von ihm nach innen betriebenen Politik sein, ohne daß damit allerdings eine Aussage über die Wirkung dieser Politik zugelassen wäre.

Eine herausragende Rolle für den Aufstieg der NSDAP im Gau spielte das Gebiet von Lippe und Schaumburg-Lippe. Immerhin hatten hier die Landtagswahlen vom 15. Januar 1933 der NSDAP bekanntlich einen Stimmenanteil von 39,5 Prozent gebracht und sie vor den Sozialdemokraten zur stärksten Fraktion erhoben. Und Meyer hatte zudem mit der Übertragung des Amtes des Reichsstatthalters persönlich von dieser Region erheblich profitiert. Meyer trug diesem Sachverhalt politisch Rechnung, indem er den errungenen Sieg in Form der alljährlich wiederkehrenden "Lippe-Feiern “ kommemorieren ließ ${ }^{45}$. Neben der Aufwertung Meyers eigener Position innerhalb des NS-Systems trug dies sicherlich auch zu einer Stärkung des Selbstwertgefühls der Region und damit auch zur Schaffung eines spezifisch nationalsozialistischen Identitätsgefühls der Bevölkerung bei. Mit

${ }^{41} \mathrm{StaDt}, \mathrm{D} 72$, Aus der Arbeit eines Gauleiters, S. 8.

${ }^{42}$ Ebd., S. 8.

${ }^{43} \mathrm{NZ}$, 17.11. 1938. Vgl. auch STAM, GL SN, Hauptleitung 6, Stimmungs- und Lagebericht für August und September 1938, Pkt. 17, wo es heißt: „Die kulturellen Veranstaltungen des Gaues Westfalen-Nord, welche in ihrer traditionellen Folge und unter sorgfältigster Beachtung der wichtigsten politischen Partei- und Volkstage in das Jahresprogramm eingereiht sind, haben erfolgreiche Arbeit im Sinne einer wirklich alle Schichten des Volkes verbindende[n] Gemeinschaft geleistet. Diese Arbeit ist umso [!] höher einzuschätzen, weil sie wirtschaftlich gesehen, [!] eine Belebung für die betreffenden Orte bedeutet, [!] und rein ideell betrachtet, volkserzieherisch garnicht [!] hoch genug bewertet werden kann."

${ }^{44}$ Vgl. zur Rolle Meyers und zur problematischen Struktur des Gaus: Arno Schröder, WestfalenNord, Berlin 1940, S. 9 u. $21 \mathrm{ff}$.

${ }^{45}$ STAM, GL WN, Hauptleitung 2, Stimmungs- und Lagebericht für den Monat Januar 1939, Pkt. 7 a, wo es heißt: „Das nunmehr zur Tradition gewordene Lippische Erinnerungstreffen ...". 
der frühzeitigen Traditionalisierung dieses Geschehens bewegte sich Meyer zudem im Kontext einer allgemein auf seiten des Nationalsozialismus feststellbaren Tendenz zur (unangemessen) frühen Historisierung der eigenen Aktivitäten ${ }^{46}$.

Die Gedenkveranstaltungen verliefen in ritualisierter Form und immer nach dem gleichen Schema. Nach der „Begrüßung“ der formiert angetretenen „Lippekämpfer“, also jener Nationalsozialisten, die - aus den verschiedensten deutschen Provinzen und NSDAP-Gauen kommend - 1933 am "Lippewahlkampf“ teilgenommen hatten, vor dem Detmolder Rathaus durch Alfred Meyer und neben den ebenfalls von den „Lippekämpfern" veranstalteten Umzügen waren Großkundgebungen mit NS-Prominenten fester Bestandteil der Feierfolge ${ }^{47}$. Höhepunkte der Inszenierung gelangen Meyer dabei in den Jahren 1934 und 1936, als er Adolf Hitler selbst zu einer Teilnahme an den Feierlichkeiten bewegen konnte ${ }^{48}$. Aber selbst in jenen Jahren, als Hitler nicht teilnahm, wußte sich Meyer dessen Unterstützung zu versichern, indem er Hitler gewissermaßen telegraphisch in das Geschehen einbezog. So auch beispielsweise 1938: „Mein Führer!“ telegraphierte Meyer am 15.Januar. „Zum fünften Male begeht der Gau Westfalen-Nord sein Erinnerungstreffen im Lande Lippe, anläßlich Ihres großen entscheidenden Wahlkampfes im Jahre 1933. Wir gedenken Ihrer, mein Führer, Ihres einzigartigen Kampfes und Sieges. Der Gau Westfalen-Nord und Ihre alten Lippekämpfer sind glücklich in dem Bewußtsein, unter Ihnen als Vorkämpfer diesen entscheidenden Wahlsieg erstritten zu haben. Der Gau WestfalenNord und das Land Lippe grüßen Sie in Treue und fester Einsatz- und Opferbereitschaft. Heil mein Führer!“ Hitler antwortete: „Für Ihre Grüße von dem Erinnerungstreffen im Lande Lippe sage ich Ihnen meinen wärmsten Dank. Auch ich erinnere mich bewegten Herzens immer wieder jener Tage, da es mit einer seltenen Kraftanstrengung gelang, die scheinbare Krise in der Entwicklung der Bewegung zu bannen und einen neuen, damals entscheidenden Sieg zu erringen. Die Zusammenarbeit und Opferbereitschaft aller Führer und Mitglieder der Partei halfen dadurch mit, die Uebernahme der Macht am 30.Januar vorzubereiten. gez.: Adolf Hitler.!“ Der Telegrammwechsel wurde tags darauf in allen (gleichgeschalteten) Zeitungen des Gaus Westfalen-Nord in vollem Umfang abgedruckt ${ }^{49}$.

Gewissermaßen eine Art Synonym für das Land Lippe bildete „Hermann, der Cherus-

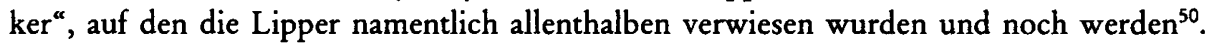
Schon aus Anlaß des Wahlkampfes im Vorfeld des 15.Januar 1933 war deshalb das regional-lippische Motiv „Hermanns, des Cheruskers, “ bewußt in die Wahlkampfstrategie der Nationalsozialisten aufgenommen worden. Dieser über die Römer siegreiche Fürst des Germanenstammes der Cherusker, dessen Name eigentlich „Arminius“ lautete, errang erstmalig Symbolkraft in der sich im ausgehenden 18. und beginnenden 19.Jahrhundert formierenden und artikulierenden nationalen Einheitssehnsucht und vaterländischen Be-

${ }^{46}$ Als exemplarisch für die von den Nationalsozialisten schon sehr frühzeitig unternommenen Versuche, ihre eigene außerordentlich kurze Geschichte zu traditionalisieren, mögen die sich von 1933 bis zum Kriegsbeginn allerorts häufenden Jubliläums- bzw. Gründungsfeierlichkeiten anläßlich des zehnjährigen Bestehens lokaler NS-Gruppen angeführt werden. Vgl. Priamus, Alfred Meyer, S.66f.

${ }^{47}$ An den "Lippe-Feiern" nahmen als Gastredner u. a. teil: Viktor Lutze, Wilhelm Frick, Robert Ley, Alfred Rosenberg, Wilhelm Börger, Bernhard Rust wie auch Prinz August Wilhelm von Preußen. Vgl. NZ vom 13., 14. u. 15.1. 1934, 11. u. 16.1. 1936, 12. u. 17.1. 1937, 11., 15. u. 16.1. 1938 sowie 20.12. 1938.

${ }^{48}$ Vgl. NZ, 14.1. 1934 u. 16.1. 1936.

${ }^{49}$ Vgl. z. B. die Berichterstattung in der NZ vom 16.1. 1938.

${ }^{50}$ Noch heute weisen etwa Straßennamen oder die Bezeichnungen von Hotels auf "Hermann" hin. 
geisterung. Die Errichtung des Hermannsdenkmals auf der Grotenburg bei Detmold im Teutoburger Wald, das am 16. August 1875 eingeweiht worden war, symbolisierte schließlich die Verbindung zwischen dem Cheruskerfürsten und dem Land Lippe, dem jetzt so genannten „Hermannsland“51.

Bereits ein halbes Jahr vor der für die Nationalsozialisten so entscheidenden Wahl war die Idee zur Nutzung dieses Motivs von Walter Steinecke, dem neu ernannten Landesleiter der lippischen NSDAP, Hitler selbst in einem Gespräch in der Münchner Parteizentrale offeriert worden, der sie begeistert aufgegriffen haben soll ${ }^{52}$. Vier Punkte dürften hierfür ausschlaggebend gewesen sein: 1. Die Bildhaftigkeit des Motivs der Befreiungsschlacht wurde vom Wähler leicht verstanden. 2. Die Verknüpfung von Geschichte und Gegenwart war unschwer möglich und erlaubte eine Parallelisierung der Intentionen des Arminius und jener der NSDAP. 3. „Hermann" wie auch die Schlacht waren positive Identifikationsobjekte und „Führersymbole“. Arminius und Adolf Hitler ließen sich unschwer in eine parallele Beziehung setzen. Als lokal- bzw. regionalpatriotisches Symbol konnte leichthin die Verbindung zwischen Land und Wahlkampf hergestellt werden. Die Bezüge zu diesem Symbol wurden so in der Folgezeit über Plakataktionen, Veranstaltungen und nicht zuletzt über Pressepublikationen, stets und ständig hergestellt ${ }^{53}$. Und nach dem nationalsozialistischen Sieg hatte Meyer formuliert: „In Lippe zerschlug Hermann der Cherusker die römischen Fesseln und schenkte den einigen deutschen Stämmen die Freiheit der Heimat wieder. In Lippe erhielt die römische Weltherrschaft den ersten Stoß zum Niedergang cäsarischer Weltmacht. In Lippe führte der Volkskanzler und Staatsmann Adolf Hitler als Führer der deutschen Freiheitsbewegung im Januar dieses Jahres den größten Wahlkampf aller Zeiten durch. Sein Sieg, nach einer gigantischen Kraftentfaltung von ihm persönlich in vorderster Linie erstritten, wurde zum leuchtenden Mahnmal für ganz Deutsch-

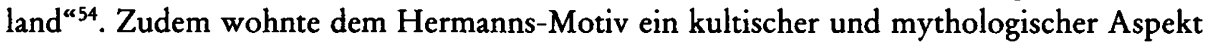
inne, an den die Nationalsozialisten gerne anknüpften. Er haftete auch den Externsteinen an, jener germanischen Kultstätte, die Meyer z.B. für eine „Weihestunde“ anläßlich des westfälischen Landesbauerntages des Jahres 1936 verwandte ${ }^{55}$.

Darüber hinaus bemühte sich Meyer, den von ihm im Auftrage Hitlers beherrschten Zwergstaat Lippe zu einer Art kultureller Zentralregion des Gaus auszubauen ${ }^{56}$. Auch hier griff er - wenigstens partiell wie im Falle der von ihm initiierten, aus Anlaß des 100 jährigen Todestages 1936 erstmalig, dann alljährlich durchgeführten „Grabbe-Tage“57 - auf regionale Spezifika zurück. War doch der Dramatiker Christian Dietrich Grabbe 1801 in Detmold geboren worden, wo er auch nach einem bewegten Leben, das ihn über Aufenthalte in Frankfurt und Düsseldorf an seinen Geburtsort zurückgeführt hatte, 1836 verstarb $^{58}$. Grabbe war aber nicht nur der regional verwurzelte, jedoch über die Grenzen

${ }^{51}$ Vgl. Ciolek-Kümper, Wahlkampf, S. 226ff.

${ }^{52} \mathrm{Vgl}$. den Hinweis auf die persönliche Äußerung Steiners, ebd., S.228.

${ }^{53}$ Ciolek-Kümper, Wahlkampf, S. 228ff.

${ }^{54}$ Sammlung von Erinnerungen und Aufzeichnungen, in: Privatbesitz Dorothee Z.

${ }^{55} \mathrm{NZ}, 30.8 .1936$.

${ }^{56}$ Vgl. dazu ausführlicher Priamus, Alfred Meyer, S.62f.

57 Vgl. grundlegend Werner Broer u. Detlev Kopp (Hg.), Grabbe im Dritten Reich. Zum nationalsozialistischen Grabbe-Kult, Bielefeld 1986.

${ }^{58} \mathrm{Zu}$ den biographischen Daten Herbert A.Frenzel u. Elisabeth Frenzel, Daten deutscher Dichtung. Chronologischer Abriß der deutschen Literaturgeschichte, Bd. II: Vom Biedermeier bis zur Gegenwart, 12. Aufl. München 1976, S. 390. 
seiner Heimat hinaus bekannt gewordene Dramatiker, er bot Meyer auch inhaltliche Ansatzpunkte, die sich propagandistisch positiv für das nationalsozialistische Herrschaftssystem vermarkten ließen. So ließ sich Grabbes Bemühen um eine originale deutsche Dramatik ebenso zu dem nationalsozialistischen Ideologiekonglomerat in Beziehung setzen wie dessen in seinen Geschichtsdramen angelegte Versuche, die eigene Epoche mit Hilfe einer überhöhten Heroendarstellung zu erfassen ${ }^{59}$. „Mit Recht begeht die Heimat Grabbes auch in diesem Jahre wieder Tage zu Ehren des Dichters. Sie gelten dem Gedächtnis eines Deutschen, der in seiner nationalpolitischen Kraft unseren bedeutenden schöpferischen Menschen in nichts nachsteht, weil er in einer Zeit tiefster völkischer Verzagtheit als nahezu Einziger [!] heldische Gesinnung trug", zitierte die National-Zeitung im Oktober 1938 in diesem Sinne "Reichsdramaturg Dr. Rainer Schlösser ", den Vorsitzenden der GrabbeGesellschaft. Und Alfred Meyer bezeichnete Grabbe bei gleicher Gelegenheit gar als „tiefgründige[n] Kämpfer für ein größeres Deutschland“60.

Die "Grabbe-Tage" umfaßten ein Bündel unterschiedlichster Veranstaltungen. In der Regel begannen sie in Anwesenheit der lokalen und regionalen $\mathrm{HJ}$ und des BDM mit einer Feierstunde, die z.B. im Jahre 1938 am Fuße des Hermanns-Denkmals vonstatten ging und bei der der „Reichsjugendführer" Baldur von Schirach die Hauptansprache hielt. Ein eigens für diesen Anlaß komponiertes Chorwerk begleitete die Feierstunde. Daran schlossen sich Fachtagungen wie die des „Reichsbundes der deutschen Freilicht- und Volksschauspiele“, aber auch Lesungen - 1938 von Heinrich George - aus den Werken Grabbes an. Den Höhepunkt bildeten schließlich die Dramen Christian Dietrich Grabbes, die von den verschiedensten Theatern aufgeführt wurden. 1938 etwa präsentierten die Bühnen Bochum, Münster und Bielefeld die Grabbe-Dramen „Hannibal“, die "Hohenstaufendramen" "Friedrich Barbarossa" und "Heinrich VI." sowie - damit den unvermeidlichen Bezug zur Region herstellend - die „Hermannsschlacht “61. Auf der Basis derartiger Veranstaltungen „führen wir im Gau Westfalen-Nord das breite und gesunde Volk zur deutschen Kunst hin", wie Meyer - wenn auch im Zusammenhang mit den gleichfalls alljährlich im Land Lippe durchgeführten „Richard-Wagner-Festwochen“ - im Jahre 1938 konstatierte ${ }^{62}$.

Wenn Meyer in Detmold seine Präsenz als Reichsstatthalter für regional orientierte politisch-kulturelle Aktionen nutzen konnte, so bot sich ihm diese Möglichkeit im Prinzip auch in der zweiten zu seinem Gau zählenden Region - dem Münsterland. Seit Oktober 1932, als die Gauleitung von Gelsenkirchen nach Münster verlegt worden war, residierte er in dieser Stadt: bis zu seiner im November 1938 erfolgten Ernennung zum Oberpräsidenten der Provinz Westfalen in der Parteizentrale, seither in dem im Zentrum der Stadt gelegenen Schloß, das Dienstsitz des Oberpräsidenten war.

Die Region Münsterland erwies sich im Gegensatz zu Lippe für Meyer jedoch als auBerordentlich schwieriges Terrain. Tief verwurzelt im Katholizismus, sperrte sie sich vehe-

${ }^{59}$ Vgl. Fritz Martini, Deutsche Literaturgeschichte. Von den Anfängen bis zur Gegenwart, 15. Aufl. Stuttgart 1968, S.393ff.

${ }^{60} \mathrm{NZ}, 15.10 .1938$.

${ }^{61}$ Vgl. STAM, GL WN, Hauptleitung 6, Stimmungs- und Lagebericht für August und September 1938, Pkt.17. Vgl. auch NZ, 15.10. 1938.

${ }^{62} \mathrm{NZ}, 25.6$. 1938. Vgl. auch STAM, GL WN, Hauptleitung 25, Stimmungs- und Lagebericht für den Monat April 1937, Pkt.17. Auf die einen wesentlich größeren Stellenwert im Kanon der Meyerschen Kultur(erziehungs)politik einnehmenden Wagner-Festwochen kann im Kontext der vorliegenden Problemstellung nicht eingegangen werden. 
ment gegen die stereotypen Vereinnahmungsbemühungen des Nationalsozialismus ${ }^{63}$. Daran hatte auch die 1937 bewußt in Münster - der Stadt, die man von seiten der Nationalsozialisten realistisch als den "sprichwörtlich katholisch-politischen Zentralpunkt Nordund Mitteldeutschlands“ bezeichnete - erfolgte Errichtung des neuen "Gauhauses" nichts geändert ${ }^{64}$. Verschärft wurde die Situation dadurch, daß sich Meyer außerordentlich stark im nationalsozialistischen Kirchenkampf engagierte. Er führte ihn insbesondere an der Seite Alfred Rosenbergs, dem er offensichtlich spätestens seit dem „Lippe-Wahlkampf“ in einer Art Geistesverwandtschaft aufs engste verbunden war.

So bejubelte die nationalsozialistische Presse z. B. zwar den Empfang Rosenbergs anläßlich des Gautreffens in Münster im Jahre 1934, als dieser in seiner Eigenschaft als „Beauftragter des Führers für die Überwachung der gesamten geistigen und weltanschaulichen Schulung und Erziehung der NSDAP“ „zu tausenden deutscher Volksgenossen“ zum Thema „Die Weltanschauung des Nationalsozialismus" sprach $^{65}$. Und auch ein Jahr darauf lautete eine sich auf das seinerzeitige Gautreffen beziehende Presseschlagzeile: „Münster jubelt Rosenberg zu! "66 In Wirklichkeit aber war gerade wegen der Kirchenfrage die allgemeine Stimmungslage in der Bevölkerung sehr schlecht. „Weite Kreise der Bevölkerung sind ... mit der Haltung des Staates in der Kirchenfrage nicht einverstanden und geben ihrer Mißstimmung unverhohlen Ausdruck “, hieß es im Lagebericht der Staatspolizeistelle für den Regierungsbezirk Münster für den Monat April 1935. „Dazu kommt, daß durch das Verhalten der im hiesigen Bezirk untergebrachten Legionäre und der HJ wiederholt die religiösen Gefühle der Katholiken verletzt worden sind, so daß es nicht wundernimmt, wenn insbesondere weite Kreise der katholischen Bevölkerung noch abseits stehen und zum Teil sogar staatsfeindlich eingestellt sind ${ }^{67}$." Und was Rosenberg angeht, so hatte sein Erscheinen in Münster keineswegs so großen Jubel ausgelöst, wie die Nationalsozialisten hatten verbreiten lassen. „Konnte in den vorhergehenden Monaten eine mehr und mehr zunehmende Aktivität des politischen Katholizismus festgestellt werden“, schrieb die Staatspolizei in ihrem Bericht für Juli 1935, „so traten im Berichtsmonat die gegensätzlichen Auffassungen des Staates und großer Teile der kath. Geistlichkeit anläßlich der Rede des Reichsleiters Rosenberg ... offen zutage." Man teile in katholischen Kreisen in keiner Weise „die Auffassung des Staates und der Bewegung in religiösen Fragen ... Man identifiziert vielmehr ganz allgemein das sogen. Neuheidentum mit der NSDAP und weist in diesem Zusammenhang weiter darauf hin, daß man unmöglich einen Unterschied machen könne zwischen dem Privatmann Alfred Rosenberg und Rosenberg als Leiter für die weltanschauliche Schulung der NSDAP“68. Meyer selbst trug

${ }^{63}$ Siehe Joachim Kuropka (Hg.), Meldungen aus Münster 1924-1944. Geheime und vertrauliche Berichte von Polizei, Gestapo, NSDAP und ihren Gliederungen, staatlicher Verwaltung, Gerichtsbarkeit und Wehrmacht über die politische und gesellschaftliche Situation in Münster, Münster 1992, S.154-164 sowie Kap.13. Vgl. auch STAM, GL WN, Hauptleitung 24, Stimmungs- und Lagebericht für den Monat März 1937, wo es - sicherlich teilweise beschönigend - heißt: „Wir sehen aus allen Berichten sehr klar, dass wirtschaftliche Schwierigkeiten keinerlei massgebliche Rolle spielen und Unzufriedenheit sich nur mehr auf dem durch kirchl. Beeinflussung vorbereiteten Boden breitmacht."

${ }^{64}$ STAM, GL WN, Hauptleitung 24, Stimmungs- und Lagebericht für den Monat März 1937.

${ }^{65} \mathrm{NZ}, 16.9 .1934$.

${ }^{66} \mathrm{NZ}, 7.7 .1935$.

${ }^{67}$ Vgl. Lagebericht der Staatspolizeistelle für den Regierungsbezirk Münster für April 1935, in: Kuropka (Hg.), Meldungen, S. 153.

${ }^{68}$ Ebd., $163 f$. 
nichts Wesentliches dazu bei, die Stimmungslage zu ändern, obgleich sie ihm schwerwiegende Probleme bereitete, was er in internen Stellungnahmen der NSDAP-Führung gegenüber unzweideutig zugab. „Ich habe auf der letzten Gauleitertagung mit grosser Genugtuung feststellen können, dass der Stellvertreter des Führers mit der von meinem Gaugebiet bisher verfolgten Kirchenpolitik durchaus einverstanden ist. Ich habe erst kürzlich auf einer grösseren Führertagung zu diesen Fragen eingehend Stellung genommen und dabei auch die Frage der Kirchenaustritte berührt. Ich habe jeden irgendwie gearteten Druck auf Entschlüsse in dieser Richtung verboten und habe festgestellt, dass diese Frage eine rein persönliche Frage ist. In meinem Gaugebiet würden wir uns an vielen massgebenden Stellen des Gaues das Vertrauen der Bevölkerung verscherzen, wenn die politischen Leiter in diesen Kirchenfragen eine verständnislos und gewaltsame Haltung einnehmen würden," schrieb Meyer der Parteiführung im März 193769. Und weiter unten in dem gleichen Bericht hieß es: „Die Lage in meinem Gau ist deshalb besonders schwierig, weil der grösste Teil der kath. Bevölkerung vollständig kirchlich gebunden ist. Die Westfalen in ihrer starrköpfigen und zäh am Alten hängenden Art sind nur mit der Zeit zu Nationalsozialisten zu machen. Es wäre falsch, hier eine Umwandlung mit Gewalt zu versuchen "70.

Andererseits verfocht Meyer die offizielle nationalsozialistische Linie und machte - dabei unmißverständlich auf den Münsteraner Bischof Kardinal Clemens August Graf von Galen hinzielend - ohne Umschweife deutlich: „Wenn aber Staat und Partei beleidigt werden und wenn Geistliche sich offensichtlich auf politischem Gebiet schädigend bewegen, dann wollen wir eisern zugreifen und nichts ungetan lassen. Im übrigen haben wir gar kein Interesse daran, Märtyrer zu machen "71. Einer propagandistischen Vereinnahmung der Region standen diese antiklerikalen Aktivitäten freilich entgegen ${ }^{72}$.

Im Gegensatz dazu schien die Distanz zwischen der münsterländischen Heimatbewegung und der NS-Ideologie gering. Begriffe wie „Heimat“, „Deutschland“ oder auch "Volksgemeinschaft" wiesen neben einer gewissen Nähe der Wurzeln der Heimatbewegung und des Nationalsozialismus scheinbare Berührungspunkte auf. Diese boten sich trotz gewisser Unterschiede, die vor allem in den für den Nationalsozialismus kontraproduktiven regionalistischen Bestrebungen der Heimatschutzbewegung lagen, zur Nutzung für propagandistische $Z$ wecke gewissermaßen geradezu an. So ist es nicht erstaunlich, daß auch der Gau Westfalen-Nord und Alfred Meyer die Heimatschutzbewegung frühzeitig für sich vereinnahmten ${ }^{73}$. Insbesondere die vor 1933 vom Westfälischen Heimatbund, nunmehr aber von der Gauleitung in Verbindung mit dem Provinzialverband durchgeführte Organisation des alljährlich stattfindenden "Westfalentages" bot der NSDAP und Alfred Meyer ein breites Feld politischer Indoktrination. „Wir alle sind stolz, Westfalens Söhne und Westfalens Töchter zu beißen “, äußerte er sich z. B. anläßlich des 1935 im ostwestfälischen Enger stattfindenden Westfalentages. „Wenn wir uns hier versammelten, so folgten wir der Stimme des Blutes. Hier, wo einst unser großer Ahne, der Sachsenherzog Widukind für das von seinen Vätern ererbte Kulturgut gegen eine große Uebermacht kämpfte,

${ }^{69}$ STAM, GL WN, Hauptleitung 24, Stimmungs- und Lagebericht für den Monat März 1937.

${ }^{70}$ STAM, GL WN, Hauptleitung 24, Stimmungs- und Lagebericht für den Monat März 1937.

${ }^{71}$ Vgl. NZ, 7.7. 1935. U.a. hatte der Münsteraner Bischof Clemens August Graf von Galen den Auftritt und die Rede Rosenbergs, die dieser im Sommer 1935 in Münster gehalten hatte, vergeblich zu verhindern gesucht.

72 Vgl. allgemein die verschiedenen Aktivitäten Meyers im Kontext des Kirchenkampfes, nach NZ, 16. 9. 1934, 7.7. 1935, 6.8.1935, 19.8. 1935, 17.10. 1935, 30.10. 1935, 16.12. 1935, 2.12. 1937 .

${ }^{73}$ Vgl. zum folgenden Ditt, Raum, S. 206-240. 
wollen auch wir alles das ablegen, was fremde Gesetzgebung schuf. ... Wenn jemand sagt, der Nationalsozialismus hätte dem Westfalen seine Eigenart geraubt und wenn es jemand behauptet, die Männer des Dritten Reiches messen mit einem besonderen Maß, dann wissen wir, daß das genaue Gegenteil der Fall ist. ... So wie einst der Stamm der Sachsen Widukind auf den Schild erhob, daß man einen Führer hatte, geradeso haben wir Menschen von heute gehandelt" ${ }^{\text {"74 }}$. Zwei Jahre später eröffnete Meyer in Enger zudem eine „Widukindgedächtnisstätte“, die „die Gestalt des Sachsenherzogs lebendig machen“ sollte ${ }^{75}$.

Ob die Region auf diese Weise auf breiter Basis für den Nationalsozialismus gewonnen werden konnte, ist gegenwärtig nicht abschließend zu entscheiden, mag jedoch allein mit Blick auf die Teilnehmerzahl der Westfalentage nach 1933 bezweifelt werden. War es, nachdem die Veranstaltungen der Vorjahre jeweils nur einige hundert Teilnehmer gezählt hatten, den Nationalsozialisten 1933 noch gelungen, auch auf diesem Feld massenmobilisierend zu wirken und zum Westfalentag dieses Jahres 150000 Menschen zur Teilnahme zu bewegen ${ }^{76}$, so kamen 1934 nur noch 31000 Teilnehmer und 1935 waren es gar nur 1500. Die "Großveranstaltung“ sank damit auf das Niveau der Weimarer Zeit ab"

Eine den Detmolder Grabbe-Tagen vergleichbare „Institution“ sollten im Münsterland nach Meyers Vorstellungen die seit 1938 veranstalteten Annette-von-Droste-HülshoffTage werden ${ }^{78}$. Meyer war zu diesem Zeitpunkt, als sich der Todestag der Dichterin zum 90. Male jährte, von der seit 1928 bestehenden Droste-Gesellschaft die Schirmherrschaft angetragen worden, was mit nahezu unumschränkten Vollmachten bis hin zur Ernennung des Vorsitzenden und bis zu vier weiteren Vorstandsmitgliedern durch den Gauleiter verbunden war. Meyer übernahm damit die Führung der Gesellschaft, nachdem er erst im September 1937 gewünscht hatte, „daß er und das Reichspropagandaamt in ein engeres Verhältnis zur Droste-Gesellschaft treten möchten “79. Wie im Falle der Grabbe-Tage war Meyer bestrebt, die Persönlichkeit der Literaturgeschichte zur Selbstdarstellung der Partei und seiner selbst zu nutzen. Gleichzeitig erfolgte der Versuch, das Werk der Dichterin umzuwerten und angebliche Kontinuitätslinien hin zur NS-Ideologie darzulegen. Seit den 1920 er Jahren wurde die Droste von Literaturhistorikern als im Westfälischen verwurzelt charakterisiert, nachdem sie in den vorhergehenden Jahrzehnten, d.h. seit der Zeit des Kulturkampfes als katholische Dichterin reklamiert worden war. Die Nationalsozialisten knüpften an die Sicht der 20 er Jahre an und erweiterten die Interpretation in unzulässiger Weise. National, sozial, bluts-, boden- und volkstumsbewußt sei sie gewesen, der nordischen Rasse zugehörig. Mit ihrer „germanisch-niederdeutschen“ Haltung wurde sie z.B. Heinrich Heine, der als jüdischer Literat apostrophiert wurde, gegenübergestellt $^{80}$. Die Droste-Hülshoff-Tage erreichten jedoch nicht den herausgehobenen Stellenwert der Grabbe-Tage, wohl nicht zuletzt deshalb, weil das nationalsozialistische „Interpretationsangebot" wenig Anklang fand, Annette von Droste-Hülshoff weiterhin traditionell interpretiert und keineswegs als irgendgeartete Vorläuferin des Nationalsozialismus betrachtet wurde ${ }^{81}$. Die vom Katholizismus in der Region ausgehende Widerwilligkeit ge-

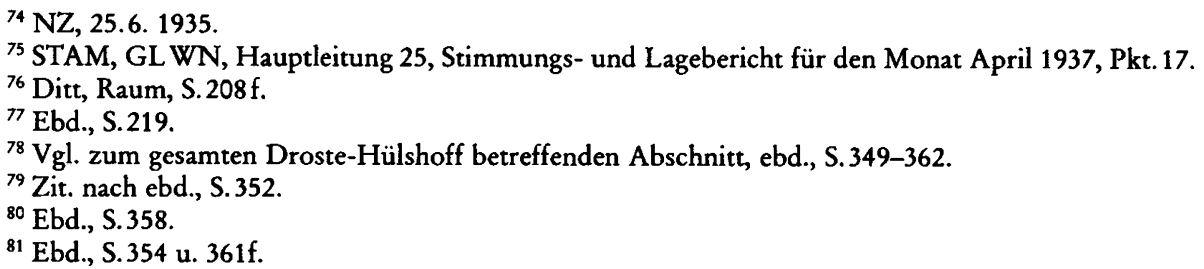


genüber dem Nationalsozialismus und seinem Gauleiter bewirkte, daß Münster als Ort der Gauparteitage zunehmend ungeeignet erschien. Vor allem aus diesem Grunde wurden sie 1936 nach Gelsenkirchen verlegt ${ }^{82}$ und nicht, wie die National-Zeitung ihre Leser am 29. April 1936 glauben machen wollte, als Dank des Gauleiters für "Gelsenkirchens Treue am 29. März“, der sogenannten „Reichstagswahl“ des Jahres 1936. In Gelsenkirchen, der als Zentrum des Emscher-Lippe-Raums zu betrachtenden Ruhrgebietsstadt, die zudem als „Wiege“ des Gaus galt, fanden die Gauparteitage bis zum Kriegsausbruch statt.

Auf eine Dauer von zwei bis drei Tagen ausgerichtet, bestanden diese ritualisierten Parteifeiern aus einer aneinandergereihten $Z$ ahl von Tagungen der verschiedenen Gausonderorganisationen der NSDAP wie z.B. RAD, HJ, NSKK u.a.m. Im Mittelpunkt jedoch standen auch für die breite Bevölkerung zugängliche Großkundgebungen mit Parteigrößen wie Goebbels, Rosenberg und Ley sowie dem Gauleiter Alfred Meyer. Als Vorbild für die Gautreffen dienten die Reichsparteitage; hinzu kamen Vorbeimärsche, Fackelzüge und diverse sportliche und kulturelle Rahmenveranstaltungen ${ }^{83}$. Außer der Selbstdarstellung der NSDAP und der Demonstration der Macht ${ }^{84}$ dienten sie - ähnlich den „LippeFeiern" - nicht zuletzt der zielgerichteten Herausbildung einer neuen nationalsozialistischen Identität dieser industriell wichtigen Region ${ }^{85}$. Diese war aus der Sicht der Nationalsozialisten angesichts von Kriegsplanung und damit verbundener Rüstung hier aus Gründen der Verläßlichkeit und Sicherheit wohl unabdingbar.

Im Unterschied zu Lippe und Schaumburg-Lippe war die politische Ausgangslage in der Emscher-Lippe-Region jedoch eine grundlegend andere. Nicht auf einen frühzeitigen starken Zuspruch, sondern auf eine überdurchschnittliche Ablehnung waren die Nationalsozialisten hier gestoßen ${ }^{86}$. Damit bestand eine oberflächliche Ähnlichkeit zur Münsteraner Region. Anders aber als im katholischen Milieu des Münsterlandes, wo die Ablehnung des Nationalsozialismus dem Grunde nach zumindest während der ersten Jahre der nationalsozialistischen Herrschaft über eine mit Hilfe der Kirche permanent vollzogene Reproduktion religiös fundierter, dem Nationalsozialismus entgegenstehender Werte nachhaltig vollzogen werden konnte, verfügte das Ruhrgebiet nach der frühzeitigen Zerschlagung der Arbeiterbewegung, die zudem ohnehin keine vollständige Einheit gebildet, sondern sich auf das kommunistische, soialdemokratische und katholische Milieu aufgeteilt hatte, über kein (breites) intaktes ethisch-moralisches antinationalsozialistisches Bollwerk. Die Bevölkerung schien also im Unterschied zum katholischen Münsterland, wo der Zusammenhalt zwischen Kirchenvolk und Amtskirche kaum erschütterbar erschien, hinsichtlich neuer Werte und Normen wenigstens beeinflußbar, ein Überwechseln aus den Arbeiterbewegungsorganisationen in die "nationalsozialistische Bewegung" nicht ausgeschlossen. „Der Kreis Emscher-Lippe besteht zum grössten Teil aus einer handarbeitenden Bevölkerung. Der Bergarbeiter beklagt sich über die geringe Bezahlung, die in keinem Verhältnis zu der zu leistenden Arbeit steht. Grundsätzlich wäre es aber falsch,

${ }^{82}$ NZ, 29.4. 1936. Vgl. Stefan Goch, Parteifeiertage. Feiern der Staatspartei, in: Priamus u. Goch, Macht S.16-20, hier S.16.

${ }^{83}$ Vgl. die Berichterstattung z. B. in: Gelsenkirchener Zeitung (GZ), 27.6. 1936, Gelsenkirchener Allgemeine Zeitung (GAZ), 27.6. 1936, GZ, 25.6. 1937, GAZ, 26.6. 1937, GAZ, 27.6. 1937, GZ, 23.6. 1938, GZ, 24.6. 1938, GAZ, 27.6. 1938, GZ, 17.6. 1939. Vgl. auch das „Minuten-Programm des Gautreffens 1937“, in: Chronik der Stadt Gelsenkirchen 1937, S. $150 \mathrm{ff}$.

${ }^{84}$ Vgl. Goch, Parteifeiertage, S.16.

${ }^{85}$ Vgl. Priamus, Alfred Meyer, S.60f.

${ }^{86}$ Vgl. Goch, Arbeiterkultur, S.340ff. 
wenn man aus dieser Klagestellung heraus annehmen wollte, dass diese Haltung aus einer nazifeindlichen Einstellung geboren wäre. Der Arbeiter im Industriegebiet ist weltanschaulich aufgeschlossen und auch bereit, die arteigene nationalsozialistische Auffassung nicht nur ganz in sich aufzunehmen, sondern hierüber hinaus auch zu vertreten“, hieß es in einem Bericht der NSDAP-Kreisleitung Emscher-Lippe vom Spätsommer 1938, den Meyer in seinem Bericht im wörtlichen Zitat und unkommentiert der Parteispitze zuleitete und in dem man fortfuhr: „Mit Recht möchte der Bergmann seine Existenz gesichert sehen und dann wird es leicht sein, ihn von der Richtigkeit der nationalsozialistischen Idee zu überzeugen. Im übrigen ist es ja auch ganz natürlich, dass der Mensch um das ihm für seine Arbeit zustehende Brotrecht ringt. Alles in allem bedeutet das für den Kreis Emscher-Lippe folgendes: Die Weltanschauung des Nationalsozialismus fest zu verankern wird hier im Augenblick leichter sein, wo man dem schwer arbeitenden Menschen den ihm zustehenden Lebensstandard einräumt ${ }^{\text {“87 }}$. Auf dieser Grundlage propagierte Meyer die These vom verführten Volk. Verführer waren die untereinander zerstrittenen und sich heillos bekämpfenden Parteien vor allem der Arbeiterbewegung, die das Volk durch falsche Versprechungen und Ideologien auf Abwege gebracht hätten. Möglich geworden sei diese Verführung aber nur vor dem Hintergrund der gerade in dieser Region herrschenden außerordentlichen sozialen Not. Erst die Nationalsozialisten hätten dann tatsächlich Abhilfe geschaffen. So ließ Meyer seine Rede auf dem ersten in Gelsenkirchen abgehaltenen Gautreffen 1936 in den pathetischen Worten gipfeln: „Nach der Machtergreifung übernahm die Bewegung hier ein Trümmerfeld, eine völlig zerstörte Wirtschaft. Wir haben in diesen Jahren oft die schwersten Sorgen gehabt, um über die Schwierigkeiten der Ernährung und der Arbeitsbeschaffung hinwegzukommen. Trotzdem ist es uns gelungen, Tausende und Abertausende Arbeiter der Stirn und der Faust, die sich zu Moskau oder Amsterdam oder sonst einer Internationale bekannt hatten, wieder nach Deutschland zurückzuführen “88. Tatsächlich schien sich die Stimmungslage in der Bevölkerung dieser Region mit steigenden (Nominal-)Löhnen nach 1936 positiv zugunsten der Nationalsozialisten zu verändern ${ }^{89}$.

Die Presseberichterstattung über die Gauparteitage durchzog eine manieriert-romantisierende Darstellung des Ruhrgebiets als "Heimat der deutschen Arbeiter“. Dabei stand das die Region verkörpernde Bild des Bergarbeiters stets im Mittelpunkt. So wird z.B. schwülstig "das schwarze, von Schweißsträhnen durchfurchte Gesicht des Bergmannes“ beschrieben, „der tief im Schacht der Erde im härtesten Kampf um Deutschlands Geltung Stellung bezogen hat und hier treu und brav seine Pflicht tut ${ }^{\circ 90}$. Und die Grubenlampe gewinnt bei dieser pathetisch-salbungsvollen Interpretation eine geradezu überhöhte Bedeutung, wenn es heißt: „Vom dunklen Schacht zum hellen Tageslicht nimmt der Bergmann jeden Tag hoffnungsvoll seinen Weg. ... So wird für uns die Grubenlampe zum leuchtenden Symbol des deutschen Aufstiegs, ein Zeichen für die Ehre schwerer Arbeit, ein Sinn-

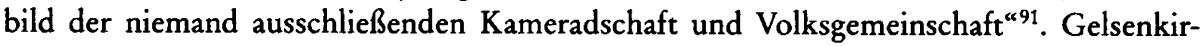
chen als der eigentliche Ort des Treffens wird stereotyp als die „Stadt der tausend Feuer"

${ }^{87}$ STAM, GL WN, Hauptleitung 6, Stimmungs- und Lagebericht für August und September 1938, Pkt. 18.

${ }^{88} \mathrm{GAZ}, 27.6 .1936$.

${ }^{89}$ Vgl. STAM, GL WN, Hauptleitung 25, Stimmungs- und Lagebericht für den Monat April 1937, Pkt. 19.

${ }^{90} \mathrm{GZ}$, 18.6. 1939.

${ }^{91} \mathrm{GAZ}, 26.6 .1937$. 
bezeichnet. Insgesamt verschmolz in einer derartigen Berichterstattung gleichsam der Anspruch der NSDAP, eine Arbeiterpartei zu sein, mit dem Ziel, eine vollendete „Volksgemeinschaft" zu schaffen".

Über die glorifizierte Figur des Bergmanns hinaus stellte der Fußballverein Schalke 04, der allein zwischen 1933 und 1945 sechs Mal deutscher Fußballmeister wurde, eines der wenigen regional verwurzelten Elemente dieses Raumes dar, das dennoch - wie im Falle des "Hermanns-Motivs" und der "Grabbe-Tage" in Lippe - einen über die Region weit hinausgehenden Bekanntheitsgrad genoß und sich daher für nationalsozialistische Propagandazwecke besonders eignete ${ }^{93}$. Durch Besuche von Spielen der Mannschaft in der heimischen "Glückaufkampfbahn", insbesondere aber mit Hilfe von Ehrung und Empfang der Sieger reklamierte Meyer den sportlichen Ruhm auch für sich und den Nationalsozialismus ${ }^{94}$. „Wir im Gau Westfalen-Nord sind stolz auf unsere Schalker Jungen“, würdigte Meyer in diesem Sinne die erneute Meisterschaft des FC Schalke 04 im Jahre 1940. "Auch im Kriege, unter erschwerten Umständen, haben sie es geschafft, wo ein Teil der Mannschaft das Ehrenkleid der Soldaten trägt und sich an der Front tapfer schlug. ... Die Anwesenheit von Vertretern des Staates, der Partei und der Wehrmacht soll Schalke ein Beweis dafür sein, wie eng wir uns alle mit ihm verbunden fühlen. Auch in den schwersten Stunden dürfen sie das Bewußtsein haben, daß ganz Westfalen hinter ihnen steht ${ }^{\text {} 95}$.

Im Unterschied zu den Regionen Lippe und Münsterland wirkten in der Emscher-LippeZone darüber hinaus in den $30 \mathrm{er} \mathrm{Jahren} \mathrm{infolge} \mathrm{des} \mathrm{industriellen} \mathrm{Strukturwandels} \mathrm{kaum}$ noch spezifische, regional fest verwurzelte traditionale Elemente nach ${ }^{96}$, die sich im Sinne des Nationalsozialismus von Meyer hätten „umwerten“ lassen. An die Stelle der „Umwertung" vorhandener Traditionen trat deshalb in dieser Region der Versuch, eigene Traditionen neu zu begründen. Dies sei am Beispiel der alljährlich am 21.Juni im NSDAP-Bezirk Emscher-Lippe veranstalteten "Ludwig-Knickmann-Gedenkfeiern“ dargestellt.

Ihren Namen bezogen diese regionalen Feierlichkeiten von Ludwig Knickmann, einem frühen, aus (Gelsenkirchen-)Buer stammenden Nationalsozialisten, der während der Ruhrbesetzung an Sabotageakten gegen die Besatzungsmächte beteiligt war. Am 21.Juni 1923 war Knickmann bei dem Versuch, die Grenze zwischen dem besetzten und dem unbesetzten Teil des Ruhrgebiets illegal zu überqueren, um einen „Verräter zu stellen“, der mit den Besatzern kollaborierte, von belgischen Besatzungssoldaten getötet worden. Ob Knickmann tatsächlich aus politischen Gründen zu Tode kam, wie die NS-Propaganda späterhin glauben machen wollte, oder deshalb erschossen wurde, weil die Belgier ihn und seinen Begleiter Karl Jackstien" beim Schmuggel von Lebensmitteln ertappt hatten,

${ }^{22}$ Vgl. Goch, Parteifeiern, S. 20.

${ }^{93}$ Vgl. Stefan Goch, FC Schalke 04. Instrumentalisierung des Zuschauersports, in: Priamus u. Goch, Macht, S. 81-92, hier S.81.

${ }^{94}$ Vgl. NZ, 27.06. 1937 mit einem Bericht über den gemeinsamen Besuch Viktor Lutzes und Meyers in der Glückaufkampfbahn, wo beide über die Bedeutung des Sports sprechen. Gleichzeitig ehrt Meyer Schalke 04 wegen der deutschen Meisterschaft. Vgl. zu den Ehrungen allgemein Goch, Schalke, S. 90ff.

${ }^{95}$ Westfälische Tageszeitung, 11.8. 1940.

${ }^{96} \mathrm{Vgl}$. Behr, Westfalen, S. 122.

97 Jackstien stieg später in der SA bis zum "Oberführer" auf und übernahm 1943 das Kommando der SA-Brigade 21 in Gleiwitz. Er kam im Jahre 1943 bei einem ${ }_{n}$ Kampfeinsatz ${ }^{*}$ zu dem er sich angeblich selbst gemeldet hatte, ums Leben. Vgl. BDC, Akte Jackstien; STAM, GLWN, Gauschatzamt 106 sowie NZ, 17.10. 1943. 
ist heute nicht mehr eindeutig zu entscheiden ${ }^{98}$. Für die vorliegende Fragestellung ist es letztendlich sogar gleich, wie die Ereignisse sich abgespielt haben mochten. Wichtig ist nur, daß der Vorfall den Nationalsozialisten die Chance bot, Ludwig Knickmann propagandistisch als „Märtyrer der Bewegung“ darzustellen. Damit gewinnt die um Knickmann betriebene Legendenbildung deutliche Ähnlichkeit mit der bekannten Glorifizierung Albert Leo Schlageters und Horst Wessels. Im Unterschied zu diesen bot Knickmann als der Region entstammendes „Opfer" der Masse der Bevölkerung indes viel eher die Möglichkeit zur Entwicklung persönlicher Betroffenheit und damit zur Identifikation ${ }^{99}$. Die Feierlichkeiten selbst verliefen stets in ritualisierter Form, ihr Ablauf war streng geregelt und enthielt quasi-liturgische Elemente. Hierzu zählte die am Morgen des alljährlichen Gedenktages stattfindende Trauerstunde am Grab des „nationalsozialistischen Blutzeugen“, wie ihn die gelenkte Presse in bewußter, aber unerlaubter Assoziation an die NSBezeichnung der anläßlich des nationalsozialistischen Putschversuches vom 9. November $1923 \mathrm{zu}$ Tode gekommenen Hitler-Anhänger bezeichnete ${ }^{100}$. Des weiteren zählte hierzu die Kranzniederlegung an dem Denkmal, das man zu Ehren Knickmanns an der Stelle errichtet hatte, wo er zu Tode gekommen war ${ }^{101}$. Darüber hinaus verharrte den ganzen Tag über eine Ehrenwache der SA an seinem Grab - üblicherweise die nach Ludwig Knickmann benannte SA-Standarte 137. Zur Ausstattung dieser Ehrenwache zählten Fahnen, Standarten und "trauerumflorte Feldzeichen“. Dabei müssen Fahnen als eine der wichtigsten Requisiten nationalsozialistischer Massenregie eingestuft werden. Auch Hitler hatte in "Mein Kampf“ der Fahne ein ganzes Kapitel gewidmet. Und Goebbels schätzte den Wert von Fahnen gar höher ein als den jeder Zeitung, da sie eben nicht an den Intellekt, sondern ausschließlich an das Gefühl appellierten ${ }^{102}$.

Die Inszenierung mußte zudem stets den Charakter einer „schlichten“, allenfalls aber einer "schlichten und innerlich großen Feier“ aufweisen. Im Gegensatz zur pompösen Feierveranstaltung dürfte dies, wie es die Nationalsozialisten selbst auszudrücken pflegten, wohl dem "gesunden Volksempfinden“ entsprochen haben und ließ somit aus den Reihen der Bevölkerung positive Resonanz erwarten. Die NSDAP nahm damit - eingedenk ihrer zu großen Teilen kleinbürgerlichen Herkunft - ganz bewußt die Ansprüche der einfachen Leute an den Staat auf. Hierzu zählten eben auch Sparsamkeit und Schlichtheit ${ }^{103}$.

Der Intention eines Kunstwerks durchaus vergleichbar, sollten diese Inszenierungselemente den "Betrachter" weniger auf der kognitiven als vielmehr auf der emotional-affektiven Ebene ansprechen. Andererseits muß der symbolhafte Charakter dieser Gedenkfeiern besonders betont werden. Die einzelnen Elemente der Inszenierung verschmolzen, nicht

${ }^{98}$ Die vormals selbständige Stadt "Buer in Westfalen" ist heute ein Teil Gelsenkirchens. Buer wurde im Zuge der kommunalen Neuordnung 1928 mit Gelsenkirchen zusammengelegt. Vgl. auch zu den Vorgängen um Knickmann sowie den nachfolgenden Aspekten Priamus, Reihen, S.78, 80f. u. 97 sowie Heinz-Jürgen Priamus, Helden- und Totenfeiern. Normiertes Totengedenken als Feiertag, in: Priamus u. Goch, Macht, S. 21-38.

${ }^{99}$ Nur zufällig fiel dieser regionale Gedenktag mit dem von den Nationalsozialisten ebenfalls gefeierten Tag der Sommersonnenwende zusammen. Dennoch dürfte damit der spirituell-religiöse Charakter dieses Tages zusätzlich akzentuiert worden sein.

${ }^{100} \mathrm{Vgl}$. GZ, 22.6. 1940.

${ }^{101}$ Die nachfolgenden Ausführungen basieren auf einer Analyse der GAZ, GZ und NZ zwischen 1933 und 1943. Da die gleichen Sprachmuster alljährlich von neuem auftraten, sei allgemein nur auf die jeweilige Berichterstattung der genannten Zeitungen am 22.6. verwiesen.

102 Gerhard Paul, Aufstand der Bilder. Die NS-Propaganda vor 1933, Bonn 1990, S. 170 f.

${ }^{103}$ Vgl. Gerhard Bauer, Sprache und Sprachlosigkeit im „Dritten Reich“, Köln 1988, S. 53. 
zuletzt wegen ihrer stereotypen Wiederholung, zu einer Art Gesamtsymbol. Mit Hilfe eines solchen Symbols, das sich aus einer Anzahl verschiedenster bildhafter Zeichen zusammensetzte, ließen sich komplexe intellektuelle Gebilde, wie geistige Werte und Utopien, den Massen gegenüber besser vermitteln als es je mit Worten möglich gewesen wäre. Schließlich haben Symbole zudem noch eine identitätsstiftende Funktion, indem sie, wie Gerhard Paul es formuliert, „das Gefühl von Zusammengehörigkeit unter einer überge-

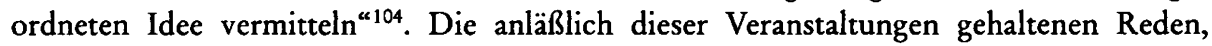
"Gedenkansprachen“ genannt, unterstrichen zusätzlich die auf der emotional-affektiven Symbolebene angestrebten Intentionen durch eine weniger konkrete als vielmehr assoziative Rhetorik.

Als Ausdruck des „Kulturwille[ns] des Gaues Westfalen-Nord“, wie es der Leiter des Gaupresseamtes, Arno Schröder, 1940 formulierte ${ }^{105}$, betrachtete Meyer auch die von ihm geplanten großen Bauvorhaben des Gaus, mit deren Hilfe er sich offenbar selbst eine gewisse Nachahmung Hitlers ist nicht zu übersehen - ein Denkmal zu setzen beabsichtigte $^{106}$. Dabei bemühte er sich offenbar, auch auf diesem Feld der regionalen Dreiteilung des Gaus Rechnung zu tragen. So waren es folgerichtig drei großangelegte städtebauliche Projekte, die Meyer im Jahre 1938 anstrebte.

Der erste Plan sah einen gigantomanischen Ausbau Münsters vor, „der Stadt, in der das gesamte Verwaltungs- und Behördenleben nicht nur des Gaues, sondern auch des ganzen Raumes Westfalen zusammenströmt, der Gauhauptstadt der Bewegung im Gau Westfalen-Nord. Wie München und Nürnberg, Berlin, Weimar und Hamburg und andere Städte im Reich begonnen haben, durch großzügige städtebauliche Umgestaltung ihrer Stadt ein neues lebensfrisches Gesicht zu geben, so wird auch Münster ... neu geformt werden. Erst die nationalsozialistische Bewegung, entsprechend der Größe ihrer Weltanschauung und ihres fanatischen Willens und Glaubens, ist berufen, ein neues Stadtgebiet ... entstehen zu lassen." Meyers Absicht, die er mit Speer und Hitler bereits abgestimmt hatte, war es, insgesamt einen riesigen Parteibezirk entstehen zu lassen. „In dieser baulichen Anlage wird der Sitz der Organisationen und Formationen sein, die den nationalsozialistischen Menschen führen und betreuen." Dominiert werden sollte der Raum von einem „aus dem Wasser steigenden, weithin sichtbaren, gewaltigen Glockenturm “. Des weiteren sollte Münster ein neues, sich an den Parteibezirk anschließendes Behördenviertel erhalten. Und nicht zuletzt bestand die Absicht, neue Wohnviertel, „geschlossene Straßenzüge in drei- und viergeschossiger Bebauung ... mit luftigen Grün- und Innenhöfen" entstehen zu lassen. „Wir sind glücklich", hieß es abschließend resümierend, „in den Tagen Adolf Hitlers den Grundstein zu einer neuen Stadt, mit dem Platz des Dritten Reiches als lebendigem Mittelpunkt, legen zu können “107.

Gerade in dem auf den Wohnungsbau ausgerichteten Teil des Münsteraner Projekts suchte Meyer seine soziale Haltung bzw. das, was die Nationalsozialisten den „Sozialis-

104 Paul, Aufstand, S. 165f. Vgl. auch Volker Ackermann, Nationale Totenfeiern in Deutschland: von Wilhelm I. bis Franz Josef Strauß; eine Studie zur politischen Semiotik, Stuttgart 1990, S. 284, der den Ritus in Anlehnung an den französischen Religionswissenschaftler Albert Réville als die „Syntax" bezeichnet, die die einzelnen Symbole, die gleichsam Sprachelemente bilden, erst zu einer Aussage zusammenfaßt.

${ }^{105}$ Schröder, Westfalen-Nord, S. 44.

${ }^{106} \mathrm{Vgl}$. NZ, 7.4. 1938, wo es über Meyer heißt, daß „dessen unermüdliche[r] Initiative allein die groBen Bauvorhaben der Partei im Gau Westfalen-Nord zu verdanken sind“.

${ }^{107}$ Alle Zitate in NZ, 7.4. 1938. 
mus der Tat" nannten, zum Ausdruck zu bringen. Dieses war auch die zentrale Intention des von ihm geplanten zweiten Großprojekts, dem Um- und Ausbau Gelsenkirchens ${ }^{108}$. Ausgangspunkt dieser Bemühungen war der in dieser Region seit Jahren herrschende katastrophale Wohnraummangel. So verkündete die National-Zeitung am 25. Juni 1938: „Um in der Stadt Gelsenkirchen aber, der Hochburg nationalsozialistischer Arbeit, auch die wirtschaftliche Freiheit zu erringen, werden wir die Zeugnisse des liberalistischen Geistes in Gestalt von schauderhaften Wohnvierteln mit häßlichen Elendshöhlen und Straßenzügen niederlegen und eine moderne Arbeiterstadt bauen, die das beredteste Zeugnis des deutschen Sozialismus der Tat und der nationalsozialistischen Sehnsucht sein soll“ ${ }^{109}$. Bestandteil des Gesamtprojekts war auch der Bau einer Einfamilienhaussiedlung im Gelsenkirchener Stadtteil Resse ${ }^{110}$, deren Grundstein am 25. Juni 1938 vom Leiter der DAF, Robert Ley, dessen Namen die Siedlung auch tragen sollte, gelegt wurde ${ }^{111}$. Im „Ortsteil Buer-Resse an der Münster Straße [!] [wird] ein Akt vollzogen“, berichtete die Presse über die Grundsteinlegung, „der über Gelsenkirchen hinaus größte Bedeutung hat. Es ist ein Akt, der vor aller Welt zeigt, wie ernst es der Nationalsozialismus mit der Verwirklichung des deutschen Sozialismus nimmt. Mitten im Industriegebiet wird sich eine neue Siedlung erheben, die von der Liebe und Fürsorge des Nationalsozialismus zum deutschen Arbeiter Zeugnis ablegt. Ist es nicht wahrhaft symbolisch, daß dieser Akt in Gelsenkirchen vollzogen wird, einer Stadt, die in ihrem unorganischen Aufbau und ihren Mietskasernen die Schäden des Wirtschaftsliberalismus verkörpert? Gerade von hier, dem Brennpunkt des Industriegebietes, der Hochburg des Wirtschaftsliberalismus, geht die Erneuerung aus. Reichsorganisationsleiter Dr. Ley ... hat im Verein mit Gauleiter und Reichsstatthalter Dr. Meyer die Pläne lange erwogen, wie man Licht und Luft in diese Stadt bringt, wie man den Arbeitern helle, freundliche Wohnungen bauen kann. Nun sind die Pläne fertig, es ist ein gewaltiges Projekt geworden, das Schule machen wird“112. Als drittes Großprojekt plante Meyer schließlich die Errichtung einer megalomanen Kultstätte auf dem Hiddeser Berg bei Detmold, die die permanente, in Stein gegossene Erinnerung an den Sieg im Lippewahlkampf des Jahres 1933 manifestieren sollte. Das Großvorhaben war von dem Münsteraner Architekten Bartels, der auch die Pläne für die SS-Ordensburg Wewelsburg entwickelt hatte, und dem in Recklinghausen ansässigen Architekten Ganteführer entworfen worden. Auch hier sollte, wie in Münster, ein riesiges Hallengebäude, eine „Halle der Volksgemeinschaft“, mit einem vorgelagerten Aufmarschplatz errichtet werden. „In Architektur und Formgebung entspricht sie in schlichter, klarer, klassischer Haltung unserer Kunstauffassung “, formulierte ein Journalist, der die Pläne in seiner Zeitung der Öffentlichkeit präsentierte. „Eine Hochschule germanischen Geistes, das ,Ahnenerbe ${ }^{113}$, wird in unmittelbarer Nähe dieser Halle stehen. Die Adolf-Hitler-Schule, die Gauschulungsburg, eine Freilichtbühne und eine Pflegestätte deutscher Musik und

${ }^{108}$ Vgl. hierzu ausführlich: „Das Wohnungsbauprogramm des Gauleiters“, in: Stadtarchiv Gelsenkirchen, Bestand 0/XII-6,1.

${ }^{109} \mathrm{NZ}, 25.6 .1938$.

${ }^{110}$ Vgl. „Das Wohnungsbauprogramm des Gauleiters“, S. 4ff.

${ }^{111}$ Vgl. Hildegunde Bussen, Die Entstehung und Entwicklung der Arbeitersiedlung Resser Mark zu einem Stadtteil Gelsenkirchens (unveröff. Prüfungsarbeit der Pädagogischen Akademie Münster), Münster 1957, S. 3ff.

${ }^{112}$ Sammlung von Erinnerungen und Aufzeichnungen in Privatbesitz Dorothee $Z$.

${ }^{113}$ Vgl. zum „Ahnenerbe“ Reinhard Bollmus, Das Amt Rosenberg und seine Gegner. Studien zum Machtkampf im nationalsozialistischen Herrschaftssystem, Stuttgart 1970, S.178ff. 
Kunst, werden diese Gesamtanlage unterhalb des Hermann-Denkmals zu einer neuen ,Akropolis' werden lassen "114. Eine Straße sollte von Detmold hinaufführen, wobei auf der Höhe des Berges das „Tor des ,15. Januar‘, eine große Säulenarkade, liegt “115.

Wegen des Krieges wurde keines der von Meyer intendierten Großbauprojekte im geplanten Gesamtumfang realisiert.

\section{IV.}

Zusammenfassend seien die wichtigsten Ergebnisse dieser Studie festgehalten:

1. Der 1931 entstandene NSDAP-Gau Westfalen-Nord stellte ein administratives Konstrukt dar und umfaßte nach sozio-kulturellen Gesichtspunkten die drei disparaten Regionen Ostwestfalen-Lippe, Münsterland und die Emscher-Lippe-Zone als den nördlichen Teil des Ruhrgebiets. Dem von ihm persönlich formulierten Selbstverständnis nach, an dem aufgrund seiner Biographie nicht zu zweifeln ist, sah sich der nordwestfälische Gauleiter Alfred Meyer in erster Linie als von einem ausgeprägten Sendungsbewußtsein getragener Volkserzieher bzw. in der Rolle eines Multiplikators des nationalsozialistischen Ideologiekonglomerats, das in der breiten Masse der Bevölkerung auf Dauer zu verankern und zu verfestigen er als zutiefst überzeugter Parteigänger der NSDAP als sein primäres Ziel erachtete.

2. Alfred Meyer betrachtete - damit keineswegs von der „ideologischen“ Norm des Nationalsozialismus abweichend - Elemente des regional fundierten Brauchtums als probaterweise einsetzbare Instrumentarien zur Erreichung dieses Ziels. Er stieß dabei in den drei Regionen seines Gaus allerdings auf graduell abstufbare unterschiedliche Ansatzpunkte und Voraussetzungen. So bot das ostwestfälisch-lippische „Hermanns-Motiv“ einen hohen Grad an Verwertbarkeit in einer Region, die im Rahmen der "Lippewahlen“ bereits eine frühzeitige Akzeptanz des Nationalsozialismus hatte erkennen lassen. Die im Münsterland als der zweiten Region des Gaus starke Heimatschutzbewegung lieferte nach außen hin augenscheinlich ähnlich positive Zugangsmöglichkeiten. Diese Ansätze wurden jedoch von Abstoßungseffekten des regional tief verwurzelten Katholizismus überlagert. In dem soziologisch von der Arbeiterschaft dominierten Emscher-LippeRaum schließlich wirkten infolge der im Zuge der Industrialisierung vollzogenen strukturellen Veränderungen kaum noch spezifische, regional fest verwurzelte traditionale Elemente nach, so daß eine Umnutzung und Umwertung von Brauchtumselementen im Sinne des Nationalsozialismus mit Blick auf die Akzeptanz durch breite Teile der Bevölkerung hier von vornherein ausgeschlossen war.

3. In der - sicherlich nicht im Sinne der hier vor 1933 starken Arbeiterbewegung, wohl aber im nationalsozialistischen Sinne - „traditions- und brauchtumslosen“ Emscher-Lippe-Region bemühte sich Meyer, der Gepflogenheit einer frühzeitigen Historisierung der eigenen Politik folgend, um die Genese neuer NS-Traditionen. Die ständige Abhaltung der Gautreffen in Gelsenkirchen ist in diesem Kontext ebenso zu nennen wie die Durchführung der Knickmann-Feiern. Eine ebensolche Traditionalisierung fand seit 1934 gleichfalls in Form der "Lippe-Feiern“ in Detmold und Umgebung statt.

4. Darüber hinaus griff Meyer in der Region verwurzelte, jedoch über sie hinausweisende Elemente aus den Bereichen Kunst, (Hoch-)Kultur und Sport auf, um sie in die spezifi- 
sche Form nationalsozialistischer Propaganda zu integrieren. Waren es im Emscher-LippeRaum die siegreichen Fußballspieler des FC Schalke 04, so wurden im Münsterland die Dichterin Annette von Droste-Hülshoff und in der Lippe-Region Christian-Dietrich Grabbe in die auf Legitimation und Affirmation des Herrschaftssystems ausgerichtete Politikvermarktungsstrategie eingebaut.

5. Meyer war bei allen diesen Aktivitäten, die neben der Verfestigung des Systems sicherlich auch der Machtsedierung und spezifischen Profilierung seiner selbst dienten, an einer gleichgewichtigen Behandlung der drei Regionen seines Gaus gelegen, was nicht zuletzt auch in der Gewichtung seiner Großbauvorhaben zum Ausdruck kommt. Dies muß auch als ein Ausdruck der von ihm betriebenen Kanalisierung regionaler Interessen gewertet werden, um daraus erwachsenden möglichen regionalistischen Bestrebungen von Anbeginn an entgegenzutreten.

6. Eindeutige Aussagen hinsichtlich der Wirkung dieses Politikkonzepts lassen sich kaum machen. Zumindest ansatzweise erkennbar ist jedoch, daß die von Meyer intendierten Ziele am ehesten in der Region Ostwestfalen-Lippe erreicht worden sein dürften. Die geringste Wirkung zeigte dieser Politikansatz wahrscheinlich in der Region Münsterland. In der dritten Region des Gaus, der Emscher-Lippe-Zone, erwies sich der regionale Politikansatz wegen fehlender eindeutig regionaler Elemente als wenig tragfähig. Deshalb betonte Meyer in diesem Raum in stärkerem Maße die soziale Komponente seiner Politik. 